\title{
Black-Legged Tick Distributions, Small Mammal Abundances, Mast Production, and Vegetative Influences on Lyme Disease Apparent Prevalence on Fort Drum Military Installation, New York
}

\author{
Samantha R. Fino
}

Follow this and additional works at: https://researchrepository.wvu.edu/etd

\section{Recommended Citation}

Fino, Samantha R., "Black-Legged Tick Distributions, Small Mammal Abundances, Mast Production, and Vegetative Influences on Lyme Disease Apparent Prevalence on Fort Drum Military Installation, New York" (2017). Graduate Theses, Dissertations, and Problem Reports. 5600.

https://researchrepository.wvu.edu/etd/5600

This Thesis is protected by copyright and/or related rights. It has been brought to you by the The Research Repository @ WVU with permission from the rights-holder(s). You are free to use this Thesis in any way that is permitted by the copyright and related rights legislation that applies to your use. For other uses you must obtain permission from the rights-holder(s) directly, unless additional rights are indicated by a Creative Commons license in the record and/ or on the work itself. This Thesis has been accepted for inclusion in WVU Graduate Theses, Dissertations, and Problem Reports collection by an authorized administrator of The Research Repository @ WVU. For more information, please contact researchrepository@mail.wvu.edu. 
Black-legged tick distributions, small mammal abundances, mast production, and vegetative influences on Lyme disease apparent prevalence on Fort Drum Military

Installation, New York

Samantha R. Fino, B. S.

Thesis submitted to the

Davis College of Agriculture, Natural Resources and Design

at West Virginia University

in partial fulfillment of the requirements

for the degree of

\section{Master of Science}

In

Wildlife and Fisheries Resources

John W. Edwards, PhD., Chair

Sheldon F. Owen, PhD.

Jeffrey Wimsatt, DVM, PhD., DACLAM

Raymond E. Rainbolt, M.S.

Division of Forestry and Natural Resources

Morgantown, West Virginia

2017

KEYWORDS: black-legged tick, Borrelia burgdorferi, cover type, diversity, Ixodes scapularis, Lyme disease, mast production, small mammals

Copyright 2017 Samantha R. Fino 


\begin{abstract}
Black-legged tick distributions, small mammal abundances, mast production, and vegetative influences on Lyme disease apparent prevalence on Fort Drum Military Installation, New York
\end{abstract}

\title{
Samantha R. Fino
}

Lyme disease is the most common infectious disease spread by black-legged ticks in the Northern Hemisphere. Lyme disease is a vector-borne zoonotic disease typically caused by bacterial spirochetes of the species Borrelia burgdorferi. The primary vector of Lyme disease in the Midwestern and eastern United States is Ixodes scapularis, the deer or black-legged tick. Although there are several preventative measures against ticks that carry Lyme disease, such as public education regarding personal protection (e.g., wearing light colored clothing, tucking pants into socks, wearing repellent, promptly inspecting oneself to remove ticks, getting pets vaccinated) and recommended control measures, it is important to understand how the disease is transmitted and which factors increase the potential risk of contracting the disease. Even with these preventative measures, which are not necessarily available worldwide, tick-borne diseases are increasing both in numbers and impact to the overall human population, and there are still several knowledge gaps and conflicting findings that need to be elucidated. For these reasons, there exists a need for further research on Lyme disease ecology to identify steps necessary to decrease disease prevalence and reduce human exposure. I conducted a field study on the Cantonment Area of Fort Drum Military Installation, New York, which is representative of a suburban community with multiple cover types. From May 2015-November 2016 I surveyed the Cantonment Area to evaluate the basic distributions of Ixodes scapularis and small mammal host species, their relationships with vegetative characteristics, and associated Lyme disease apparent 
prevalence. This will allow resource managers to assess and communicate the likelihood of encountering a Lyme-positive tick and to take necessary actions to minimize that risk. Specifically, our objective was to assess the apparent prevalence of Lyme disease based on the distributions and indice of abundance of the vector and host populations on Fort Drum.

I used tick drags to evaluate black-legged tick temporal and spatial distributions in six different cover types discriminated by developmental stage. Total index of tick abundance was related to (1) temperature, (2) humidity, (3) coarse woody debris, (4) leaf litter depth, (5) tree species richness (6) average tree dbh, and (7) patch size. Adult index of abundance was greatest in the spring and fall, while nymph index of abundance was greatest in early summer and larval index of abundance was greatest at the end of summer. Tick and Lyme-positive tick indices of abundance were greatest in the coniferous and mixed cover type and lowest in the shrub and deciduous cover type. Overall Lyme disease apparent prevalence on the Cantonment Area of Fort Drum was 35\% (434/1246). These results provide objective criteria for understanding a baseline of tick distributions on a temporal and spatial scale, and assist in developing management recommendations to decrease Lyme disease apparent prevalence on the landscape.

I used Sherman and Tomahawk traps to capture individuals from the overall small mammal host community during June-August. The small mammal community was composed mostly of Peromyscus sp. $(\mathrm{n}=79 ; 38 \%)$, chipmunk $(\mathrm{n}=59 ; 28 \%)$, red squirrel $(\mathrm{n}=33 ; 16 \%)$, gray squirrel $(\mathrm{n}=18 ; 9 \%)$. Trapping success, as well as Simpson's and Shannon's indices of diversity were greatest in the developed and coniferous forest cover types. Indices of abundance of small mammals were greatest in the developed cover type, followed by coniferous forest. We modeled the relation between estimated index of abundance of ticks with the estimated index of abundance of all small mammal host species, as well as the relationship between estimated index 
of abundance of Lyme-positive ticks and small mammal host Simpson's and Shannon's indices of diversity. Although Peromyscus sp. had a greater number of individuals with tick burdens, there was significantly greater estimated index of abundance of Lyme-positive tick burdens on chipmunks. Furthermore, a significantly greater proportion of sampled chipmunks $(58 \%)$ had Lyme-positive ear punches.

My results suggest that habitat management in the coniferous and mixed forest that target vector and host habitat is necessary in order to decrease Lyme disease prevalence and reduce risk of human exposure. Recommendations such as removal of the leaf/pine litter and coarse woody debris, which provide stable microhabitat for ticks and small mammals alike, a selective cut of large conifer trees, allowing sunlight and wind penetration that encourages tick desiccation, and creating and mowing grassland barrier habitat between human developed areas and forested areas are possible solutions for decreasing Lyme disease prevalence and human risk of exposure on the landscape. Public education seminars regarding black-legged tick spatial and temporal distributions, as well as explaining recommended control measures for personal property should also be developed in order to communicate Lyme disease risk to residents on Fort Drum Military Installation. 


\section{ACKNOWLEDGMENTS}

There are several people who have helped me along my journey at WVU to be a rewarding and worthwhile one. I would first like to thank my graduate advisor, Dr. John Edwards, for his consistent support, assistance, and guidance, with which this experience would otherwise have not been possible. I would like to thank the rest of my thesis committee, Dr.

Owen, Dr. Wimsatt, and Ray Rainbolt for also assisting me through this process with their ample guidance. All committee members have been extremely helpful with the development, sample collection, data analysis, and writing aspects of this project, donating several hours of their time. I would also like to express gratitude for my technician and friend at Fort Drum, James Maine. Without his day to day field work accompanied by a positive attitude and endless knowledge, data collection for this project would not have been possible. I would also like to thank Brian Hendrick of WVU OLAR as well as Melissa Miller and Meagan Marshall at Fort Meade Public Health Command for their contributions toward tick pathogen testing. Additionally, I am thankful for my fellow graduate students, friends, and family who have all provided endless support during this chapter in my life. This project could not have been completed without the contributions from everyone involved, and for that I am extremely appreciative. 


\section{TABLE OF CONTENTS}

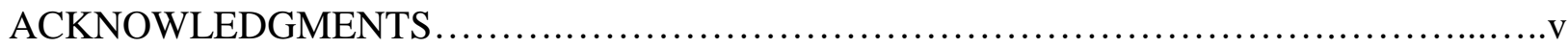

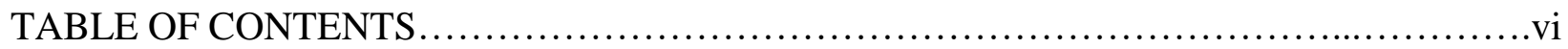

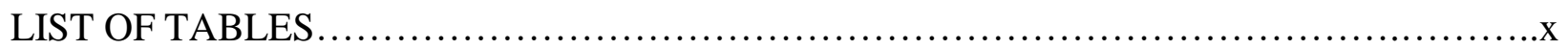

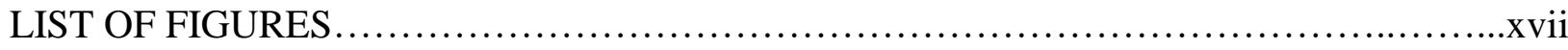

CHAPTER 1: LITERATURE REVIEW ..............................................

Lyme disease (Borrelia burgdorferi) and other tick-borne diseases.........................2

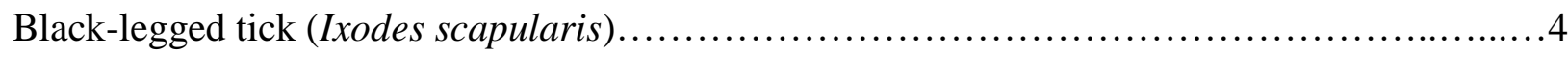

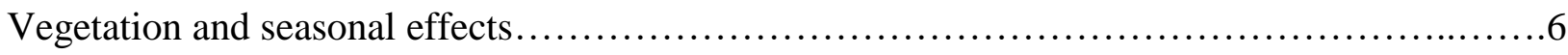

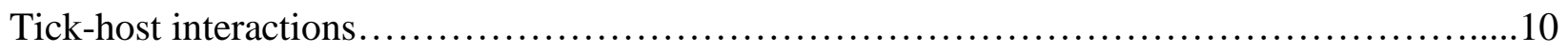

Habitat selection of host species................................................. 16

CHAPTER 2: LYME DISEASE (BORRELIA BURGDORFERI) APPARENT PREVALENCE AND BLACK-LEGGED TICK (IXODES SCAPULARIS) DISTRIBUTIONS ON A TEMPORAL AND SPATIAL SCALE ON FORT DRUM MILITARY INSTALLATION, NEW

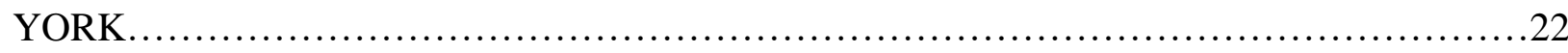

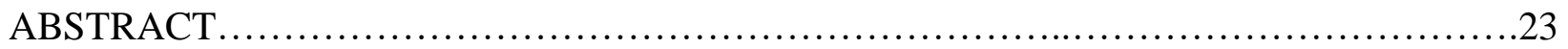

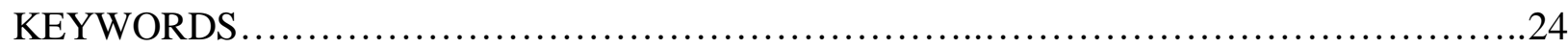


INTRODUCTION.

STUDY AREA.

METHODS

Off-host tick collection. .28

Borrelia burgdorferi detection .29

Vegetation surveys. .31

Statistical analysis 32

RESULTS .34

DISCUSSION 36

CHAPTER 3: INFLUENCE OF SMALL MAMMAL ABUNDANCE AND DIVERSITY ON BLACK-LEGGED TICK (IXODES SCAPULARIS) ABUNDANCE AND LYME DISEASE (BORRELIA BURGDORFERI) PREVELANCE ON FORT DRUM MILITARY

INSTALLATION, NEW YORK.

ABSTRACT.

KEYWORDS

METHODS . .48

Small mammal capture. .48 
Mast collection.

Statistical analysis

RESULTS .54

DISCUSSION

CHAPTER 4: MANAGEMENT RECOMMENDATIONS FOR LYME DISEASE (BORRELIA

BURGDORFERI) ON FORT DRUM MILITARY INSTALLATION, NEW YORK .63

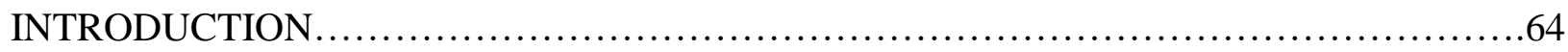

MANAGEMENT RECOMMENDATIONS .........................................65

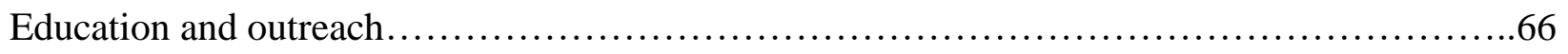

Habitat management.........................................................67

Tick management........................................................... 70

Small mammal management.................................................... 71

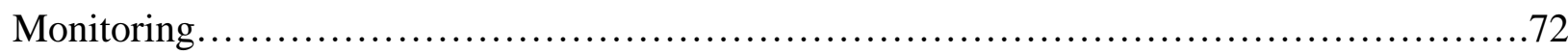

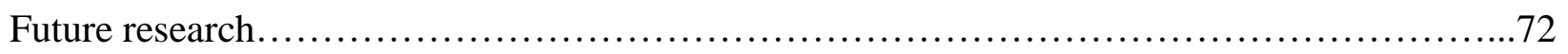

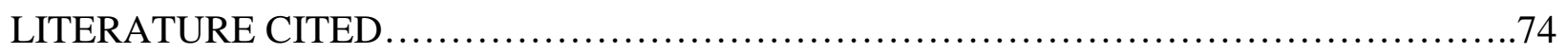

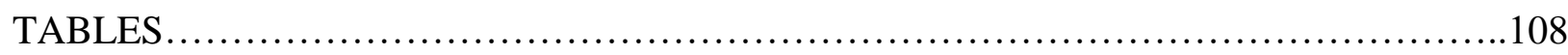




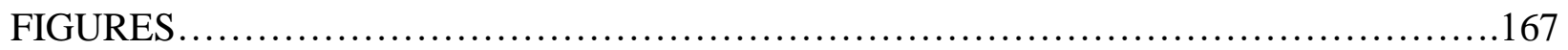

APPENDICES .................................................................... 193 


\section{LIST OF TABLES}

Table 2.1. Explanatory variables used in candidate Poisson models to evaluate variation in estimated index of abundance of black-legged ticks on Fort Drum Military Installation, New York, during April-November, 2015-2016.

Table 2.2. Relative support for 16 candidate Poisson models of estimated index of abundance of total questing ticks (A) on Fort Drum Military Installation, New York, during April-November, 2015-2016. $K$ indicates the number of model parameters, AICc is Akaike's information criterion corrected for small sample size, $\triangle \mathrm{AICc}$ is the difference in AICc units from the best approximating model, while $w$ is the model weight. See Table 2.1 for description of model variables.

Table 2.3. Model parameter estimates for Poisson models of estimated index of abundance of total questing ticks (A) on Fort Drum Military Installation, New York, during April-November, 2015-2016 within $\triangle \mathrm{AICc}$ of 2 used in model averaging to determine the final model. Parameter estimates $(\beta)$ are presented with standard errors (SE) as well as $\mathrm{Z}$ and $\mathrm{p}(\mathrm{Pr})$ values.

Table 2.4. Model parameter estimates for Poisson models of estimated index of abundance of adult questing ticks (Aa) on Fort Drum Military Installation, New York, during April-November, 2015-2016 within $\triangle \mathrm{AICc}$ of 2 used in model averaging to determine the final model. Parameter estimates $(\beta)$ are presented with standard errors (SE) as well as $\mathrm{Z}$ and $\mathrm{p}(\mathrm{Pr})$ values.

Table 2.5. Model parameter estimates for Poisson models of estimated index of abundance of questing nymphs (An) on Fort Drum Military Installation, New York, during April-November, 2015-2016 within $\triangle \mathrm{AICc}$ of 2 used in model averaging to determine the final model. Parameter estimates $(\beta)$ are presented with standard errors (SE) as well as $\mathrm{Z}$ and $\mathrm{p}(\mathrm{Pr})$ values. 
Table 2.6. Model parameter estimates for Poisson models of estimated index of abundance of questing nymphs (Al) on Fort Drum Military Installation, New York, during April-November, 2015-2016 within $\triangle \mathrm{AICc}$ of 2 used in model averaging to determine the final model. Parameter estimates $(\beta)$ are presented with standard errors (SE) as well as $\mathrm{Z}$ and $\mathrm{p}(\mathrm{Pr})$ values.

Table 2.7. Model parameter estimates for Poisson models of estimated index of abundance of questing nymphs $(\mathrm{Pa})$ on Fort Drum Military Installation, New York, during April-November, 2015-2016 within $\triangle \mathrm{AICc}$ of 2 used in model averaging to determine the final model. Parameter estimates $(\beta)$ are presented with standard errors (SE) as well as $\mathrm{Z}$ and $\mathrm{p}(\mathrm{Pr})$ values.

Table 2.8. Model parameter estimates for Poisson models of estimated index of abundance of questing nymphs (Pn) on Fort Drum Military Installation, New York, during April-November, 2015-2016 within $\triangle \mathrm{AICc}$ of 2 used in model averaging to determine the final model. Parameter estimates $(\beta)$ are presented with standard errors (SE) as well as $\mathrm{Z}$ and $\mathrm{p}(\mathrm{Pr})$ values.

Table 2.9. Parametric bootstrapped estimates of index of abundance of ticks from a generalized linear Poisson model on Fort Drum Military Installation, New York, during April-November, 2015-2016 spatially and temporally. Statistical significance with a 95\% confidence interval estimated by bootstrapping is noted by an asterisk $(\mathrm{alpha}=0.05)$. The symbol $>$ indicates the item in the column on the left is significantly greater than the item in the column on the right. The symbol < indicates the item in the column on the right is significantly greater than the item in the column on the left. NAs represent that no ticks of that developmental stage were collected during that month.

Table 2.10. Parametric bootstrapped estimates of index of abundance of Lyme-positive ticks from a generalized linear Poisson model on Fort Drum Military Installation, New York, during 
April-November, 2015-2016 spatially and temporally. Statistical significance with a 95\%

confidence interval estimated by bootstrapping is noted by an asterisk (alpha $=0.05)$. The symbol > indicates the item in the column on the left is significantly greater than the item in the column on the right. The symbol < indicates the item in the column on the right is significantly greater than the item in the column on the left. NAs represent that no ticks of that developmental stage were collected during that month.

Table 2.11. Apparent prevalence of Borrelia burgdorferi on a spatial and temporal scale on Fort Drum Military Installation, New York during 2015-2016.

Table 2.12. Percentage of positive-Borrelia burgdorferi tick per 100 square meters on Fort Drum Military Installation, New York, during April-November 2015-2016.

Table 2.13. Apparent prevalence of Borrelia miyamotoi on a spatial and temporal scale on Fort Drum Military Installation, New York during 2015-2016.

Table 2.14. Apparent prevalence of Anaplasma phagocytophilum on a spatial and temporal scale on Fort Drum Military Installation, New York during 2015-2016.

Table 3.1. Model parameter estimates for Poisson models of estimated index of abundance of total questing ticks (A) on Fort Drum Military Installation, New York, during April-November, 2015-2016 within $\triangle \mathrm{AICc}$ of 2 used in model averaging to determine the final model. Parameter estimates ( $\beta$ ) are presented with standard errors (SE) as well as $\mathrm{Z}$ and $\mathrm{p}(\mathrm{Pr})$ values.

Table 3.2. Model parameter estimates for Poisson models of estimated index of abundance of Borrelia burgdorferi-positive questing ticks (P) on Fort Drum Military Installation, New York, during April-November, 2015-2016. Parameter estimates ( $\beta$ ) are presented with standard errors (SE) as well as $\mathrm{Z}$ and $\mathrm{p}(\mathrm{Pr})$ values. 
Table 3.3. Relative support for 5 candidate Poisson models of estimated index of abundance of Peromyscus sp. (D) on Fort Drum Military Installation, New York, 2015-2016. $K$ indicates the number of model parameters, AICc is Akaike's information criterion corrected for small sample size, $\triangle \mathrm{AICc}$ is the difference in AICc units from the best approximating model, while $\mathrm{W}$ is the model weight. See Table 2.1 for description of model variables.

Table 3.4. Model parameter estimates for Poisson models of estimated index of abundance of Peromyscus sp. (D) on Fort Drum Military Installation, New York, 2015-2016 within $\Delta$ AICc of 2 used in model averaging to determine the final model. Parameter estimates $(\beta)$ are presented with standard errors (SE) as well as $\mathrm{Z}$ and $\mathrm{p}(\mathrm{Pr})$ values.

Table 3.5. Relative support for 5 candidate Poisson models of estimated index of abundance of chipmunk (C) on Fort Drum Military Installation, New York, 2015-2016. $K$ indicates the number of model parameters, AICc is Akaike's information criterion corrected for small sample size, $\triangle \mathrm{AICc}$ is the difference in AICc units from the best approximating model, while $\mathrm{W}$ is the model weight. See Table 2.1 for description of model variables.

Table 3.6. Model parameter estimates for Poisson models of estimated index of abundance of chipmunk (C) on Fort Drum Military Installation, New York, 2015-2016 within $\Delta$ AICc of 2 used in model averaging to determine the final model. Parameter estimates $(\beta)$ are presented with standard errors (SE) as well as $\mathrm{Z}$ and $\mathrm{p}(\mathrm{Pr})$ values.

Table 3.7. Relative support for 5 candidate Poisson models of estimated index of abundance of red squirrel (R) on Fort Drum Military Installation, New York, 2015-2016. K indicates the number of model parameters, AICc is Akaike's information criterion corrected for small sample size, $\triangle \mathrm{AICc}$ is the difference in AICc units from the best approximating model, while $\mathrm{W}$ is the model weight. See Table 2.1 for description of model variables. 
Table 3.8. Model parameter estimates for Poisson models of estimated index of abundance of red squirrel (R) on Fort Drum Military Installation, New York, 2015-2016 within $\Delta \mathrm{AICc}$ of 2 used in model averaging to determine the final model. Parameter estimates $(\beta)$ are presented with standard errors (SE) as well as $\mathrm{Z}$ and $\mathrm{p}(\mathrm{Pr})$ values.

Table 3.9. Relative support for 5 candidate Poisson models of estimated index of abundance of gray squirrel $(\mathrm{G})$ on Fort Drum Military Installation, New York, 2015-2016. $K$ indicates the number of model parameters, AICc is Akaike's information criterion corrected for small sample size, $\triangle \mathrm{AICc}$ is the difference in AICc units from the best approximating model, while $\mathrm{W}$ is the model weight. See Table 2.1 for description of model variables.

Table 3.10. Model parameter estimates for Poisson models of estimated index of abundance of gray squirrel (G) on Fort Drum Military Installation, New York, 2015-2016 within $\triangle$ AICc of 2 used in model averaging to determine the final model. Parameter estimates $(\beta)$ are presented with standard errors (SE) as well as $\mathrm{Z}$ and $\mathrm{p}(\mathrm{Pr})$ values.

Table 3.11. Relative support for 5 candidate Poisson models of estimated index of abundance of all host species $(\mathrm{H})$ on Fort Drum Military Installation, New York, 2015-2016. $K$ indicates the number of model parameters, AICc is Akaike's information criterion corrected for small sample size, $\triangle \mathrm{AICc}$ is the difference in AICc units from the best approximating model, while $\mathrm{W}$ is the model weight. See Table 2.1 for description of model variables.

Table 3.12. Model parameter estimates for Poisson models of estimated index of abundance of all host species $(\mathrm{H})$ on Fort Drum Military Installation, New York, 2015-2016 within $\Delta$ AICc of 2 used in model averaging to determine the final model. Parameter estimates $(\beta)$ are presented with standard errors (SE) as well as $\mathrm{Z}$ and $\mathrm{p}(\mathrm{Pr})$ values. 
Table 3.13. Parametric bootstrapped estimates of index of abundance of small mammal hosts from a generalized linear Poisson model on Fort Drum Military Installation, New York, 20152016. Statistical significance with a $95 \%$ confidence interval estimated by bootstrapping is noted by an asterisk (alpha=0.05). The symbol $>$ indicates the item in the column on the left is significantly greater than the item in the column on the right. The symbol < indicates the item in the column on the right is significantly greater than the item in the column on the left.

Table 3.14. Trapping success, Simpson's diversity index and Shannon's diversity index on Fort Drum Military Installation, New York, 2015-2016.

Table 3.15. Parametric bootstrapped estimates of average trapping success, Simpson's diversity index and Shannon's diversity index from a generalized linear Poisson model on Fort Drum Military Installation, New York, 2015-2016. Statistical significance with a 95\% confidence interval estimated by bootstrapping is noted by an asterisk (alpha $=0.05)$. The symbol $>$ indicates the item in the column on the left is significantly greater than the item in the column on the right. The symbol < indicates the item in the column on the right is significantly greater than the item in the column on the left.

Table 3.16. Jaccard's index of similarity between cover types on Fort Drum Military Installation, New York, 2015-2016.

Table 3.17. Individuals with tick burdens and individuals exposed to Borrelia burgdorferi via Lyme-positive tick burdens on Fort Drum Military Installation, New York, during 2015-2016.

Table 3.18. Model parameter estimates for binomial models of estimated index of abundance of individuals with tick burdens (T) on Fort Drum Military Installation, New York, 2015-2016 
within $\triangle \mathrm{AICc}$ of 2 used in model averaging to determine the final model. Parameter estimates ( $\beta$ ) are presented with standard errors (SE) as well as $\mathrm{Z}$ and $\mathrm{p}(\mathrm{Pr})$ values.

Table 3.19. Model parameter estimates for binomial models of estimated index of abundance of individuals with Lyme-positive tick burdens (B.burg) on Fort Drum Military Installation, New York, 2015-2016 within $\triangle \mathrm{AICc}$ of 2 used in model averaging to determine the final model. Parameter estimates $(\beta)$ are presented with standard errors (SE) as well as $\mathrm{Z}$ and p (Pr) values. Table 3.20. Parametric bootstrapped estimates of number of tick burdens and Lyme-positive tick burdens off host species from a generalized linear Poisson model on Fort Drum Military Installation, New York, 2015-2016. Statistical significance with a 95\% confidence interval estimated by bootstrapping is noted by an asterisk $(\mathrm{alpha}=0.05)$. The symbol $>$ indicates the item in the column on the left is significantly greater than the item in the column on the right. The symbol < indicates the item in the column on the right is significantly greater than the item in the column on the left. No Lyme-positive tick burdens were found on gray squirrel of the shrub forest cover type.

Table 3.21. Summary statistics of small mammal captured individuals on Fort Drum Military Installation, New York, during 2015-2016.

Table 3.22. Summary statistics of Lyme-disease apparent prevalence from ear punch samples on Fort Drum Military Installation, New York, during 2016. 


\section{LIST OF FIGURES}

Figure 1.1. Study area: Fort Drum Military Installation, New York.

Figure 1.2. The cover types within the Cantonment Area of Fort Drum Military Installation, New York.

Figure 2.1. A vegetation survey plot on Fort Drum Military Installation, New York.

Figure 2.2. Estimated index of abundance of questing adult ticks with a $95 \%$ confidence interval on Fort Drum Military Installation, New York, during April-November, 2015-2016.

Figure 2.3. Estimated index of abundance of questing nymphal ticks with a $95 \%$ confidence interval on Fort Drum Military Installation, New York, during April-November, 2015-2016.

Figure 2.4. Estimated index of abundance of questing larval ticks with a 95\% confidence interval on Fort Drum Military Installation, New York, during April-November, 2015-2016.

Figure 2.5. Estimated index of abundance of B. burgdorferi-positive questing adult ticks with a 95\% confidence interval on Fort Drum Military Installation, New York, during April-November, 2015-2016.

Figure 2.6. Estimated index of abundance of B. burgdorferi-positive questing nymphal ticks with a 95\% confidence interval on Fort Drum Military Installation, New York, during AprilNovember, 2015-2016.

Figure 2.7. Estimated index of abundance of ticks related to temperature with a $95 \%$ confidence interval on Fort Drum Military Installation, New York, during April-November, 2015-2016. 
Figure 2.8. Estimated index of abundance of ticks related to relative humidity with a $95 \%$ confidence interval on Fort Drum Military Installation, New York, during April-November, 20152016.

Figure 2.9. Estimated index of abundance of ticks related to coarse woody debris decay with a 95\% confidence interval on Fort Drum Military Installation, New York, during April-November, 2015-2016.

Figure 2.10. Estimated index of abundance of ticks related to leaf litter depth with a $95 \%$ confidence interval on Fort Drum Military Installation, New York, during April-November, 20152016.

Figure 2.11. Estimated index of abundance of ticks related to tree species richness with a $95 \%$ confidence interval on Fort Drum Military Installation, New York, during April-November, 20152016.

Figure 2.12. Estimated index of abundance of ticks related to $\mathrm{dbh}(\mathrm{cm})$ with a $95 \%$ confidence interval on Fort Drum Military Installation, New York, during April-November, 2015-2016.

Figure 2.13. Estimated index of abundance of ticks related to patch size $\left(\mathrm{m}^{2}\right)$ with a $95 \%$ confidence interval on Fort Drum Military Installation, New York, during April-November, 20152016.

Figure 3.1. Species composition of the small mammal community with a $95 \%$ confidence interval within the Cantonment Area of Fort Drum Military Installation, New York during 2015-2016.

Figure 3.2. Estimated index of abundance of red squirrel related to stem density with a $95 \%$ confidence interval on Fort Drum Military Installation, New York, 2015-2016. 
Figure 3.3. Estimated index of abundance of gray squirrel related to tree species richness with a 95\% confidence interval on Fort Drum Military Installation, New York, 2015-2016.

Figure 3.4. Estimated index of abundance of gray squirrel related to snag decay with a $95 \%$ confidence interval on Fort Drum Military Installation, New York, 2015-2016.

Figure 3.5. Estimated index of abundance of gray squirrel related to midstory cover with a 95\% confidence interval on Fort Drum Military Installation, New York, 2015-2016.

Figure 3.6. Estimated index of abundance of small mammal hosts related to snag decay with a $95 \%$ confidence interval on Fort Drum Military Installation, New York, 2015-2016.

Figure 3.7. Estimated index of abundance of ticks related to estimated index of abundance of all small mammal host species with a 95\% confidence interval on Fort Drum Military Installation, New York, 2015-2016.

Figure 3.8. Estimated index of abundance of Lyme-positive ticks related to small mammal host Shannon's index of diversity with a 95\% confidence interval on Fort Drum Military Installation, New York, 2015-2016.

Figure 3.9. Estimated index of abundance of Lyme-positive ticks related to small mammal host Simpson's index of diversity with a 95\% confidence interval on Fort Drum Military Installation, New York, 2015-2016.

Figure 3.10. Estimated index of abundance of small mammal hosts with a tick burden with a 95\% confidence interval on Fort Drum Military Installation, New York, 2015-2016. 
Figure 3.11. Estimated index of abundance of small mammal hosts exposed to a Lyme-positive tick burden with a 95\% confidence interval on Fort Drum Military Installation, New York, 20152016. 
CHAPTER 1

LITERATURE REVIEW 


\section{LITERATURE REVIEW}

\section{Lyme disease (Borrelia burgdorferi) and other tick-borne diseases}

Lyme disease is the most common infectious disease spread by black-legged ticks (Ixodes scapularis) in the Northern Hemisphere (Berger 2014). Lyme disease is a vector-borne zoonotic disease typically caused by bacterial spirochetes of the species Borrelia burgdorferi (Burgdorfer et al. 1982, Johnson et al. 1984). The disease is spreading across North America (CDC 2014) but predominantly exists in the Northeast and upper Midwest (CDC 2013). The number of confirmed cases of Lyme disease increased from 11,700 in 1995 to 27,203 in 2013 (CDC 2014, CDC 2015c). There are more than 30,000 cases reported to the Center for Disease Control (CDC) annually, but the total number of people diagnosed is estimated to be 10 times higher and the number of unreported cases is likely higher still (CDC 2013). Lyme disease has been reported in all states except Hawaii, but the majority (96\%) of the cases occur in 13 states of the Northeast and upper Midwest (CDC 2013). Infection rates in the southeastern and western states are between 1-5\% (Lane et al. 1991, Ginsberg 1994). Although there are effective antibiotic treatments such as doxycycline, amoxicillin, or cefuroxime axetil, ceftriaxone and penicillin, that can alleviate symptoms in individuals with acute infections, previous unrecognized chronic Lyme disease can be difficult if not impossible to treat. Likewise, post-Lyme (autoimmune) sequelae have been reported (CDC 2015b). Although antibiotics alleviate the symptoms, in a subset of "nonresponders" there is likely no cure for the disease (CDC 2015d). It has been estimated that to significantly decrease the rate of transmission, black-legged tick densities, the primary vector of Borrelia burgdorferi, must be lowered so that humans get bitten <1 time a year to reduce the rates of human infection (Ginsberg 1994). 
The primary vector of Lyme disease in the Midwestern and eastern United States is Ixodes scapularis, the deer or black-legged tick. The black-legged tick is located along the east coast, into the south and west into Texas, as well as in the upper Midwest. Ixodes pacificus, the western black-legged tick, located along the west coast and Amblyomma americanus, the Lone Star tick, located in the eastern half of the country except for the northern portions, can also transmit Lyme disease (Armstrong et al. 2001). The ability of a tick to transmit or contract Borrelia burgdorferi is dependent on the amount of time it is attached to the host. Potential risk for infection significantly declines if a tick is removed within 36-48 hours (CDC 2017b). Borrelia burgdorferi is ingested through a blood meal and resides in the midgut of the tick. During the tick's next blood meal, Borrelia burgdorferi detaches and penetrates the stomach lining into the hemocoel, or body cavity, and then migrates into the salivary glands. Borrelia burgdorferi is then passed to the host with the salivary fluid during a blood meal (Tilly et al. 2008).

Although there are several preventative measures against Lyme disease, such as public education regarding personal protection (e.g., wearing light colored clothing, tucking pants into socks, wearing repellent, promptly inspecting oneself to remove ticks, getting pets vaccinated) (Ginsberg 1994) and recommended control measures (Stafford 2004), it is important to understand how the disease is transmitted and which factors increase the potential risk of contracting the disease. Even with these preventative measures, which are not necessarily available worldwide, tick-borne diseases are increasing both in numbers and impact to the overall human population, and there are still several knowledge gaps and conflicting findings that need to be elucidated. For these reasons, there exists a need for further research on tick- 
borne disease ecology to identify steps necessary to decrease disease prevalence and reduce human exposures.

There are several factors that influence the prevalence of Lyme disease on a landscape. Because individual black-legged ticks (Ixodes scapularis) spend 98\% of their life off-host, environmental conditions, specifically temperature and humidity, determine tick distributions, host-seeking ability and success, and survival (Needham and Teel 1991, Fish 1993, Lindsay et al. 1995, Bertrand and Wilson 1996, Jones and Kitron 2000). If conditions put ticks at risk of desiccation they will not quest, which is the behavior where ticks climb vegetation and lay on their back with legs splayed in search of a host. The probability of encountering a host depends on host abundance and distribution (Ostfeld et al. 1995, Ostfeld et al. 1996c, Brunner and Ostfeld 2008) while successful feeding and transmission of the disease depends in large measure on host specificity (Van Buskirk and Ostfeld 1995, Wilder and Meikle 2006, LoGiudice et al. 2008). Density and diversity of host populations are heavily dependent on the availability of food resources, specifically mast or seed production (Ostfeld et al. 1996a, McKracken et al. 1999, McShea 2000, Elias et al. 2004). These contributors to the prevalence and risk of Lyme disease vary among cover types as a result of specific vegetation characteristics preferred by vector and host species.

\section{Black-legged tick (Ixodes scapularis)}

The complete life cycle of a black-legged tick spans about 2 years, has 4 developmental stages (egg, larva, nymph, adult), and requires 3 successful blood meals, each from a distinct vertebrate host (Hazler and Ostfeld 1995, Bertrand and Wilson 1996, Ostfeld et al. 1996a). About 2,000 eggs are layed by a gravid female and typically hatch midsummer with the exact timing 
depending on the year. The larvae that hatch acquire their first blood meal from an animal in the following months; each feeding lasts 3-7 days. Fed larva will molt into a nymph after about a month and overwinter in leaf litter. The second blood meal is also from an animal and obtained during the following summer whereby the nymph molts into an adult in the fall (Ginsberg 1994, Shaw 2001). White-tailed deer (Odocoileus virginianus) are the primary hosts for adult Ixodes scapularis (Piesman et al. 1979, Anderson and Magnarelli 1980, Schulze et al. 1984, Spielman et al. 1985), which typically quest in the fall or the following spring (if finding a blood meal is unsuccessful before this) (Bertrand and Wilson 1996). Blood-fed adults will mate in the fall on deer, and females deposit egg masses under leaf litter. Larvae congregate in early summer primarily in forested habitat corresponding to locations occupied by white-tailed deer (Wilson et al. 1985, Maupin et al. 1991, Fish 1993, Ostfeld et al 1995). As a result of their life cycle, tick populations are often dominated by a particular developmental stage during different times of the year. Nymphs predominate in early to mid-summer while larvae predominate early spring and again in late summer (Mannelli et al. 1994, Ostfeld et al. 1995, Brunner and Ostfeld 2008). Different populations of black-legged ticks have two peaks of the nymph with the second being in late summer (Arsnoe et al. 2015). However, by fall, adults are the dominant developmental stage with the greatest abundance of tick populations found in oak woodlands favored by whitetailed deer (Ostfeld et al. 1995, Brunner and Ostfeld 2008). Ostfeld et al. (1996a) found that in deciduous forests of the eastern United States, larval densities were 10 times higher in oak (Quercus sp.) predominant forests than in any other habitats when acorn production was high and in maple (Acer sp.) predominated forests when acorn production was poor.

The prevalence of human Lyme disease is most directly influenced by the abundance of nymphs which is determined by the success of larvae from the previous year that were able to 
feed on hosts without being compromised by biotic and abiotic influences on survivorship and molting success (Hazler and Ostfeld 1995). Spirochetes are not passed from adult female ticks to progeny efficiently, so larvae typically emerge free of Borrelia burgdorferi (Shaw 2001). Larval Ixodes scapularis, remaining within a few meters from the location of hatching (Daniels and Fish 1990, Stafford 1992), obtain Borrelia burgdorferi during their first blood meal if the host is infected (Anderson 1988, Lane et al. 1991). Ixodes scapularis can become infected by the host during any of their blood meals, and remain infected for the rest of their life cycle (Shaw 2001). Questing, infected nymphs are the greatest threat to humans because of their small size (1 mm) and difficulty of detection (Falco and Fish 1989, Ostfeld et al. 1996c, Schmidt et al. 1999). Additionally, peak nymphal tick activity occurs in the midsummer months when humans are more active in tick habitat (Lane et al. 1991, Barbour and Fish 1993, Shaw 2001).

\section{Vegetation and seasonal effects}

Environmental conditions, land cover, and landscape patterns, influence the abundance and distributions of vector hosts as well as vertebrate reservoirs of Lyme disease (Pavlovsky 1966, Randolph 1993, Ostfeld et al. 1996b, Kitron 1998, Hay et al. 2000, Lindgren et al. 2000). Temperature and humidity, largely influence and regulate tick population distributions, hostseeking ability, and tick survival (Jones and Kitron 2000, Lindsay et al. 1995). Because Ixodes scapularis spends about $98 \%$ of its life cycle off of the host, seasonal changes in temperature and humidity will greatly affect population growth and the spread of black-legged ticks (Needham and Teel 1991, Fish 1993, Bertrand and Wilson 1996). Measuring environmental conditions is important to characterize these potential influences on tick questing success and survivability in conjunction with sampling tick populations. 
Methods to estimate the non-feeding tick population include the use of tick drags or flags constructed of a piece of light-colored cloth attached to wooden dowels with a rope handle that is dragged for a prescribed distance or time period to pick up questing ticks that attach to the fabric (Schulze and Jordan 2006). Drag sampling in dense herbaceous, shrub, or forested habitat, may underestimate the abundance of juvenile black-legged ticks that typically remain on or near the ground when questing because the cloth, by necessity, is dragged over taller vegetation (Ginsberg and Ewing 1989, Falco and Fish 1992, Schultze et al. 1997). Feeding tick populations can also be monitored by counting ticks on trapped small mammals (Schulze and Jordan 2006).

Seasonal changes in temperature and humidity will greatly affect the population growth and spread of black-legged ticks (Needham and Teel 1991, Fish 1993, Bertrand and Wilson 1996). Seasonal variables, such as cold temperatures and low humidity, not only slow development and growth rates of all stages in the life cycle (Needham and Teel 1991), but adverse conditions can prevent them from contributing to the spread of Lyme disease (Brownstein et al. 2003). Bertrand and Wilson (1996) found that increased temperatures and decreased relative humidity negatively affected development, oviposition, and hatching success, as well as overall survival. Ixodes scapularis is highly susceptible to desiccation when relative humidity drops below approximately 90\% (Stafford 1994).

Ostfeld et al. (1995) and Bertrand and Wilson (1996) found that, overall, black-legged ticks experienced higher rates of mortality in open field habitats than in forested habitats because both air and soil temperature are higher and relative humidity is lower. Similarly, smaller fragments, or areas of habitat that are separated from other patches of habitat, with greater edge effects undergo more frequent tick extinctions due to greater environmental fluctuations and 
harsher environmental conditions. In wetter years, questing behavior can occur higher up in the vegetation and hosts will likely be larger, thus affecting less reservoir-competent species such as squirrels (LoGuidice et al. 2008). Additionally, to better represent the desiccation risk, the average daily survival rate of black-legged ticks decreased as the vapor pressure deficit increased. Because ticks can accommodate fluctuating temperatures by seeking refuge under leaf litter, under conditions such as a higher vapor pressure, or the combination of both temperature and relative humidity, ground cover can serve as a compensating environmental factor (Bertrand and Wilson 1996).

Distributions of Ixodes scapularis among different habitat types have been extensively studied in a variety of locations. Although Ixodes scapularis has been found in all vegetation types, the highest densities are typically found in areas with trees (Daniel et al. 1977, Eisen et al. 2010, Dobson et al. 2011). Black-legged ticks are primarily detected in deciduous forest habitats of New England (Carey et al. 1980, Anderson and Magnarelli 1984), transition zones between coniferous and deciduous forest communities in Wisconsin (Godsey et al. 1987), and in dense woods of suburban Westchester County, New York (Maupin et al. 1991). Maupin et al. (1991) and Ostfeld et al. (1995) found, in general, that forested habitat types contained the highest densities of black-legged ticks compared to forest edge, shrubby or herbaceous habitat, respectively. In fact, forested habitats can maintain black-legged tick densities that are approximately 5 times greater than those in nearby open areas (Dobson et al. 2011). An area with dense woody vegetation inhibits wind, which in turn reduces saturation deficit (Gray 1991), enabling black-legged ticks to quest for longer periods of time (Perret et al. 2000) and at higher locations on vegetation, all while using less energy (Randolph and Storey 1999). Successional stage of the forest, or the forest's growth and maturity, also plays a role in suitability for ticks. 
Sites with increased tree sapling density were correlated with a decreased probability of tick-host interactions because of increased light penetration. Reduced light: 1) prevents photolytic low strata shrub vegetation growth (Richburg et al. 2001), thus causing tick desiccation; 2) less complex stems that provide a less suitable questing substrate; 3) less leaf cover at ground level causing a less hospitable habitat due to an increased saturation deficit, and desiccating conditions (Lindsay et al. 1999, Schultze and Jordan 2005).

Additionally, areas with more ground covered by surface water, saturated soil, and inundated leaf litter all had low Borrelia burgdorferi prevalence because of unsuitable conditions for molting and overwintering (Prusiniski et al. 2006), while sandy, well-drained soils provided improved habitat (Kitron et al. 1992, Glass et al. 1994). Tick densities are positively correlated with underlying sedimentary bedrock that is associated with increased particle size (Curtis 1959, Guerra et al. 2002). Although, leaf litter provides a more suitable microhabitat, which explains why black-legged ticks are more abundant in deciduous forests than in coniferous forests (Curtis 1959, Guerra et al. 2002), excessive moisture is negatively associated with Ixodes scapularis populations (Zhioua et al. 1999, Guerra et al. 2002). Soils with increased acidity and a high proportion of clay retain a greater amount of moisture, which can enhance the growth of fungi and entomophagous nematodes that negatively affect tick populations (Zhioua et al. 1999, Gerra et al. 2002). Furthermore, soil types influence the type of vegetation, and oak species prefer sandier soils (Curtis 1959, Guerra et al. 2002).

Although black-legged ticks are primarily found in woodlands and edge areas (Carey et al. 1980, Ginsberg and Ewing, 1989, Stafford and Magnarelli 1993), an uneven distribution of black-legged ticks may occur if there exists differential mortality of black-legged tick stages 
among habitat types, differential natality rates across habitat types, movements by the blacklegged ticks themselves, and similar such movements by their vertebrate hosts (Ostfeld et al. 1995). Abundance of larvae tick populations were greatest in forested habitats dominated by maple during the summer months, but forested habitats dominated by either maple or oak habitats support nymph tick populations that were about equal in abundance (Ostfeld et al. 1995). Although environmental conditions may significantly influence the maintenance of reproducing populations, factors such as host density and species composition might have a greater influence controlling tick population size and tick infection rates (Brownstein et al. 2003).

\section{Tick-host interactions}

Tick-host interactions leading to disease contraction and transmission are based on the strength of the host's immune response to tick antigens in the saliva as well as the ability of the tick to evade the immune response. While feeding, there are periodic interruptions for salivation that trigger a host immune response resulting in decreased feeding success or even rejection (Sononshine 1993). Therefore, heightened host immune and grooming responses are expected when there is a higher tick feeding density, which will reduce the quality or the quantity of each blood meal, as well as overall feeding success (Ostfeld et al. 1995, Brossard and Wikel 2004). Hazler and Ostfeld (1995) and Allan and Appel (1993) suggest that the host may develop resistance against Ixodes scapularis as the weight and percentage of engorged black-legged ticks decreased on pre-exposed hosts compared to naïve hosts. However, black-legged tick saliva contains anti-inflammatory and immunosuppressive agents that suppress host inflammatory responses and prevent hemostasis. Therefore, higher tick densities on a host may actually facilitate feeding (Ribeiro et al. 1985, Davidar et al. 1989). 
There are over 60 vertebrate species (Shaw 2001), approximately 29 species of mammals, 49 species of birds, and even some reptile species, that can serve as hosts for Ixodes scapularis, suggesting they are indiscriminate during host selection (Oliver 1989, James and Oliver 1990, Reed 1993, Schmidt 1999). In the Northeast, the most important host of immature black-legged ticks, particularly as relates to Lyme disease transmission, is the white-footed mouse (Peromyscus leucopus) (Bosler et al. 1984, Levine et al. 1985, Anderson et al. 1987, Magnarelli et al. 1988, Mather et al. 1989, Anderson and Magnarelli 1993, Apperson 1993, Levin and Fish 1998). This reflects not only its high abundance, widespread distribution, and frequency of tick parasitism, but also because it is the most competent reservoir of the Lyme disease spirochete. Hence black-legged ticks feeding on this species have a high probability of becoming infected with Borrelia burgdorferi during a blood meal from an infected individual (Shaw 2001); likewise these same ticks have a higher molting success into the next developmental stage compared to the same species of ticks feeding on other hosts (Davidar et al. 1989, James \& Oliver 1990, Mannelli et al. 1993, Mather \& Ginsberg 1994). Schmidt and Ostfeld (2000) reported this host's reservoir competence at $>90 \%$ based on newly molted nymphs; and Mather (1993) reported between 40-80\% of larvae feeding on an infected Peromyscus leucopus obtain Borrelia burgdorferi. The primary attachment site on white-footed mice is located on the auditory pinnae (Main et al. 1982). Finally, Ostfeld and Keesing (2012) found that white-footed mice were less likely to remove feeding ticks than other species of rodents or shrews.

The abundance and proportion of host-seeking and host feeding by black-legged ticks is influenced by population density and the distribution of the host species. The diversity and abundance of host species may help to assess the risk of Lyme disease to the human population (Ostfeld et al. 1995). The abundance of host-seeking ticks, as well as tick burdens on hosts, and 
their distributions are directly related to host densities (Ostfeld et al. 1995, Brunner and Ostfeld 2008). However, while tick density is a function of host density, spirochete prevalence is a function of each host's reservoir competence (Van Buskirk and Ostfeld 1998). Ostfeld et al. $(1995,1996 c)$ found that the probability of a black-legged tick encountering a host as well as the proportion of the total number of black-legged ticks attached to an individual white-footed mouse increases dramatically at higher population densities, such as above 10 mice per hectare. Van Buskirk and Ostfeld $(1995,1998)$ found that a highly infected tick population is maintained when the density of mice is at or above 20 per hectare for juveniles and white-tailed deer populations reach 5 per hectare for adults. At higher densities, although individual mice may experience a density-dependent reduction in their home range, the population will occupy a greater proportion of the landscape and therefore questing black-legged ticks maintain higher feeding success rates (Wolff 1985, Ostfeld et al. 1996c, Brunner and Ostfeld 2008). Although Peromyscus are territorial (Sadleir 1965, Healey 1967, Metzgar 1971, Fairbairn 1978, Wolff et al. 1983), which conceivably could contribute to the regulation of population densities, and even black-legged tick densities, under such circumstances, population densities of mice still appear to increase and expand in the presence of environmentally suitable habitats (Adler and Wilson 1987). A greater population of Peromyscus leucopus will provide increased opportunities for larvae to successfully feed and acquire Borrelia burgdorferi, resulting in a high abundance of infected nymphs and a greater risk to human populations the following year (Ostfeld et al. 2001).

Other small mammals abundant in deciduous eastern forests include the eastern chipmunk, Tamias striatus, as well as the short-tailed shrew, Blarina brevicauda, and the masked shrew, Sorex cinereus, and represent other major hosts for Ixodes scapularis nymphs (Schmidt et al. 1999, Shaw 2001, Brisson et al. 2008). These species in aggregate, along with 
Peromyscus sp., contribute 80-90\% of Borrelia infected ticks (Brisson et al. 2008). Chipmunks and shrews, however, are slightly less competent reservoirs and less efficient compared to mice at infecting black-legged ticks; it is believed this is due to protective physiological immune responses possessed by these hosts to the pathogen (Nupp and Swihart 2000, Ostfeld and Keesing 2000a, Anderson et al. 2003, Wilder and Meikle 2006). Schmidt et al. (1991) and Shaw (2001) determined that larval tick burdens are about 3 times higher on white-footed mice than on chipmunks in the same environment potentially due to their immunoresponse differences, however, larval burdens on mice decreased with increasing chipmunk abundance and burdens of nymphs on chipmunks declined with increasing mice abundance. Furthermore, male mice have larger burdens of ticks compared to females (Davidar et al. 1989, Schmidt et al. 1999, Perkins et al. 2003) and younger mice have a greater burdens compared to adults; these trends were not consistently found in chipmunks (Brunner and Ostfeld 2008). While black-legged ticks are thought of as opportunistic, Mannelli et al (1993) and Brunner and Ostfeld (2008) found Ixodes scapularis prefer different rodent hosts based on developmental stage potentially due to their questing height on the vegetation, with larvae preferring mice and nymphs preferring chipmunks, allowing for the most efficient reservoir to influence the abundance of infected nymphs and thus also the risk of infection by maintaining lower disease prevalences compared to an area occupied by only mice (Brisson et al. 2008).

The spread of Lyme disease is also dependent on host abundance, host-tick encounter rates, and the ability of the preferred host to transmit the agent to a feeding tick (Shaw 2001). Although mice were found to be more efficient groomers than chipmunks, their higher tick burdens counteract this ability (Shaw 2001). Additionally, allogrooming of young by mothers may also facilitate removal of ticks, however, this does not seem to be true for nymphs feeding 
on juvenile mice (Brunner and Ostfeld 2008). Keesing et al. (2009) found that certain species such as opossums (Didelphis virginiana) and squirrels (Sciurus sp.) have a more effective species-specific immune response, allowing these individuals to kill between $83-96 \%$ of tick burdens while increased grooming reduces infestations. Only 3\% and $15 \%$ of ticks that feed on opossums and squirrels, respectively, are successful (Keesing et al. 2009). Yet, squirrels receive 5 to 37 times as many infected tick bites compared to other host species (Randolph and Craine 1995), however, they are more effective groomers. Vertebrate species such as squirrels, deer, voles, raccoons, opossums and skunks are considered to be dilution hosts because they are poor reservoirs for Borrelia burdgorferi (Levi et al. 2016, LoGiudice et al. 2003, Brisson and Dykhuizen 2004). Because Ixodes scapularis can feed on many hosts, the ability to make a choice of hosts in the wild is only possible if potential hosts are abundant and the probability of specific host encounters is high. However, black-legged ticks are opportunistic and will attach to the first host they encounter (Shaw 2001). Thus, tick burdens will be more frequent on the most abundant host of the community, and in the Northeast, that host is the white-footed mouse. Similarly, when there is a high proportion of competent reservoir hosts for Borrelia burgdorferi, the potential risk of encountering an infected black-legged tick is greater (Keesing et al. 2009).

Ostfeld and Keesing (2000b) suggest the reason behind the increased reservoir competence of Peromyscus is because of its disproportionate, abundant population density in the community, and therefore more frequent and higher tick burdens that lead to successful molting. As a result, specialization on the most abundant host would allow increased survival of Ixodes scapularis. Borrelia burgdorferi may also have adapted to a specific vertebrate species to increase its reservoir competence (Shaw 2001). White-footed mice appear to better adapt to anthropogenic changes and forest fragmentation (LoGiudice et al. 2008) while coincidentally, 
these habitats cannot sustain a diversity of competitors and predators (Nupp and Swihart 1996, Krohne and Hoch 1999, Rosenblatt et al. 1999). In fact, Peromyscus leucopus densities have been found to rapidly increase in patch sizes <2 ha (Nupp and Swihart 1996, Krohne and Hoch 1999), and concentrate on edges of these patches in the absence of abundant mast (Ostfeld et al. 1995); conversely, densities decrease as distance from the edge increases (Horobik et al. 2001). As a result, nymphal infection prevalence increases with decreasing patch size (Allen et al. 2003). Similarly, there is a strong correlation between habitat fragmentation and both tick density and infection prevalence (Steere et al. 1978, Falco and Fish 1988, Frank et al. 1998, Ostfeld and Keesing 2000b, Brownstein et al. 2005). One reason for this is that white-tailed deer prefer edge habitat (Leopold 1933), and concomitantly, this results in the adult ticks dropping off and laying eggs at these sites. More importantly, it has been hypothesized that to reduce the risk of human exposure to Lyme disease, an increase in diversity of hosts, many of which are less competent reservoirs, will replace tick meals from mice and decrease infected black-legged tick associated prevalence (Van Buskirk and Ostfeld 1995, Rosenblatt et al. 1999, Ostfeld and Keesing 2000a, Ostfeld and Keesing 2000b). Brunner and Ostfeld (2008) found that as chipmunk densities declined, tick burdens on mice increased. Similarly, if the populations of competitor and predator species declined, more resources become available for mice populations and their reproductive success, survival and abundance will increase (Ostfeld and Keesing 2000, Schmidt and Ostfeld 2001, Keesling et al. 2009). As black-legged ticks are generalists and opportunistic in nature, a species-rich habitat with equal frequencies of host species would be expected to decrease the potential risk of encountering an infected black-legged tick (LoGiudice et al. 2008). However, in areas with high forest fragmentation, mice dominate the landscape near human communities increasing the risk of exposure. 


\section{Habitat selection of host species}

Human development often causes patchy landscapes, which in turn influences the distributions and abundances of wildlife species and their ectoparasites. Although Mannelli et al. (1994) found that habitat type did not play a significant role in the abundance of black-legged ticks on white-footed mice, Maupin et al. (1991) and Adler et al. (1992) both found that tick burdens on white-footed mice increased with density of woody vegetation and decreased with herbaceous vegetation. Other studies have found an increased probability of tick-host interactions and elevated tick burdens occur in areas with dense shrubby understory, specifically increased vegetation density at the lowest strata, including snags and coarse woody debris, due to its stable microclimate, increased relative humidity, and reduced predation risk for both black-legged ticks and hosts, all of which promote tick survival (Ginsberg and Ewing 1989, Adler et al. 1992, Goddard 1992, Stafford 1994, Lindsay et al. 1999, Schmidt et al. 1999, Lubelczyk et al. 2004, Prusiniski et al. 2006). Woody debris and brush piles, common in forested habitats, also provide the above benefits and have been found to increase overwinter survival in small mammals (Carey and Johnson 1995, Loeb 1996, Davis et al. 2010). Although the density of Peromyscus increases with denser woody vegetation (Myton 1974, Adler and Wilson 1987), Prusiniski et al. (2006) found that as density of woody vegetation and shrub coverage increased, small mammal diversity decreased; however, there was still a high occurrence of Borrelia burgdorferi infection due to the mice population. Regardless, because individual ticks can only move a few meters themselves (Falco and Fish 1989, Carroll and Schmidtmann 1996), the abundance and dispersal of blacklegged ticks across habitat types is heavily reliant on host distributions and movements, which are determined by patch size and juxtaposition (Ostfeld et al. 1995, Van Buskirk and Ostfeld 1998). 
Peromyscus leucopus are primarily dense woodland inhabitants (Baker 1968, Kaufman and Fleharty 1974, Bee et al. 1981, Kamler and Pennock 2004, Stancampiano and Schnell 2004). However, they can occupy a range of microhabitat types at high population densities, and are classified as habitat generalists (Adler et al. 1984, Clark et al. 1987, Seamon and Adler 1996, Kamler and Pennock 2004) and even thrive in low-diversity and degraded forest fragments (Nupp and Swihart 1996, Allen et al. 2003, LoGiudice et al. 2008, Keesing et al. 2009). Peromyscus is the only competent host species to be captured in all habitat types (Ostfeld et al. 1995). They are also known to more readily expand their range from forested habitat into small patches of shrubby or herbaceous habitat (Grant 1972, M'Closkey and Lajoie 1975, Ostfeld et al. 1995), compared to large patches of herbaceous habitat where competition with voles exists (Abramsky et al. 1979, Grant 1972). Movements of this sort may represent expanded access to foraging areas, dispersal routes, or a spillover that occurs at high population densities (Stancampiano and Schnell 2004). Ostfeld et al. (1995) and Dobson et al. (2011) suggested that black-legged ticks disperse when they attach to a host in small herbaceous patches in or near adjacent forests, but then drop off when the host is no longer in these areas. This would explain the presence of black-legged ticks on lawns (Maupin et al. 1991, Carroll et al. 1992, Stafford and Magnarelli 1993) or in areas with short grass where humans more often spend time, compared to dense vegetation (Dobson et al. 2011). However, Boyard et al. $(2007,2008)$ found that as the distance from forests increased, there was a decrease in the relative abundance of black-legged ticks because Peromyscus leucopus prefer forested habitats. Peromyscus maniculatus, the North American deer mouse, primarily utilize open grasslands (Kaufman and Fleharty 1974, Bee et al. 1981, Stancampiano and Schnell 2004), but may frequent mixed forests (Graves et al. 1988, Choate et al. 1994, Garmen et al. 1994). Even so, both species of Peromyscus occur in mid- 
successional vegetation along edge (Kamler 1998), Peromyscus leucopus is more often encountered in transitional areas because of their potential to utilize a greater variety of microhabitats (Kamler and Pennock 2004). However, both of these species can serve as hosts for black-legged ticks in areas with a high level of human contact. The distribution of blacklegged ticks across various habitat types is dependent on host species' movements, which are markedly influenced by mast production (Ostfeld et al. 1995).

Jones et al. (1998) and Wolff (1996) suggest that there are higher densities of Ixodes scapularis in forests because abundant seeds and fruits from the vegetation attract a wide diversity as well as a high abundance of host species. The diets of Peromyscus and Tamias, as well as species of Sciurus, vary with season. More fleshy fruit, specifically blueberries (Vaccinium sp.), raspberries and blackberries (Rubus sp.), are eaten in the summer whereas more nuts, specifically acorns (Quercus sp.), hickory nuts (Carya sp.), beechnuts (Fagus sp.), and ripening seeds, are eaten in the fall and winter reflecting seasonal availability (Hamilton 1941, Whitaker 1966, Wolff et al. 1985). Diet is supplemented with arthropods throughout the year (Wolff et al. 1985). The population density and breeding season abundance of mice has been found to be directly correlated to the previous year's mast index and acorn abundance, as acorns are a staple of their diet (Wolff 1996, Ostfeld et al. 1996a, McKracken et al. 1999, McShea 2000, Elias et al. 2004). In fact, years with a high mast index even allowed Peromyscus to breed over the winter in response to an excess of stored acorns (Pucek et al. 1993, Ostfeld 1996a). A similar relationship of mast production influencing the abundance and distribution of whitetailed deer has also been examined (Jones et al. 1998). A high mast index also attracts more deer, which often carry large numbers of adult male and female ticks, and result in a large population of larvae the following year (Ostfeld 1996a, Wolff 1996, Jones et al. 1998, Ostfeld et al. 2001). 
Jones et al. (1998) found that deer spend eight times as long feeding in oak stands during a year of high mast production compared to a year with poor mast production. As a result, tick burdens on hosts will increase even though many desiccate while questing or get consumed when the host grooms. In contrast, nuts from hickory (Carya sp.) trees are too hard to be utilized by mice and more often attract squirrels. In years with an abundance of hickory mast production, the squirrelto-mouse ratio is high (LoGiudice et al. 2008). When there is high mast index and acorn abundance, host species will experience greater reproductive success and thus a population increase, allowing for more opportunities and a higher success for a large population of questing larval black-legged ticks in the following year, which then leads to large population of infected nymphs the following year (Wolff 1996, Jones et al. 1998, Ostfeld et al. 2001). These factors increase infection prevalence and amplify the risk to the human population (Ostfeld et al. 2001). Jones et al. (1998) found that the density of host-seeking larval black-legged ticks and the number of ticks attached to mice was directly correlated with the abundance of acorns, and therefore acorn production was a good indicator of Lyme disease risk 2-years hence. Additionally, years of poor acorn production influence the movement of hosts out of forest habitats and into marginal areas (Van Buskirk and Ostfeld 1998).

Non-native and invasive species in human developed areas may also influence the distribution of host species indirectly through food preference. Eckert (2012) found that Peromyscus maniculatus preferred the seeds of non-native non-invasive blue spruce (Picea pungens) over native white spruce (Picea glauca). Nowalk (2007) conducted a similar experiment to examine the relative seed preference of Peromyscus maniculatus for invasive species when presented with native species of the same genus. No consistent preference for native or invasive seeds was found across all genera (Nowalk 2007). Pearson et al. (2011) found 
that Peromyscus maniculatus avoided consuming the seeds of strongly invasive Centaurea stoebe relative to the other 12 weakly invasive and native species tested and weakly invasive species experienced a greater release from seed predation compared to strongly invasive species, but this was not the case for native species (Pearson et al. 2011). Knight et al. (2007) found that mice avoid common buckthorn (Rhamnus cathartica), which is an invasive species typically found in shrubby habitat. Based on the various results, it seems that Peromyscus species are opportunistic generalists.

Mast production is influenced by several factors. While the timing and amount of mast production varies across species, the total amount of mast produced also depends on tree density; likewise, mast production can be heavily influenced and cued by environmental conditions. Several tree species are sensitive to weather conditions and mast-seeding is strongly correlated to water availability and air temperature. As a result, many species have considerable interannual variability in mast production, and individual species have different abiotic requirements and functional strategies when stressed (Kelly et al. 2013). For example, dryer conditions during a specific year may cause a decline in mast production in deciduous forests, while alternatively, warmer temperatures during a specific year may cause declines in mast production in coniferous forests (Perez-Ramos et al. 2015). Diminished rainfall will impact subsequent floral initiation and acorn development (Sork et al. 1993, Koenig et al. 1994, Koenig and Knops 2013). Additionally, environmental conditions favoring wet and warm weather during the spring immediately prior to acorn maturation is an important influence on mast production because it allows for flower pollination and fertilization leading to acorn development (Olson and Boyce 1971). Intense wind, late frost, prolonged rain, and cold temperatures negatively affect the opening of the anthers and the dissemination of pollen (Sharp and Chisman 1961). Additionally, 
the loss of fruits often occurs because of premature abscission (Olson and Boyce 1971). It may not be extreme weather conditions that affect masting, but rather a drastic change from one year to the next (Kelly et al. 2013). However, there has yet to be a study that identifies a single environmental influence of acorn production (Koenig and Knops 2013). Although extreme weather conditions may affect acorn production, quick changes in environmental conditions also negatively affect masting (Koenig et al. 2013).

Soft mast production (e.g., berries) is also affected by similar environmental factors. Both hard and soft mast producers benefit from larger and well-developed crowns, or an open or edge habitat, allowing for a greater rate of photosynthesis. Although light intensity and soil nutrient concentrations are positively correlated with larger mast crops, temperature and rainfall seem to be the more important. Warmer temperatures in the spring followed by cooler temperatures in the summer produce a more abundant mast crop, however a lack of moisture will reduce overall production. As found with hard mast production, frost and freezing during flowering will significantly impact total annual mast production. Genetics and age may also play a role in both hard and soft mast production (Weeks 1999). 


\section{CHAPTER 2}

LYME DISEASE (BORRELIA BURGDORFERI) APPARENT PREVALENCE AND BLACK-LEGGED TICK (IXODES SCAPULARIS) DISTRIBUTIONS ON A TEMPORAL AND SPATIAL SCALE ON FORT DRUM MILITARY INSTALLATION, NEW YORK 
Formatted for submission to Journal of Medical Entomology

Lyme Disease (Borrelia burgdorferi) Apparent Prevalence and Black-legged Tick (Ixodes scapularis) Temporal and Spatial Distributions on Fort Drum Military Installation, New York

SAMANTHA R. FINO, Division of Forestry and Natural Resources, West Virginia University, Morgantown, WV 26506, USA

JOHN W. EDWARDS, Division of Forestry and Natural Resources, West Virginia University, Morgantown, WV 26506, USA

SHELDON F. OWEN, Division of Forestry and Natural Resources, West Virginia University, Morgantown, WV 26506, USA

JEFFERY WIMSATT, School of Medicine, West Virginia University, Morgantown, WV 26506, USA

RAYMOND E. RAINBOLT, Natural Resources Branch, US Army, Fort Drum, NY 13602, USA

MEAGAN MARSHALL, Public Health Command, US Army, Fort Meade, MD 20755, USA

\begin{abstract}
Lyme disease (Borrelia burgdorferi) is the most common infectious vector-borne zoonotic disease spread by black-legged ticks (Ixodes scapularis) in the Northern hemisphere. The objective of this study was to determine if tick adundance and Borrelia burgdorferi apparent prevalence in ticks are associated with time of year, abiotic factors, and vegetation
\end{abstract}


characteristics at Fort Drum Military Installation. Questing ticks were collected using a 1-m² tick drag in 3 grids per cover type (coniferous forest, deciduous forest, developed, grassland, mixed forest, shrub forest) each consisting of $350-\mathrm{m}$ transects and tested with a real-time PCR multiplex for Borrelia burgdorferi. Overall Lyme disease apparent prevalence was estimated to be 35\%. Both tick and B. burgdorferi-positive tick indices of abundance were highest in coniferous forest during April and November, largely due to the adult developmental stage peak, and correspondingly, lowest in the shrub and deciduous forests during August and September dominated by the larval developmental stage peak. Knowledge of the basic spatial and temporal patterns of Ixodes scapularis will allow resource managers to better assess and communicate the potential risk of exposure and contraction of Lyme disease to the human population, as well as develop habitat management practices to decrease prevalence of Lyme disease and other tickborne illnesses on the landscape.

KEYWORDS black-legged tick, Borrelia burgdorferi, cover type, Ixodes scapularis, Lyme disease

\section{INTRODUCTION}

Lyme disease is caused by the bacterial spirochete, Borrelia burgdorferi, and is commonly spread by contact with black-legged ticks (Ixodes scapularis). There are more than 30,000 cases reported to the Center for Disease Control (CDC) annually, but the total number of people diagnosed is estimated to be 10 times higher (Berger 2014) and the number of unreported cases is likely higher still (CDC 2013). One method to substanially decrease the rate of transmission is to decrease black-legged tick densities in order to prevent human-tick interactions (Ginsberg 1994). 
Environmental conditions, land cover, and landscape patterns influence the abundance and distributions of vectors and vertebrate hosts of Lyme disease (Pavlovsky 1966, Randolph 1993, Ostfeld et al. 1996b, Kitron 1998, Hay et al. 2000, Lindgren et al. 2000). Temperature and humidity largely influence and regulate tick population distributions, host-seeking ability, and tick survival (Jones and Kitron 2000, Lindsay et al. 1995). Variability within a season, such as cold temperatures and low humidity, can slow developmental success and growth rates of all stages in the tick life cycle (Needham and Teel 1991). In addition, adverse conditions can also cause black-legged ticks to freeze or desiccate, limiting their distribution and survival, and thus preventing them from contributing to the spread of Lyme disease (Brownstein et al. 2003). Bertrand and Wilson (1996) found that increasing temperatures and decreasing relative humidity negatively affected development, oviposition, and hatching success, as well as overall survival. Ixodes scapularis is highly susceptible to desiccation when relative humidity drops below approximately 90\% (Stafford 1994). Alternatively, when there are higher temperatures and humidity, questing behavior can occur higher up on vegetation (LoGuidice et al. 2008). Because Ixodes scapularis spends about $98 \%$ of its life cycle off of a host, seasonal changes in temperature and humidity will greatly affect population growth and the spread of black-legged ticks (Needham and Teel 1991, Fish 1993, Bertrand and Wilson 1996).

Although Ixodes scapularis has been found in all vegetation types, the highest densities are typically recorded in forested areas (Daniel et al. 1977, Eisen et al. 2010, Dobson et al. 2011). Black-legged ticks are primarily detected in deciduous forest habitats in New England (Carey et al. 1980, Anderson and Magnarelli 1984), transition zones between coniferous and deciduous forest communities in Wisconsin (Godsey et al. 1987), and in dense woods of suburban Westchester County, New York (Maupin et al. 1991). Maupin et al. (1991) and 
Ostfeld et al. (1995) found that forested vegetation types contained the highest densities of blacklegged ticks compared to forest edge, shrubby or herbaceous vegetation, respectively. Dense woody vegetation inhibits wind, which in turn reduces saturation deficit (Gray 1991), enabling black-legged ticks to quest for longer periods of time (Perret et al. 2000) and at higher locations on vegetation, all while using less energy (Randolph and Storey 1999). Successional stage of the forest, or the forest's growth and maturity, also plays a role in suitability for ticks. Increased light penetration promotes tick desiccation and supports less suitable questing substrate (Lindsay et al. 1999, Schultze and Jordan 2005). Leaf litter and coarse woody debris provide a more suitable microhabitat, where ticks can tolerate fluctuating temperatures by seeking refuge (Curtis 1959, Guerra et al. 2002).

Military installations in the Northeast contain large tracts of forested lands suitable for Ixodes scapularis. Although the branch of military and specific mission may differ among installations, the potential for exposure of active duty personnel to Lyme disease while training or to personnel and family members while engaged in recreational activities is a growing concern for the Department of Defense (Piacentino and Schwartz 2002). Fort Drum Military Installation near Watertown, New York is the largest $\left(433 \mathrm{~km}^{2}\right)$ in the Northeast and is home to approximately 19,605 active duty soldiers and their families. The U.S. Army Public Health Command Human Tick Test Kit Program reported an increase in Lyme disease incidences of 5.7\% from 2006-2012 on Fort Drum (Rossi et al. 2015). Of recorded Lyme diagnoses, Fort Drum had 38 absolute incident cases of Lyme disease during 2004-2013, making it one of the highest in the nation (Hurt and Dorsey 2014). 
The potential risk for Fort Drum personnel and their dependents to be exposed to Lyme disease via encounters with infected ticks warrants research to better manage the level of risk. Knowledge of the basic spatial and temporal patterns of Ixodes scapularis will allow resource managers to assess and communicate the likelihood of encountering a Lyme-positive tick and to take necessary actions to minimize that risk. Specifically, our objective was to assess the potential risk of Lyme disease based on the distributions and densities of the vector populations on Fort Drum.

\section{STUDY AREA}

Our study was conducted on the Cantonment Area of Fort Drum located in Jefferson County, New York (44.05 ${ }^{\circ}$ N $75.77^{\circ}$ W) (Dobony and Rainbolt 2008, INRMP 2011) (Figure 1.1). Fort Drum $(43,422 \mathrm{ha})$ is located in the Great Lake Plains region, also known as the Erie-Ontario lowlands, between the Tug Hill Plateau and the edge of the Adirondack Mountains. Elevation on Fort Drum ranges from approximately $125-245 \mathrm{~m}$. Soils in the Cantonment Area are generally classified as sand, silt loam, and silty clay (Web Soil Survey 2015). The annual average temperature was $-10.14{ }^{\circ} \mathrm{C}$ in 2015 and $-4.94{ }^{\circ} \mathrm{C}$ in 2016 . The total precipitation was $9.88 \mathrm{~cm}$ of rainfall and $151.08 \mathrm{~cm}$ of snowfall in 2015 and $6.02 \mathrm{~cm}$ of rainfall and $58.70 \mathrm{~cm}$ of snowfall in 2016 (U.S. Climate Data 2015, 2016).

The Cantonment Area is approximately 4,000 ha and consists of 30\% developed, 30\% grassland, 9\% mixed forest, 5\% coniferous forest, $8 \%$ shrub, and 18\% deciduous forest (Figure 1.2). The developed areas (Appendix 23) included those that were in close proximity to human infrastructure and buildings. All buildings, residential homes, land navigation courses, parks and green spaces, such as lawns, and recreation areas were considered developed. These areas were 
often surrounded by mowed grass (Poaceae) and/or adjacent to forest edges. The grassland cover type areas (Appendix 24) were without human development and often included fields containing grasses, wildflowers and other herbaceous plants. Common species included: Carex sp., Cirsium sp., Cyperus sp., Juncus sp., Panicum sp., Aster sp., Centaurea sp., Galium sp., Megalodonta sp., Polygonum sp., Potamogeton sp., Solidago sp., Trillium spp, and Veronica sp. (Fort Drum 2009).

The remaining four cover types also occurred in areas separated from human development but used for military training exercises. The shrub cover type (Appendix 26) was characterized by woody plants $<8 \mathrm{~m}$ tall. This type was densely vegetated with both native and invasive species, and contained Cornus sp., Lonicera sp., Malus sp., Rhamnus sp., Salix sp., Vaccinium sp., Viburnum sp. (Fort Drum 2009). Unlike the shrub cover type, deciduous, coniferous and mixed cover types included trees that were $>8 \mathrm{~m}$ tall. The deciduous cover type (Appendix 22) contained Acer sp., Carya sp., Fagus sp., Fraxinus sp., Nyssa sp., Populus sp., Rubus sp., among others (Fort Drum 2009). Dominate herbaceous plants in this cover type included Caulophyllum sp. and Gallium sp. (Fort Drum 2009). The ground was covered in leaf litter and coarse woody debris, and as a result, the soil was typically rich in organic matter. Coniferous cover type (Appendix 21) contained evergreen species such as Picea sp., Pinus sp., Tsuga sp., among others (Fort Drum 2009). The ground was covered in needle litter and coarse woody debris. The mixed cover type (Appendix 25) contained species present in both deciduous and coniferous cover types.

\section{METHODS}

\section{Off-host tick collection}


Field sampling occurred within the study area from April 2015 through November 2016. Nonfeeding tick populations were estimated using a tick-drag method. Rulison et al. (2013) found that neither flagging nor dragging demonstrated a clear advantage for sampling Ixodes scapularis but due to efficacy tick drags have been historically used on Fort Drum. The tick-drag device was a $1-\mathrm{m}^{2}$ corduroy cloth to which questing ticks come in contact and are removed from the vegetation. The cloth was dragged on the ground along 50-m transects and checked every 10-m (approximately 30 seconds) to prevent losing ticks that drop off (Insect Diagnostic Laboratory 2012). Each tick-drag plot consisted of 3 parallel transects $10 \mathrm{~m}$ apart (Appendix 28). Three tickdrag plots were established in each of 6 cover types. Directional azimuths for the three tick-drag plots in each cover type were determined randomly as follows (in degrees): 335, 225, and 100 for coniferous, 160, 28, and 260 for deciduous, 70, 245, and 295 for grassland, 109, 28, and 15 for developed, 285, 325, and 40 for mixed, and 200, 170, and 190 for shrub. Ticks were removed from the tick drag using tape, identified by species, stage and gender, transferred into empty plastic vials using tweezers which were sterilized using $70 \%$ rubbing alcohol, stored in a freezer at $-18{ }^{\circ} \mathrm{C}$, and sent with ice packs to the Army Public Health Command at Fort Meade, MD for diagnostic testing. Tick drags were conducted biweekly and temperature, humidity, wind speed and barometric pressure were recorded from the local weather station at the time of each tick drag grid.

\section{Borrelia burgdorferi detection}

Once received by Fort Meade, ticks were identified and individually placed in $100 \mu \mathrm{L}$ of Tissue Lysis Buffer (Qiagen, Valencia, CA). Ticks were macerated by the addition of a $5 \mathrm{~mm}$ borosilicate bead on the Qiagen Tissue Lyser for 3 minutes at a frequency of 20 beats per second. 
Samples were spun down and an additional 400uL of buffer was added to each. Samples were then incubated with the addition of proteinase $\mathrm{K}$ prior to nucleic acid purification according to kit directions with the DNeasy Blood \& Tissue Kit (Qiagen). Starting material for isolation was $200 \mathrm{uL}$ of the incubated tick lysate and purified nucleic acids were eluted with $100 \mu \mathrm{L}$ of elution buffer. The macerated ticks, remaining lysate and purified nucleic acids were stored at $-80^{\circ} \mathrm{C}$ for future analysis.

Purified nucleic acid preparations from individual Ixodes scapularis ticks were screened for Borrelia and Anaplasma species by a multiplex assay targeting the 23S rRNA and msp2 genes of Borrelia and Anaplasma, respectively as described by Courtney et al. (2004). In addition, the samples determined positive for Borrelia species were further confirmed as Borrelia burgdorferi using qPCR targeting the N40.seq gene (Straubinger 2000) and the 16s rDNA of $B$. miyamotoi (Tsao et al. 2004). Likewise, Anaplasma species positive samples were further tested with a qPCR singleplex targeting a 106-bp fragment of the 16s rRNA gene (Pusterla et al. 1999). All qPCR assays were performed using the LightCycler FastStart DNA Master HybProbe kit (Roche) on the Roche LightCycler 2.0 or LightCycler® 480 Probes Master (Roche) on the Roche LightCycler 480.

In 2016, a 20\% subsample, by developmental stage, cover type and month, was tested at the WVU Wildlife Genomics Laboratory for confirmation testing and method validation. DNA was extracted using Thermo Fisher Scientific Genomic DNA Purification Kit ${ }^{\circledR}$ and followed manufacturer recommendations for extraction. Extracted DNA were stored at $-80^{\circ} \mathrm{C}$ for future analysis. Individual Ixodes scapularis ticks were screened for Borrelia species by a multiplex assay targeting the 23S rRNA gene of Borrelia using Tawman with fluorescent probes as adapted 
from Courtney et al. (2004). We ran a qPCR as described in Appendix 1 for detect Borrelia burgdorferi presence.

\section{Vegetation surveys}

Vegetation measurements in each cover type were conducted in summer 2016 (Appendix 19). We established 16 plots per cover type. Each plot was 0.04 ha with two nested plots, one 0.01 ha and the other 0.001 ha (Figure 2.1). In the 0.04-ha plot, species, crown class (USDA Forest Service 2002), and diameter at breast height (dbh) for all trees greater than $8 \mathrm{~cm}$ dbh was recorded. The number and height of snags, and their diameter and decay stage (score of 1-9; Maser et al. 1979, Thomas et al. 1979) within the 0.04-ha plot was also recorded. A canopy cover measurement was taken in the center of the plot, and at $10 \mathrm{~m}$ in each cardinal direction, to calculate an average canopy cover estimate. The 0.04 -ha plot was divided into quadrants. Midstory cover/vegetation density was measured using a cover board (Interagency Handbook 1996) in the nested 0.01-ha quadrant plot that was in the north direction. The cover board was placed in the corner and the observer was on the opposite corner. Percentage of mid-story cover was recorded for all corners of the north 0.01-ha quadrant to calculate an average. Also within the nested 0.01-ha quadrant, coarse woody debris was classified into a decay classes (score of 1-5; Maser et al. 1979, Thomas et al. 1979) and length and diameter was measured for calculation of volume. Coarse woody debris was considered as any downed $\log >10 \mathrm{~cm}$ in diameter (Harmon et al. 1986, Spies and Cline 1988, Loeb 1996, Butts and McComb 2000). In a nested 0.001-ha plot, leaf litter depth and composition of vegetative ground cover, measured by relative abundance of stems, were recorded. An average leaf litter depth was determined from measurements taken in each corner of the 0.001 ha plot. The 0.04 ha plots were $30 \mathrm{~m}$ away from 
each corner of the small mammal trapping grids on the same azimuths of its transects. In the event that the azimuth from the trapping grid led to a location that was uncharacteristic of that cover type, a random azimuth that did not overlap with another vegetation plot was used. In the developed cover type, vegetation plots were $30 \mathrm{~m}$ in the north direction from every fourth small mammal trapping point because trapping stations were not in a grid for this cover type. No sampling occurred in small mammal trapping grids because of our disturbance of vegetation during small mammal trapping.

\section{Statistical Analysis}

Summary statistics for each developmental stage were calculated on a temporal and spatial scale for both tick count and positive-Borrelia burgdorferi tick-count data. Infection apparent prevalence was estimated for each developmental stage, as well as for each cover type. We used a Poisson distribution to model-estimated index of abundance of black-legged ticks (adults, nymphs, larvae) among cover types and months. $Y_{i}$ denoted estimated index of abundance, which we modeled as a Poisson random variable: $y_{i} \sim$ Poisson $\left(\lambda_{\mathrm{i}}\right)$ because data were formatted as count data. We conducted parametric bootstrapped pairwise comparisons with a $95 \%$ confidence interval to observe any statistical differences in estimated index of abundance among months or cover types. This was done for both tick count data and positive-Borrelia burgdorferi tick count data in Program R x64 3.0.2.

We modeled estimated index of abundance of black-legged ticks (response variable) as a function of predictor variables month, year, cover type, temperature, humidity, wind speed, pressure, as well as various vegetative characteristics (Table 2.1). An initial pairwise comparison analysis indicated that months of April, June, October and November 2015 were statistically 
different from months of April, June, October and November 2016. As a result, we used sum-tozero coding with year effect and the predictive variables year and month were interaction terms in the model (Yandell 1997). All other predictor variables (environmental and vegetative) were additive, as the relationship with estimated index of abundance did not change in different months, cover types, or for tick developmental stage. For index of abundance of each developmental stage, we only used the predictor variables of year, month and cover type as our focus was on the spatial and temporal distributions for each developmental stage. We developed the following models: (1) estimated index of abundance of adult ticks (Table 2.4), (2) estimated index of abundance of nymphs (Table 2.5), (3) estimated index of abundance of larvae (Table 2.6), (4) total estimated index of abundance of ticks (Tables 2.2 and 2.3), (5) estimated index of abundance of B. burgdorferi-positive adults (Table 2.7), and (6) estimated index of abundance of B. burgdorferi-positive nymphs (Table 2.8). We chose to model B. burgdorferi-positive count data instead of apparent prevalence because infection rate can be misleading as a result of sample size. Model selection for total index of abundance of ticks was based on the Wald's test $(\mathrm{p}<0.05)$ and lowest relative AICc score (highest relative AICc weight). The top model (Tables 2.2 and 2.3) for estimated index of abundance of total tick count data was used to predict estimated index of abundance as a function of significant environmental and vegetative predictor variables as these variables do not influence spirochete apparent prevalence in the population, but rather estimated index of abundance of questing ticks themselves (regardless of developmental stage). The predictor variables month, year and cover type were not included in evaluation of models because our focus was on the relationship between these environmental and vegetative predictor variables with total index of abundance of ticks. Because several of these vegetative characteristics had high collinearity of a $\mathrm{r}$ value $>0.70$ (Appendix 20), we ran each vegetative 
characteristic as an independent model and then selected the top models that did not have vegetative predictor variables that had high covariance with previously selected vegetative characteristics. Lastly, using ArcGIS®, the influence of patch size $\left(\mathrm{m}^{2}\right)$ on total tick index of abundance was also examined. The combination of vegetative characteristics and environmental predictor variables comprised the top model. An alpha level of 0.05 was used in data analyses.

\section{RESULTS}

Overall estimated apparent prevalence of Borrelia burgdorferi in the black-legged tick population on Fort Drum was approximately $35 \%$ based on adult and nymph count data (Table 2.11). Approximately $48 \%$ of adults and $18 \%$ of nymphs were infected with Borrelia burgdorferi (Table 2.11). Our subsample had similar apparent prevalence estimates of $48 \%$ for adults, $18 \%$ for nymphs and $36 \%$ overall positive for Borrelia burgdorferi. The coniferous cover type had the greatest estimated black-legged tick index of abundance while the shrub and deciduous cover types had the lowest (Figs. 2.2-2.4). Estimated adult black-legged tick index of abundance was greatest in November and lowest in July and August (Fig. 2.2). The coniferous cover type had the highest estimated adult black-legged tick indices of abundance while the deciduous cover type had the lowest (Fig. 2.2). Estimated nymph index of abundance was greatest in June and lowest in April, October and November (Fig. 2.3). The coniferous cover type had the highest estimated nymph index of abundance while the shrub cover type had the lowest (Fig. 2.3). Estimated larval index of abundance was greatest in August and September and lowest in April and November (Fig. 2.4). The mixed cover type had the greatest estimated larval index of abundance while the shrub cover type had the lowest (Fig. 2.4). 
While estimated tick indices of abundance were highest in November and April due to adults (Fig. 2.2), in June due to nymphs (Fig. 2.3), in August and September due to larvae (Fig. 2.4), estimated Lyme disease-positive tick indices of abundance were highest in November, April, and October due to adults (Fig. 2.5), followed by June due to nymphs (Fig. 2.6), and lowest in August and September due to larvae (Figs. 2.5 and 2.6). Lyme disease-positive index of abundance was greatest in the coniferous forest and lowest in the deciduous forest cover type for adults (Fig. 2.5) and in developed cover type for nymphs (Fig. 2.6). No questing ticks were detected in the grassland cover type. Estimated indices of abundance of Lyme-positive ticks follows the same significance trends as tick indices of abundance (Table 2.9 and 2.10). Probability of recovering (via tick drags) positive-Borrelia burgdorferi ticks was greatest in the coniferous cover type for adult and nymph developmental stages, and lowest in the deciduous forest type for adults and in the developed cover type for nymphs (Table 2.12).

Tick indices of abundance on Fort Drum increased as both temperature and humidity increased (Wald test $p=<0.001$ and $p=<0.001$, respectively). The slope coefficient for temperature predicted a $3.0 \%$ increase in expected tick count with a $1^{\circ} \mathrm{C}$ increase in temperature (Fig. 2.7). The slope coefficient for humidity predicted a $28.0 \%$ increase in expected tick count with a $1 \%$ increase in relative humidity (Fig. 2.8). These results indicate that humidity is a more influential factor on tick index of abundance than temperature.

Tick index of abundance increased as both leaf litter depth, tree species richness, and average tree dbh increased (Wald test $p \leq 0.001$ for all), and decreased as coarse woody debris decay and patch size increased (Wald test $p \leq 0.001$ for both). The slope coefficient for leaf litter depth predicted a $10.8 \%$ increase in expected tick count with a $1-\mathrm{cm}$ increase in leaf litter depth 
(Fig. 2.10). The slope coefficient for tree species richness predicted a $26.7 \%$ increase in expected tick count with each additional tree species (Fig. 2.11). The slope coefficient for average tree dbh predicted a $0.69 \%$ increase in expected tick count with each additional tree species (Fig. 2.12). The slope coefficient for coarse woody debris decay predicted a 33.7\% decrease in expected tick count with a 1-unit increase in decay on a scale of 1-5 (Fig. 2.9). Because cover type was not a predictive variable in this model, the slopes and influence of the predictive environmental and vegetative variables on total tick index of abundance is constant throughout cover types (Table 2.3). Tick index of abundance increased as patch size decreased. The slope coefficient for patch size predicted a $0.65 \%$ decrease in expected tick count with a $1-\mathrm{m}^{2}$ increase in patch size (Fig. 2.13). These results indicate that environmental and vegetative characteristics are more influential factor on tick index of abundance than cover type.

\section{DISCUSSION}

The overall infection apparent prevalence among ticks on Fort Drum Military Installation was approximately $35 \%$. Adults had a higher infection incidence of approximately $48 \%$ compared to that of nymphs at approximately $18 \%$, likely due to the possibility of more vector-host interactions and exposure to the spirochete during their previous two blood meals (Hazler and Ostfeld 1995, Bertrand and Wilson 1996, Ostfeld et al. 1996a). The temporal peaks in occurrence and number of B. burgdorferi-positive adults, nymphs and larvae followed the expected trends reported in the literature; adults peak in spring (April) and fall (October and November), while nymphs peak early summer (June) (Ginsberg 1994, Bertrand and Wilson 1996, Shaw 2001). The peak of the larval developmental life stage on Fort Drum was similar to other studies, peaking at the end of summer (August and September) (Wilson et al. 1985, Maupin 
et al. 1991, Fish 1993, Ostfeld et al 1995). In contrast to other reports, we did not find a secondary peak of the nymph or larval developmental stage (Mannelli et al. 1994, Ostfeld et al. 1995, Brunner and Ostfeld 2008), which may be due to increased latitude. Because spirochetes are not passed from adult female to offspring efficiently (Shaw 2001), B. burgdorferi was not detected in collected larvae, which explains the low index of abundance of B. burgdorferipositive ticks at the end of the summer. Our estimated indices of abundance are conservative because we were only able to collect questing ticks; unsampled ticks may not have been questing due to environmental conditions, movement, or they were questing on lower strata on vegetation. However, because we did not conduct a nested PCR to identify the specific Borrelia burgdorferi DNA sequences, specifically the16S-23S rRNA IGS locus, we cannot confirm if this estimated apparent prevalence reflects the prevalence of Borrelia burgdorferi that cause infection in humans (Bunnikis et al. 2004). Similarly, approximately $1 \%$ and $4 \%$ of ticks were infected with Borrelia miyamotoi and Anaplasma phagocytophilum respectfully (Table 2.13 and 2.14), althought sequencing was not conducted to estimate prevlance that cause infection in humans.

We consistently found ticks at high indices of abundance in forested areas (Daniel et al. 1977, Eisen et al. 2010, Dobson et al. 2011) as the dense woody vegetation inhibits wind, which in turn reduces any saturation deficit (Gray 1991), thus increasing questing success and survivability (Randolph and Storey 1999, Perret et al. 2000). We observed the highest indices of abundance for all developmental stages in the coniferous and mixed forest cover types. This was likely due to the presence of high-quality food resources for hosts that are burdened by ticks (Ostfeld et al. 1995, Brunner and Ostfeld 2008), as well as higher tree density, canopy cover (both of which reduce sunlight penetration and wind), and leaf litter depth all of which provide refuge for the vector species. With tick index of abundance positively related to increasing leaf 
litter depth and tree species richness (highly collinear with tree density and canopy cover), as well as negatively related to coarse woody debris decay, this suggests increased probability of tick-host interactions and elevated tick burdens with increased vegetation density at the lowest strata, including leaf litter and coarse woody debris (Carey and Johnson 1995, Loeb 1996, Davis et al. 2010). This microhabitat provides a stable microclimate with increased relative humidity as well as reduced predation risk for both black-legged ticks and hosts, all of which promote tick survival (Ginsberg and Ewing 1989, Adler et al. 1992, Goddard 1992, Stafford 1994, Lindsay et al. 1999, Schmidt et al. 1999, Lubelczyk et al. 2004, Prusiniski et al. 2006). Similar support was provided by Carey et al. (1980) and Anderson and Magnarelli (1984) who observed higher occurrences of black-legged ticks in deciduous forest habitats of New England and Godsey et al. (1987) who resported highest densities in transition zones between coniferous and deciduous forest communities in Wisconsin. The coniferous cover type, which had the highest tick indices of abundance, existed in the smallest patch sizes, explaining the negative relation patch size has on highest tick indices of abundance. We observed no questing ticks in the grassland cover type, likely due to higher air and soil temperature and lower relative humidity as a result of greater sun exposure which causes high tick mortality (Ostfeld et al. 1995, Bertrand and Wilson 1996). However, we do recognize that tick drags only push down the top of the vegetation without being able to sample ticks that may be questing on the lower strata of the vegetation.

Shrub cover types on Fort Drum have low tick indices of abundance. The shrub cover type had a significantly lower average tree dbh (diameter at breast height), potentially allowing for more sunlight and wind penetration, ultimately leading to more tick desiccation or ticks seeking refuge rather than questing. Increased light penetration promotes less complex stems causing a less suitable questing substrate, while less leaf debris at ground level causes a less 
hospitable habitat due to an increased saturation deficit, all potentially causing desiccation (Lindsay et al. 1999, Schultze and Jordan 2005). Although stem density was high, potentially providing a greater amount of substrate for questing, there was significantly lower leaf litter depth in the shrub cover type, resulting in a lack of suitable microhabitat for refuge. While there were low adult tick indices of abundance in the deciduous cover type, there were higher relative indices of abundance for nymphs and larvae. The high index of abundance in larvae may indicate that deciduous forests have an ample amount of food resources for hosts such as deer, the primary host for adult ticks (Piesman et al. 1979, Anderson and Magnarelli 1980, Schulze et al. 1984, Spielman et al. 1985) in the winter, resulting in frequent egg masses. The high index of abundance in nymphs in the deciduous cover type may indicate that there are greater and higher quality food resources for small mammals, the primary hosts for nymphs (Maupin et al. 1991, Ostfeld et al 1995), in the summer when their developmental stage peak occurs. The high stem/sapling density and greater depth of leaf litter provides a greater amount of questing substrate and a more suitable microhabitat for winter dormancy, respectfully, which explains why black-legged ticks are often abundant in deciduous forests (Curtis 1959, Guerra et al. 2002). The developed cover type, which is transitional areas between human developed areas (open areas) and forested edges, has moderate to low indices of abundance due to its composition of shared cover types with potentially harsh environmental conditions.

The high indices of Ixodes scapularis abundance and Borelia burgdorferi apparent prevalence in the Cantonment Area of Fort Drum is likely due to the lake-effect environmental conditions found in this part of the Northeast. With an average annual precipitation of $109.5 \mathrm{~cm}$ of rainfall and $289.6 \mathrm{~cm}$ of snowfall (U.S. Climate Data), Fort Drum has a consistent level of high humidity. Humidity below approximately 90\% (Stafford 1994), results in slowed 
developmental success and growth rates of all stages in the tick's life cycle (Needham and Teel 1991), which negatively affects oviposition and hatching success, and decreases overall survival due to desiccation (Bertrand and Wilson 1996, Brownstein et al. 2003). A weakness in our models was that we recorded environmental conditions from a local weather station; we would suggest future studies record environmental conditions at the ground level of each tick drag to observe differences in the environmental conditions of the microhabitat among cover types, as well as soil moisture content. 


\section{CHAPTER 3}

INFLUENCE OF SMALL MAMMAL ABUNDANCE AND DIVERSITY ON BLACKLEGGED TICK (IXODES SCAPULARIS) ABUNDANCE AND LYME AGENT (BORRELIA BURGDORFERI) PREVELANCE ON FORT DRUM MILITARY INSTALLATION, NEW YORK 
Formatted for submission to Wildlife Society Bulletin

\title{
Influence of Small Mammal Abundance and Diversity on Black-legged Tick (Ixodes scapularis) Abundance and Lyme Agent (Borrelia burgdorferi) Apparent Prevalence on Fort Drum Military Installation, New York
}

SAMANTHA R. FINO, Division of Forestry and Natural Resources, West Virginia University, Morgantown, WV 26506, USA

JOHN W. EDWARDS, Division of Forestry and Natural Resources, West Virginia University, Morgantown, WV 26506, USA

SHELDON F. OWEN, Division of Forestry and Natural Resources, West Virginia University, Morgantown, WV 26506, USA

JEFFERY WIMSATT, School of Medicine, West Virginia University, Morgantown, WV 26506, USA

RAYMOND E. RAINBOLT, Natural Resources Branch, US Army, Fort Drum, NY 13602, USA MEAGAN MARSHALL, Public Health Command, US Army, Fort Meade, MD 20755, USA

\begin{abstract}
Lyme disease (Borrelia burgdorferi) is the most common infectious vector-borne zoonotic disease spread by black-legged ticks (Ixodes scapularis) in the Northern hemisphere. The spatial distribution of black-legged ticks is dependent on the movements of their hosts. Tick abundance is dependent in large measure on host abundance, however prevalence of Lyme disease is
\end{abstract}


dependent on host specificity. The objective of our study was to determine the spatial distributions and index of abundance of the host populations as well as the vector-host interactions on Fort Drum Military Installation as they relate to Borrelia burgdorferi apparent prevalence. Small mammals were captured and marked during the summers of 2015-2016 using Sherman and Tomahawk traps in $26 \times 6$ grids per cover type (coniferous forest, deciduous forest, developed, grassland, mixed forest, shrub forest). Tick Borrelia burgdorferi burdens and ear punches were tested using a real-time PCR multiplex assay that detected Borrelia burgdorferi. The small mammal community was dominated by Peromyscus sp. and members of the family Sciuridae, effective reservoirs that adapt well to fragmented, human developed areas. We found a positive relation between both vector and host indices of abundance as well as between indices of host diversity and index of abundance of Lyme-positive ticks. Although there was significantly higher tick burden occurances on individual Peromyscus sp., there were significantly greater Lyme-positive tick burden occurances on chipmunks. Additionally, a greater proportion of chipmunks had ear punches that tested positive for Lyme disease. Cover types with high small mammal indices of abundance also had high small mammal diversity, as well as high indices of abundance of ticks and Lyme-positive ticks, supporting an amplification effect. Knowledge of the basic spatial patterns of the small mammal host community and the vector-host relationship will allow resource managers to better assess and communicate the potential risk of exposure to the human population, as well as develop habitat management strategies to decrease disease prevalence by reducing human exposures.

KEYWORDS black-legged tick, Borrelia burgdorferi, cover type, diversity, host species, Ixodes scapularis, Lyme disease, small mammal abundance 
Lyme disease (Borrelia burgdorferi) is the most common infectious vector-borne zoonotic disease spread by black-legged ticks (Ixodes scapularis) in the Northern Hemisphere. Ticks require 3 successful blood meals, each from a separate vertebrate host to complete their life cycle (Hazler and Ostfeld 1995, Bertrand and Wilson 1996, Ostfeld et al. 1996a). There are over 60 vertebrate species (Shaw 2001), 29 recorded mammals, 49 birds, and even some reptile species, that can serve as hosts for Ixodes scapularis, suggesting they are indiscriminate in host selection (Oliver 1989, James and Oliver 1990, Schmidt 1999), althought the successful feeding and molting of the tick may vary based on the host species. In the Northeast, the most important host of immature black-legged ticks relative to Lyme disease transmission is the white-footed mouse (Peromyscus leucopus) (Bosler et al. 1984, Levine et al. 1985, Anderson et al. 1987, Magnarelli et al. 1988, Mather et al. 1989, Anderson and Magnarelli 1993, Apperson 1993, Levin and Fish 1998). White-footed mice are not only disporpotionately represented in the small mammal community(Ostfeld and Keesing 2000b), with a widespread distribution due to their adaptability to anthropogenic changes (LoGiudice et al. 2008) and frequency of tick parasitism, but they are also the most competent reservoir of the Lyme disease spirochete. Hence, black-legged ticks feeding on an infected host have a high probability of becoming infected with Borrelia burgdorferi (Shaw 2001). Schmidt and Ostfeld (2001) reported white-footed mouse reservoir competence at $>90 \%$, based on the production of newly molted infected nymphs. In another study, Mather (1993) reported between 40-80\% of larvae feeding on an infected Peromyscus leucopus obtain Borrelia burgdorferi.

Other small mammals abundant in eastern deciduous forests include eastern chipmunk, Tamias striatus, as well as the short-tailed shrew, Blarina brevicauda, and the masked shrew, Sorex cinereus, which also serve as hosts for Ixodes scapularis (Schmidt et al. 1999, Shaw 2001, 
Brisson et al. 2008). These species, along with Peromyscus sp., transmit Borrelia burgdorferi to 80-90\% of infected ticks (Brisson et al. 2008). Chipmunks and shrews, however, are slightly less competent reservoirs and are not as efficient as white-footed mice in transmitting Borrelia burgdorferi to uninfected black-legged ticks due to specific physiological immune responses by the host to the pathogen (Nupp and Swihart 2000, Ostfeld and Keesing 2000a, Anderson et al. 2003, Wilder and Meikle 2006). Additionally, Schmidt et al. (1999) and Shaw (2001) determined that larval tick burdens are about 3 times higher on white-footed mice than on chipmunks in the same environment. However, more mice on the landscape draw larvae away from chipmunks while more chipmunks on the landscape draw nymphs away from mice (Mannelli et al. 1993, Brunner and Ostfeld 2008). This then allows for the most efficient reservoir to influence the abundance of infected nymphs (Brisson et al. 2008).

The abundance of host-seeking as well as feeding black-legged ticks is influenced by population density and distribution of host species. The abundance of host-seeking ticks in the environment, as well as tick burdens on hosts, and their distributions are directly related to host densities (Ostfeld et al. 1995, Brunner and Ostfeld 2008). However, while tick density is a function of host density, spirochete prevalence is a function of each hosts' reservoir competencies as well (Van Buskirk and Ostfeld 1998). Ostfeld et al. $(1995,1996 c)$ found that the probability of a black-legged tick encountering a host and the proportion of total black-legged ticks attached to an individual white-footed mouse increases dramatically at population densities above 10 mice per hectare. At such densities, mice will occupy a greater proportion of the landscape and therefore questing black-legged ticks have higher success rates (Wolff 1985, Ostfeld et al. 1996b, Brunner and Ostfeld 2008). A greater population of Peromyscus leucopus will provide increased opportunities for larvae and nymphs to successfully feed and acquire 
Borrelia burgdorferi, resulting in a high abundance of infected nymphs the following year (Ostfeld et al. 2001).

The prevalence of Lyme disease is dependent on host abundance, host-tick encounter rates, and the ability of the preferred host to transmit disease to a feeding tick. While both poor groomers, mice were found to be more efficient groomers than chipmunks, although their higher tick burdens counteract this ability (Shaw 2001). Keesing et al. (2009) found that certain species such as opossums (Didelphis virginiana) and squirrels (Sciurus sp.) have a more effective immune response, allowing these individuals to kill between $83-96 \%$ of tick burdens because increased grooming reduces infestations. Only 3\% and 15\% of ticks that feed on opossums and squirrels, respectively, are successful (Keesing et al. 2009). Yet, squirrels receive 5 to 37 times as many infected tick bites compared to other host species (Randolph and Craine 1995). Vertebrate species such as squirrels, deer, voles, raccoons, opossums and skunks are considered to be dilution hosts because they are poor reservoirs for Borrelia burdgorferi (Levi et al. 2016, LoGiudice et al. 2003, Brisson and Dykhuizen 2004). As a result, high host diversity on the landscape will divert tick-host interactions away from effective reservoirs. Due to the difficulty of discriminating Peromyscus leucopus and Peromyscus maniculatus in the field, there is a lack of research on reservoir competence differences (Oliver et al. 2006), although one study reports the effective reservoir competence for Peromyscus maniculatus to be about 33\% (Peavey and Lane 1995). Black-legged ticks are opportunistic and will attach to the first host they encounter (Shaw 2001), thus, tick burdens will be more frequent on the most abundant host of the community. 
The distributions of Peromyscus and Tamias, as well as species of Sciurus, are heavily dependent on the microhabitat characteristics and mast production. The population density and breeding season abundance of mice has been found to be directly related to the previous year's mast production, specifically acorn abundance (Wolff 1996, Ostfeld et al. 1996a, McKracken et al. 1999, McShea 2000, Elias et al. 2004). In fact, years with a high mast production allowed Peromyscus to breed over the winter in response to an excess of stored acorns (Pucek et al. 1993, Ostfeld 1996a). Maupin et al. (1991) and Adler et al. (1992) both found that tick burdens on white-footed mice increased with density of woody vegetation, where mast production is more likely, and decreased with herbaceous vegetation. Other studies have found that increased probability of tick-host interactions and elevated tick burdens occur in areas with increased vegetation density at ground level, due to its stable microclimate, increased relative humidity, and reduced predation risk for both black-legged ticks and hosts (Ginsberg and Ewing 1989, Adler et al. 1992, Goddard 1992, Stafford 1994, Lindsay et al. 1999, Schmidt et al. 1999, Lubelczyk et al. 2004, Prusiniski et al. 2006). Woody debris and brush piles, common in forested habitats, also provide the above benefits and have been found to increase overwinter survival in small mammals (Carey and Johnson 1995, Loeb 1996, Davis et al. 2010). Prusiniski et al. (2006) found that as density of woody vegetation and shrub coverage increased, small mammal diversity decreased. However, there was likely still a high occurrence of Borrelia burgdorferi infection because the density of Peromyscus increases with denser woody vegetation (Myton 1974, Adler and Wilson 1987). Regardless, because individual ticks can only move a few meters themselves (Falco and Fish 1989, Carroll and Schmidtmann 1996), the abundance and dispersal of black-legged ticks across habitat types is heavily reliant on host distributions and 
movements, which are determined by patch size and vegetative qualities (Ostfeld et al. 1995, Van Buskirk and Ostfeld 1998).

The high risk of Lyme disease to the human population calls for research that analyzes the relationship between vector and host populations' distributions and abundances in consideration of habitat differences. A primary goal of this project was to understand the distributions and abundances of the host populations on Fort Drum as a function of cover type, as well as to determine the estimated prevalence of Lyme disease within the small mammal community. Knowledge of the basic spatial patterns of various small mammal species will allow resource managers to better assess and communicate the likelihood of encountering a Lymepositive tick.

\section{METHODS}

Our study area was located on the Cantonment Area of Fort Drum Military Installation (Chapter 2). Off-host tick collection, Borrelia burgdorferi detection, and vegetation surveys followed the same methodology as described in Chapter 2.

\section{Small mammal capture}

Small mammal trapping occurred from June - July 2015 and 2016 to target small mammal peak activity (O'Farrell 1975, Hanser et al. 2011). While mice are active all year (O’Farrell 1975), many small mammals (i.e., chipmunks) enter into torpor during winter months and only emerge when there are available food resources (MacMillen, 1964, O'Farrell 1975). Live-capture Sherman traps (H.B. Sherman Inc., Tallahassee, USA) $8.9 \times 7.6 \times 22.9 \mathrm{~cm}$ were used for animal capture. To improve the likelihood of capturing animals too large for Sherman 
traps, 49.0×15.2×15.2-cm live-capture \#202 Tomahawk traps (Tomahawk Live Trap Co., Tomahawk, WI) were also used.

Small mammal trapping was conducted in each of the 6 cover types used in tick sampling (Fig. 1.2). Two Sherman traps and one tomahawk trap were placed at each trapping station with their rear corners touching one another and their openings facing outward. Each trap triad was placed at each point of a $6 \times 6$ grid (Appendix 29). Thus, each trapping grid contained 72 Sherman traps and 36 tomahawk traps. Each trapping station was $10 \mathrm{~m}$ apart from one another. Small mammal trapping grids were replicated (2) in each cover type to increase sample sizes and better survey host populations across the Cantonment Area landscape.

Traps were deployed between 0700-0900 on Monday of a trapping week. Each trap was baited with a peanut butter-honey-oats mixture on a $\sim 2.5-\mathrm{cm}^{2}$ square of paper and also contained a palm-sized ball of polyester batting for nesting. Traps were not placed in excessively wet areas or in areas without shade. Traps were checked beginning at 0700 each morning and again at 1500 each afternoon for three consecutive days; 3 consecutive days of continuous trap placement in a trapping array was considered the minimum required to assess local species richness (Manley et al. 2002). Checked traps were rebaited and resupplied with polyester batting as necessary. All non-functioning traps, meaning the door was closed without a capture, the bait was missing without a capture, or a trap was missing or broken, were reset, rebaited or replaced (Nelson and Clark 1973). After each trapping session, traps were soaked in a mild beach solution (CDC recommends $45 \mathrm{ml} / 3.8$ liters) for 10 minutes to reduce the risk of Hantavirus (Mills et al. 1995). 
During trap checks, trap outcomes, whether each trap was open, sprung, or sprung with a capture, were noted. Captured animals were released into a plastic or cloth bag depending on the animal's size and type of trap. Small mammals were grasped at the nape of the neck for examination (Manley et al. 2006). Captured individuals were identified to species, sexed, aged (juveniles or adults), examined for breeding status (pregnant, lactating, enlarged testes or nonbreeding), weighed and released (Kunz et al. 1996). Because Peromyscus leucopus and Peromyscus maniculatus are difficult to discriminate in the field, both were recorded as Peromyscus sp. All new captures were marked with numbered ear tags (Kent Scientific Cooperation). Captures of previously marked animals were recorded. Non-target animals were released without processing. Ticks were removed from captured animals with tweezers and placed in labeled individual vials per tick for diagnostic sampling of Borrelia burgdorferi. In 2016, ear punches were taken from captured animals and placed in labeled vials with $80 \%$ ethanol for diagnostic sampling for Borrelia burgdorferi.

\section{Mast collection}

Hard and soft mast were surveyed in deciduous, coniferous, mixed, and shrub cover types from August 2015 through December 2015 and again from May 2016 through December 2016. One mast trap (Appendix 31) consisted of four 5-gallon plastic buckets each $28.9 \mathrm{~cm}$ in diameter. Five holes were drilled at the bottom of each bucket to allow for water drainage. Buckets were arranged in $2 \times 2$ array with a sample area of $0.26 \mathrm{~m}^{2}$. A fitted aluminum wire screen was placed in the bottom of the bucket to prevent any mast materials from escaping through the drilled holes. Bucket arrays were attached around a 1.82-m tall metal t-post with wire hooks. Buckets were covered with poultry wire secured with 16 gauge tie wire to deter animals from entering the buckets. Mast traps were placed $20.1 \mathrm{~m}$ apart along transects. There 
were 39 mast traps placed within a one-hectare plot (Appendix 30). Transects were oriented on randomly chosen azimuth of 320 degrees in the deciduous plot, 50 degrees in the shrub plot, 100 degrees in the coniferous plot and 300 degrees in the mixed plot.

All mast traps were cleaned of debris and organic materials the week of 13 July 2015. Mast trap collections occurred biweekly, starting the first week of August, 2015, and ended the week of 7 December 2015. In 2016, all mast traps were cleaned of debris and organic material the week of 25 April. Mast trap collections occurred biweekly, starting the first week of May, 2016, and ended the week of 14 November 2016 due to snow. Seed and fruit material was removed from individual mast traps and placed into a paper bag. Ground-plot mast surveys were conducted at each mast trap site to survey mast production below the height of the mast traps. An azimuth in increments of 30 degrees was assigned randomly for each sample period, without repetition. A 1- $\mathrm{m}^{2}$ PVC frame was placed $6.1 \mathrm{~m}$ from the mast trap " $\mathrm{t}$-post" in the specified random azimuth direction. Seed and fruit material within the sample frame was removed and placed into a separate paper bag. All samples were stored in a freezer to prevent decay.

Hard and soft mast was separated by species and placed in individual containers made of noncorrosive metal or glass. The sample within the container was no more than $0.3 \mathrm{~g}$ per $\mathrm{cm}^{2}$ and spread evenly within the container to allow for air circulation (Nitrate Elimination Co. 2012). To achieve a constant weight measurement, seeds and fruit were dried in an oven at $100^{\circ}$ $\mathrm{C}$ for 72 hours to remove moisture, and then weighed to the nearest $0.0001 \mathrm{~g}$ (Braun 2005).

\section{Statistical analysis}

Small mammal species composition was calculated across both years. Average Shannon (Shannon and Weaver 1949) and Simpson Diversity Indices (Simpson 1949), and Jaccard's 
index of similarity (Jaccard 1908), were calculated for all cover types to evaluate and compare small mammal diversity (Hamilton et al. 2015, Ostfeld and Keesing 2000a, Payne and Caire 1999, Hayslett 1992). Average trapping success was also calculated for each cover type as well as for each species. Pairwise comparisons were used to observe any statistically significant difference in diversity indices or trapping success. Index of abundance estimates for cover types and for each species were calculated using the minimum number of unique individuals of our limited recapture success. Apparent infection prevalence of attached ticks was estimated, as well as the proportion of rodents exposed to Borrelia burgdorferi. The rate of positive ear punches per rodent species was also calculated. Lastly, the relationship between positive tick burdens and positive ear punches was examined.

We used a Poisson distribution to model small mammal indices of abundances (Peromyscus sp., Eastern chipmunk; hereafter chipmunk, American red squirrel; hereafter red squirrel, Eastern gray squirrel; hereafter gray squirrel, all hosts) in different cover types. $Y_{i}$ denoted estimated index of abundance, which we modeled as a Poisson random variable: $y_{i} \sim$ Poisson $\left(\lambda_{\mathrm{i}}\right)$ because the data were formatted as count data. These resulting indices of abundances were used as predictor variables in the models for tick index of abundance and Lyme-positive tick index of abundance (Chapter 2). Model selection for total index of abundance was based on the Wald's test $(\mathrm{p}<0.05)$ and lowest relative AICc score (highest relative AICc weight). The predictor variable month, vegetative characteristics and environmental conditions were not included in evaluation of models for total index of abundance of ticks because our focus was the relationship it had with index of abundance of small mammal host species. Model selection for total Lyme-positive index of abundance of ticks included the predictor variables of year, cover type, and host species. Likewise, the model selection for index of abundance of various host 
species included predictor variables year and cover type as our focus was on the spatial distribution of the host community. We conducted parametric bootstrapped pairwise comparisons with a $95 \%$ confidence interval to observe any statistical differences in estimated index of abundance among cover types. This was done for tick count data, positive-Borrelia burgdorferi tick count data, and small mammal count data discriminated by species.

We modeled estimated index of abundance (response variable) as a function of additive predictor variables year, cover type, and various vegetative measurements (Table 2.1). Because several of these vegetative characteristics had high collinearity $r$ value $>0.70$ (Appendix 20), we ran each vegetative characteristic as an independent model and then selected the top models that did not have vegetative predictor variables that had high covariance with previously selected vegetative characteristics. Sum-to-zero coding was used for year effect (Yandell 1997). The count data of small mammal index of abundance was used as a predictive variable for blacklegged tick index of abundance (Table 3.1). Additionally, small mammal host diversity indices were used as predictive variables for Lyme-positive tick index of abundance (Table 3.2). We developed the following models: (1) estimated index of abundance of Peromyscus sp. (Tables 3.3 and 3.4), (2) estimated index of abundance of chipmunk (Tables 3.5 and 3.6), (3) estimated index of abundance of red squirrel (Tables 3.7 and 3.8), (4) estimated index of abundance of gray squirrel (Tables 3.9 and 3.10), and (5) estimated index of abundance of all small mammal hosts (Tables 3.11 and 3.12). Within the estimated index of abundance of each small mammal host species, we evaluated predictive vegetative variables that help to explain index of abundance.

Additionally, we used a binomial distribution to model Lyme-positive tick burdens on small mammal hosts and Lyme-positive ear punches from small mammal hosts with the 
predictor variables of host species or cover type. $Y_{i}$ denoted whether a tick or ear punch was positive for Borrelia burgdorferi, which we modeled as a binomial random variable: $y_{i} \sim$ binomial $\left(\theta_{\mathrm{i}}\right)$. Model selection was based on the Wald's test $(\mathrm{p}<0.05)$ and lowest relative AICc score (highest relative AICc weight) (Table 3.18, Table 3.19 and Table 3.23).

\section{RESULTS}

The species composition of the small mammal community was comprised of Peromyscus sp. (n $=79 ; 38 \%)$, followed by chipmunk $(\mathrm{n}=59 ; 28 \%)$, red squirrel $(\mathrm{n}=33 ; 16 \%)$ and gray squirrel $(\mathrm{n}$ $=18 ; 9 \%)$. The remaining species composition included: meadow vole $(<3 \%)$, meadow jumping mouse $(<1 \%)$, short-tailed shrew $(<2 \%)$, northern flying squirrel $(<1 \%)$, southern flying squirrel $(<2 \%)$, long-tailed weasel $(<2 \%)$, stripped skunk $(<1 \%)$, and Virginia opossum $(<$ 1\%). Average trapping success was significantly greater (Table 3.15) in the developed cover type at 13.54 captures per 100 trapping events, followed by coniferous forest (Tables 3.14 and 3.15). There was a higher index of abundance of small mammal hosts in the developed cover type, followed by coniferous forest (Fig. 3.1, Table 3.21). More individual Peromyscus sp. were captured in the developed, deciduous and coniferous forests while more individual chipmunks were captured in the developed cover type (Table 3.21). There were significantly more individual Peromyscus sp. captured, followed by chipmunk, and there were significantly more small mammal captures in the developed cover type, followed by coniferous forest (Table 3.13). Vegetative characteristics did not predict index of abundance of Peromyscus sp. (Tables 3.3 and 3.4) and chipmunk (Tables 3.5 and 3.6). Index of abundance of red squirrel was negatively related to increasing ground stem density (Fig. 3.2). Index of abundance for gray squirrels was positively related to increasing tree species richness and snag decay (Figs. 3.3 and 3.4), and was 
negatively related to increasing midstory cover (Fig. 3.5). The index of abundance of all small mammal host species was negatively related to increasing snag decay, or the degradation of suitable snags (Fig. 3.6).

Estimated index of abundance of black-legged ticks and Lyme-positive ticks was greatest in the coniferous cover type (Figs. 2.2-2.6). Estimated index of abundance of black-legged ticks was positively related to increasing estimated index of abundance of all small mammal host species (Fig. 3.7). Jaccard's index of similarity and dissimilarity indicated that the grassland cover type was significantly different (Wald test $p<0.001$ ) than other cover types while mixed and coniferous cover types were the most similar in regards to species composition (Table 3.16). Average indices of diversity were greatest in the developed and coniferous forest cover types (Table 3.14). Estimated index of abundance of Lyme-positive ticks was positively related to increasing average small mammal host Simpson's index of diversity (Fig. 3.9) as well as average small mammal host Shannon's index of diversity (Fig. 3.8).

Of the 209 individual small mammals captured, 95 (45\%) had one of more ticks attached to their head at the time of capture, hereafter referred to as tick burden. This is half of the individuals captured in areas with observed tick burdens (Table 3.17). There was a greater number of Peromyscus sp. individuals with tick burdens compared to other small mammal host species. In addition, a greater number of individuals captured in the developed cover type that had tick burdens compared to individuals captured in other cover types (Table 3.17). From our models (Table 3.18 and 3.19), Peromyscus sp. and gray squirrel had significantly greater tick burdens than chipmunk (Fig. 3.10), and the developed and mixed-forest cover types had small mammal individuals with significantly greater tick burdens than in the shrub cover type (Table 3.20). 
Of the 95 individuals with tick burdens, $42(44 \%)$ indivdiuals had an attached tick that tested positive for Borrelia burgdorferi. The apparent infection prevalence of tick burdens on small mammals was $32 \%$ (56/174). There was a significantly greater estimated index of abundance of Lyme-positive tick burdens on chipmunks (Fig. 3.11, Table 3.20) compared to Peromyscus sp. and gray squirrels based on our model (Table 3.19). Likewise, there was a greater estimated index of abundance of Lyme-positive tick burdens in the developed cover type (Table 3.17), although it was not significant (Table 3.20). Of the 115 ear punches collected in 2016, 41 (35.65\%) were positive for Borrelia burgdorferi. A greater number of individuals tested positive for Lyme disease in the developed cover type $(n=22)$ compared to the other cover types (Table 3.22). There were 15 individual Peromyscus sp. and chipmunks that tested positive for Borrelia burgdorferi, however, there was a greater proportion of sampled chipmunks (57.69\%) than sampled Peromyscus sp. (30.61\%) that were positive for Lyme disease (Table 3.22). The proportion of red squirrels positive for Borrelia burgdorferi was comparable to that of Peromyscus sp. at 35.29\% (Table 3.22). Based on the model (Table 3.23), there were no significant differences in Borrelia burgdorferi apparent prevalence among species and cover types (Table 3.24). There were 10 individuals with an attached tick as well as an ear punch that tested positive for Borrelia burgdorferi: 4 Peromyscus sp., 4 chipmunk, and 2 red squirrel; 7 were captured in the developed, 1 in the mixed, 1 in the coniferous, and 1 in the deciduous cover types. There were 15 individuals with an attached tick that tested positive for Borrelia burgdorferi but had ear punch that tested negative: 8 Peromyscus sp., 2 red squirrel, and 5 gray squirrel; 5 were captured in the developed, 2 in the mixed, 5 in the coniferous, and 3 in the deciduous cover types. There were no individuals that had an ear punch that tested positive for Borrelia burgdorferi but attached ticks that tested negative. 


\section{DISCUSSION}

The small mammal community within the heavily fragmented Cantonment Area of Fort Drum Military Installation was dominated by Peromyscus sp. and chipmunks (66\% together), known effective reservoirs of Lyme disease (Brisson et al. 2008). Red (16\%) and gray (9\%) squirrels also had a large presence in the small mammal community, indicating that these species may be more competent reservoirs than previously thought. Because Peromyscus sp., chipmunks, red and gray squirrels can all better adapt to anthropogenic changes and forest fragmentation (LoGiudice et al. 2008), their disproportionate, abundant population densities in the community allow for more frequent and higher tick burdens on effective reservoirs (Ostfeld and Keesing 2000b). The high indices of abundance of effective reservoirs may also be due to the decline or lack of competitor and predator species, such as raccoon, opossum, red and gray fox, in such a fragmented landscape, and as a result, more resources become available for small mammal host populations and their reproductive success, survival and abundance increase (Ostfeld and Keesing 2000a, Schmidt and Ostfeld 2001, Keesling et al. 2009). However, there was no significant difference between indices of abundance of small mammal species, suggesting that any or all of these species may be contributing to the Lyme disease system on Fort Drum. While our methodology did include both Sherman and Tomahawk traps in hopes of detecting the mammal community's diversity, these traps target the species we captured most often and provide only a preliminary estimate of the index of abundance. Despite the selectiveness of our trapping methodology, we captured 12 different mammalian species.

The coniferous and deciduous cover types had high small mammal and tick indices of abundance, likely due to the favorable microhabitat characteristics. They also had the lowest 
mast production in comparison to the shrub and mixed forest cover types. Because the distribution of black-legged ticks across various cover types is dependent on host species' movements, which are largely influenced by mast production (Ostfeld et al. 1995, Wolff 1996, Jones et al. 1998), the abundances of the vector and hosts on Fort Drum was expected to be as high if not higher in the deciduous cover type compared to the mixed and coniferous cover types. Although the limited length of this study impedes the ability to model a time series of mast production and small mammal host index of abundance, this information suggests that properties of the specific cover type other than mast production may be driving the distribution of small mammal hosts. Furthermore, the lifespan of small mammals may differ by cover type, therefore implying a more aggressive transmission dynamic to maintain high prevelance of Borrelia burgdorferi in the vector and host populations if survival was low. Models for index of abundance of red squirrels and gray squirrels indicate that ground stem density, tree species richness, snag decay and midstory cover, all of which may serve as refuge habitat (Carey and Johnson 1995, Loeb 1996, Davis et al. 2010), are significant predictors of their distributions on the landscape. Models for index of abundance of Peromyscus sp. and chipmunk, however, indicated that vegetative characteristics were not significant predictors of their distributions. This also suggests the successful ability of these competent reservoir hosts to adapt to developed and fragmented areas (Ostfeld and Keesing 2000b, LoGiudice et al. 2008).

The developed and coniferous cover types both had a high index of abundance of small mammal hosts, with comparatively high chipmunk and squirrel captures, a high index of abundance of Lyme-positive questing ticks, and a high average diversity index, as index of diversity was positively related to increasing index of abundance of Lyme-positive ticks in the model. In contrast, the deciduous cover type had a relatively high index of abundance of small 
mammal hosts, consisting of primarily Peromyscus sp., a low index of abundance of Lymepositive questing ticks, and a low average diversity index. This was the opposite trend we were expecting and unlike other documented Lyme disease systems it does not indicate a dilution effect but rather an amplification effect (Levi et al. 2016, Keesing et al. 2006). Areas with high diversity often exhibit low Borrelia burgdorferi apparent prevalence on the landscape as poor reservoirs will serve as dilution hosts (LoGiudice et al. 2003, Brisson and Dykhuizen 2004, Keesing et al. 2009). It has been hypothesized that an increase in diversity of hosts, many of which are less competent reservoirs, will reduce the risk of human exposure to Lyme disease (Van Buskirk and Ostfeld 1995, Rosenblatt et al. 1999, Ostfeld and Keesing 2000a, Ostfeld and Keesing 2000b). Albeit, the presence of certain diversifying hosts may be more important than the diversity index of a cover type. However, our results indicated that increased diversity was positively related to increasing Lyme-positive ticks. For example, coniferous forests and developed areas had species compositions with a large chipmunk and squirrel presence and a higher prevalence of Lyme-positive tick counts. It is important to note that because it is difficult to discriminate Peromyscus species in the field as species hybridization has been reported in the northeastern United States due to their overlapping distributions (Tessier et al. 2004); in any case, we identified Peromyscus only to the genus level. As a result, the apparent prevalence estimates for Peromyscus sp. are likely influenced if they include samples taken from Peromyscus sp. hybrids or from the less competent reservoir represented by Peromyscus maniculatus (Peavey and Lane 1995).

Although we found a greater number of individual Peromyscus sp. with a tick burden and a Lyme-positive tick burden $(n=46,58 \%$ and $n=18,39 \%$, respectfully), chipmunks had a significantly greater proportion of individuals with Lyme-positive tick burdens ( $\mathrm{n}=15,79 \%)$ 
compared to Peromyscus sp. and gray squirrel. The proportions of individuals with tick and Lyme-positive tick burdens indicated that red squirrels (52\% and 29\%, respectively), which was not statistically significant from Lyme-positive tick burdens on chipmunks, and gray squirrels (72\% and 30\%, respectively) may also serve as important hosts and potential reservoirs. This may be realted to the fact that gray and red squirrels are more frequent in cover types with high tick and Lyme-positive tick counts (Table 3.21 and 2.11). All cover types except shrub forest had a high proportion (> 50\%) of individuals with tick burdens, however, the greatest number of individuals with Lyme-positive tick burdens occurred in the developed cover type $(\mathrm{n}=21)$, although there was no significant difference of individuals with Lyme-positive tick burdens between cover types. Although the same number of individual Peromyscus sp. and chipmunk had ear punches that tested positive for Lyme disease, there was a greater proportion of positive chipmunks (58\%) compared to Peromyscus sp. (31\%) that had the capability of transmitting Lyme diesae to an uninfected tick. Additionally, there was a greater proportion of red squirrels with positive ear punches (35\%) compared to Peromyscus sp., suggesting that other small mammal hosts may be acting as effective reservoirs for Lyme disease due to observation that these species are more frequent in cover types with high tick and Lyme-positive tick counts (Table 3.21 and 2.11). Furthermore, of the 10 individuals with an attached tick as well as an ear punch that tested positive for Borrelia burgdorferi, 4 were Peromyscus sp., 4 were chipmunk and 2 were red squirrel while of the 15 individuals with an attached tick that tested positive for Borrelia burgdorferi but had ear punch that tested negative, 8 were Peromyscus sp., 2 were red squirrel, and 5 were gray squirrel. Not only were there more negative Peromyscus sp. ear punches for Borrelia burgdorferi when there was a Lyme-positive attached tick on that individual, but there were also no chipmunks that had an attached tick that tested positive for 
Borrelia burgdorferi but had ear punch that tested negative, suggesting chipmunks may play a greater role than previously thought in Lyme disease prevalence on the landscape. Additionally, the same number of red squirrels with an attached tick that tested positive for Borrelia burgdorferi had ear punches that tested positive and negative, futher supporting their potential effective reservoir competence. Surprisingly, meadow voles, only captured in the grassland cover type where no ticks were detected, had a very high infection apparent prevalence of $75 \%$, which may indicate that tick drags are an ineffective method for observing the presence of ticks. The developed cover type, with the highest small mammal indices of abundance, had the greatest number of individuals positive for Borrelia burgdorferi $(\mathrm{n}=22)$. It is important to note that this is not a measure of reservoir competence, which involves both the successful feeding of a tick and transmission of the spirochete.

Our results suggest that the Lyme-disease system on Fort Drum is different than those previously documented and described. This may be due to unique qualities of Fort Drum, such as the lake-effect environmental conditions found in this part of the Northeast resulting in high humidity and harsh winters, the heavily fragmented and developed nature of the Cantonment Areas, and or that the deciduous forests lack oak trees forcing rodents to seek food resources elsewhere. These qualities may encourage unexpected competent reservoirs in the Lyme-disease system on Fort Drum. Although we did not have sufficient recaptures for a proper spatially explicit mark-recapture analysis and sample sizes were small, our indices of small mammal abundance are conservative as they are the minimum number of individuals within that area. Furthermore, this information provides a basis to help understand the vector-host relationships and distributions on the Cantonment Area of Fort Drum Military Installation. Because blacklegged ticks do not move large distances on their own, host distributions and movements, which 
are determined by patch size and juxtaposition, need to be researched in order to determine concentrated areas with higher Lyme disease prevalence (Ostfeld et al. 1995, Van Buskirk and Ostfeld 1998). We would suggest future studies discriminate the genus Peromyscus to species and focus on the reservoir competence of and Lyme disease prevalence in other small mammal host species that exist in the community to better understand the vector-host relationships in the Cantonment Area. 


\section{CHAPTER 4}

MANAGEMENT RECOMMENDATIONS FOR LYME DISEASE (BORRELIA BURGDORFERI) ON FORT DRUM MILITARY INSTALLATION, NEW YORK 


\section{Management Recommendations for Lyme Disease (Borrelia burgdorferi) on Fort Drum Military Installation, New York}

SAMANTHA R. FINO, Division of Forestry and Natural Resources, West Virginia University, Morgantown, WV 26506, USA

\section{INTRODUCTION}

There are 22 military installations in the Northeast (above the Mason-Dixon Line and Pennsylvania as the western boundary) collectively within the range of Ixodes scapularis that can carry Lyme disease. Installations range in size from Fort Drum at $433 \mathrm{~km}^{2}$ to Fort Devens at less than $20 \mathrm{~km}^{2}$ and most contain diverse habitat types suitable for Ixodes scapularis. Although the branch of military and specific mission may differ among installations, the potential for exposure of active duty personnel and their families to Lyme disease is a growing concern for the Department of Defense (Piacentino and Schwartz 2002). Fort Drum Military Installation near Watertown, New York is the largest military installation $\left(433 \mathrm{~km}^{2}\right)$ in the Northeast and home to approximately 19,500 active duty soldiers and their families.

The U.S. Army Public Health Command Human Tick Test Kit Program reported a mean annual Lyme disease incidence of $52.2 \pm 7.6$ per 100,000 person-years in soldiers between January 1, 2006 and December 31, 2012. Of 14 military treatment facility locations, Fort Drum had the highest proportion of Ixodes scapularis, as opposed to other tick species, found attached to service members at 92\%. The U.S. Army Public Health Command Human Tick Test Kit Program also reported an increase in Lyme disease incidences of 5.7\% from 2006-2012 (Rossi et al. 2015). Of recorded Lyme diagnoses, Fort Drum, NY had 38 incident cases of Lyme disease during 2004-2013, making it one of the highest in the nation (Hurt and Dorsey 2014). Despire 
this status, no previous intensive survey of Ixodes scapularis and its hosts relative to season and habitat has taken place on Fort Drum Military Installation. With rising prevalence rates, temporal- and spatial-specific recommendations and management efforts are necessary.

Our study (Chapters 2 and 3) and the following management recommendations are specific to the Cantonment Area. The Cantonment Area is approximately 4,000 ha and consists of $30 \%$ developed landscape, $30 \%$ grassland, $9 \%$ mixed forest, $5 \%$ coniferous forest, $8 \%$ shrub, and $18 \%$ deciduous forest (Figure 1.2). The Cantonment Area includes buildings, residential homes, barracks, motor pools, land navigation courses, local training areas, and recreation areas, such as parks, sports fields, green spaces and trails.

The potential risk for Fort Drum personnel and their family members to be exposed to Lyme disease via encounters with infected ticks warrants research to better manage the level of risk. Knowledge of the basic spatial and temporal patterns of Ixodes scapularis will allow resource managers to assess and communicate the likelihood of encountering a Lyme-positive tick and to take necessary actions to minimize that risk. Specifically, our objective was to develop management recommendations based on the distributions, densities, and Lyme disease apparent prevalence of the vector and host populations on Fort Drum. The following management recommendations are for the Cantonment Area of Fort Drum Military Installation.

\section{MANAGEMENT RECOMMENDATIONS}

With a Borrelia burgdorferi apparent prevalence of 35\% (Table 2.11), and other pathogens such as Borrelia miyamotoi with a apparent prevalence of $<1 \%$ (Table 2.13) and Anaplasma phagocytophilum with a apparent prevalence of $4 \%$ (Table 2.14$)$, as well as co- $(\mathrm{n}=29)$ and tri-infected $(n=2)$ ticks, there is a need to implement management practices that decrease the 
risk of human exposure to tick-borne illnesses on the Cantonment Area of Fort Drum.

However, such practices can be costly in both equipment and personnel. The following habitat and wildlife management recommendations should, at minimum, be executed on areas in contact with or in close proximity to human developed areas as well as in areas of high use by soldiers and family members. More intensive practices should be confined to areas of high human use. There are several options and alternatives of habitat and wildlife management that can be done individually or in conjunction with one another. Possible options include, but are not limited to: (1) educational and outreach practices, (2) residential landscape alteration/modification, (3) leaf litter and questing substrate removal, (4) a selective cut, (5) grassland restoration and invasive species removal, (6) mowing surroundings of high human use areas, (7) the use of fungi as a biological control, and (8) the distribution of bait boxes.

\section{Education and outreach}

Whenever outside, it is important to practice personal preventative measures against Lyme disease, such as wearing light colored clothing, tucking pants into socks, wearing repellent, promptly inspecting oneself to remove ticks, exposing untreated clothing under high dryer heat for 10 minutes, and getting pets treated or vaccinated (Ginsberg 1994). Lyme disease-positive black-legged tick abundance was found greatest in the coniferous and mixed forest cover types in spring and fall months (due to the adult developmental stage peaks) (Fig. 2.5). This is due in part to the fact that adults have the highest infection apparent prevalence compared to other developmental stages at $48 \%$ (Table 2.11). Furthermore, coniferous and mixed cover types provide ticks a more suitable microhabitat. Although these cover types are only $5 \%$ and $9 \%$ of the Cantonment Area respectively, they have the highest Lyme disease apparent prevalence 
(Table 2.11) and probability of encountering a Lyme-positive tick (Table 2.12). The percentage of positive-Borrelia burgdorferi tick declines significantly during summer months and in cover types that are less hospitable for ticks, such as shrub and deciduous forests (Table 2.12). Ideally, humans would refrain from activity in coniferous and mixed forest patches during the spring (once the snow melts through May) and fall months (starting in October until there is snow cover); whereas activity in grassland, shrub or deciduous areas could continue through the year with minimal exposure to Borrelia burgdorferi. Furthermore, because index of abundance of questing ticks are positively related to increasing humidity (Fig. 2.8) and temperature (Fig. 2.7), human activity could be decreased on relatively humid and hot days. Additionally, the Army could utilize information available from the CDC or NYSDOH to educate the public on tick-borne diseases and/or develop public education seminars regarding black-legged tick spatial and temporal distributions specific to Fort Drum, as well as preventative personal protective measures, and symptom reviews should they acquire a Lyme disease infection in the future.

\section{Habitat management}

Entities responsible for landscaping (e.g., Directorate of Public Works, Directorate of Family, Morale, Welfare \& Recreation, Fort Drum Mountain Community Homes) should remove leaf litter piles (Fig. 2.10), coarse woody debris (Fig. 2.9), and stone walls (Stafford 2004) from residential yards and other areas with high levels of human use. These landscape features provide suitable microhabitat for both vector and host species. The CDC (2017) also recommends planting deer resistant crops in gardens to prevent attracting deer carrying tick burdens from entering the yard. If additional children's playsets are constructed, the CDC 
(2017) suggests that their location be in direct sunlight where ticks will likely desiccate (Ostfeld et al. 1995, Bertrand and Wilson 1996).

In regards to habitat management outside of residential developments in the Cantonment Area, I would suggest a removal (raking or burning) of leaf litter and coarse woody debris that serve as refuge microhabitat, as well as ground-cover vegetation that may be used as questing substrate, in areas with high tick and Lyme-positive tick counts. The positive relationship tick index of abundance has with leaf litter depth (Figure 2.10) as well as the negative relationship with coarse woody debris decay (Figure 2.9), suggest increased probability of tick-host interactions and elevated tick burdens with increased vegetation density at the lowest strata closest to the ground, including leaf litter and coarse woody debris (Carey and Johnson 1995, Loeb 1996, Davis et al. 2010). The stable microclimate under leaf litter and coarse woody debris, with increased relative humidity and reduced predation risk for both black-legged ticks and hosts, promotes tick survival (Ginsberg and Ewing 1989, Adler et al. 1992, Goddard 1992, Stafford 1994, Lindsay et al. 1999, Schmidt et al. 1999, Lubelczyk et al. 2004, Prusiniski et al. 2006). Therefore, the duff and leaf litter layer should be raked monthly throughout the fall when needles begin to drop in the coniferous and mixed forest cover types. Furthermore, this should be done annually as different tree species hold their leaves for different periods of time.

Additionally, because estimated index of abundance of ticks was positively related to increasing tree species richness (Fig. 2.11), which is highly collinear with tree density and canopy cover (Appendix 20), I would suggest a selective cut of large, mast producing, dominant or co-dominant pine and hemlock trees in the coniferous and mixed-forest cover types. A selective cut would not only remove food resources from host species (Yamasaki et 
al. 2000), but also to increase sunlight penetration and allow for wind movement through the forest. This management effort would also decrease pine needle depth and therefore microhabitat suitability for black-legged ticks, resulting in increased desiccation. Thinning based on basal area of coniferous and mixed stands with high canopy cover and basal area (Appendix 19) would likely decrease tick index of abundance due to their higher risk of desiccation (Ostfeld et al. 1995, Bertrand and Wilson 1996). Conifer thinning or pruning should occur in the spring before mast and needles drop and every 5 years to compete with regeneration (LandOwner Resource Centre, American Forest Foundation 2014). While I understand that these may interfere with the success of other wildlife species, such as interfering with thermal cover for deer (MNDNR 2009), in a fragmented landscape that is heavily developed such as the Cantonment Area, the decrease of Lyme disease on the landscape is of the greatest importance for the residents of Fort Drum. Hardwood trees, such as oak trees, which are primarily present in the coniferous and mixed cover types and serve as roosting habitat for endangered bat species (Jachowski et al. 2016), should not be removed.

As part of the invasive species management effort on Fort Drum, I would recommend converting the shrub cover type, dominated by common buckthorn (Rhamnus cathartica) and honeysuckle (Lonicera sp.), into restored grassland fields. Although the shrub cover type had low tick and Lyme-positive tick indices of abundance (Fig. 2.2-2.6), we did not detect any ticks in the grassland cover type (Chapter 2) most likely due to sunlight and wind causing desiccation. Early successional fields composed of native grass and wildflower species vegetation serve as great habitat for migratory birds, bees, butterflies, as well as other insects, pollinators, and species of conservation concern (NRCS 2013). By converting the shrub cover type into 
grassland cover type, invasive species are removed and native habitat for pollinators and migratory birds is promoted without encouraging the presence and success of black-legged ticks.

Additionally, areas of high human use, such as hiking trails, playgrounds, and recreational fields, should be surrounded by a 3 meter buffer of mowed grasses followed by a 1 meter barrier of dark colored wood chips (CDC 2017a). Mowed and woodchip areas should act as a barrier with high sunlight exposure between human-developed areas and forested areas to prevent human-tick interactions. Additionally, trees that provide cover over these areas of high human-use should be removed. Instead, gazebos and pavilions can provide localized shade.

\section{Tick management}

Metarhizium burnneum/anisopliae and Beauveria bassiana, fungi that act as a parasitoid, can also be used to reduce risk of exposure of Lyme disease (Hornbostel et al. 2005). Nest boxes or tubes can be constructed with batting treated with the fungus. As the Peromyscus sp. use these nest boxes or tubes, fungus will get on their fur, as well as current or subsequent tick burdens. The fungus penetrates the cuticle and penetrates into the tick body where it proliferates. The substances produced by the fungus inside the tick are toxic and lethal (Bioforsk 2013). Futhermore, the fungus can cause ticks to feed on host blood more poorly, as well as reduce their success in molting into the next developmental stage or laying eggs (Hornbostel et al. 2004). The fungus can also grow in the soil where it can come into contact with other hosts with tick burdens or off-host ticks. I would suggest dusting the leaf/needle litter annually in coniferous and mixed forests, as well as developed areas, in spring as the small mammals emerge from hibernation or torpor. This would allow efficient transfer of the fungi from host to tick during the nymphal peak as the fungi is temperature sensitive (Bharadwaj and Stafford 
2012). Three treatments are recommended per year throughout the spring and early summer in conjunction with the nymphal peak (Allabouttrees.com). I would also supplement dusting with the annual distribution of nesting boxes and tubes on trees. I would suggest 5 constructed and treated nests per $50 \mathrm{~m}^{2}$, and they should be monitored weekly for replenishment, repair or replacement. Metarhizium burnneum/anisopliae is an EPA-approved biological control which can be purchased online and is competitive to chemical treatments, such as pesticides that prevent or kill ticks and herbicides that kill herbaceous cover which serve as questing substrate.

\section{Small mammal management}

Bait box stations that apply Fipronil to small mammals that enter the bait box station (CDC 2015a) or tick tubes treated with acaricide permethrin (Ticksinmaine.com) would be encouraged for developed areas, as well as areas in close proximity to trails and recreational areas that run through coniferous, mixed and deciduous cover types. The bait box and tick tube treatment reduce infestation prevalence on hosts and risk of exposure to an infected tick by 97\% (Schulze et al. 2017, Ticktubes.com). Bait boxes or tick tubes should be deployed at the start of spring and Fipronil/permethrin should be replenished in July. Weekly monitoring of bait boxes is necessarly to replenish bait accordingly. This would need to be done annually due to likely immigration/emigration and increased reproductive rates. Furthermore, these treatments should be executed at a higher magnitude of 1 bait box or tick tube per $50 \mathrm{~m}^{2}$ in cover types with greater indices of abundances (Fig. 3.1). Bait boxes cost approximately $\$ 50$ per box and tick tubes cost approximately $\$ 25$ for a 6-count pack. Alternatively, vaccinated bait, such as with doxycycline which reduced Lyme disease by $94.3 \%$ (Dolan et al. 2011), could be distributed in a similar manner, although it is important to note that this method may 
encourage antibiotic resistence. With Peromyscus sp. and chipmunks having the greatest black-legged tick burdens and Lyme-positive tick burdens, respectively (Table 3.17), as well as an observed positive relationship between index of abundance of vector and hosts (Fig. 3.7), wildlife management practices that negatively impact these species is vital in order to decrease Lyme disease prevalence on the landscape and human risk of exposure.

\section{Monitoring}

If Fort Drum decides to move forward with these habitat and wildlife management recommendations, I would suggest developing 1-ha plots (based on the constraints of some of the forest fragments) evenly spaced throughout the Cantonment Area. There would be a plot for each habitat/wildlife management recommendation individually, a plot for each various combination of habitat/wildlife management recommendation, and a control plot where no habitat/wildlife management occurred. In the following year after the habitat/wildlife management was executed, tick densities and Lyme disease prevalence should be monitored biweekly after snow melt through June and again starting in October until the first snow fall in order to capture the adult and nymph peaks (Figs. 2.2 and 2.3), and as described in the methods of Chapter 2 because samples collected from tick drags are a better representation of potential human-tick interactions and human risk of exposure. Based on the results, a particular management plan can be developed, established, and modified with annual black-legged tick monitoring via tick drags.

\section{Future research}

It is evident that the Fort Drum Lyme disease system may be different than that of previously studied systems. With one nymphal peak (Fig. 2.3) and low indices of host 
abundance (Fig. 3.1), there may be other components of the ecosystem that are contributing to the high Lyme disease apparent prevalence in the Cantonment Area. Because Fort Drum has primarily well-drained sandy soils (Web Soil Survey 2015) that provide high quality habitat (Kitron et al. 1992, Glass et al. 1994), future research should investigate the relationship of soil and moisture content with tick distributions and prevalence. Additionally, other potential hosts, such as large rodents and mesocarnivores (e.g., groundhogs, fox, skunks, raccoons), should be explored in regards to their reservoir competence and distributions. Similarly, the relationship between the distributions of white-tailed deer, the primary hosts for adult Ixodes scapularis (Piesman et al. 1979, Anderson and Magnarelli 1980, Schulze et al. 1984, Spielman et al. 1985), and tick distributions should be observed. Lastly, an investigation of the predator community (raptors, carnivores) within the Cantonment Area should be conducted to gain a better understanding of what may be controlling the small mammal populations. All in all, this study provides a baseline for the tick and small mammal distributions on Fort Drum and clearly indicates that there are likely other components that are contributing to the Lyme disease prevalence. 


\section{LITERATURE CITED}

Abraham, S. T., D. N. Zaya, W. D. Koenig, and M. V. Ashley. 2011. Interspecific and intraspecific pollination patterns of valley oak, Quercus lobata, in a mixed stand in coastal central California. International Journal of Plant Science 172:691-699.

Abramsky, Z., M. I. Dyer, and P D. Harrison. 1979. Competition among small mammals in experimentally perturbed areas of the shortgrass prairie. Ecology 60:530-536.

Adler, G. H., L. M. Reich, and R .H. Tamarin. 1984. Characteristics of white-footed mice in woodland and grassland in eastern Massachusetts. Acta Theriologica 29:57-62.

Adler, G. H. and M. L. Wilson. 1987. Demography of a habitat generalist, the white-footed mouse, in a heterogeneous environment. Ecology 68:1785-1796.

Adler, G. H., S. R. Telford, III, M. L. Wilson, and A. Spielman. 1992. Vegetation structure influences the burden of immature Ixodes dammini on its main host, Peromyscus leucopus. Parasitology 105:105-110.

Alejano R., R. Tapias, M. Fernández, E. Torres, J. Alaejos, and J. Domingo. 2008. Influence of pruning and the climatic conditions on acorn production in holm oak (Quercus ilex L.) dehesas in SW Spain. Annals of Forest Science 65:209.

All about trees. 2017. All about trees. http://www.all-about-trees.com/services/tick-control/. American Forest Foundation. 2017. Tree thinning 101. https://www.forestfoundation.org/woodland-tree-thinning-101.

Anderson, C. S., A. B. Cady, and D. B. Meikle. 2003. Effects of vegetation structure and edge habitat on the density and distribution of white-footed mice (Peromyscus leucopus) in small and large forest patches. Canadian Journal of Zoology 81:897-904. 
Anderson, J. F. 1988. Mammalian and avian reservoirs for Borrelia burgdorferi. Annals of the New York Academy of Science, 539:180-191.

Anderson, J. F. and L. A. Magnarelli. 1980. Vertebrate host relationships and distributions of ixodid ticks (Acari: Ixodidae) in Connecticut, USA. Journal of Medical Entomology $17: 314-323$.

Anderson, J. F. and L. A. Magnarelli. 1984. Avian and mammalian hosts for spirochete-infected ticks and insects in a Lyme disease focus in Connecticut. Yale Journal of Biology and Medicine 57:627-641.

Anderson, J. F. and L. A. Magnarelli. 1993. Natural history of Borrelia burgdorferi in vectors and vertebrate hosts. Pp. 11-24, in Ecology and environmental management of Lyme disease (H.S. Ginsberg, ed.) Rutgers University Press, New Brunswick, New Jersey, $224 p p$.

Anderson, J. F., P. H. Duray, and L. A. Magnarelli. 1987. Prevalence of Borrelia burgdorferi in white-footed mice and Ixodes dammini at Fort McCoy, Wisconsin. Journal of Clinical Microbiology 25:1495-1497.

Apperson, C. S., J. F. Levine, T. L. Evans, A. Braswell, and J. Heller. 1993. Relative utilization of reptiles and rodents as hosts by immature Ixodes scapularis (Acari:Ixodidae) in the coastal plain of North Carolina, USA. Experimental and Applied Acarology 17:719-731.

Armstrong, P. M., L. R. Brunet, A. Spielman, and S. R. Telford. 2001. Risk of Lyme disease: preceptions of residents of a Lone Star tick-infested community. Bulletin of the World Health Organization 79:916-925. 
Arsnoe, I. M., G. J. Hickling, H. S. Ginsberg, R. McElreath, J. I. Tsao. 2015. Different populations of black-legged tick nymphs exhibit difference in question behavior that have implications for human Lyme disease risk. Plos One 10(5): e0e127450.

Baker, R. H. 1968. Habitats and distributions. Pages 98-126 in J. A. King, editor. Biology of Peromyscus (Rodentia). American Society of Mammalogists Publication Number 2.

Barbour, A. G., and D. Fish. 1993. The biological and social phenomenon of Lyme disease. Science 260:1610-1616.

Bee, J. W., G. Glass, R. S. Hoffman, and R. R. Patterson. 1981. Mammals in Kansas. University of Kansas Printing Service, Lawrence, 300 p.

Berger, Stephen (2014). Lyme disease: Global Status 2014 Edition. GIDEON Informatics Inc. p. 7. $\underline{\text { ISBN }} \underline{9781498803434}$.

Bertrand, M .R. and M. L. Wilson. 1996. Microclimate-dependent survival of unfed adult Ixodes scapularis (Acari: Ixodidae) in nature: life cycle and study design implications. Journal of Medical Entomology 33:619-627.

Bharadwaj, A. and K. C. Stafford, III. 2012. Susceptibility of Ixodes scapularis (Acari: Ixodidae) to Metarhizium brunneum F52 (Hypocreales: Clavicipitaceae) using three exposure assays in the laboratory. Journal of Economic Entomology 105:222-231.

Bioforsk - Norwegian Institute for Agricultural and Environmental Research. "Fungus kills ticks.” ScienceDaily. ScienceDaily, 12 November 2013. https://www.sciencedaily.com/releases/2013/11/131112091005.htm.

Bonal R., A. Muñoz, and M. Díaz. 2007. Satiation of predispersal seed predators: the importance of considering both plant and seed levels. Evolutionary Ecology 21:367-380. 
Bonner, F. T. 1981. Measurements and management of tree seed moisture. United States Department of Agriculture, New Orleans, LA, USA.

Bosler, E. M., B. G. Ormiston, J. L. Coleman, J. P. Hanrahan, and J. L. Benach. 1984. Prevalence of the Lyme disease spirochete in populations of white-tailed deer and whitefooted mice. Yale Journal of Biology and Medicine 57:651-659.

Boyard, C., J. Barnouin, P. Gasqui, and G. Vourc'h. 2007. Local environmental factors characterizing Ixodes rictnus nymph abundance in grazed permanent pastures for cattle. Parasitology 134:987-994.

Braun, C. (2005). Techniques for Wildlife Investigations and Management. Sixth Edition. The Wildlife Society, Bethesda, MD.

Brei, B., J. S. Brownstein, J. E. George, J. M. Pound, J. A. Miller, T. J. Daniels, R. C. Falco, K. C. Stafford, III, T. L. Schulze, T. N. Mather, J. F. Carroll, and D. Fish. 2009. Evaluation of the United States Department Of Agriculture Northeast Area-wide Tick Control Project by meta-analysis. Vector Borne Zoonotic Diseases 9:423-430.

Brisson, D. and D. E. Dykhuizen. 2004. ospC diversity in Borrelia burgdorferi: different hosts are different niches. Genetics 168:713-722.

Brisson, D., D. E. Dykhuizen, and R. S. Ostfeld. 2008. Conspicuous impacts of inconspicuous hosts on the Lyme disease epidemic. Proceedings of the Royal Society 275:227-235.

Brossard, M., and S. K. Wikel. 2004. Tick immunobiology. Parasitology 129:161-176.

Brownstein, J. S., D. K. Skelly, T. R. Holford, and D. Fish. 2005. Forest fragmentation predicts loca scale heterogeneity of Lyme disease risk. Oecologia 146:469-475. 
Brownstein, J.S., T. R. Holford, and D. Fish. 2003. A climate-based model predicts the spatial distribution of the Lyme disease vector Ixodes scapularis in the United States. Environmental Health Perspectives 111:1152-1157.

Brunner, J. and R. S. Ostfeld. 2008. Multiple causes of variable tick burdens on small-mammal hosts. Ecology 89: 2259-2272.

Burgdorfer, W., A. G. Barbour, S. F. Hayes, J. L. Benach, E. Grunwaldt and J. P. Davis. 1982. Lyme disease-A tick-borne spirochetosis? Science 216:1317-1319.

Burger J. R., A. S. Chesh, R. A. Castro, L. Ortiz Tolhuysen, I. Torre, L. A. Ebensperger and L. D. Hayes. 2009. The influence of trap type on evaluating population structure of the semifossorial and social rodent Octodon degus. Acta Theriologica 54: 311-320.

Butler, J. 2013. Vector-borne disease surveillance report, Fort Drum, NY June 2013. U.S. Army Public Health Command, Maryland, USA.

Carey A.B., and M. L. Johnson. 1995. Small mammals in managed, naturally young, and oldgrowth forests. Ecological Applications 5:336-352.

Carey, A. B., W. L. Krinsky, and A. J. Main. 1980. Ixodes dammini (Acari: Ixodidae) and associated ixodid ticks in south-central Connecticut, USA. Journal of Medical Entomology 17:89-99.

Carroll, J. F., and E. T. Schmidtmann. 1996. Dispersal of black-legged tick (Acari: Ixodidae) nymphs and adults at the woods-pasture interface. Journal of Medical Entomology 33:554-558.

Carroll, M. C., H. S. Ginsburg, K. E. Hyland, and R. Hu. 1992. Distributions of Ixodes dammini (Acari: Ixodidae) in residential lawns on Prudence Island, Rhode Island. Journal of Medical Entomology 29:1052-1055. 
Centers for Disease Control and Prevention [CDC]. 2013. CDC provides estimate of Americans diagnosed with Lyme disease each year. U.S. Department of Health and Human Services.

Centers for Disease Control and Prevention [CDC]. 2014. Interactive Lyme disease map. U.S. Department of Health and Human Services.

Centers for Disease Control and Prevention [CDC]. 2015a. Bait Box Study (Connecticut). U.S. Department of Health and Human Services.

Centers for Disease Control and Prevention [CDC]. 2015b. Post-treatment Lyme disease syndrome. U.S. Department of Health and Human Services.

Centers for Disease Control and Prevention [CDC]. 2015c. Reported cases of Lyme disease by year, United States, 1995-2013. U.S. Department of Health and Human Services.

Centers for Disease Control and Prevention [CDC]. 2015d. Treatment. U.S. Department of Health and Human Services.

Centers for Disease Control and Prevention [CDC]. 2016. Tickborne diseases of the United States. U.S. Department of Health and Human Services.

Centers for Disease Control and Prevention [CDC]. 2017a. Preventing Ticks in the Yard. U.S. Department of Health and Human Services.

Centers for Disease Control and Prevention [CDC]. 2017b. Transmission. U.S. Department of Health and Human Services.

Choate, J. R., J. K. Jones, Jr., and C. Jones. 1994. Handbook of mammals of the south-central states. Louisiana State University Press, Baton Rouge.

Clark, B. K., D. W. Kaufman, G. A. Kaufman, and E. J. Finck. 1987. Use of tallgrass prairie by Peromyscus leucopus. Journal of Mammalogy 68:158-160. 
Courtney, J. W., L. M. Kostelnik, N. S. Zeidner, and R. F. Massung. 2004. Multiplex real-time PCR for detection of Anaplasma phagocytophilum and Borrelia burgdorferi. Journal of Clinical Microbiology 42:3164-3168.

Crooks, K. R. and M. E. Soule. 1999. Mesopredator release and avifaunal extinctions in a fragmented system. Nature 400:53-566.

Curtis, J. T. The vegetation of Wisconsin. Madison, WI: University of Wisconsin Press; 1959.

Daniel, M., V. Cerny, F. Dusbabek, E. Honzakova, and J. Olejnicek. 1977. Influence of microclimate on the life cycle of the common tick Ixodes rictnus (I.) in an open area in comparison with forest habitats. Folia Parasitology 24:149-160.

Daniels, T. J. and D. Fish. 1990. Spatial distribution and dispersal of unfed larval Ixodes dammini (Acari: Ixodidae) in southern New York. Environmental Entomology 19:10291033.

Davidar, P., M. Wilson, and J. M. C. Ribeiro. 1989. Differential distribution of immature Idoxes dammini (Acari: Ixodidae) on rodent hosts. Journal of Parasitology 75:898-904.

Davis, J.C., S. B. Castleberry, and J. C. Kilgo. 2010. Influence of coarse woody debris on the soricid community in southeastern Coastal Plain pine stands. Journal of Mammalogy 91:993-999.

Díaz, M., C. L. Alonso, E. Beamonte, M. Fernández, and C. Smit. 2011. Desarrollo de un protocolo de seguimiento a largo plazo de los organismos clave para el funcionamiento de los bosques mediterráneos. In: Ramírez L, Asensio B (eds) Proyectos de investigación en Parques Nacionales: 2007-2010. Organismo Autónomo Parques Nacionales, Madrid, pp 47-75. Available at http://www.marm.es/es/ministerio/organizacion/organismospublicos/ 03_INVESTIGACION_OK_tcm7-180265.pdf 
Dobony, C. A., and R. E. Rainbolt. 2008. American woodcock on Fort Drum Military Installation, New York. Northeastern Naturalist 15:241-248.

Dobony, C. A., A. C. Hicks, K. E. Langwig, R. I. von Linden, J. C. Okoniewski, and R. E. Rainbolt. 2011. Little brown myotis persist despite exposure to white-nose syndrome. Journal of Fish and Wildlife Management 2:190-195.

Dobson, A. D. M., J. L. Taylor, and S. E. Randolph. 2011. Ticks (Ixodes ricinus) abundance and seasonality at recreational sites in the UK: Hazards in relation to fine-scale habitat types revealed by complementary sampling methods. Ticks and Tick-borne Diseases 2:67-74.

Dolan, M. C., T. L. Schulze, R. A. Jordan, G. Dietrich, C. J. Schulze, A. Hojgaard, A. J. Ullmann, C. Sackal, N. S. Zeidner, and J. Piesman. 2011. Am. J. Trop. Med. Hyg. $85: 1114-1120$.

Eckertt, L. E. 2012. Preferential foraging behavior of forest deer mice (Peromyscus maniculatus gracilis) on native and non-native Picea seeds. Thesis, University of Norte Dame, Notre Dame, IN, USA.

Eisen, R. J., L. Eisen, Y. A. Girard, N. Fedorova, J. Mun, B. Slikas, S. Leonhard, U. Kitron, and R. S. Lane. 2010. A spatially explicit model of acarological risk of exposure to Borrelia burgdorfer-infected Ixodes pacificus nymphs in northwestern California based on woodland type, temperature, and water vapor. Ticks and Tick-borne Diseases 1:35-43.

Elias, S. P., J. W. Withman, and M. L. Hunter Jr. 2004. Peromyscus leucopus abundance and acorn mast: population fluctuation patterns over 20 years. Journal of Mammalogy 85:743-747.

Estes, J. A., J. Terborgh, J. S. Brashares, M. E. Power, J. Berger, W. J. Bond, S. R. Carpenter, T. E. Essington, R. D. Holt, J. B. C. Jackson, R. J. Marquis, L. Oksanen, T. Oksanen, R. T. 
Paine, E. K. Pikitch, W. J. Ripple, S. A. Sandin, M. Scheffer, T. W. Schoener, J. B. Shurin, A. R. E. Sinclair, M. E. Soule, R. Virtanen, D. A. Wardle. 2011. Trophic downgrading of planet Earth. Science 333:301-306.

Fairbairn, D. J. 1978. Behavior of dispering deer mice (Peromyscus maniculatus). Behavioral Ecology and Sociobiology 3:265-282.

Falco R. C. and D. Fish. 1988. Prevalence of Ixodes scapularis near the homes of Lyme disease patients in Westchester County, New York. American Journal of Epidemiology 126:826830.

Falco, R. C. and D. Fish. 1989. Potential for tick exposure in recreational parks in a Lyme disease endemic area. American Journal of Public Health, 79:12-15.

Falco, R. C. and D. Fish. 1992. A comparison of methods for sampling the deer tick, Ixodes dammini, in a Lyme disease endemic area. Experimental and Applied Acarology 14:165173.

Fish, D. 1993. Population ecology of Ixodes dammini. In Ecology and environmental management of Lyme disease, H. S. Ginsberg (ed.). Rutgers University Press, New Brunswick, New Jersey, p. 25-42.

Fort Drum Department of Natural Resources. 2009. Appendix 5: Flora known to occur on Fort Drum.

Frank, D. H., D. Fish, and F. H. Moy. 1998. Landscape features associated with Lyme disease risk in a suburban residential environment. Landscape Ecology 13:27-36.

Garden J. C., C. A. McAlpine, H. P. Possingham, and D. N. Jones. 2007. Using multiple survey methods to detect terrestrial reptiles and mammals: what are the most successful and cost-efficient combinations? Wildlife Research 34: 218227. 
Garman, S. L., A. F. O’Connell, Jr., and J. H. Connery. 1994. Habitat use and distribution of mice Peromyscus leucopus and Peromyscus maniculatus on Mount Desert Island, Maine. Canadian Field-Naturalist 108:67-71.

Garnett, J. M., N. P. Connally, K. C. Stafford, III, and M. L. Cartter. 2011. Evaluation of deertargeted interventions on Lyme disease incidence in Connecticut. Public Health Rep. 126:446-454.

Gier, H.T. 1968. Coyotes in Kansas (revised). Kansas State College Agricultural Experiment Station Bulletin 393. Manhattan, Kansas. Mech, D. 2000.

Ginsberg, H. S. 1994. Lyme disease and conservation. Conservation Biology 8:343-355.

Ginsberg, H. S. and C. P. Ewing. 1989. Habitat distribution of Ixodes dammini (Acari: Ixodidae) and Lyme disease spirochetes on Fire Island, New York. Journal of Medical Entomology 26:183-189.

Glass, G. E., F. P. Amerasinghe, J. M. Morgan, III, and T. W. Scott. 1994. Predicting Ixodes scapularis abundance on white-tailed deer using geographic information systems. American Journal of Tropical Medicine and Hygiene 51:538-544.

Goddard, J. 1992. Ecological studies of adult Ixodes scapularis in central Mississippi: questing activity in relation to time of year, vegetation type, and meteorologic conditions. Journal of Medical Entomology 29:501-506.

Godsey, M. S., Jr., T. E. Amundson, E. C. Burgess, W. Schell, and J. P. Davis. 1987. Lyme disease ecology in Wisconsin: distribution and host preference of Ixodes dammini, and prevelance of antibody to Borrelia burgdorferi in small mammals. American Journal of Tropical Medicine and Hygiene 37:180-187. 
Grant, P. R. 1972. Experimental studies of competitive interaction in two-species systems. III. Microtus and Peromyscus species in enclosures. Journal of Animal Ecology 40:323-335.

Graves, S., J. Maldonado, and J. O. Wolff. 1988. Use of ground and arboreal microhabitats by Peromyscus leucopus and Peromyscus maniculatus. Canadian Journal of Zoology 66:277-278.

Gray, J. S. 1998. The ecology of ticks transmitting Lyme Borreliosis. Experimental and Applied Acarology 22:249-258.

Gray, J. S. 1991. The development and seasonal activity of the tick Ixodes rictnus: a vector of Lyme borreliosis. Review of Medical and Veterinary Entomology 79:323-333.

Guerra, M., E. Waler, C. Jones, S. Paskewitz, M. R. Cortinas, A. Stancil, L. Beck, M. Bobo, and U. Kitron. 2002. Predicting the risk of Lyme disease: habitat suitability for Ixodes scapularis in the North Central United States. Emerging Infectious Disease 8:289-297.

Hamilton, W. J. 1941. The food of small forest mammals in eastern United States. Journal of Mammalogy 22:250-263.

Hamilton, B. T., B. L. Roeder, K. A. Hatch, D. L. Eggett, D. Tingey. 2015. What is small mammal diversity higher in riparian areas than in uplands? Journal of Arid Environments 119:41-50.

Hanser, S. E., M. Leu, C. L. Aldridge, S. E. Nielsen, and S. T. Knick. (2011). Chapter 9: Occurrence of small mammals: Deer mice and the challenge of trapping across large spatial extents. Sagebrush Ecosystem Conservation and Management: Ecoregional assessment tools and models for the Wyoming Basins. Allen Press, Lawrence, KS.

Hay, S. I., S. E. Randolph and D. J. Rogers. 2000. Remote sensing and geographical information systems in epidemiology. New York: Academic Press. 
Hayes, E. B., G. O. Maupin, G. A. Mount, J. Piesman. 1999. Assessing the prevention effectiveness of local Lyme disease and control. Journal of Public Health Management Practice 5:84-92.

Hayne, D.W. 1949. Calculation of size of home range. Journal of Mammology. 30: 1-18.

Hayslett, L. A. 1992. Small mammal diversity and abundances in three central Iowa grassland habitat types. Thesis, Iowa State University, Ames, IA, USA.

Hazler, K. R. and R. S. Ostfeld. 1995. Larval Density and feeding success of Ixodes scapularis on two species of Peromyscus. Journal of Parasitology 81:870-875.

Healey, M. C. 1967. Aggression and self-regulation of population size in deer mice. Ecology 48:377-392.

Hoen, A. G., L. G. Rollend, M. A. Papero, J. F. Carroll, T. J. Daniels, T. N. Mather, T. L. Schulze, K. C. Stafford, III, and D. Fish. 2009. Effects of tick control by acaricide selftreatment of white-tailed deer on host-seeking tick infection prevalence and entomologic risk for Ixodes scapularis-borne pathogens. Vector Borne Zoonotic Diseases 9:431-438.

Horobik, V. C., R. S. Ostfeld, and F. Keesing. 2001. An investigation of Lyme disease risk along old field-forest edges in southeastern New York. Cary Institute of Ecosystem Studies. Millbrook, New York.

Hornbostel, V.L., R.S. Ostfeld, E. Zhioua and M. A. Benjamin. 2004. Sublethal effects of Metarhisium anisopliae (Deuteromycetes) on engorged larval, nymphal, and adult Ixodes scapularis (Acari: Ixodidae). Journal of Medical Entomology 41:922-929.

Hornbostel, V.L., R.S. Ostfeld, and M.A. Benjamin. 2005. Effectiveness of Metarhizium anisopliae (Deuteromycetes) against Ixodes scapularis (Acari: Ixodidae) engorging on Peromyscus leucopus. J. Vector. Ecol. 30:91-101. 
Hurt, L. and K. A. Dorsey. 2014. The geographic distribution of incident Lyme disease among active component service members stationed in the Continental United States, 20042013. Medical Surveillance Monthly Report 21:13.

Insect Diagnosis Laboratory. 2012. Integrated Pest Management for the Deer Tick. Cornell University, Dept. of Entomology, Ithaca, NY.

Integrated Natural Resources Management Plan. 2011. Fort Drum New York. Prepared by Natural Resources Branch Environmental Division Directorate of Public Works.

Jaccard, P. 1908. Nouvelles recherches sur la distribu- tion florale. Bull. Soc. Vaudoise Sci. Nat. 44:223-270.

Jachowski, D. S., C. T. Rota, C. A. Dobony, W. M. Ford, and J. W. Edwards. 2016. Seeing the forest through the trees: Considering roost-site selection at multiple spatial scales. PLOS One 11: e0150011.

James, A. and J. Oliver. 1990. Feeding and host preference of Immature Ixodes dammini, I. scapularis, and I. pacificus (Acari: Ixodidae). Journal of Medical Entomology 27:324329.

Johnson, R. C., G. P. Schmid, F. W. Hyde, A. G. Steigerwalt, and D. J. Brenner. 1984. Borrelia burgdorferi sp. nov.: Etiologic agent Lyme disease. International Journal of Systemic Bacteriology 34:496-497.

Jones, C. G., R. S. Ostfeld, M. P. Richard, E. M. Schauber, and J. O. Wolff. 1998. Chain reactions linking acorns to Gypsy Moth outbreaks and Lyme disease risk. Science 279:1023-1026. 
Jones, C. J. and U. D. Kitron. 2000. Populations of Ixodes scapularis (Acari: Ixodidae) are modulated by drought at a Lyme disease focus in Illinois. Journal of Medical Entomology $37: 408-415$.

Kamler, J. F. and D. S. Pennock. 2004. Microhabitat selection of Peromyscus leucopus and P. maniculatus in mid-successional vegetation. Transactions of the Kansas Academy of Science 107:89-92.

Kamler, J. F., D. S. Pennock, C. Welsh, and R. J. Pennock. 1998. Variation in morphological characteristics of the white-footed mouse (Peromyscus leucopus) and the deer mouse ( $P$. maniculatus) under allotropic and syntopic conditions. American Midland Naturalist 140:170-179.

Kaufman, D. W. and E. D. Fleharty. 1974. Habitat selection by nine species of rodents in northcentral Kansas. Southwestern Naturalist 18:443-452.

Keesing, F., J. Brunner, S. Duerr, M. Killilea, K. LoGiudice, K. Schmidt, H. Vuong, and R. S. Ostfeld. 2009. Hosts as ecological traps for the vector of Lyme disease. Proceedings of the Royal Society 276:3911-3919.

Keesing, F., R. D. Holt and R. S. Ostfeld. 2006. Effects of species diversity on disease risk. Ecology Letters 9:485-498.

Kelly D., A. Geldenhuis, A. James, E. P. Holland, M. J. Plank, R. E. Brockie, P. E. Cowan, G. A. Harper, W. G. Lee, M. J. Maitland, A. F. Mark, J. A. Mills, P. R. Wilson, and A. E. Byrom. 2013. Of mast and mean: differential temperature cue makes mast seeding insensitive to climate change. Ecological Letters 16:90-98. 
Kilpatrick, H. J., A. M. LaBonte, K. C. Stafford, III. 2014. The relationship between deer density, tick abundance, and human cases of Lyme disease in a residential community. Journal of Medical Entomology 51:777-784.

Kilpatrick, H. J. and A. M. LaBonte. 2003. Deer hunting in a residential community: the community's perspective. Wildlife Society Bulletin 31:340-348.

Kitron, U. 1998. Landscape ecology and epidemiology of vector-borne diseases: tools for spatial analysis. Journal of Medical Entomology 35:435-445.

Kitron, U., C. J. Jones, J. K. Bouseman, J. A. Nelson, and D. L. Baumgartner. 1992. Spatial analysis of the distribution of Ixodes dammini (Acari: Ixodidae) on white-tailed deer in Ogle County, Illinois. Journal of Medical Entomology 29:259-266.

Knight, K. S., J. S. Kurylo, A. G. Endress, J. R. Stewart, and P. B. Reich. 2007. Ecology and ecosystem impacts of common buckthorn (Phamnus cathartica): a review. Biological Invasions 9:925-937.

Koenig, W. D., and J. M. H. Knops. 2013. Environmental correlates of acorn production by four species of Minnesota oaks. The Society of Population Ecology and Springer Japan.

Koenig, W. D., and J. M. H. Knops. 2005. The mystery of masting in trees. American Scientist $93: 340-347$.

Koenig, W. D., and J. M. H. Knops. 1998. Scale of mast-seeding and tree-ring growth. Nature 396:225-226.

Koenig W. D., J. M. H. Knops, W. J. Carmen, and R. D. Sage. 2009. No trade-off between seed size and number in the valley oak Quercus lobata. American Naturalist 173:682-688.

Koenig, W.D., R. L. Mumme, W. J. Carmen, M. T. Stanback. 1994. Acorn production by oaks in central coastal California: variation within and among years. Ecology 75:99-109. 
Krohne, D. T., and G. A. Hoch. 1999. Demography of Peromyscus leucopus populations on habitat patches: the role of dispersal. Canadian Journal of Zoology 77:1247-1253.

Kunz, T. H., C. Wemmer, and V. Hayssen. (1996). Appendix 5: Sex, age, and reproductive condition of mammals. In Measuring and Monitoring Biological Diversity: Standard Methods for Mammals. Washington, D. C.: Smithsonian Press.

Lane, R. S., J. Piesman, and W. Burgdorfer. 1991. Lyme borreliosis: relation of its causative agent to its vectors and hosts in North America and Europe. Annual Review in Entomology 36:587-609.

Llewellyn, L. M. and F. M. Uhler. 1952. The foods of fur animals of the Patuxent Research Refuge, Maryland. American Midland Naturalist 48:193-203.

LoGiudice K., R. S. Ostfeld, K. A. Schmidt, and F. Keesing. 2003. The ecology of infectious disease: effects of host and diversity and community composition on Lyme disease risk. Proceedings of the National Academy of Science 100:567-571.

LoGiudice, K., S. T. K. Duerr, M. J. Newhouse, K. A. Schmidt, M. E. Killilea, and R. S. Ostfeld. 2008. Impact of host community composition on Lyme disease risk. Ecology 89:28412849.

Lambert T. D., J. R. Malcolm, and B. L. Zimmerman. 2005. Variation in small mammal species richness by trap height and trap type in southeastern Amazonia. Journal of Mammalogy 86: 982-990.

LandOwner Resource Centre. Conifer Fact Sheet: Extension Notes. http://www.Irconline.com/Extension_Notes_English/pdf/Conifer\%20Fact\%20Sheet.pdf. 
Lane, R. S., J. Piesman, and W. Burgdorfer. 1991. Lyme borreliosis: relation of its causative agent to its vectors and hosts in North America and Europe. Annual Review of Entomology, 36:587-609.

Leopold, A. 1933. Game Management. Charles Scribner's Sons, New York.

Levi, T., F. Keesing, R. D. Holt, M. Barfield, R. S. Ostfeld. 2016. Quantifying dilution and amplification in a community of hosts for tick-borne pathogens. Ecological Applications 26:484-498.

Levin, M.L. and D. Fish. 1998. Density-dependent factors regulating feeding success of Ixodes scapularis Larvae (Acari: Ixodidae). Journal of Parasitology 84:36-43.

Levine, J. F., M. L. Wilson, and A. Spielman. 1985. Mice as reservoirs of the Lyme disease spirochete. American Journal of Tropical Medicine and Hygiene 34:355-360.

Lindgren, E., L. Talleklint, and T. Polfeldt. 2000. Impact of climatic change on the northern latitude limit and population density of the disease-transmitting European tick Ixodes ricinus. Environmental Health Perspective 108:119-123.

Lindsay, L. R., I. K. Barker, G. A. Surgeoner, S. A. McEwen, T. J. Gillespie, and J. T. Robinson. 1995. Survival and development of Ixodes scapularis (Acari: Ixodidae) under various climatic conditions in Ontario, Canada. Journal of Medical Entomology 32:143-152.

Lindsay, L. R., S. W. Mathison, I. K. Barker, S. A. McEwen, T. J. Gillespie, and G. A. Surgeoner. 1999. Microclimate and habitat in relation to Ixodes scapularis (Acari: Ixodidae) population on Long Point, Ontario, Canada. Journal of Medical Entomology $36: 255-262$.

Loeb, S.C. 1996. The role of coarse woody debris in the ecology of southeastern mammals. Pages 108-118 in McMinn J.W., Crossley D.A. Jr, editors. Biodiversity and coarse 
woody debris in southern forests. USDA Forest Service General Technical Report SE-94 (see Supplemental Material, Reference S2, http://dx.doi.org/10.3996/022015-JFWM012.S6; also available at: http://www.srs.fs.usda.gov/pubs/gtr/gtr_se094.pdf (September 2015).

LoGiudice, K., S. T. K. Duerr, M. J. Newhouse, K. A. Schmidt, M. E. Killilea, and R. S. Ostfeld. 2008. Impact of host community composition on Lyme disease risk. Ecology 89: 28412849.

Lubelcyzk, C. B., S. P. Elias, P. W. Rand, M. S. Holman, E. H. Lacombe, and R. P. Smith, Jr. 2004. Habitat associations of Ixodes scapularis (Acari: Ixodidae) in Maine. Envirnomental Entomology 33:900-906.

Lymedisease.org. 2017. About ticks and Lyme disease. https://www.lymedisease.org/lymebasics/ticks/about-ticks/.

MacMillen, R. E. 1964. Population ecology, water relations, and social behavior of a southern California semi-desert rodent fauna. Univ. Calif. Publ. Zool. 71.66 p.

Magnarelli, L. A., J. F. Anderson, K .E. Hyland, D. Fish, and J. B. McAninch. 1988. Serologic analyses of Peromyscus leucopus, a rodent reservoir for Borrelia burgdorferi, in northeastern United States. Journal of Clinical Microbiology 26:1138-1140.

Magurran, A. E. Ecological diversity and its measurements. (1988). Chapter 2: Diversity indices and species abundance models. Princeton, N.J.: Princeton University Press.

Main, A. J., A. B. Carey, M. G. Carey, and R. H. Goodwin. 1982. Immature Ixodes dammini (Acari: Ixodidae) on small animals in Connecticut, USA. Journal of Wildlife Entomology $19: 655-664$. 
Manley, P. N., B. V. Horne, J. K. Roth, W. J. Zielinski, M. M. McKenzie, T. J. Weller, F. W. Weckerly, C. Vojta. (2006). Chapter 5: Small Mammal Monitoring. In Multiple Species Inventory and Monitoring Technical Guide. Washington, D.C.: U.S. Department of Agriculture, Forest Service.

Manley, P.N., M.D. Schlesinger, M.M. Manning, M.M. McKenzie, and J.K. Roth. 2002. 2001 field pilot report, Multiple Species Monitoring, Sierra Nevada Framework Project. Unpublished final report. USDA Forest Service, Pacific Southwest Region, Vallejo, CA.

Mannelli, A. U. Kitron, C. J. Jones, and T. L. Slajchert. 1993. Role of the eastern chipmunk as a host for immature Ixodes dammini (Acari: Ixodidae) in northwestern Illinois. Journal of Medical Entomology 30:87-93.

Mannelli, A. U. Kitron, C. J. Jones, and T. L. Slajchert. 1994. Influence of season and habitat on Ixodes scapularis infestation on white-footed mice in northwestern Illinois. Journal of Parasitology 80:1038-1042.

Mather, T. N. 1993. The dynamics of spirochete transmission between ticks and vertebrates. Pages 43-60 in H.S. Ginsberg, editor. Ecology and environmental management of Lyme disease. Rutgers University Press. New Brunswick, New Jersey.

Mather, T. N., and H. S. Ginsberg. 1994. Vector-host-pathogen relationships: transmission dynamics of tick-borne infections. Pages 68-90 in D. E. Sonenshine and T. N. Mather, editors. Ecological dynamics of tick-borne zoonoses. Oxford University Press, New York.

Mather, T. N., M. L. Wilson, S. I. Moore, J. M. C. Ribeiro and A. Spielman. 1989. Comparing the relative potential of rodents as reservoirs of the Lyme disease spirochete (Borrelia burgdorferi). American Journal of Epidemiology 130:143-150. 
Maupin, G. O., D. Fish, J. Zultowsky, E. G. Campos, and J. Piesman. 1991. Landscape ecology of Lyme disease in a residential area of Westchester County, New York. American Journal of Epidemiology 133:1105-1113.

McCracken, K. E., J. W. Withman, and M. L. Hunter Jr. 1999. Relationships between seed fall of three tree species and Peromyscus leucopus and Clethrionomys gapperi during 10 years in an oak-pine forest. Journal of Mammalogy 80:1288-1296.

M'Closkey, R .T. and D. T. Lajoie. 1975. Determinants of local distributions and abundance in white-footed mice. Ecology 56:467-472.

McShea, W. J. 2000. The influence of acorn crops on annual variation in rodent and bird populations. Ecology 81:228-238.

Metzgar, L. H. 1971. Behavioral population regulation in the woodmouse, Peromyscus leucopus. American Midland Naturalist 86:434-448.

Metzgar, L. H. 1979. Dispersion patterns in a Peromyscus population. Journal of Mammalogy 60:129-145.

Michigan emerging disease issues. 2017. Transmission and development. Michigan govt. http://www.michigan.gov/emergingdiseases/0,4579,7-186-25890-75867--,00.html.

Michigan State University. 2017. Fall needle drop: A natural phenomenon in conifers. MSU Extension. http://msue.anr.msu.edu/news/fall_needle_drop_a_natural_phenomenon_in_conifers. Mills, J.N., T.L. Yates, J.E. Childs, R.R. Parmenter, T.G. Ksiazek, P.E. Rollin, and C.J. Peters. 1995. Guidelines for working with rodents potentially infected with Hantavirus. Journal of Mammalogy 76:716-722. 
Minnesota Department of Natural Resources. 2009. Managing your woodland for white-tailed deer. State of Minnesota Department of Natural Resources.

Mount, G. A., D. G. Haile, and E. Daniels. 1997. Simulation of blacklegged tick (Acari:Ixodidae) population dynamics and transmission of Borrelia burgdorferi. Journal of Medical Entomology 34:461-484.

Mount, G. A., D. G. Haile, and E. Daniels. 1997. Simulation of management strategies for the blacklegged tick (Acari: Ixodidae) and the Lyme disease spirochete, Borrelia burgdorferi. Journal of Medical Entomology 34:672-683.

Myton, B. 1974. Utilization of space by Peromyscus leucopus and other small mammals. Ecology 55:277-290.

Needham, G. R., and P. D. Teel. 1991. Off-host physiological ecology of ixodid ticks. Annual Review of Entomology 36:659-681.

Nelson, L.J., and F.W. Clark. 1973. Correction for sprung traps in catch/effort calculations of trapping results. Journal of Mammalogy 54:295-298.

Nitrate Elimination Co. 2012. Suggested protocols for drying samples to constant weight. The Nitrate Elimination Co., Inc.

Nowalk, M. 2007. Relative seed predation by Peromysucus maniculatus on invasive and native species pairs of four plant genera found in Palouse Grass Prairies of Western Montana. Thesis, University of Norte Dame, Notre Dame, IN, USA.

NRCS. 2013. Pollinator biology and habitat. USDA. https://www.nrcs.usda.gov/Internet/FSE_PLANTMATERIALS/publications/mipmctn11 774.pdf. 
Nupp, T. E. and R. K. Swihart. 2000. Landscape-level correlates of small-mammal assemblages in forest fragments of farmland. Journal of Mammalogy 81:512-526.

Nupp, T. E., and R. K. Swihart. 1996. Effect of forest patch area on population attributes of white-footed mice (Peromyscus leucopus) in fragmented landscapes. Canadian Journal of Zoology 74:467-472.

O’Farrell, M., W. A. Clark, F. H. Emmerson, S. M. Juarez, F. R. Kay, T. M. O'Farrell, and T .Y. Goodlet. 1994. Use of mesh live trap for small mammals: are results from Sherman live traps deceptive? Journal of Mammalogy 75:692-699.

O'Farrell, T. P. 1975. Seasonal and altitudinal variations in populations of small mammals on Rattlesnake Mountain, Washington. American Midland Naturalist 94:190-204

Oliver, J. 1989. Biology and Systematics of Ticks (Acari: Ixodidae). Annual Review of Ecological Systems 20: 397-430.

Oliver, J. R. G. Means, S. Kogurt, M. Prusinski, J. J. Howard, L. J. Layne, F. K. Chu, A. Reddy, L. Lee, and D. J. White. 2006. Prevalence of Borrelia burgdorferi in small mammals in New York State. Journal of Medical Entomology 43:924-935.

Olson Jr, D.F., and S.G. Boyce. 1971. Factors affecting acorn production and germination and early growth of seedlings and seedling sprouts. P. 44-48 in Proc. of the Oak symposium. USDA For. Serv. Northeastern For. Exp. St., Upper Darby, PA.

Ostfeld, R. S. and F. Keesing. 2012. Effects of host diversity on infectious disease. Annual Review of Ecology, Evolution, and Systematics 43:157-182.

Ostfeld, R. S. and F. Keesing. 2000a. Biodiversity and disease risk: the case of Lyme disease. Conservation Biology 14:722-728. 
Ostfeld, R. S. and F. Keesing. 2000b. The function of biodiversity in the ecology of vectorborne zoonotic diseases. Canadian Journal of Zoology 78: 2061-2078.

Ostfeld, R. S. and R. D. Holt. 2004. Are predators good for your health? Evaluating evidence for top-down regulation of zoonotic disease reservoirs. Frontiers in Ecology and the Environment 2:13-20.

Ostfeld R. S., E. M. Schauber, C. D. Canham, F. Keesing, C. G. Jones and J. O. Wolff. 2001. Effects of acorn productions and mouse abundance on abundance and Borrelia burgdorferi infection prevalence of nymphal Ixodes scapularis ticks. Vector borne and zoonotic diseases 1:55-63.

Ostfeld, R .S., C. G. Jones, and J. O. Wolff. 1996a. Of mice and mast. Bioscience 46:323-330.

Ostfeld, R. S., K. R. Hazler, and O. M. Cepeda. 1996b. Temporal and spatial dynamics of Ixodes scapularis (Acari:Ixodidae) in a rural landscape. Journal of Medical Entomology 33:9095 .

Ostfeld, R. S., M. C. Miller, and K. R. Hazler. 1996c. Causes and consequences of tick (Ixodes scapularis) burdens of white-footed mice (Peromyscus leucopus). Journal of Mammalogy 77:266-273.

Ostfeld, R. S., O. M. Cepeda, K. R. Hazler, and M. C. Miller. 1995. Ecology of Lyme disease: Habitat associations of ticks (Ixodes scapularis) in a rural landscape. Ecological Applications 5:353-361.

Pavlovsky, E. N. 1966. Natural nidality of transmissible diseases, with special reference to the landscape epidemiology of zooanthroponse. Urbana, IL:University of Illinois Press. 
Payne, T. and W. Caire. 1999. Species diversity of small mammals in the Tallgrass Prairie Preserve, Osage county, Oklahoma. Thesis, University of Central Oklahoma, Edmond, OK, USA.

Pearson, D. E., R. M. Callaway, and J. L. Maron. 2011. Biotic resistance via granivory: establishment by invasive, naturalized and native asters reflects generalist preference. Ecology 92: 1748-1757.

Peavey, C. A. and R. S. Lane. 1995. Transmission of Borrelia burgdorferi by Ixodes pacificus nymphs and reservoir competence of deer mice (Peromyscus maniculatus) infected by tick-bite. Journal of Parasitology 81:175-178.

Perez-Ramos, I. M., C. M. Padilla-Diaz, W. D. Koenig, T. Maranon. 2015. Environmental drivers of mast-seeding in Mediterranean oak species: does leaf habit matter? Journal of Ecology 103:691-700.

Perkins, S. E., I. M. Cattadori, V. Tagliapietra, A. P. Rizzoli, and P. J. Hudson. 2003. Empirical evidence for key hosts in persistence of a tick-borne disease. International Journal for Parasitology 33:909.

Perret, J. L., E. Guigoz, O. Rais, and I. Gern. 2000. Influence of saturation deficit and temperature on Ixodes rictnus tick questing activity in a Lyme borrelosis-endemic area (Switzerland). Parasitology Research 86:554-557.

Piacentino, J. D. and B. S. Schwartz. 2002. Occupational risk of Lyme disease: an epidemiological review. Occupational Environmental Medicine 59: 75-84.

Piesman, J., A. Spielman, P. Etkind, T. K. Ruebush, 2 ${ }^{\text {nd }}$, and D. D. Juranek. 1979. Role of deer in the epizootiology of Babesia microti in Massachusetts, USA. Journal of Medical Entomology 15:537-540. 
Piesman, J., T. N. Mather, G. J. Dammin, S. R. Telford III, C. C. Lastavica, and A. Spielman. 1987. Seasonal variation of transmission risk of Lyme disease and human babesiosis. American Journal of Epidemiology 126:1187-1189.

Pound, J. M., J. A. Miller, J. E. George, and C. A. Lemeilleur. 2000. The “4-poster” passive topical treatment device to apply acaricide for controlling ticks (Acari: Ixodidae) feeding on white-tailed deer. Journal of Medical Entomology 37:588-594.

Pound, J. M., J. A. Miller, J. E. George, and C. A. Lemeilleur. 2000. Efficacy of amitraz applied to white-tailed deer by the "4-poster" topical treatment device in controlling free-living lone star ticks (Acari: Ixodidae). Journal of Medical Entomology 37:878-884.

Pound, J. M., J. A. Miller, J. E. George, D. Fish, J. F. Carroll, T. L. Schulze, T. J. Daniels, R. C. Falco, K. C. Stafford, III, and T. N. Mather. 2009. The United States Department of Agriculture's Northeast Area-wide tick control project: summary and conclusions. Vector Borne Zoonotic Diseases 9:439-448.

Prugh, L. R., C. J. Stoner, C. W. Epps, W. T. Bean, W. J. Ripple, A. S. Laliberte, J. S. Brashares. 2009. The rise of the mesopredator. BioScience 59:779-791.

Prusinski, M. A., H. Chen, J. M. Drobnack, S. J. Kogut, R. G. Means, J. J. Howard, J. Oliver, G. Lukacik, P. B. Backenson, and D. J. White. 2006. Habitat structure associated with Borrelia burgdorferi prevalence in small mammals in New York state. Environmental Entomology 35:308-319.

Pucek, Z., W. Jedrzejewski, B. Jedrzejewski, and M. Pucek. 1993. Rodent population dynamics in a primeval deciduous forest (Bialowieza National Park) in relation to weather, seed crop, and predation. Acta Theriologica 38:199-232. 
Pulido F.J., M. Díaz. 2005. Regeneration of a Mediterranean oak: a whole-cycle approach. Écoscience 12:92-102.

Pulido F.J., E. García, J. J. Obrador, and G. Moreno. 2010. Multiple pathways for tree regeneration in anthropogenic savannas: incorporating biotic and abiotic drivers into management schemes. Journal of Applied Ecology 47:1272-1281.

Pusterla, N., J. B. Huder, C. M. Leutenegger, U. Braun, J. E. Madigan, and H. Lutz. 1999. Quantitative real-time PCR for detection of members of the Ehrlichia phagocytophila genogroup in host animals and Ixodes ricinus ticks. Journal of Clinical Microbiology 37:1329-1331.

Randolph, S. E. 1993. Climate, satellite imagery and the seasonal abundance of the tick Rhipicepgalus appendiculatus in southern Africa: a new perspective. Medical Veterinary Entomology 7:243-258.

Randolph, S E. and N. Craine. 1995. General framework for comparative quantitative studies on transmission of tick-borne disease using Lyme Borreliosis in Europe as an example. Journal of Medical Entomology 32:765-777.

Randolph, S. E. and K. Storey. 1999. Impact of microclimate on immature tick-rodent interactions (Acari: Ixodidae): implications for parasite transmission. Journal of Medical Entomology 36:741-748.

Richburg, J. A., A. C. Dibble and W. A. Patterson, III. 2001. Woody invasive species and their role in altering fire regimes of the northeast and Mid-Atlantic states. Proceedings of the invasive species workshop: the role of fire in the control and spread of invasive species. Fire conference 2000: the first national congress on fire ecology, prevention, and management. Tall Timbers Research Station, Tallahassee, FL. 27 Nov.-1 Dec. 2000. 
Robeiro, J. M. C., G. T. Makoul, J. Levine, D. R. Robinson, and A. Spielman. 1985. Antihemostatic, anti-inflammatory, and immunosuppressive properties of the saliva of a tick, Ixodes dammini. Journal of Experimental Medicine 161:332-344.

Rosenblatt, D. L., E. J. Heske, S. L. Nelson, D. M. Barber, M. A. Miller, and B. MacAllister. 1999. Forest fragments in east-central Illinois: Islands or habitat patches for mammals? American Midland Naturalist 141:115-123.

Rossi, C., E. Y. Stromdahl, P. Rohrbeck, C. Olsen, and R. F. DeFraites. 2015. Characterizing the relationship between tick bites and Lyme disease in active component U.S. Armed Forces in the Eastern United States. Medical Surveillance Monthly Report 22:2-10.

Rulison, E. L., I Kuczaj, G. Pang, G. J. Hickling, J. I. Tsao, and H. S. Ginsberg. 2013. Flagging versus dragging as sampling methods for nymphal Ixodes scapularis (Acari: Ixodidae). Journal of Vector Ecology 38:163-167.

Sadleir, R. M. F. S. 1965. The relationships between agonistic behavior and population changes in the deer mouse, Peromyscus maniculatus. Journal of Animal Ecology 34: 331-352.

Samia, N. I., K. L. Kausrud, H. Heesterbeek, V. Ageyev, M. Begon, K. S. Chan, and N. C. Stenseth. 2011. Dynamics of the plague-wildlife-human system in central Asia are controlled by two epidemiological thresholds. Proceedings of the National Academy of Sciences 108:14527-14532.

Schmidt, K. A. and R. S. Ostfeld. 2001. Biodiversity and the dilution effect in disease ecology. Ecology 82:609-619.

Schulze, T. E., M. F. Lakat, G. S. Bowen, W. E. Parkin, and J. K. Shisler. 1984. Ixodes dammini (Acari: Ixodidae) and other Ixodes ticks collected from white-tailed deer in New Jersey, 
USA. 1. Geographical distribution and its relation to selected environmental and physical factors. Journal of Medical Entomology 21:741-749.

Schulze, T. L. and R. A. Jordan. 2006. Assessment and management of vector tick populations in New Jersey. Freehold Township Health Department.

Schulze, T. L., R. A. Jordan, C. J. Schulze, S. P Healy, M. B. Jahn, and J. Piesman. 2007. Integrated use of 4-poster passive topical treatment devices for deer-targeted acaricide applications, and Maxforce TMS bait boxes to rapidly suppress populations of Ixodes scapularis (Acari: Ixodidae) in a residential landscape. Journal of Medical Entomology 44:830-839.

Schulze, T. L., R. A. Jordan, M. Williams, and M. C. Dolan. 2017. Evaluation of the SELECT Tick Control System (TCS), a host-targeted bait box, to reduce exposure to Ixodes scapularis (Acari: Ixodidae) in a Lyme disease endemic area of New Jersey. Journal of Medical Entomology 54:1019-1024.

Schultze, T. I. and R. A. Jordan. 2001. Effects of habitat structure on the retention of Ixodes scapularis and Amblyomma americanum (Acari: Ixodidae) adults during drag sampling surveys. Journal of Medial Entomology 38:606-608.

Schultze, T. I. and R. A. Jordan. 2005. Influence of meso- and microscale habitat structure on focal distributions of sympatric Ixodes scapularis and Amblgomma americanum (Acari: Ixodidae). Journal of Medical Entomology 42:285-294.

Schultze, T. I., R. A. Jordan, and R. W. Hung. 1997. Biases associated with several sampling methods used to estimate abundance of Ixodes scapularis and Amblgomma americanum (Acari: Ixodidae). Journal of Medical Entomology 34:615-623. 
Seamon, J. O. and G. H. Adler. 1996. Population performance of generalist and specialist rodents along habitat gradients. Canadian Journal of Zoology 74:1130-1139.

Shannon, C.E. and W. Weaver. 1949. The Mathematical Theory of Communication. University of Illinois Press, Urbana.

Sharp, W. M., and H. H. Chisman. 1961. Flowering and fruiting in white oaks. I. Staminate flowering through pollen dispersal. Ecology 42: 365-372.

Shaw, M. 2001. Infestation of Peromyscus leucopus and Tamias striatus by Ixodes scapularis (Acari: Ixodidae) as a result of tick host preference, host grooming efficiency, and habitat utilization. Bard College, Annandale-on-Hudson, NY, USA.

Simpson, E. H. 1949. Measurement of species diversity. Nature 163: 688.

Smith C.C., and S. D. Fretwell. 1974. The optimal balance between size and number of offspring. American Naturalist 108:499-506.

Soil Survey of Jefferson, County. 1989. USDA Soil Conservation Service.

Solberg, V. B., J. A. Miller, T. Hadfield, R. Burge, J. M. Scheck and J. M. Pound. 2003. Control of Ixodes scapularis (Acari: Ixodidae) with topical self-application of permethrin by white-tailed deer inhabiting NASA, Beltsville, Maryland. Journal of Vector Ecology 28:117-134.

Sonenshine, D. E. 1993. Biology of ticks, Vol. 2. Oxford University Press, New York, New York, $465 \mathrm{p}$.

Sork, V. L., J. Bramble and O. Sexton. 1993. Ecology of mast-fruiting in three species of North American deciduous oaks. Ecology 74:528-541.

Spielman, A., M. L. Wilson, J. E. Levine, and J. Piesman. 1985. Ecology of Ixodes damminiborne human babesiosis and Lyme disease. Annual Review for Entomology 30:439-460. 
Stafford, K. C., III. 1994. Survival of immature Ixodes scapularis (Acari: Ixodidae) at different relative humidities. Journal of Medical Entomology 31:310-314.

Stafford, K. C., III. 1992. Oviposition and larval dispersal of Ixodes dammini (Acari: Ixodidae). Journal of Medical Entomology 29:129-132.

Stafford, K. C. and L. A. Magnarelli. 1993. Spatial and temporal patterns of Ixodes scapularis (Acari: Ixodidae) in south central Connecticut. Journal of Medical Entomology 30:762771.

Stafford, K. C., III and S. C. Williams. 2014. Deer, ticks and Lyme disease: Deer management as a strategy for the reduction of Lyme disease. Connecticut Agricultural Experiment Station.

Stancampiano, A. J. and G. D. Schnell. 2004. Microhabitat affinities of small mammals in southwestern Oklahoma. Journal of Mammalogy 85:948-958.

Steere, A. C., T. F. Broderick, S. E. Malawista. 1978. Erythema chronicum migrans and Lyme arthritis: epidemiologic evidence for a tick vector. American Journal of Epidemiology 108:312-321.

Straubinger, R. K. 2000. PCR-based quantification of Borrelia burgdorferi organisms in canine tissues over a 500-day postinfection period. Journal of Clinical Microbiology 38:21912199.

Tessier, N., S. Noel, and F. J. Lapointe. 2004. A new method to discriminate the deer mouse (Peromyscus maniculatus) from the white-footed mouse (Peromyscus leucopus) using species-specific primers in multiplex PCR. Canadian Journal of Zoology 82:1832-1835.

Tick Tubes. 2017. How Tick Tubes Work. Damminix. http://www.ticktubes.com/works.html 
Ticks in Maine. 2017. Target mice. Maine Medical Center Research Institute Vector-borne disease laboratory. http://www.ticksinmaine.com/tick-control/target-mice.

Tilly, K. P. A. Rosa, and P. E. Stewart. 2008. Biology of infection with Borrelia burgdorferi.

Torre I., A. Arrizabalaga, and C. Flaquer. 2004. Three methods for assessing richness and composition of small mammal communities. Journal of Mammalogy 85:524-530.

Torre, I., D. Guixe, and F. Sort. 2010. Comparing three live trapping methods for small mammal sampling in cultivated areas of NE Spain. Hystrix International Journal of Mammalogy 21:147-155.

Tsao, J. I., J. T. Wootton, J. Bunikis, M. G. Luna, D. Fish, and A. G. Barbour. 2004. An ecological approach to preventing human infection: vaccinating wild mouse reservoirs intervenes in the Lyme disease cycle. Proceedings of the National Academy of Sciences 101: 18159-18164.

Umetsu F., L. Naxara and R. Pardini. 2006. Evaluating the efficiency of pitfall traps for sampling small mammals in the neotropics. Journal of Mammalogy 87: 757- 765.

University of Nebraska. 2017. Natural Needle Drop. Institute of Agriculture and Natural Resources: Backyard Farmer. http://byf.unl.edu/natural-needle-drop.

U.S. Climate Data. 2016. Climate Watertown - New York. http://www.usclimatedata.com/climate/watertown/new-york/unitedstates/usny1525/2016/1.

U.S. Climate Data. 2015. Climate Watertown - New York. http://www.usclimatedata.com/climate/watertown/new-york/unitedstates/usny1525/2015/1. 
USDA Forest Service. 2002. Forest inventory and analysis phase 3 field guide--crowns: Measurements and sampling. Internal rep. on file with USDA For. Serv., FIA Washington, DC.

Van Buskirk, J. and R. S. Ostfeld. 1998. Habitat heterogeneity, dispersal, and local risk of exposure to Lyme disease. Ecological Applications 8:365-378.

Van Buskirk, J. and R. S. Ostfeld. 1995. Controlling Lyme disease by modifying the density and species composition of tick hosts. Ecological Applications 5:1133-1140.

Venable, D.L. 1992. Size-number trade-offs and the variation of seed size with plant resource status. American Naturalist 140:287-304.

Walters, B. 1989. Differential capture of deer mice with pitfalls and live traps. Acta Theriologica 34:643-647.

Web Soil Survey. 2015. NRCS, USDA.

Weeks, H. P., Jr. 1999. Central Hardwood Notes: Mast Importance, Production and Management. USDA North Central Forest Experiment Station. Purdue University Press, West Lafayette, Indiana, 3pp.

Whitaker, J. O. 1966. Food for Mus musculus, Peromyscus maniculatus bairdii and Peromyscus leucopus from Ithaca, N.Y. Journal of Mammalogy 44:418-419.

Wilbur, H.M. 1977. Propagule size, number, and dispersion pattern in Ambystoma and Asclepias. American Naturalist 111:43-68.

Wilder, S. M., and D. B. Meikle. 2006. Variation in effects of fragmentation on the white-footed mouse (Peromyscus leucopus) during the breeding season. Journal of Mammalogy $87: 117-123$. 
Wilson, M. L., G. H. Adler, and A. Spielman. 1985. Correlation between deer abundance and that of the deer tick Ixodes dammini (Acari: Ixodidae). Annals of the Entomological Society of America 78:172-176.

Wolff, J. O. 1996. Population fluctuations of mast-eating rodents are correlated with production of acorns. Journal of Mammalogy 77:850-856.

Wolff, J. O. 1985. The effects of density, food, and interspecific interference on home range size in Peromyscus leucopus and P. maniculatus. Canadian Jounral of Zoology 63:2657-2662.

Wolff, J. O., M. H. Freeberg, and R. D. Dueser. 1983. Interspecific territoriality in two sympatric species of Peromyscus (Rodentia: Cricetidae). Behavioral Ecology and Sociobiology $12: 237-242$.

Wolff, J. O., R. D. Dueser, and K. S. Berry. 1985. Food habits of sympatric Peromsycus leucopus and Peromsycus maniculatus. Journal of Mammalogy 66:795-798.

Yamasaki, M., W. B. DeGraaf, J. W. Lanier. 2000. Wildlife habitat associations in Eastern hemlock - birds, smaller mammals and forest carnivores. Proceedings: symposium on sustainable management of hemlock ecosystems in eastern North American (eds. K. A. McManus, K. S. Shields, and D. R. Souto), pp. 135-143. USDA General Technical Report 267. Newtown Square, PA.

Yandell, B. S. 1997. Practical Data Analysis for Designed Experiments. Taylor \& Francis Group, LLC.

Yunger, J.A., and L.A. Randa. 1999. Trap decontamination using hypochlorite: effects on trapability of small mammals. Journal of Mammalogy 80(4): 1336-1340. 
Zhioua E., H. S. Ginsberg, R. A. Humber, and R. A. Lebrun. 1999. Preliminary survey of entomopathogenic fungi associated with Ixodes scapularis (Acari: Ixodidae) in southern New York and New England, USA. Journal of Medical Entomology 36:635-637. 
Table 2.1. Explanatory variables used in candidate Poisson models to evaluate variation in estimated index of abundance of black-legged ticks on Fort Drum Military Installation, New York, during April-November, 2015-2016.

\begin{tabular}{|c|c|c|}
\hline Variable Type & Variable & Description \\
\hline \multirow[t]{2}{*}{ Temporal } & $\mathrm{m}$ & Month of study \\
\hline & $\mathrm{y}$ & Year of study (2015 or 2016) \\
\hline \multirow[t]{2}{*}{ Spatial } & ct & Cover type \\
\hline & patch & Patch size (square meters) \\
\hline \multirow[t]{4}{*}{ Environmental } & $\mathrm{h}$ & Humidity (\%) \\
\hline & $\mathrm{p}$ & Pressure $(\mathrm{mmHg})$ \\
\hline & $\mathrm{t}$ & Temperature (C) \\
\hline & $\mathrm{w}$ & Wind speed (mph) \\
\hline \multirow[t]{9}{*}{ Vegetative } & cwd & Coarse woody debris decay (scale $1-5$ ) \\
\hline & 1 & Leaf litter depth $(\mathrm{cm})$ \\
\hline & spp & Tree species richness \\
\hline & $\mathrm{dbh}$ & Tree dbh $(\mathrm{cm})$ \\
\hline & $\mathrm{c}$ & Canopy cover (\%) \\
\hline & $\mathrm{sd}$ & Snag decay (scale 1-9) \\
\hline & sdbh & Snag dbh (cm) \\
\hline & cwdc & Corase woody debris density \\
\hline & $\operatorname{mid}$ & Midstory cover (scale 1-6) \\
\hline
\end{tabular}


sh

$\operatorname{sspp}$

stem

cwddbh

cwdl

tree

Other

Snag height (m)

Stem species richness

Stem count

Coarse woody debris dbh (cm)

Coarse woody debris length (m)

Tree density

Small mammal index of abundance

shan

Shannon's index of diversity

$\operatorname{simp}$

Simpson's index of diversity 
Table 2.2. Relative support for 5 candidate Poisson models of estimated index of abundance of total questing ticks (A) on Fort Drum Military Installation, New York, during April-November, 2015-2016. $K$ indicates the number of model parameters, AICc is Akaike's information criterion corrected for small sample size, $\triangle \mathrm{AICc}$ is the difference in $\mathrm{AICc}$ units from the best approximating model, and $w$ is the model weight. See Table 2.1 for description of model variables.

\begin{tabular}{lllll}
\hline Model & $\mathrm{K}$ & AICc & $\Delta \mathrm{AICc}$ & $w$ \\
\hline $\mathrm{A}(\sim \mathrm{h}+\mathrm{t}+\mathrm{cwd}+\mathrm{l}+\mathrm{spp}+\mathrm{dbh}+$ patch $)$ & 8 & 2649.12 & 0.00 & 0.66 \\
$\mathrm{~A}(\sim \mathrm{t}+\mathrm{cwd}+\mathrm{l}+\mathrm{spp}+\mathrm{dbh}+\mathrm{patch})$ & 7 & 2650.69 & 1.55 & 0.31 \\
$\mathrm{~A}(\sim \mathrm{h}+\mathrm{t}+\mathrm{cwd}+\mathrm{spp}+\mathrm{dbh}+$ patch $)$ & 7 & 2656.41 & 7.24 & 0.02 \\
$\mathrm{~A}(\sim \mathrm{t}+\mathrm{cwd}+\mathrm{spp}+\mathrm{dbh}+$ patch $)$ & 6 & 2657.55 & 8.33 & 0.01 \\
$\mathrm{~A}(\sim \mathrm{h}+\mathrm{t}+\mathrm{cwd}+\mathrm{l}+\mathrm{spp}+$ patch $)$ & 7 & 2661.39 & 12.29 & 0.01 \\
\hline
\end{tabular}


Table 2.3. Model parameter estimates for Poisson models of estimated index of abundance of total questing ticks (A) on Fort Drum Military Installation, New York, during AprilNovember, 2015-2016 within $\triangle \mathrm{AICc}$ of 2 used in model averaging to determine the final model. Parameter estimates ( $\beta$ ) are presented with standard errors (SE) as well as $\mathrm{Z}$ and p ( $\operatorname{Pr}$ ) values.

\begin{tabular}{|c|c|c|c|c|c|}
\hline Model & Parameter & $\boldsymbol{\beta}$ & SE & $Z$ value & $\operatorname{Pr}(>|z|)$ \\
\hline \multicolumn{6}{|c|}{$\overline{\mathrm{A}(\sim \mathrm{h}+\mathrm{t}+\mathrm{cwd}+\mathrm{l}+\mathrm{spp}}$} \\
\hline \multirow{8}{*}{$+\mathrm{dbh}+$ patch) } & Intercept & -3.86 & 0.28 & -13.61 & $<0.001$ \\
\hline & $\mathrm{t}$ & 0.03 & 0.01 & 10.47 & $<0.001$ \\
\hline & $\mathrm{h}$ & 0.25 & 0.13 & 1.91 & 0.01 \\
\hline & spp & 0.24 & 0.03 & 7.19 & $<0.001$ \\
\hline & cwd & -0.41 & 0.08 & -4.86 & $<0.001$ \\
\hline & 1 & 0.10 & 0.03 & 3.02 & $<0.001$ \\
\hline & $\mathrm{dbh}$ & 0.01 & 0.01 & 3.79 & $<0.001$ \\
\hline & patch & -0.01 & 0.01 & -6.59 & $<0.001$ \\
\hline
\end{tabular}


Table 2.4. Model parameter estimates for Poisson models of estimated index of abundance of adult questing ticks (Aa) on Fort Drum Military Installation, New York, during AprilNovember, 2015-2016 Parameter estimates ( $\beta$ ) are presented with standard errors (SE) as well as $\mathrm{Z}$ and $\mathrm{p}(\mathrm{Pr})$ values.

\begin{tabular}{|c|c|c|c|c|c|}
\hline Model & Parameter & $\boldsymbol{\beta}$ & SE & $Z$ value & $\operatorname{Pr}(>|z|)$ \\
\hline \multirow[t]{18}{*}{$\mathrm{Aa}\left(\sim \mathrm{y}^{*} \mathrm{~m}+\mathrm{ct}\right)$} & Intercept & $\begin{array}{l}-3.44 \\
\end{array}$ & 0.11 & -30.86 & $<0.001$ \\
\hline & August & 19.61 & 970.00 & -0.02 & 0.98 \\
\hline & July & 19.54 & 929.87 & -0.02 & 0.98 \\
\hline & June & -1.96 & 0.27 & -7.24 & 0.00 \\
\hline & May & -0.35 & 0.13 & -2.72 & 0.01 \\
\hline & November & 0.69 & 0.12 & 5.81 & 0.00 \\
\hline & October & 0.07 & 0.13 & 0.55 & 0.58 \\
\hline & September & -3.03 & 0.42 & -7.21 & 0.00 \\
\hline & $\mathrm{y}$ & 0.05 & 0.10 & 0.46 & 0.64 \\
\hline & Deciduous & -1.10 & 0.15 & -7.34 & 0.00 \\
\hline & Developed & -0.30 & 0.12 & -2.49 & 0.01 \\
\hline & Mix & -0.08 & 0.09 & -0.96 & 0.34 \\
\hline & Shrub & -1.09 & 0.18 & -5.98 & 0.00 \\
\hline & August:y & -0.06 & 970.00 & 0.00 & 1.00 \\
\hline & July:y & -0.07 & 929.87 & 0.00 & 1.00 \\
\hline & June:y & -0.44 & 0.27 & -1.64 & 0.10 \\
\hline & May:y & -0.16 & 0.13 & -1.20 & 0.23 \\
\hline & November:y & -0.25 & 0.12 & -2.13 & 0.03 \\
\hline
\end{tabular}




\begin{tabular}{lllll} 
October:y & -0.27 & 0.13 & -2.06 & 0.04 \\
September:y & -0.08 & 0.42 & -0.20 & 0.85 \\
\hline
\end{tabular}


Table 2.5. Model parameter estimates for Poisson models of estimated index of abundance of nymphal questing ticks (An) on Fort Drum Military Installation, New York, during AprilNovember, 2015-2016. Parameter estimates ( $\beta$ ) are presented with standard errors (SE) as well as $\mathrm{Z}$ and $\mathrm{p}(\mathrm{Pr})$ values.

\begin{tabular}{|c|c|c|c|c|c|}
\hline Model & Parameter & $\beta$ & SE & $Z$ value & $\operatorname{Pr}(>|z|)$ \\
\hline \multirow[t]{18}{*}{$\operatorname{An}\left(\sim y^{*} m+c t\right)$} & Intercept & -22.72 & 1057.25 & -0.02 & 0.98 \\
\hline & August & 18.75 & 1057.25 & 0.02 & 0.99 \\
\hline & July & 19.45 & 1057.25 & 0.02 & 0.99 \\
\hline & June & 20.05 & 1057.25 & 0.02 & 0.99 \\
\hline & May & 18.85 & 1057.25 & 0.02 & 0.99 \\
\hline & November & 0.02 & 1365.06 & 0.00 & 1.00 \\
\hline & October & 8.33 & 1284.60 & 0.01 & 1.00 \\
\hline & September & 17.61 & 1057.25 & 0.02 & 0.99 \\
\hline & $\mathrm{y}$ & -0.03 & 1057.25 & 0.00 & 1.00 \\
\hline & Deciduous & -0.98 & 0.14 & -6.78 & $<0.001$ \\
\hline & Developed & -1.08 & 0.17 & -6.43 & $<0.001$ \\
\hline & Mix & -0.44 & 0.10 & -4.33 & $<0.001$ \\
\hline & Shrub & -1.40 & 0.23 & -6.14 & $<0.001$ \\
\hline & August:y & -0.12 & 1057.25 & 0.00 & 1.00 \\
\hline & July:y & 0.07 & 1057.25 & 0.00 & 1.00 \\
\hline & June:y & -0.11 & 1057.25 & 0.00 & 1.00 \\
\hline & May:y & -0.43 & 1057.25 & 0.00 & 1.00 \\
\hline & November:y & -0.02 & 1365.06 & 0.00 & 1.00 \\
\hline
\end{tabular}


October:y

$-8.48 \quad 1284.60$

$-0.01$

1.00

September:y

$0.04 \quad 1057.25$

0.00

1.00 
Table 2.6. Model parameter estimates for Poisson models of estimated index of abundance of larval questing ticks (Al) on Fort Drum Military Installation, New York, during AprilNovember, 2015-2016. Parameter estimates ( $\beta$ ) are presented with standard errors (SE) as well as $\mathrm{Z}$ and $\mathrm{p}(\mathrm{Pr})$ values.

\begin{tabular}{|c|c|c|c|c|c|}
\hline Model & Parameter & $\beta$ & SE & $Z$ value & $\operatorname{Pr}(>|\mathbf{z}|)$ \\
\hline \multirow[t]{18}{*}{$\mathrm{Al}\left(\sim \mathrm{y}^{*} \mathrm{~m}+\mathrm{ct}\right)$} & Intercept & -22.11 & 647.65 & -0.03 & 0.97 \\
\hline & August & 19.09 & 647.65 & 0.03 & 0.98 \\
\hline & July & 16.97 & 647.65 & 0.03 & 0.98 \\
\hline & June & 18.45 & 647.65 & 0.03 & 0.98 \\
\hline & May & 16.97 & 647.65 & 0.03 & 0.98 \\
\hline & November & 0.04 & 836.43 & 0.00 & 1.00 \\
\hline & October & 16.77 & 647.65 & 0.03 & 0.98 \\
\hline & September & 19.38 & 647.65 & 0.03 & 0.98 \\
\hline & $\mathrm{y}$ & 0.00 & 647.65 & 0.00 & 1.00 \\
\hline & Deciduous & -0.04 & 0.11 & -0.34 & 0.74 \\
\hline & Developed & -0.38 & 0.12 & -3.25 & 0.00 \\
\hline & Mix & 0.06 & 0.08 & 0.81 & 0.42 \\
\hline & Shrub & -1.77 & 0.30 & -5.99 & $<0.001$ \\
\hline & August:y & 1.06 & 647.65 & 0.00 & 1.00 \\
\hline & July:y & -0.27 & 647.65 & 0.00 & 1.00 \\
\hline & June:y & 0.18 & 647.65 & 0.00 & 1.00 \\
\hline & May:y & -0.58 & 647.65 & 0.00 & 1.00 \\
\hline & November:y & -0.05 & 836.43 & 0.00 & 1.00 \\
\hline
\end{tabular}


October:y

$0.43 \quad 647.65$

0.00

1.00

September:y

$-0.17$

647.65

0.00

1.00 
Table 2.7. Model parameter estimates for Poisson models of estimated index of abundance of Lyme-positive adult questing ticks (Pa) on Fort Drum Military Installation, New York, during April-November, 2015-2016. Parameter estimates ( $\beta$ ) are presented with standard errors (SE) as well as $\mathrm{Z}$ and $\mathrm{p}(\mathrm{Pr})$ values.

\begin{tabular}{|c|c|c|c|c|c|}
\hline Model & Parameter & $\boldsymbol{\beta}$ & SE & $Z$ value & $\operatorname{Pr}(>|\mathbf{z}|)$ \\
\hline \multirow[t]{18}{*}{$\mathrm{Pa}(\sim \mathrm{y} * \mathrm{~m}+\mathrm{ct})$} & Intercept & -3.92 & 0.15 & -26.96 & $<0.001$ \\
\hline & August & -20.15 & 1601.46 & -0.01 & 0.99 \\
\hline & July & -20.10 & 1552.24 & -0.01 & 0.99 \\
\hline & June & -3.01 & 0.59 & -5.10 & $<0.001$ \\
\hline & May & -0.59 & 0.17 & -3.40 & $<0.001$ \\
\hline & November & 0.36 & 0.16 & 2.31 & 0.02 \\
\hline & October & -0.45 & 0.20 & -2.26 & 0.02 \\
\hline & September & -20.19 & 1660.77 & -0.01 & 0.99 \\
\hline & $\mathrm{y}$ & 0.04 & 0.13 & 0.29 & 0.77 \\
\hline & Deciduous & -1.23 & 0.23 & -5.32 & $<0.001$ \\
\hline & Developed & -0.21 & 0.17 & -1.26 & 0.21 \\
\hline & Mix & -0.06 & 0.13 & -0.43 & 0.66 \\
\hline & Shrub & -1.01 & 0.26 & -3.89 & $<0.001$ \\
\hline & August:y & -0.06 & 1601.46 & 0.00 & 1.00 \\
\hline & July:y & -0.06 & 1552.24 & 0.00 & 1.00 \\
\hline & June:y & -0.85 & 0.59 & -1.44 & 0.15 \\
\hline & May:y & -0.10 & 0.17 & -0.60 & 0.55 \\
\hline & November:y & -0.28 & 0.16 & -1.76 & 0.08 \\
\hline
\end{tabular}


October:y

September:y
$-0.57$

$-0.12$
0.20

$-2.84<0.001$

1660.77

0.00

1.00 
Table 2.8. Model parameter estimates for Poisson models of estimated index of abundance of Lyme-positive nymphal questing ticks (Pn) on Fort Drum Military Installation, New York, during April-November, 2015-2016. Parameter estimates ( $\beta$ ) are presented with standard errors (SE) as well as $\mathrm{Z}$ and $\mathrm{p}(\mathrm{Pr})$ values.

\begin{tabular}{|c|c|c|c|c|c|}
\hline Model & Parameter & $\boldsymbol{\beta}$ & SE & $Z$ value & $\operatorname{Pr}(>|z|)$ \\
\hline \multirow[t]{18}{*}{$\operatorname{Pn}\left(\sim y^{*} \mathrm{~m}+\mathrm{ct}\right)$} & Intercept & -23.67 & 1695.00 & -0.01 & 0.99 \\
\hline & August & 17.15 & 1695.00 & 0.01 & 0.99 \\
\hline & July & 18.92 & 1695.00 & 0.01 & 0.99 \\
\hline & June & 19.23 & 1695.00 & 0.01 & 0.99 \\
\hline & May & 17.93 & 1695.00 & 0.01 & 0.99 \\
\hline & November & -0.08 & 2222.00 & 0.00 & 1.00 \\
\hline & October & 7.93 & 2098.00 & 0.00 & 1.00 \\
\hline & September & 17.33 & 1695.00 & 0.01 & 0.99 \\
\hline & $\mathrm{y}$ & $<0.001$ & 1695.00 & 0.00 & 1.00 \\
\hline & Deciduous & -0.86 & 0.34 & -2.54 & 0.01 \\
\hline & Developed & -2.32 & 0.72 & -3.21 & $<0.001$ \\
\hline & Mix & -0.30 & 0.23 & -1.30 & 0.19 \\
\hline & Shrub & -1.24 & 0.47 & -2.63 & 0.01 \\
\hline & August:y & 0.83 & 1695.00 & 0.00 & 1.00 \\
\hline & July:y & -0.56 & 1695.00 & 0.00 & 1.00 \\
\hline & June:y & -0.22 & 1695.00 & 0.00 & 1.00 \\
\hline & May:y & 0.45 & 1695.00 & 0.00 & 1.00 \\
\hline & November:y & -0.09 & 2222.00 & 0.00 & 1.00 \\
\hline
\end{tabular}


October:y

September:y
$-8.28 \quad 2098.00$

0.00

1.00

$0.31 \quad 1695.00$

0.00

1.00 
Table 2.9. Parametric bootstrapped estimates of index of abundance of ticks from a generalized linear Poisson model on Fort Drum Military Installation, New York, during April-November, 2015-2016 spatially and temporally. Statistical significance with a 95\% confidence interval estimated by bootstrapping is noted by an asterisk $(\mathrm{alpha}=0.05)$. The symbol $>$ indicates the item in the column on the left is significantly greater than the item in the column on the right. The symbol < indicates the item in the column on the right is significantly greater than the item in the column on the left. NAs represent that no ticks of that developmental stage were collected during that month.

\begin{tabular}{|c|c|c|c|}
\hline Comparison 1 & Comparison 2 & $\begin{array}{l}\text { Adult index of } \\
\text { abundance } \\
\text { confidence } \\
\text { intervals of } \\
\text { bootstrap } \\
\text { estimates }\end{array}$ & $\begin{array}{l}\text { Nymph index of } \\
\text { abundance } \\
\text { confidence } \\
\text { intervals of } \\
\text { bootstrap } \\
\text { estimates }\end{array}$ \\
\hline
\end{tabular}

Cover type

$\begin{array}{lrrr}\text { Coniferous } & \text { Deciduous } & (0.016,0.029)^{*}> & (0.008,0.016)^{*>} \\ \text { Coniferous } & \text { Developed } & (0.002,0.015)^{*>} & (0.008,0.017)^{*>} \\ \text { Coniferous } & \text { Mixed } & (-0.002,0.008) & (0.004,0.010)^{*>} \\ \text { Coniferous } & \text { Shrub } & (0.015,0.029)^{*>} & (0.010,0.019)^{*>} \\ \text { Deciduous } & \text { Developed } & (-0.021,-0.007)^{*<} & (-0.002,0.003) \\ \text { Deciduous } & \text { Mixed } & (-0.026,-0.014)^{*<} & (-0.008,-0.002)^{*<} \\ & & & \\ \text { Deciduous } & \text { Shrub } & (-0.005,0.005) & (-0.001,0.005)\end{array}$


Developed

Developed

Mixed

\section{Month}

April

April

April

April

April

April

April

May

May

May

May

May

May
Mixed

$(-0.012,0.001)$

Shrub

Shrub

May

June

July

August

September

October

November

June

July

August

September

October

November

NA

NA
$(0.007,0.020)^{*}>$

$(-0.001,0.005)$

$(0.013,0.026)^{*}>$

$(0.004,0.011)^{*>}$
NA

NA

NA

NA

NA

NA

NA

$(-0.042,-0.022) *<$

$(0.014,0.023)^{*}>$

$(-5.506,-1.542)^{*<}$

$(-2.542,-0.444)^{*}<$

$(0.788,1.490)^{*}>$

$(0.495,1.015)^{*}>$

$(-1.699,1.439)$

NA 


\begin{tabular}{|c|c|c|c|}
\hline June & July & NA & $(0.934,3.326)^{*>}$ \\
\hline June & August & NA & $(2.370,6.999)^{*>}$ \\
\hline June & September & $(0.001,0.006) *>$ & $(2.142,6.463)^{*>}$ \\
\hline June & October & $(-0.038,-0.024)^{*<}$ & $(-1.699,6.383)$ \\
\hline June & November & $(-0.070,-0.050)^{*<}$ & NA \\
\hline July & August & NA & $(1.275,3.954)^{*>}$ \\
\hline July & September & NA & $(1.045,3.356)^{*>}$ \\
\hline July & October & NA & $(-1.699,3.698)$ \\
\hline July & November & NA & NA \\
\hline August & September & NA & $(-0.717,-0.162)^{*}<$ \\
\hline August & October & NA & $(-1.699,2.477)$ \\
\hline August & November & NA & NA \\
\hline September & October & $(-0.041,-0.027)^{*<}$ & $(-0.717,-0.162)^{*}<$ \\
\hline September & November & $(-0.073,-0.054)^{*<}$ & NA \\
\hline October & November & $(-0.040,-0.019)^{*<}$ & NA \\
\hline
\end{tabular}


Table 2.10. Parametric bootstrapped estimates of index of abundance of Lyme-positive ticks from a generalized linear Poisson model on Fort Drum Military Installation, New York, during April-November, 2015-2016 spatially and temporally. Statistical significance with a 95\% confidence interval estimated by bootstrapping is noted by an asterisk (alpha=0.05). The symbol > indicates the item in the column on the left is significantly greater than the item in the column on the right. The symbol < indicates the item in the column on the right is significantly greater than the item in the column on the left. NAs represent that no ticks of that developmental stage were collected during that month.

\begin{tabular}{|c|c|c|c|}
\hline Comparison 1 & Comparison 2 & $\begin{array}{c}\text { Adult index of } \\
\text { abundance } \\
\text { confidence } \\
\text { intervals of } \\
\text { bootstrap } \\
\text { estimates }\end{array}$ & $\begin{array}{c}\text { Nymph index of } \\
\text { abundance } \\
\text { confidence } \\
\text { intervals of } \\
\text { bootstrap } \\
\text { estimates }\end{array}$ \\
\hline
\end{tabular}

Cover type

$\begin{array}{lrrr}\text { Coniferous } & \text { Deciduous } & (0.014,0.026)^{*}> & (0.006,0.011)^{*}> \\ \text { Coniferous } & \text { Developed } & (0.002,0.014)^{*}> & (0.006,0.012)^{*>} \\ \text { Coniferous } & \text { Mixed } & (-0.002,0.007) & (0.003,0.008)^{*}> \\ \text { Coniferous } & \text { Shrub } & (0.013,0.026)^{*>} & (0.007,0.014)^{*>} \\ \text { Deciduous } & \text { Developed } & (-0.018,-0.006)^{*}< & (-0.001,0.003) \\ \text { Deciduous } & \text { Mixed } & (-0.024,-0.012)^{*}< & (-0.005,-0.001)^{*}< \\ \text { Deciduous } & \text { Shrub } & (-0.005,0.004) & (-0.001,0.004)\end{array}$


Developed

Developed

Mixed

\section{Month}

April

April

April

April

April

April

April

May

May

May

May

May

May
Mixed

Shrub

Shrub

May

June

July

August

September

October

November

June

July

August

September

October

November
$(-0.011,0.001)$

$(0.005,0.020)^{*}>$

$(-0.001,0.003)$

$(0.011,0.024) *>$

$(0.003,0.007)^{*>}$
NA

NA

NA

NA

NA

NA

NA

$(-0.037,-0.016) *<$

$(0.014,0.023) *>$

$(-5.863,-1.340)^{*<}$

NA

$(-1.998,-0.127)^{*<}$

NA

$(1.065,2.112) *>$

$(0.583,1.306)^{*}>$

$(-1.699,2.016)$
$(0.017,0.027)^{*}>$

$(-0.017,-0.002)^{*<}$

$(-0.045,-0.022)^{*<}$

NA 


\begin{tabular}{|c|c|c|c|}
\hline June & July & NA & $(1.014,4.341)^{*>}$ \\
\hline June & August & NA & $(2.414,7.970)^{*>}$ \\
\hline June & September & $(0.001,0.006)^{*>}$ & $(2.094,7.034)^{*}>$ \\
\hline June & October & $(-0.035,-0.020)^{*}<$ & $(-1.699,7.123)$ \\
\hline June & November & $(-0.063,-0.039)^{*<}$ & NA \\
\hline July & August & NA & $(1.272,4.053)^{*>}$ \\
\hline July & September & NA & $(0.914,3.060)^{*>}$ \\
\hline July & October & NA & $(-1.699,3.564)$ \\
\hline July & November & NA & NA \\
\hline August & September & NA & $(-1.187,-0.259)^{*<}$ \\
\hline August & October & NA & $(-1.699,0.023)$ \\
\hline August & November & NA & NA \\
\hline September & October & $(-0.038,-0.024)^{*}<$ & $(-1.699,1.045)^{*}<$ \\
\hline September & November & $(-0.066,-0.043)^{*}<$ & NA \\
\hline October & November & $(-0.035,-0.012)^{*}<$ & NA \\
\hline
\end{tabular}


Table 2.11. Apparent prevalence of Borrelia burgdorferi on a spatial and temporal scale on Fort Drum Military Installation, New York during 2015-2016.

\begin{tabular}{|c|c|c|c|}
\hline Categorical variable & $\begin{array}{l}\text { No. individuals } \\
\text { positive for } B \text {. } \\
\text { burgdorferi }\end{array}$ & No. total individuals & $\%$ infection rate \\
\hline \multicolumn{4}{|l|}{ Developmental stage } \\
\hline Adult & 340 & 711 & $47.82 \%$ \\
\hline Nymph & 97 & 535 & $17.57 \%$ \\
\hline \multicolumn{4}{|l|}{ Cover type } \\
\hline Coniferous & 177 & 540 & $32.78 \%$ \\
\hline Deciduous & 34 & 113 & $30.09 \%$ \\
\hline Developed & 52 & 135 & $38.51 \%$ \\
\hline Mixed & 152 & 403 & $37.72 \%$ \\
\hline Shrub & 22 & 55 & $40.00 \%$ \\
\hline \multicolumn{4}{|l|}{ Month } \\
\hline April & 68 & 108 & $62.96 \%$ \\
\hline May & 90 & 314 & $28.66 \%$ \\
\hline June & 39 & 342 & $11.40 \%$ \\
\hline July & 29 & 154 & $18.83 \%$ \\
\hline August & 7 & 451 & $1.55 \%$ \\
\hline September & 6 & 310 & $1.94 \%$ \\
\hline October & 65 & 174 & $37.36 \%$ \\
\hline November & 133 & 299 & $44.48 \%$ \\
\hline
\end{tabular}


Total

437

1246

$35.07 \%$ 
Table 2.12. Percentage of positive-Borrelia burgdorferi tick per 100 square meters on Fort Drum Military Installation, New York, during April-November 2015-2016.

\begin{tabular}{lllr}
\hline Month & Cover type & Adult & Nymph \\
\hline April & & & \\
& Coniferous & $86.20 \%$ & $0.00 \%$ \\
& Deciduous & $43.92 \%$ & $0.00 \%$ \\
& Developed & $79.86 \%$ & $0.00 \%$ \\
& Mixed & $84.65 \%$ & $0.00 \%$ \\
& Shrub & $51.40 \%$ & $0.00 \%$ \\
& & & \\
& Coniferous & $70.46 \%$ & $18.54 \%$ \\
& Deciduous & $29.95 \%$ & $8.30 \%$ \\
& Developed & $62.71 \%$ & $10.99 \%$ \\
& Mixed & $68.47 \%$ & $14.11 \%$ \\
& Shrub & $35.86 \%$ & $5.75 \%$
\end{tabular}

June

$\begin{array}{lrr}\text { Coniferous } & 20.47 \% & 77.14 \% \\ \text { Deciduous } & 6.47 \% & 46.41 \% \\ \text { Developed } & 16.91 \% & 13.51 \% \\ \text { Mixed } & 19.48 \% & 66.53 \% \\ \text { Shrub } & 8.00 \% & 34.73 \%\end{array}$

July
Coniferous
$0.00 \% \quad 60.00 \%$ 


$\begin{array}{lll}\text { Deciduous } & 0.00 \% & 32.15 \% \\ \text { Developed } & 0.00 \% & 8.62 \% \\ \text { Mixed } & 0.00 \% & 49.32 \% \\ \text { Shrub } & 0.00 \% & 23.27 \%\end{array}$

August

$\begin{array}{lll}\text { Coniferous } & 0.00 \% & 6.23 \% \\ \text { Deciduous } & 0.00 \% & 6.23 \% \\ \text { Developed } & 0.00 \% & 2.68 \% \\ \text { Mixed } & 0.00 \% & 0.63 \% \\ \text { Shrub } & 0.00 \% & 1.84 \%\end{array}$

September

$\begin{array}{lll}\text { Coniferous } & 0.00 \% & 12.17 \% \\ \text { Deciduous } & 0.00 \% & 5.34 \% \\ \text { Developed } & 0.00 \% & 1.27 \% \\ \text { Mixed } & 0.00 \% & 9.18 \% \\ \text { Shrub } & 0.00 \% & 3.68 \%\end{array}$

October

$\begin{array}{lrr}\text { Coniferous } & 89.23 \% & 0.00 \% \\ \text { Deciduous } & 47.85 \% & 0.00 \% \\ \text { Developed } & 83.52 \% & 0.00 \% \\ \text { Mixed } & 87.87 \% & 0.00 \% \\ \text { Shrub } & 55.61 \% & 0.00 \%\end{array}$

November 


$\begin{array}{lll}\text { Coniferous } & 97.66 \% & 0.00 \% \\ \text { Deciduous } & 66.62 \% & 0.00 \% \\ \text { Developed } & 95.21 \% & 0.00 \% \\ \text { Mixed } & 97.14 \% & 0.00 \% \\ \text { Shrub } & 74.60 \% & 0.00 \%\end{array}$


Table 2.13. Apparent prevalence of Borrelia miyamotoi on a spatial and temporal scale on Fort Drum Military Installation, New York during 2015-2016.

\begin{tabular}{ll}
\hline Categorical variable & No. individuals \\
& No. total individuals $\%$ infection rate \\
& miyamotoi $B$.
\end{tabular}

Developmental stage

Adult

Nymph

Cover type

Coniferous

Deciduous

Developed

Mixed

Shrub

Month

April

May

June

July

August

September

October

November
3

4

9

8

2

1

1

0

2

2

0

0

0

0

4
711

$1.27 \%$

535

$0.56 \%$

540

$1.48 \%$

113

$1.77 \%$

135

$0.74 \%$

403

$0.25 \%$

55

$0.00 \%$ 
Total

12

1246

$0.96 \%$ 
Table 2.14. Apparent prevalence of Anaplasma phagocytophilum on a spatial and temporal scale on Fort Drum Military Installation, New York during 2015-2016.

\begin{tabular}{ll}
\hline Categorical variable & $\begin{array}{l}\text { No. individuals } \\
\text { positive for } A .\end{array}$ \\
& phagocytophilum
\end{tabular}

Developmental stage

Adult

46

711

$6.47 \%$

Nymph

4

535

$0.75 \%$

Cover type

Coniferous

25

540

$4.63 \%$

Deciduous

4

113

$3.54 \%$

Developed

10

135

$7.41 \%$

Mixed

10

403

$2.48 \%$

Shrub

1

55

$1.82 \%$

Month

April

May

16

314

$5.10 \%$

June

4

342

$1.17 \%$

July

1

154

$0.65 \%$

August

0

451

$0.00 \%$

September

0

310

$0.00 \%$

October

10

174

$5.75 \%$

November

10

299

$3.34 \%$ 
Total

$4.01 \%$ 
Table 3.1. Model parameter estimates for Poisson models of estimated index of abundance of total questing ticks (A) on Fort Drum Military Installation, New York, during AprilNovember, 2015-2016 within $\triangle \mathrm{AICc}$ of 2 used in model averaging to determine the final model. Parameter estimates ( $\beta$ ) are presented with standard errors (SE) as well as $\mathrm{Z}$ and p ( $\operatorname{Pr}$ ) values.

\begin{tabular}{llcccc}
\hline Model & Parameter & $\boldsymbol{\beta}$ & SE & Z value & $\operatorname{Pr}(>|\mathbf{z}|)$ \\
\hline $\mathrm{A}(\sim \mathrm{y}+\mathrm{ct}+\mathrm{sm})$ & Intercept & 1.92 & 0.23 & 8.19 & $<0.001$ \\
$\mathrm{y}$ & 0.03 & 0.03 & 1.02 & 0.31 \\
& $\mathrm{sm}$ & 0.03 & 0.02 & 1.35 & 0.18 \\
& Deciduous & -0.44 & 0.12 & -3.57 & $<0.001$ \\
& Developed & -0.75 & 0.24 & -3.07 & $<0.001$ \\
& Mixed & 0.13 & 0.17 & 0.78 & 0.44 \\
& Shrub & -1.17 & 0.17 & -6.76 & $<0.001$ \\
\hline
\end{tabular}


Table 3.2. Model parameter estimates for Poisson models of estimated index of abundance of total questing ticks $(\mathrm{P})$ on Fort Drum Military Installation, New York, during AprilNovember, 2015-2016. Parameter estimates ( $\beta$ ) are presented with standard errors (SE) as well as $\mathrm{Z}$ and $\mathrm{p}(\mathrm{Pr})$ values.

\begin{tabular}{llcccc}
\hline Model & Parameter & $\boldsymbol{\beta}$ & SE & $\mathbf{Z}$ value & $\operatorname{Pr}(>|\mathbf{z}|)$ \\
\hline $\mathrm{P}(\sim \mathrm{y}+\mathrm{ct}+$ shan+simp $)$ & Intercept & -3.59 & 0.31 & -11.60 & $<0.001$ \\
& $\mathrm{y}$ & -0.30 & 0.06 & -4.85 & $<0.001$ \\
& Deciduous & -1.03 & 0.23 & -4.47 & $<0.001$ \\
& Developed & -0.35 & 0.16 & -2.15 & 0.03 \\
& Mix & -0.12 & 0.21 & -0.56 & 0.58 \\
& Shrub & -0.88 & 0.27 & -3.20 & $<0.001$ \\
& shan & 0.02 & 0.34 & 0.05 & 0.96 \\
& simp & 0.04 & 0.58 & 0.07 & 0.95 \\
\hline
\end{tabular}


Table 3.3. Relative support for 5 candidate Poisson models of estimated index of abundance of Peromyscus sp. (D) on Fort Drum Military Installation, New York, 2015-2016. K indicates the number of model parameters, AICc is Akaike's information criterion corrected for small sample size, $\triangle \mathrm{AICc}$ is the difference in AICc units from the best approximating model, while $w$ is the model weight. See Table 2.1 for description of model variables.

\begin{tabular}{lcccc}
\hline Model & K & AICc & $\Delta \mathbf{A I C c}$ & $\boldsymbol{w}$ \\
\hline $\mathrm{D}(\sim \mathrm{ct})$ & 6 & 101.50 & 0.00 & 0.34 \\
$\mathrm{D}(\sim \mathrm{ct}+\mathrm{c})$ & 7 & 102.19 & 0.69 & 0.24 \\
$\mathrm{D}(\sim \mathrm{ct}+\mathrm{sd})$ & 7 & 103.96 & 2.46 & 0.10 \\
$\mathrm{D}(\sim \mathrm{ct}+\mathrm{sdbh})$ & 7 & 105.27 & 3.77 & 0.05 \\
$\mathrm{D}(\sim \mathrm{ct}+1)$ & 7 & 105.53 & 4.04 & 0.05 \\
\hline
\end{tabular}


Table 3.4. Model parameter estimates for Poisson models of estimated index of abundance of Peromyscus sp. (D) on Fort Drum Military Installation, New York, 2015-2016 within $\Delta$ AICc of 2 used in model averaging to determine the final model. Parameter estimates $(\beta)$ are presented with standard errors (SE) as well as $\mathrm{Z}$ and $\mathrm{p}(\mathrm{Pr})$ values.

\begin{tabular}{llcccc}
\hline Model & Parameter & $\boldsymbol{\beta}$ & $\mathbf{S E}$ & $\mathbf{Z}$ value & $\operatorname{Pr}(>|\mathbf{z}|)$ \\
\hline $\mathrm{D}(\sim)$ & Intercept & 3.91 & 1.86 & 2.10 & 0.04 \\
& Deciduous & 0.04 & 0.31 & 0.14 & 0.89 \\
& Developed & -0.59 & 0.74 & -0.80 & 0.43 \\
& Grassland & -22.21 & 2858.77 & -0.01 & 0.99 \\
& Mix & -1.26 & 0.47 & -2.70 & 0.01 \\
& Shrub & -1.06 & 0.44 & -2.41 & 0.02 \\
& $\mathrm{c}$ & -0.02 & 0.02 & -1.24 & 0.21 \\
\hline
\end{tabular}


Table 3.5. Relative support for 5 candidate Poisson models of estimated index of abundance of chipmunk (C) on Fort Drum Military Installation, New York, 2015-2016. $K$ indicates the number of model parameters, AICc is Akaike's information criterion corrected for small sample size, $\triangle \mathrm{AICc}$ is the difference in AICc units from the best approximating model, while $w$ is the model weight. See Table 2.1 for description of model variables.

\begin{tabular}{lcccc}
\hline Model & K & AICc & $\Delta$ AICc & $w$ \\
\hline C( ct+cwdc+mid+sh $)$ & 9 & 83.68 & 0.00 & 0.24 \\
C( ct+mid $)$ & 7 & 83.97 & 0.29 & 0.21 \\
C( ct+cwdc $)$ & 7 & 84.46 & 0.78 & 0.16 \\
C( ct+mid+cwdc $)$ & 8 & 85.03 & 1.35 & 0.12 \\
C( ct+cwdc+sspp $)$ & 8 & 85.35 & 1.67 & 0.10 \\
\hline
\end{tabular}


Table 3.6. Model parameter estimates for Poisson models of estimated index of abundance of chipmunk (C) on Fort Drum Military Installation, New York, 2015-2016 within $\Delta$ AICc of 2 used in model averaging to determine the final model. Parameter estimates $(\beta)$ are presented with standard errors (SE) as well as $\mathrm{Z}$ and $\mathrm{p}(\mathrm{Pr})$ values.

\begin{tabular}{lccccc}
\hline Model & Parameter & $\boldsymbol{\beta}$ & $\mathbf{S E}$ & $\mathbf{Z}$ value & $\operatorname{Pr}(>|\mathbf{z}|)$ \\
\hline $\mathrm{C}(\sim \mathrm{ct}+\mathrm{cwdc}+\mathrm{mid}+\mathrm{sh})$ & Intercept & -12.51 & 1916.40 & -0.01 & 1.00 \\
& Deciduous & 15.75 & 2524.26 & 0.01 & 1.00 \\
& Developed & -296.37 & 39177.38 & -0.01 & 0.99 \\
& Grassland & -32.75 & 3984.23 & -0.01 & 0.99 \\
& Mix & 47.90 & 6313.86 & 0.01 & 0.99 \\
& Shrub & 277.92 & 38428.99 & 0.01 & 0.99 \\
& cwdc & 21.15 & 3320.08 & 0.01 & 1.00 \\
& mid & -139.68 & 19264.73 & -0.01 & 0.99 \\
& sh & -69.77 & 10147.11 & -0.01 & 1.00 \\
\end{tabular}


Table 3.7. Relative support for 5 candidate Poisson models of estimated index of abundance of red squirrel (R) on Fort Drum Military Installation, New York, 2015-2016. K indicates the number of model parameters, AICc is Akaike's information criterion corrected for small sample size, $\triangle \mathrm{AICc}$ is the difference in AICc units from the best approximating model, while $w$ is the model weight. See Table 2.1 for description of model variables.

\begin{tabular}{lcccc}
\hline Model & K & AICc & $\Delta$ AICc & $w$ \\
\hline $\mathrm{R}(\sim \mathrm{ct}+$ stem $)$ & 7 & 65.27 & 0.00 & 0.30 \\
$\mathrm{R}(\sim \mathrm{ct}+$ stem+dbh $)$ & 8 & 65.36 & 0.09 & 0.29 \\
$\mathrm{R}(\sim \mathrm{ct}+$ stem+l $)$ & 8 & 66.44 & 1.17 & 0.17 \\
$\mathrm{R}(\sim \mathrm{ct}+\mathrm{cwddbh}+$ stem $)$ & 8 & 69.77 & 4.51 & 0.03 \\
$\mathrm{R}(\sim \mathrm{ct}+\mathrm{sh}+\mathrm{stem})$ & 8 & 70.04 & 4.78 & 0.03 \\
\hline
\end{tabular}


Table 3.8. Model parameter estimates for Poisson models of estimated index of abundance of red squirrel (R) on Fort Drum Military Installation, New York, 2015-2016 within $\triangle \mathrm{AICc}$ of 2 used in model averaging to determine the final model. Parameter estimates $(\beta)$ are presented with standard errors (SE) as well as $\mathrm{Z}$ and $\mathrm{p}(\mathrm{Pr})$ values.

\begin{tabular}{llcccr}
\hline Model & Parameter & $\boldsymbol{\beta}$ & SE & Z value & $\operatorname{Pr}(>|\mathbf{z}|)$ \\
\hline $\mathrm{R}(\sim \mathrm{ct}+$ stem $)$ & Intercept & -0.28 & 0.52 & -0.54 & 0.59 \\
& Deciduous & -19.83 & 4921.30 & -0.004 & 1.00 \\
& Developed & 1.98 & 0.49 & 4.07 & $<0.001$ \\
& Grassland & -17.00 & 4713.31 & -0.004 & 1.00 \\
Mix & -1.51 & 0.78 & -1.93 & 0.05 \\
& Shrub & -0.96 & 0.67 & -1.44 & 0.15 \\
& stem & -1.56 & 0.57 & -2.74 & $<0.001$ \\
\hline
\end{tabular}


Table 3.9. Relative support for 5 candidate Poisson models of estimated index of abundance of gray squirrel (G) on Fort Drum Military Installation, New York, 2015-2016. $K$ indicates the number of model parameters, AICc is Akaike's information criterion corrected for small sample size, $\triangle \mathrm{AICc}$ is the difference in AICc units from the best approximating model, while $w$ is the model weight. See Table 2.1 for description of model variables.

\begin{tabular}{lllll}
\hline Model & K & AICc & $\Delta$ AICc & $w$ \\
\hline G( mid+spp+sd $)$ & 4 & 40.92 & 0.00 & 0.60 \\
G( c cwdl+mid+spp+sd $)$ & 5 & 43.59 & 2.67 & 0.16 \\
G( $\sim \mathrm{dbh}+$ mid+spp+sd $)$ & 5 & 44.22 & 3.29 & 0.12 \\
$\mathrm{G}(\sim \mathrm{cwdl}+\mathrm{mid}+\mathrm{spp})$ & 4 & 45.13 & 4.21 & 0.07 \\
$\mathrm{G}(\sim \mathrm{cwdl}+\mathrm{dbh}+\mathrm{mid}+\mathrm{spp}+\mathrm{sd})$ & 6 & 45.76 & 4.83 & 0.05 \\
\hline
\end{tabular}


Table 3.10. Model parameter estimates for Poisson models of estimated index of abundance of gray squirrel (G) on Fort Drum Military Installation, New York, 2015-2016 within $\Delta$ AICc of 2 used in model averaging to determine the final model. Parameter estimates $(\beta)$ are presented with standard errors (SE) as well as $\mathrm{Z}$ and $\mathrm{p}(\mathrm{Pr})$ values.

\begin{tabular}{lrlccc}
\hline Model & Parameter & $\boldsymbol{\beta}$ & SE & Z value & $\operatorname{Pr}(>|\mathbf{z}|)$ \\
\hline G( mid+spp+sd $)$ & Intercept & -7.27 & 2.79 & -2.61 & $<0.001$ \\
spp & 3.69 & 1.05 & 3.52 & $<0.001$ \\
sd & 8.16 & 3.17 & 2.57 & 0.01 \\
mid & -4.45 & 1.68 & -2.65 & $<0.001$ \\
\hline
\end{tabular}


Table 3.11. Relative support for 5 candidate Poisson models of estimated index of abundance of all host species (H) on Fort Drum Military Installation, New York, 2015-2016. K indicates the number of model parameters, AICc is Akaike's information criterion corrected for small sample size, $\triangle \mathrm{AICc}$ is the difference in AICc units from the best approximating model, while $w$ is the model weight. See Table 2.1 for description of model variables.

\begin{tabular}{lcccc}
\hline Model & K & AICc & $\Delta$ AICc & $w$ \\
\hline $\mathrm{H}(\sim \mathrm{ct}+\mathrm{sd})$ & 7 & 142.55 & 0.00 & 0.50 \\
$\mathrm{H}(\sim \mathrm{ct}+\mathrm{sd}+\mathrm{dbh})$ & 8 & 145.16 & 2.62 & 0.13 \\
$\mathrm{H}(\sim \mathrm{ct}+\mathrm{sd}+\mathrm{cwdl})$ & 8 & 146.09 & 3.54 & 0.08 \\
$\mathrm{H}(\sim \mathrm{ct}+\mathrm{sd}+\mathrm{sdbh})$ & 8 & 146.51 & 3.96 & 0.07 \\
$\mathrm{H}(\sim \mathrm{ct}+\mathrm{spp})$ & 8 & 146.53 & 3.98 & 0.07 \\
\hline
\end{tabular}


Table 3.12. Model parameter estimates for Poisson models of estimated index of abundance of all host species (H) on Fort Drum Military Installation, New York, 2015-2016 within $\Delta$ AICc of 2 used in model averaging to determine the final model. Parameter estimates $(\beta)$ are presented with standard errors (SE) as well as $\mathrm{Z}$ and $\mathrm{p}(\mathrm{Pr})$ values.

\begin{tabular}{llcccc}
\hline Model & Parameter & $\boldsymbol{\beta}$ & SE & Z value & $\operatorname{Pr}(>|\mathbf{z}|)$ \\
\hline $\mathrm{H}(\sim \mathrm{ct}+\mathrm{sd})$ & Intercept & 3.62 & 0.24 & 15.11 & $<0.001$ \\
& Deciduous & -1.34 & 0.30 & -4.54 & $<0.001$ \\
& Developed & 0.78 & 0.18 & 4.27 & $<0.001$ \\
& Grassland & -7.32 & 1.07 & -6.77 & $<0.001$ \\
& Mix & -1.76 & 0.32 & -5.58 & $<0.001$ \\
& Shrub & -1.26 & 0.27 & -4.70 & $<0.001$ \\
& sd & -2.08 & 0.39 & -5.33 & $<0.001$ \\
\hline
\end{tabular}


Table 3.13. Parametric bootstrapped estimates of index of abundance of small mammal hosts from a generalized linear Poisson model on Fort Drum Military Installation, New York, 20152016. Statistical significance with a $95 \%$ confidence interval estimated by bootstrapping is noted by an asterisk (alpha=0.05). The symbol $>$ indicates the item in the column on the left is significantly greater than the item in the column on the right. The symbol < indicates the item in the column on the right is significantly greater than the item in the column on the left.

\begin{tabular}{|c|c|c|}
\hline Category 1 & Category 2 & $\begin{array}{l}\text { Index of abundance } \\
\text { confidence intervals of } \\
\text { bootstrap estimates }\end{array}$ \\
\hline
\end{tabular}

Cover type

\begin{tabular}{|c|c|c|}
\hline Coniferous & Deciduous & $(2.37,8.72)^{*>}$ \\
\hline Coniferous & Grassland & $(8.19,13.90)^{*}>$ \\
\hline Coniferous & Developed & $(-16.63,-7.42)^{*<}$ \\
\hline Coniferous & Mixed & $(5.85,11.72)^{*}>$ \\
\hline Coniferous & Shrub & $(3.40,9.73)^{*>}$ \\
\hline Deciduous & Grassland & $(3.62,7.72)^{*>}$ \\
\hline Deciduous & Developed & $(-21.54,-13.28)^{*}<$ \\
\hline Deciduous & Mixed & $(0.97,5.53)^{*>}$ \\
\hline Deciduous & Shrub & $(-1.54,3.52)$ \\
\hline Grassland & Developed & $(-26.94,-18.83)^{*<}$ \\
\hline Grassland & Mixed & $(-4.01,-0.98)^{*}<$ \\
\hline Grassland & Shrub & $(-6.46,-2.74)^{*}<$ \\
\hline Developed & Mixed & $(16.49,24.52)^{*>}$ \\
\hline Developed & Shrub & $(14.23,22.81)^{*>}$ \\
\hline
\end{tabular}


Mixed

Shrub

$(-4.32,-0.02)^{*<}$

Species

Peromyscus sp.

Gray squirrel

$(0.27,0.44)^{*>}$

Peromyscus sp.

Red squirrel

$(0.25,0.41)^{*}>$

Peromyscus sp.

Chipmunk

$(0.21,0.34)^{*>}$

Gray squirrel

Gray squirrel

Red squirrel

$(-0.06,-0.01)^{*}<$

Chipmunk

$(-0.13,-0.04)^{*<}$

Red squirrel
Chipmunk
$(-0.09,-0.01)^{*<}$ 
Table 3.14. Average trapping success per 100 capture events, Simpson's diversity index and Shannon's diversity index on Fort Drum Military Installation, New York, 2015-2016.

\begin{tabular}{|c|c|c|c|c|c|c|}
\hline & Developed & Grassland & Coniferous & Mixed & Deciduous & Shrub \\
\hline Trapping & 13.54 & 0.70 & 4.82 & 1.58 & 2.29 & 2.61 \\
\hline \multicolumn{7}{|l|}{ Success } \\
\hline Simpson's & 0.57 & 0.12 & 0.53 & 0.26 & 0.23 & 0.38 \\
\hline \multicolumn{7}{|l|}{ Diversity } \\
\hline \multicolumn{7}{|l|}{ Index } \\
\hline Shannon's & 0.96 & 0.17 & 0.97 & 0.44 & 0.35 & 0.70 \\
\hline \multicolumn{7}{|l|}{ Diversity } \\
\hline Index & & & & & & \\
\hline
\end{tabular}


Table 3.15. Parametric bootstrapped estimates of average trapping success, Simpson's diversity index and Shannon's diversity index from a generalized linear Poisson model on Fort Drum Military Installation, New York, 2015-2016. Statistical significance with a 95\% confidence interval estimated by bootstrapping is noted by an asterisk (alpha=0.05). The symbol $>$ indicates the item in the column on the left is significantly greater than the item in the column on the right. The symbol < indicates the item in the column on the right is significantly greater than the item in the column on the left.

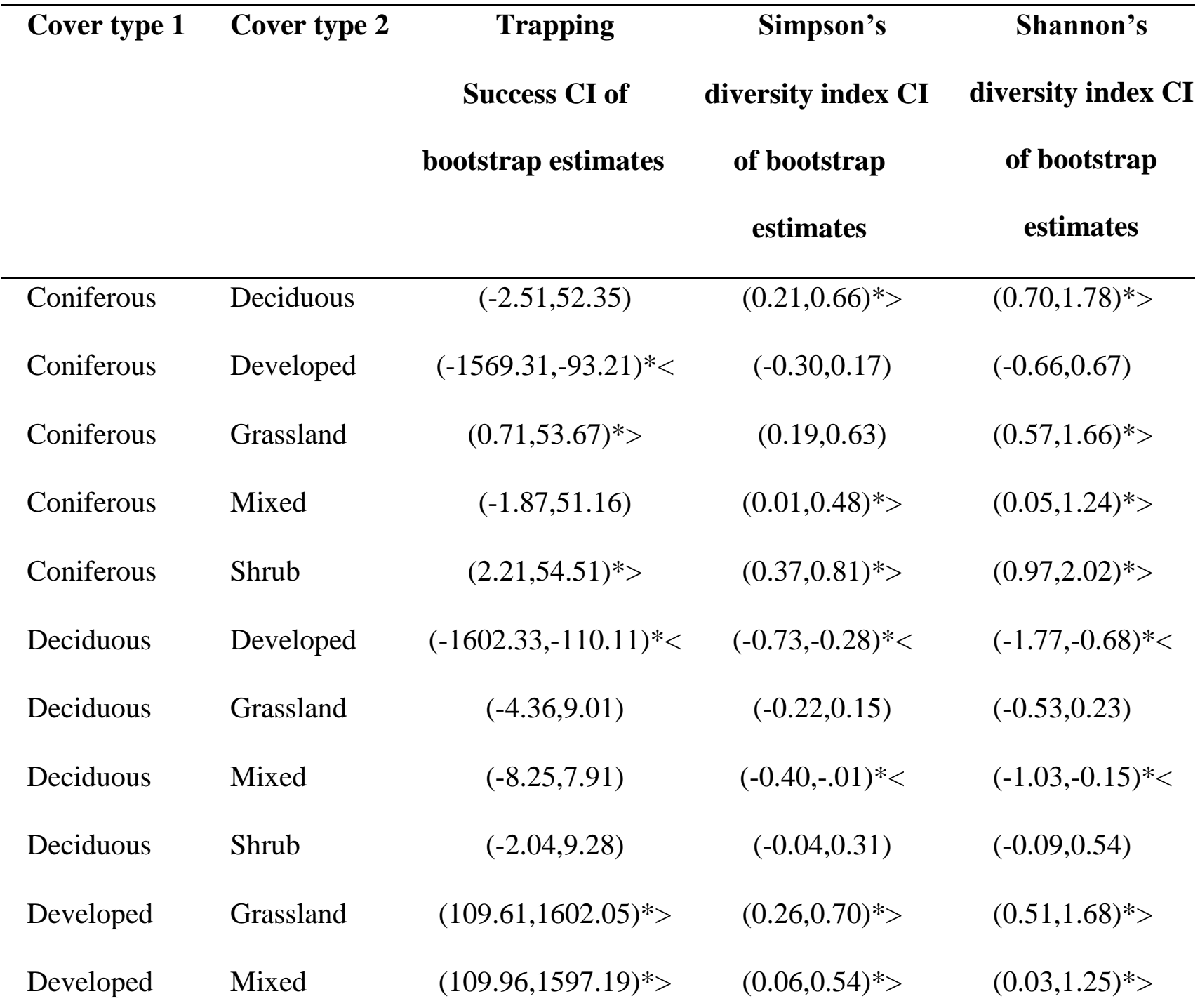




\begin{tabular}{llccc} 
Developed & Shrub & $(111.10,1601.74)^{*>}$ & $(0.44,0.86)^{*>}$ & $(0.90,2.02)^{*>}$ \\
Mixed & Grassland & $(-9.52,4.38)$ & $(-0.38,0.02)$ & $(-0.90,0.02)$ \\
Mixed & Shrub & $(-3.12,5.45)$ & $(-0.01,0.34)$ & $(0.04,0.73)^{*>}$ \\
Shrub & Grassland & $(-2.21,9.95)$ & $(0.16,0.51)^{*>}$ & $(0.44,1.27)^{*>}$ \\
\hline
\end{tabular}


Table 3.16. Jaccard's index of similarity between cover types on Fort Drum Military Installation, New York, 2015-2016.

\begin{tabular}{|c|c|c|c|}
\hline Cover type & Jaccard's & $\%$ similarity & $\%$ dissimilar \\
\hline Developed - Grassland & 0.00 & 0.00 & 100.00 \\
\hline Developed - Mixed & 0.38 & 37.50 & 62.50 \\
\hline Developed - Shrub & 0.67 & 66.67 & 33.33 \\
\hline Developed - Deciduous & 0.67 & 66.67 & 33.33 \\
\hline Developed - Coniferous & 0.57 & 57.14 & 42.86 \\
\hline Mixed - Grassland & 0.00 & 0.00 & 100.00 \\
\hline Mixed - Shrub & 0.57 & 57.14 & 42.86 \\
\hline Mixed - Deciduous & 0.38 & 37.50 & 62.50 \\
\hline Mixed - Coniferous & 0.71 & 71.43 & 28.57 \\
\hline Shrub - Grassland & 0.00 & 0.00 & 100.00 \\
\hline Shrub - Deciduous & 0.43 & 42.86 & 57.14 \\
\hline Shrub - Coniferous & 0.38 & 37.50 & 62.50 \\
\hline Deciduous - Grassland & 0.00 & 0.00 & 100.00 \\
\hline Deciduous - Coniferous & 0.57 & 57.14 & 42.86 \\
\hline Grassland - Coniferous & 0.00 & 0.00 & 100.00 \\
\hline
\end{tabular}


Table 3.17. Individuals with tick burdens and individuals exposed to Borrelia burgdorferi via Lyme-positive tick burdens on Fort Drum Military Installation, New York, during 2015-2016.

\begin{tabular}{|c|c|c|c|c|c|}
\hline & & \# & & & \\
\hline & & Individuals & & & Total \\
\hline & & captured in & & \# & individuals \\
\hline & & cover types & $\%$ of total & Individuals & captured \\
\hline & \# & with & individuals & with a & with tick \\
\hline & Individuals & observed & captured & positive & burden \\
\hline Categorical & with tick & tick & with tick & tick & that is \\
\hline variable & burdens & burdens & burden & burdens & positive \\
\hline \multicolumn{6}{|l|}{ Species } \\
\hline \multicolumn{6}{|l|}{ Peromyscus } \\
\hline sp. & 46 & 79 & $58 \%$ & 18 & $39.13 \%$ \\
\hline Chipmunk & 19 & 59 & $32 \%$ & 15 & $78.95 \%$ \\
\hline \multicolumn{6}{|l|}{ Red } \\
\hline squirrel & 17 & 33 & $52 \%$ & 5 & $29.41 \%$ \\
\hline \multicolumn{6}{|l|}{ Gray } \\
\hline squirrel & 13 & 18 & $72 \%$ & 4 & $30.77 \%$ \\
\hline \multicolumn{6}{|l|}{ Cover Type } \\
\hline Coniferous & 23 & 45 & $51 \%$ & 8 & $34.78 \%$ \\
\hline Deciduous & 13 & 24 & $54 \%$ & 8 & $61.54 \%$ \\
\hline Developed & 47 & 90 & $52 \%$ & 21 & $44.68 \%$ \\
\hline
\end{tabular}




\begin{tabular}{cccccc} 
Mixed & 8 & 11 & $73 \%$ & 4 & $50.00 \%$ \\
Shrub & 4 & 19 & $21 \%$ & 1 & $25.00 \%$ \\
Total & 95 & 189 & $50 \%$ & 42 & $44.21 \%$ \\
\hline
\end{tabular}


Table 3.18. Model parameter estimates for binomial models of estimated index of abundance of individuals with tick burdens (T) on Fort Drum Military Installation, New York, 2015-2016 within $\triangle \mathrm{AICc}$ of 2 used in model averaging to determine the final model. Parameter estimates $(\beta)$ are presented with standard errors (SE) as well as $\mathrm{Z}$ and $\mathrm{p}(\mathrm{Pr})$ values.

\begin{tabular}{llcccc}
\hline Model & Parameter & $\boldsymbol{\beta}$ & $\mathbf{S E}$ & $\mathbf{Z}$ value & $\operatorname{Pr}(>|\mathbf{z}|)$ \\
\hline $\mathrm{T}(\sim$ host+ct $)$ & Intercept & 0.02 & 0.37 & 0.07 & 0.95 \\
& gray squirrel & 0.58 & 0.58 & 1.00 & 0.32 \\
& red squirrel & -0.44 & 0.45 & -0.99 & 0.32 \\
chipmunk & -0.97 & 0.42 & -2.32 & 0.02 \\
& Deciduous & 0.20 & 0.55 & 0.36 & 0.72 \\
& Developed & 0.56 & 0.42 & 1.31 & 0.19 \\
& Mixed & 1.69 & 0.88 & 1.93 & 0.05 \\
& Shrub & -0.87 & 0.68 & -1.30 & 0.20 \\
\hline
\end{tabular}


Table 3.19. Model parameter estimates for binomial models of estimated index of abundance of individuals with Lyme-positive tick burdens (B.burg) on Fort Drum Military Installation, New York, 2015-2016 within $\triangle \mathrm{AICc}$ of 2 used in model averaging to determine the final model.

Parameter estimates $(\beta)$ are presented with standard errors (SE) as well as $\mathrm{Z}$ and $\mathrm{p}(\mathrm{Pr})$ values.

\begin{tabular}{llcccc}
\hline Model & Parameter & $\boldsymbol{\beta}$ & $\mathbf{S E}$ & $\mathbf{Z}$ value & $\operatorname{Pr}(>|\mathbf{z}|)$ \\
\hline B.burg( host+ct) & Intercept & -1.42 & 0.84 & -1.69 & 0.09 \\
& gray squirrel & -16.15 & 1769.26 & -0.01 & 0.99 \\
& red squirrel & 0.24 & 1.05 & 0.23 & 0.82 \\
& chipmunk & 1.03 & 0.88 & 1.16 & 0.24 \\
& Deciduous & 1.17 & 1.09 & 1.07 & 0.28 \\
& Developed & 1.02 & 1.01 & 1.01 & 0.31 \\
& Mixed & 1.49 & 1.57 & 0.95 & 0.34 \\
& Shrub & 17.96 & 3956.18 & 0.01 & 0.10 \\
& & & & \\
\hline
\end{tabular}


Table 3.20. Parametric bootstrapped estimates of number of tick burdens and Lyme-positive tick burdens off host species from a generalized linear Poisson and binomial model respectively on Fort Drum Military Installation, New York, 2015-2016. Statistical significance with a 95\% confidence interval estimated by bootstrapping is noted by an asterisk (alpha=0.05). The symbol > indicates the item in the column on the left is significantly greater than the item in the column on the right. The symbol < indicates the item in the column on the right is significantly greater than the item in the column on the left.

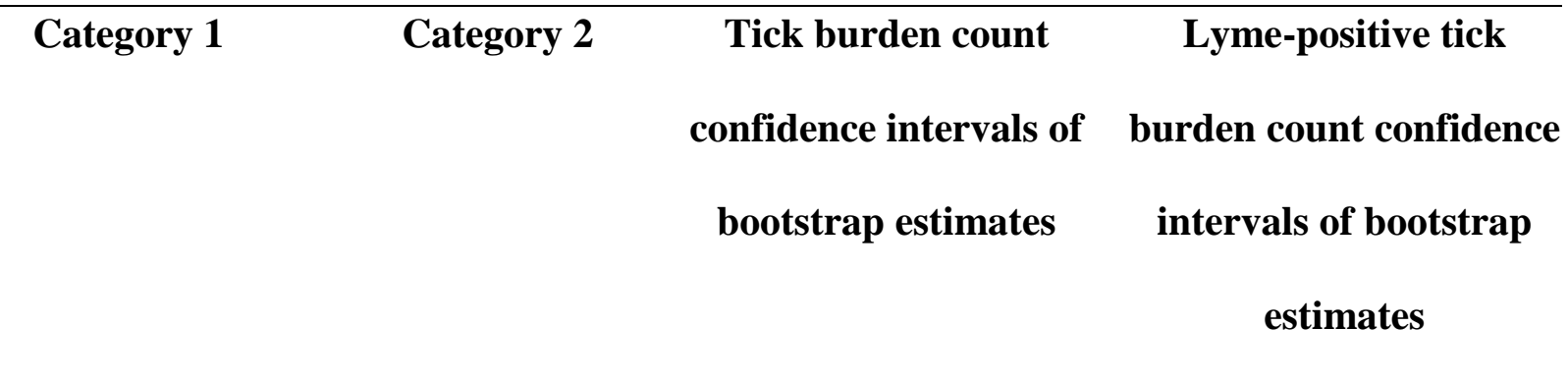

Cover type

$\begin{array}{llll}\text { Coniferous } & \text { Deciduous } & (-1.70,0.10) & (-1.18,0.18) \\ \text { Coniferous } & \text { Developed } & (-2.37,0.37) & (-0.22,0.38) \\ \text { Coniferous } & \text { Mixed } & (-24.99,0.18) & (-0.51,0.38) \\ \text { Coniferous } & \text { Shrub } & (-0.43,1.68) & (-0.75,0.52) \\ \text { Deciduous } & \text { Developed } & (-2.20,1.11) & (-0.03,1.20) \\ \text { Deciduous } & \text { Mixed } & (-25.20,0.69) & (-0.22,1.12) \\ \text { Deciduous } & \text { Shrub } & (-0.30,2.33) & (-0.50,1.25) \\ \text { Developed } & \text { Mixed } & (-23.36,0.92) & (-0.49,0.22) \\ \text { Developed } & \text { Shrub } & (0.24,2.96)^{*>} & (-0.77,0.37) \\ \text { Mixed } & \text { Shrub } & (0.35,25.69)^{*>} & (-0.75,0.62)\end{array}$




\section{Species}

\begin{tabular}{llll} 
Peromyscus sp. & Gray squirrel & $(-3.53,0.64)$ & $(-0.49,0.40)$ \\
Peromyscus sp. & Red squirrel & $(-0.46,1.38)$ & $(-1.51,0.01)$ \\
Peromyscus sp. & Chipmunk & $(0.06,1.50)^{*>}$ & $(-3.81,-0.28)^{*<}$ \\
Gray squirrel & Red squirrel & $(-0.18,3.81)$ & $(-1.72,0.18)$ \\
Gray squirrel & Chipmunk & $(0.20,4.19)^{*>}$ & $(-3.98,-0.13)^{*<}$ \\
Red squirrel & Chipmunk & $(-0.23,1.02)$ & $(-3.10,0.20)$ \\
\hline
\end{tabular}


Table 3.21. Summary statistics of small mammal captured individuals on Fort Drum Military

Installation, New York, during 2015-2016.

\begin{tabular}{|c|c|c|c|c|c|c|c|}
\hline & $\begin{array}{l}\text { Deciduous } \\
\text { forest }\end{array}$ & Developed & $\begin{array}{l}\text { Coniferous } \\
\text { forest }\end{array}$ & Grassland & $\begin{array}{l}\text { Mixed } \\
\text { forest }\end{array}$ & Shrub & Total \\
\hline \multicolumn{8}{|l|}{ Peromyscus } \\
\hline $\mathrm{sp}$. & 21 & 25 & 20 & 0 & 6 & 7 & 79 \\
\hline Chipmunk & 2 & 42 & 3 & 0 & 3 & 9 & 59 \\
\hline \multicolumn{8}{|l|}{ Red } \\
\hline squirrel & 0 & 18 & 10 & 0 & 2 & 3 & 33 \\
\hline \multicolumn{8}{|l|}{ Gray } \\
\hline squirrel & 1 & 5 & 12 & 0 & 0 & 0 & 18 \\
\hline \multicolumn{8}{|l|}{ Meadow } \\
\hline vole & 0 & 0 & 0 & 6 & 0 & 0 & 6 \\
\hline \multicolumn{8}{|l|}{ Short-tailed } \\
\hline shrew & 0 & 0 & 1 & 0 & 1 & 1 & 3 \\
\hline \multicolumn{8}{|l|}{ Long-tailed } \\
\hline weasel & 0 & 0 & 0 & 0 & 1 & 2 & 3 \\
\hline \multicolumn{8}{|l|}{ S. flying } \\
\hline squirrel & 1 & 0 & 2 & 0 & 0 & 0 & 3 \\
\hline \multicolumn{8}{|l|}{ Striped } \\
\hline skunk & 1 & 1 & 0 & 0 & 0 & 1 & 3 \\
\hline \multicolumn{8}{|l|}{ Meadow } \\
\hline jumping & & & & & & & \\
\hline
\end{tabular}


mouse

0

Total

26

91

48

8

13

23

209 
Table 3.22. Summary statistics of Lyme-disease apparent prevalence from ear punch samples on Fort Drum Military Installation, New York, during 2016.

\begin{tabular}{|c|c|c|c|}
\hline Categorical variable & $\begin{array}{l}\text { No. individuals } \\
\text { positive for } B \text {. } \\
\text { burgdorferi }\end{array}$ & No. total individuals & Infection rate \\
\hline \multicolumn{4}{|l|}{ Cover type } \\
\hline Coniferous & 5 & 27 & $18.52 \%$ \\
\hline Deciduous & 4 & 13 & $30.77 \%$ \\
\hline Developed & 22 & 52 & $42.31 \%$ \\
\hline Grassland & 3 & 6 & $50.00 \%$ \\
\hline Mixed & 2 & 8 & $25.00 \%$ \\
\hline Shrub & 5 & 9 & $55.56 \%$ \\
\hline \multicolumn{4}{|l|}{ Species } \\
\hline Peromyscus sp. & 15 & 49 & $30.61 \%$ \\
\hline Chipmunk & 15 & 26 & $57.69 \%$ \\
\hline Red squirrel & 6 & 17 & $35.29 \%$ \\
\hline Gray squirrel & 2 & 15 & $13.33 \%$ \\
\hline Meadow vole & 3 & 4 & $75.00 \%$ \\
\hline Flying squirrel & 0 & 2 & $0.00 \%$ \\
\hline \multicolumn{4}{|l|}{ Meadow jumping } \\
\hline mouse & 0 & 2 & $0.00 \%$ \\
\hline Total & 41 & 115 & $35.65 \%$ \\
\hline
\end{tabular}


Table 3.23. Model parameter estimates for binomial models of estimated index of abundance of individuals with Lyme-positive ear punches (EP) on Fort Drum Military Installation, New York, 2016 within $\triangle \mathrm{AICc}$ of 2 used in model averaging to determine the final model. Parameter estimates $(\beta)$ are presented with standard errors (SE) as well as $\mathrm{Z}$ and $\mathrm{p}(\mathrm{Pr})$ values.

\begin{tabular}{lllccc}
\hline Model & Parameter & $\boldsymbol{\beta}$ & SE & Z value & $\operatorname{Pr}(>|\mathbf{z}|)$ \\
\hline EP( host+ct $)$ & Intercept & -1.15 & 0.60 & -1.92 & 0.06 \\
& gray squirrel & -0.85 & 0.88 & -0.97 & 0.33 \\
& red squirrel & 0.23 & 0.63 & 0.36 & 0.72 \\
& chipmunk & 1.04 & 0.61 & 1.71 & 0.09 \\
& Deciduous & 0.34 & 0.85 & 0.40 & 0.69 \\
& Developed & 0.37 & 0.66 & 0.57 & 0.57 \\
& Mixed & -0.01 & 0.99 & -0.01 & 1.00 \\
& Shrub & 1.11 & 0.88 & 1.26 & 0.21 \\
\hline
\end{tabular}


Table 3.24. Parametric bootstrapped estimates of Lyme-positive ear punches of host species from a generalized linear binomial model on Fort Drum Military Installation, New York, 2016.

Statistical significance with a $95 \%$ confidence interval estimated by bootstrapping is noted by an asterisk (alpha $=0.05)$. The symbol $>$ indicates the item in the column on the left is significantly greater than the item in the column on the right. The symbol < indicates the item in the column on the right is significantly greater than the item in the column on the left.

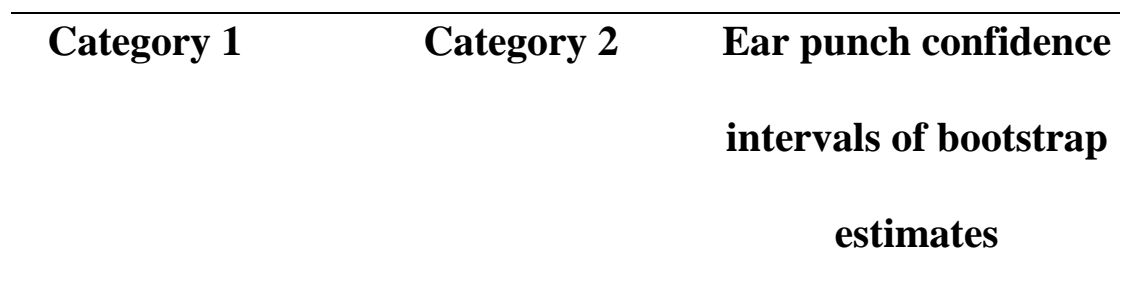

Cover type

Coniferous

Deciduous

$(-1.25,0.59)$

Coniferous

Developed

$(-0.80,0.47)$

Coniferous

Mixed

$(-1.22,0.73)$

Coniferous

Shrub

$(-3.61,0.32)$

Deciduous

Developed

$(-0.77,1.11)$

Deciduous

Mixed

Deciduous

Shrub

Developed

Mixed

Developed

Shrub

Mixed

Shrub

$(-3.81,0.70)$

Species

Peromyscus sp. Gray squirrel

$(-0.31,0.81)$

Peromyscus sp. Red squirrel

$(-1.09,0.43)$ 
Peromyscus sp. Chipmunk (-3.15,0.06)

Gray squirrel Red squirrel $\quad(-1.54,0.34)$

Gray squirrel Chipmunk $\quad(-3.63,0.03)$

Red squirrel Chipmunk $\quad(-2.91,0.32)$ 


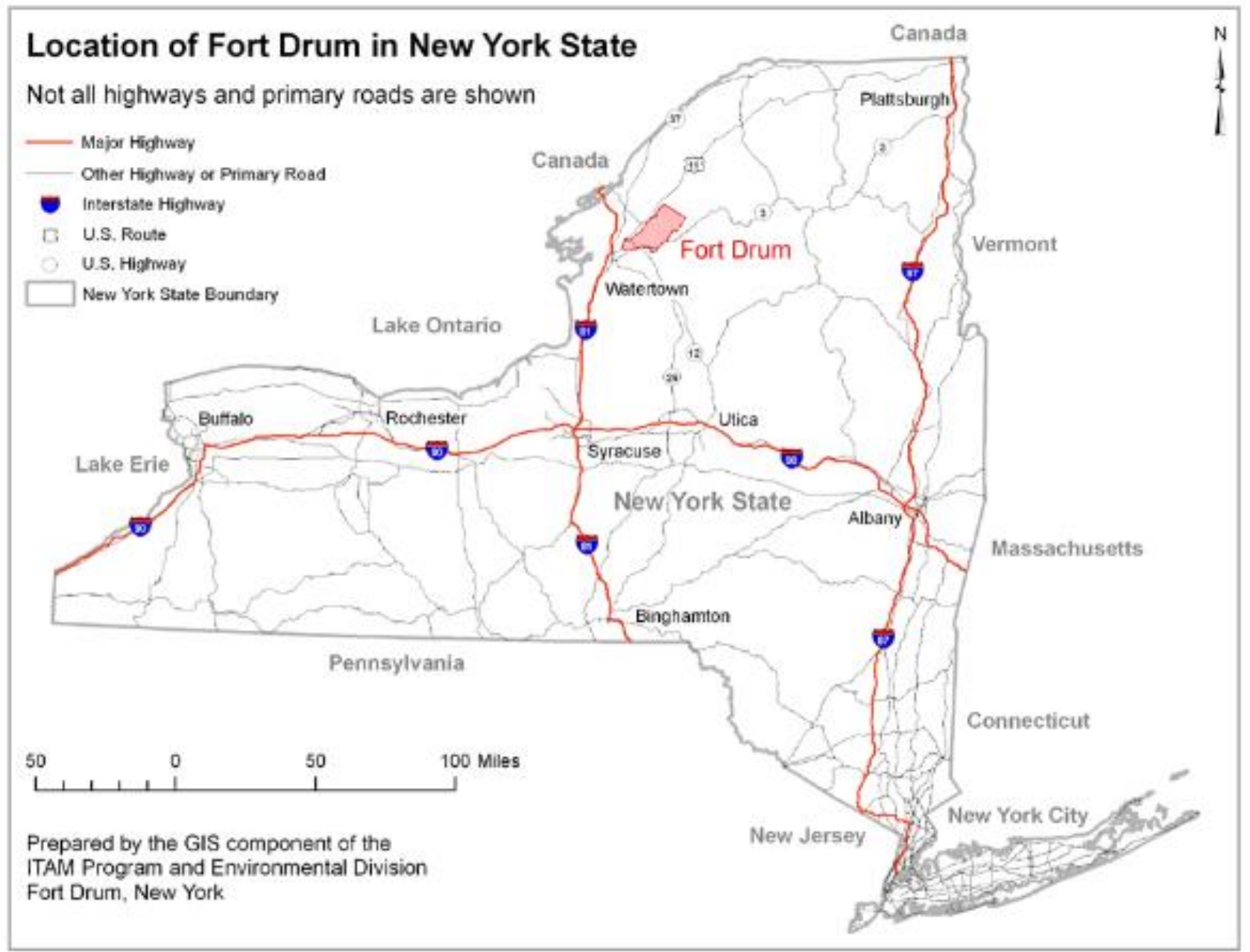

Figure 1.1. Fort Drum Military Installation located in Jefferson County in northwestern New York. 


\section{Cover types of Fort Drum Military Installation, New York}
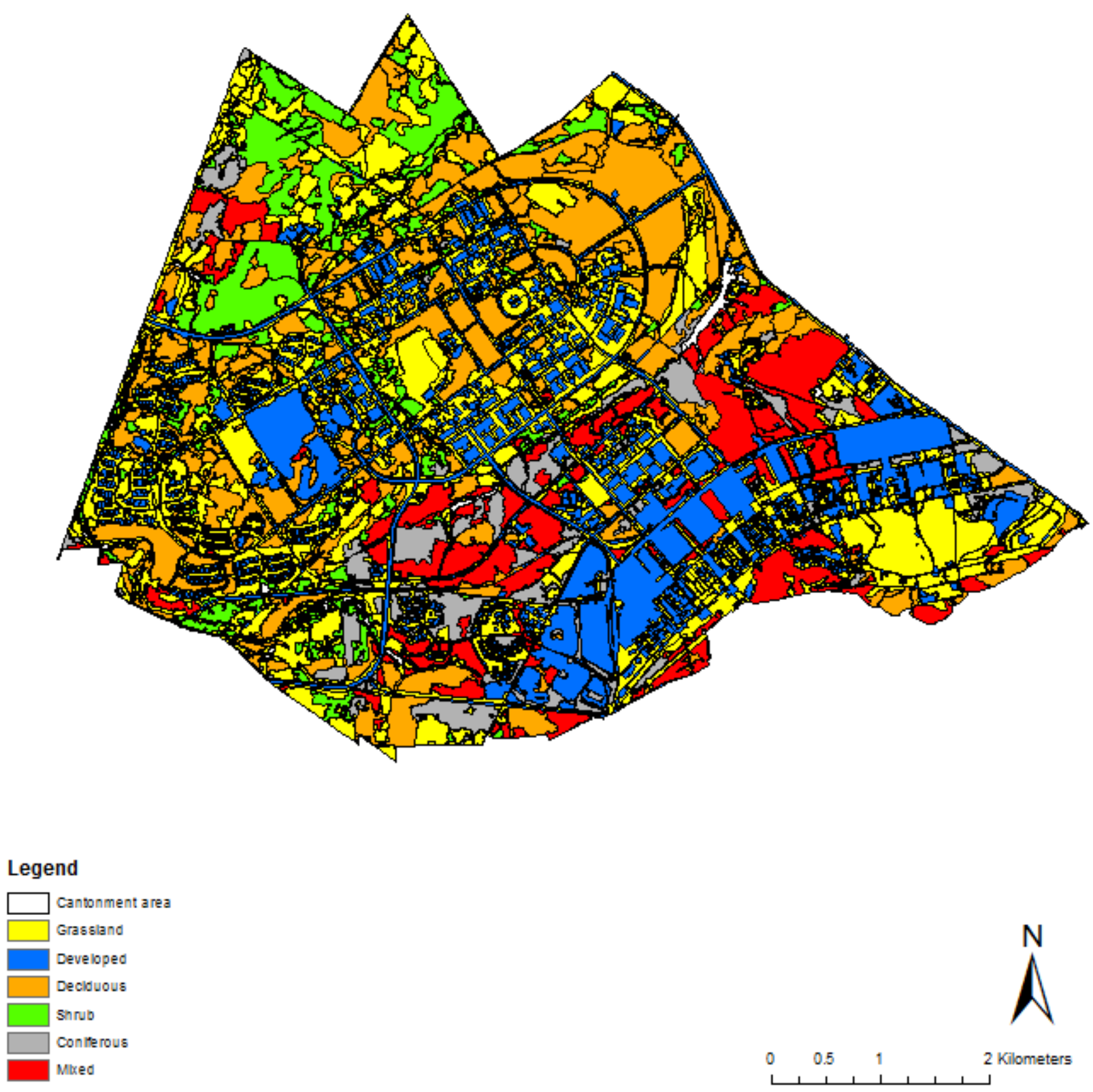

Figure 1.2. Cover types within the Cantonment Area of Fort Drum Military Installation, New York. Approximations of area are as follows: Deciduous $=752$ ha, Developed $=1277$ ha, Coniferous $=$ 200 ha, Grassland = 1221 ha, Mixed = 364 ha, Shrub = 312 ha. 


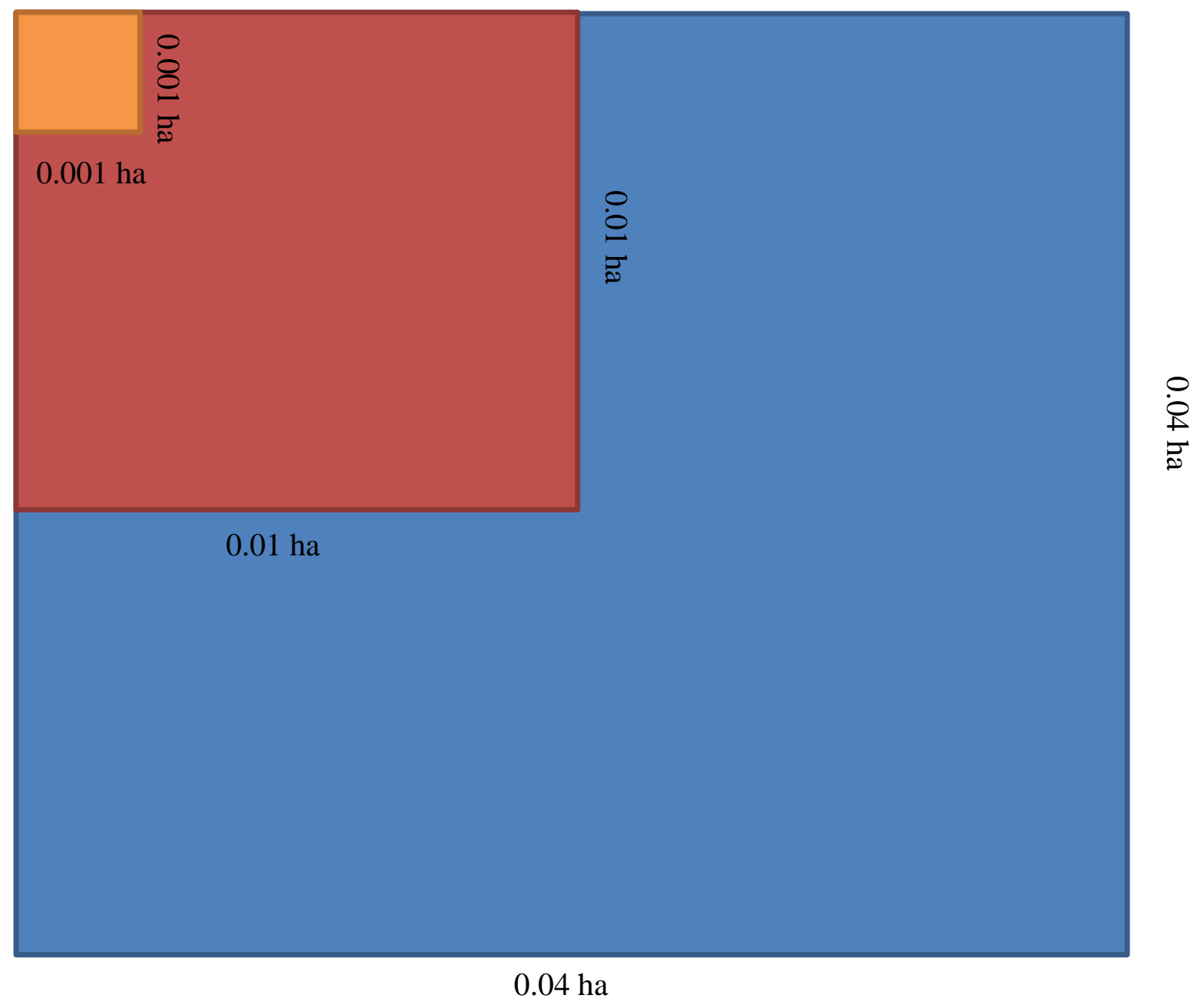

Figure 2.1. A vegetation survey plot on Fort Drum Military Installation, New York. 


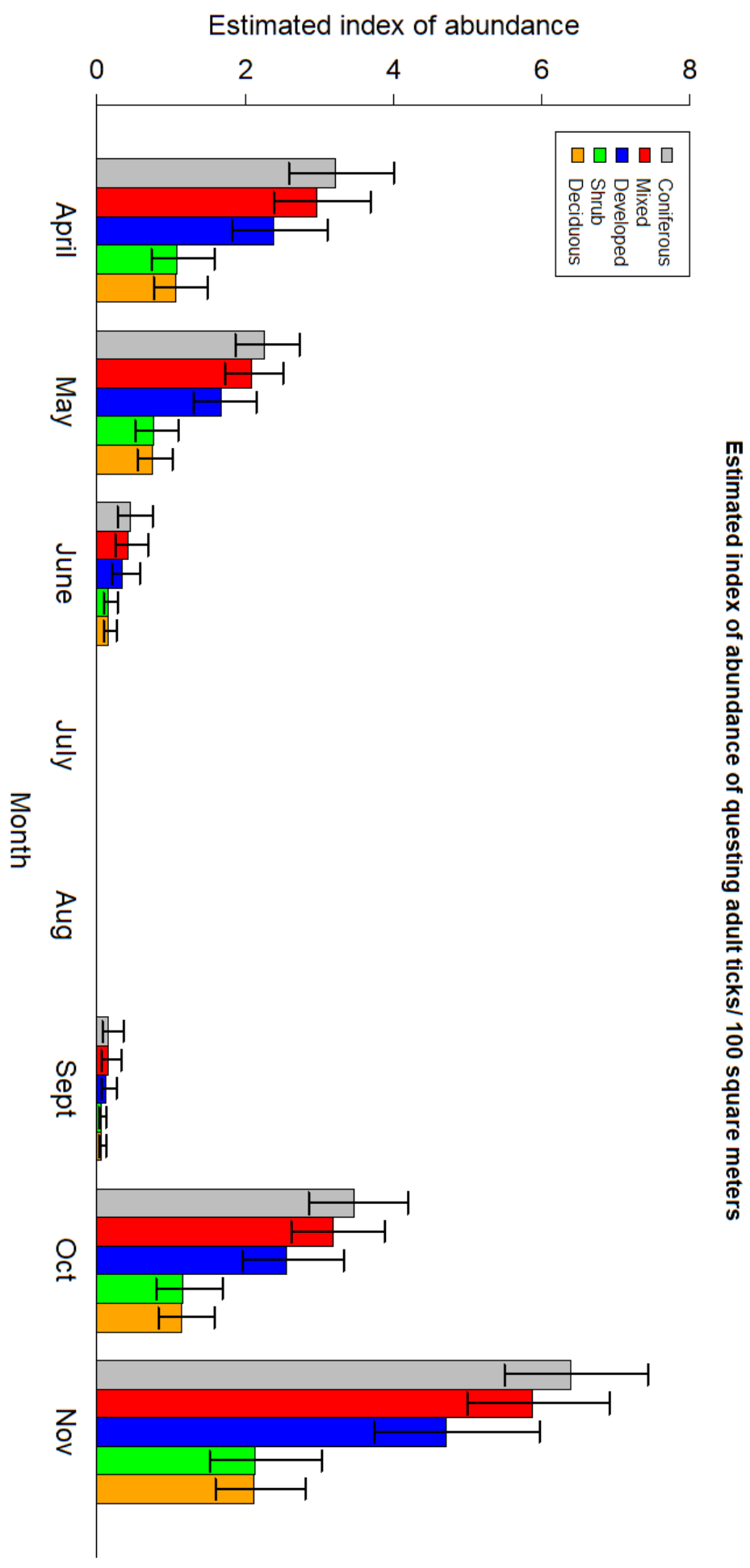

Figure 2.2. Estimated index of abundance of questing adult ticks with a $95 \%$ confidence interval on Fort Drum Military Installation, New York, during April-November, 2015-2016. 


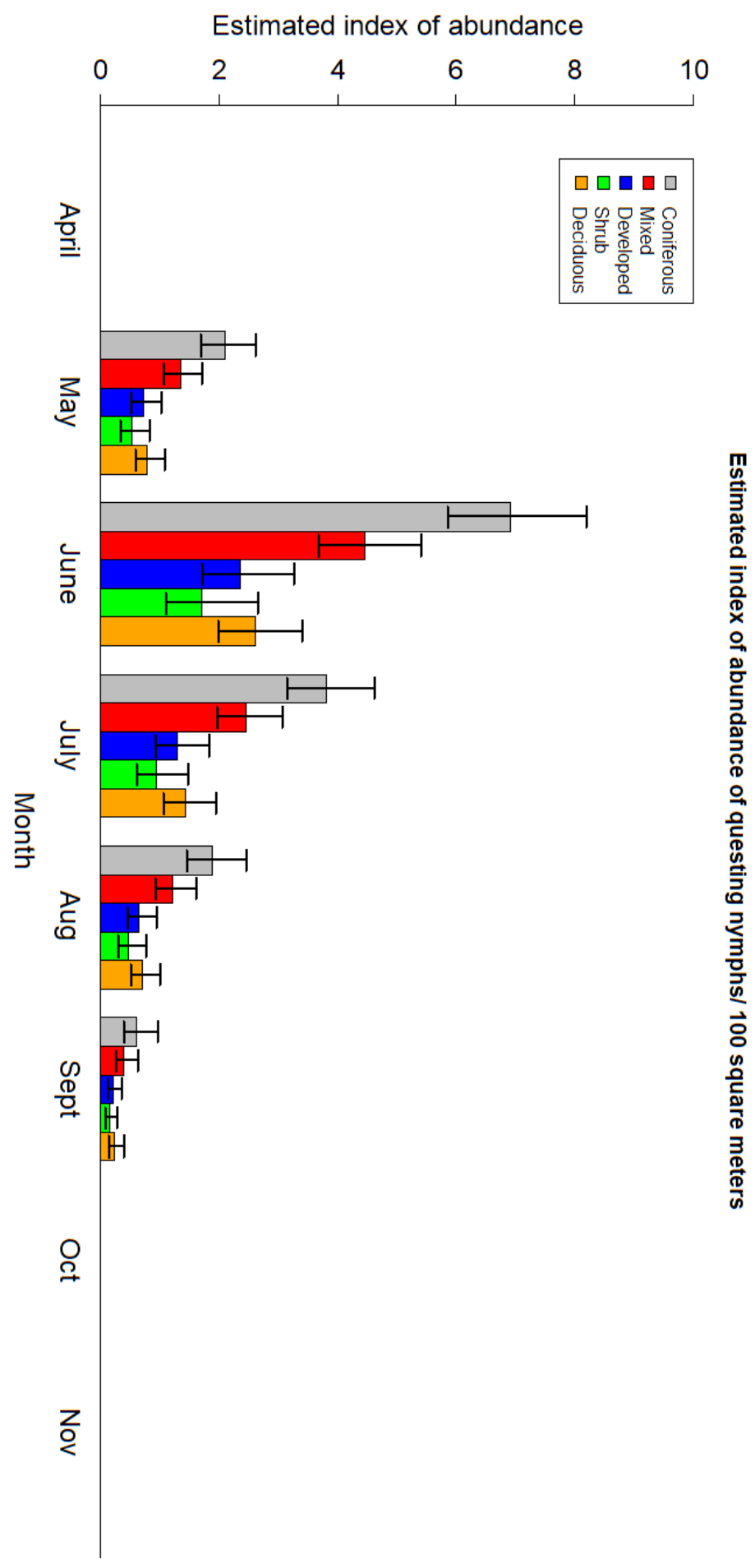

Figure 2.3. Estimated index of abundance of questing nymphal ticks with a $95 \%$ confidence interval on Fort Drum Military Installation, New York, during April-November, 2015-2016. 


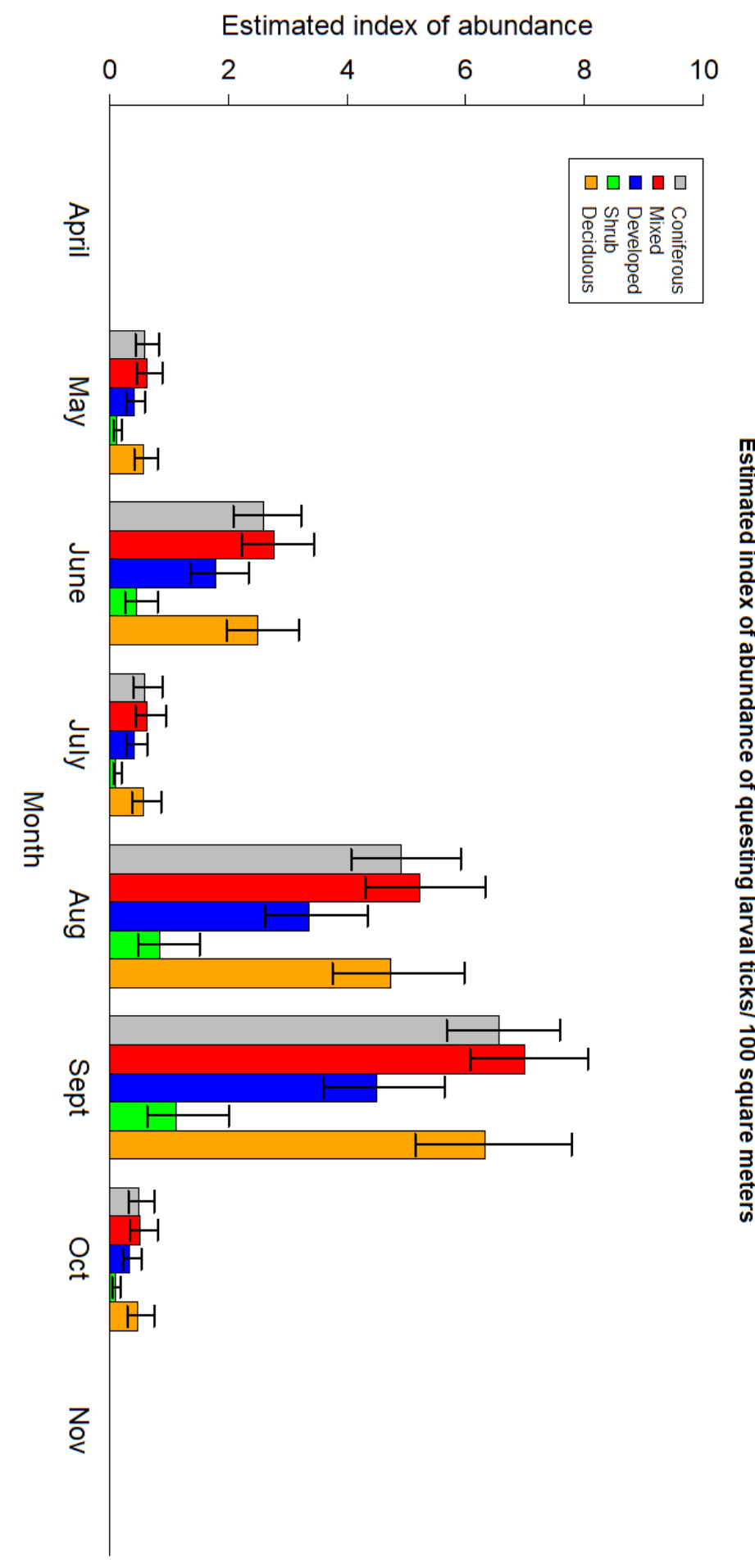

Figure 2.4. Estimated index of abundance of questing larval ticks with a $95 \%$ confidence interval on Fort Drum Military Installation, New York, during April-November, 2015-2016. 


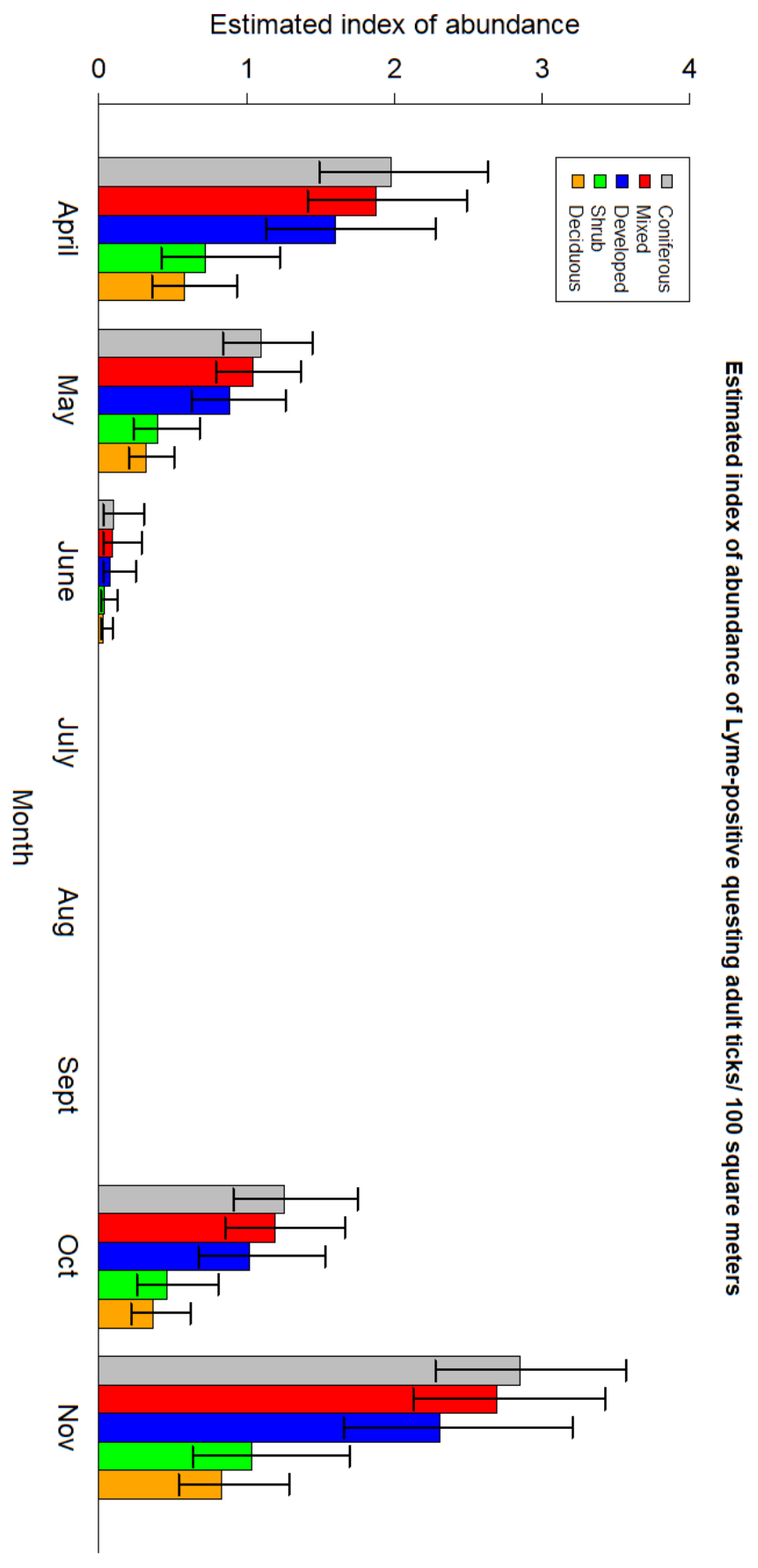

Figure 2.5. Estimated index of abundance of $B$. burgdorferi-positive questing adult ticks with a 95\% confidence interval on Fort Drum Military Installation, New York, during April-November, 2015-2016. 


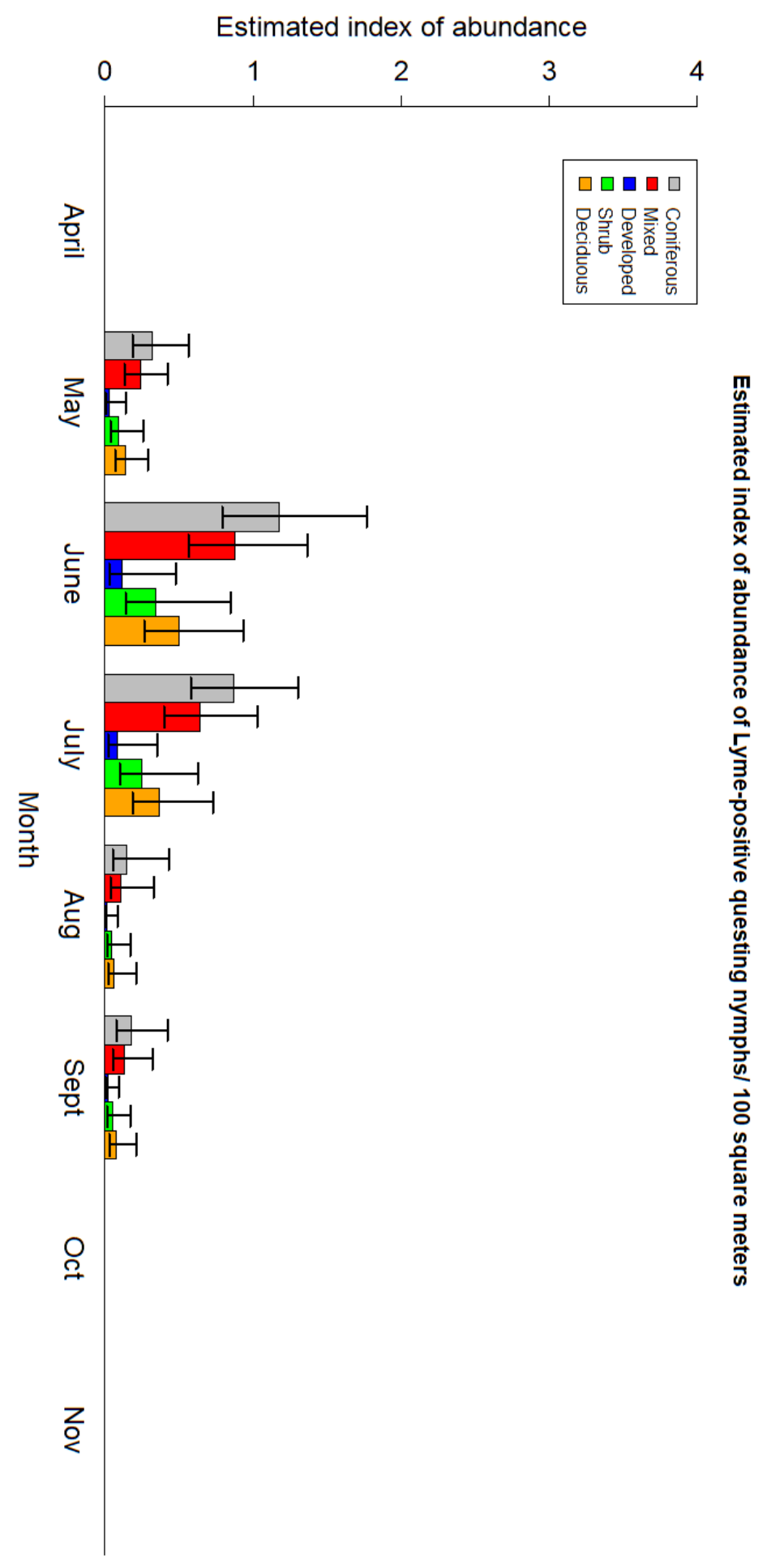

Figure 2.6. Estimated index of abundance of B. burgdorferi-positive questing nymphal ticks with a 95\% confidence interval on Fort Drum Military Installation, New York, during April-November, 2015-2016. 


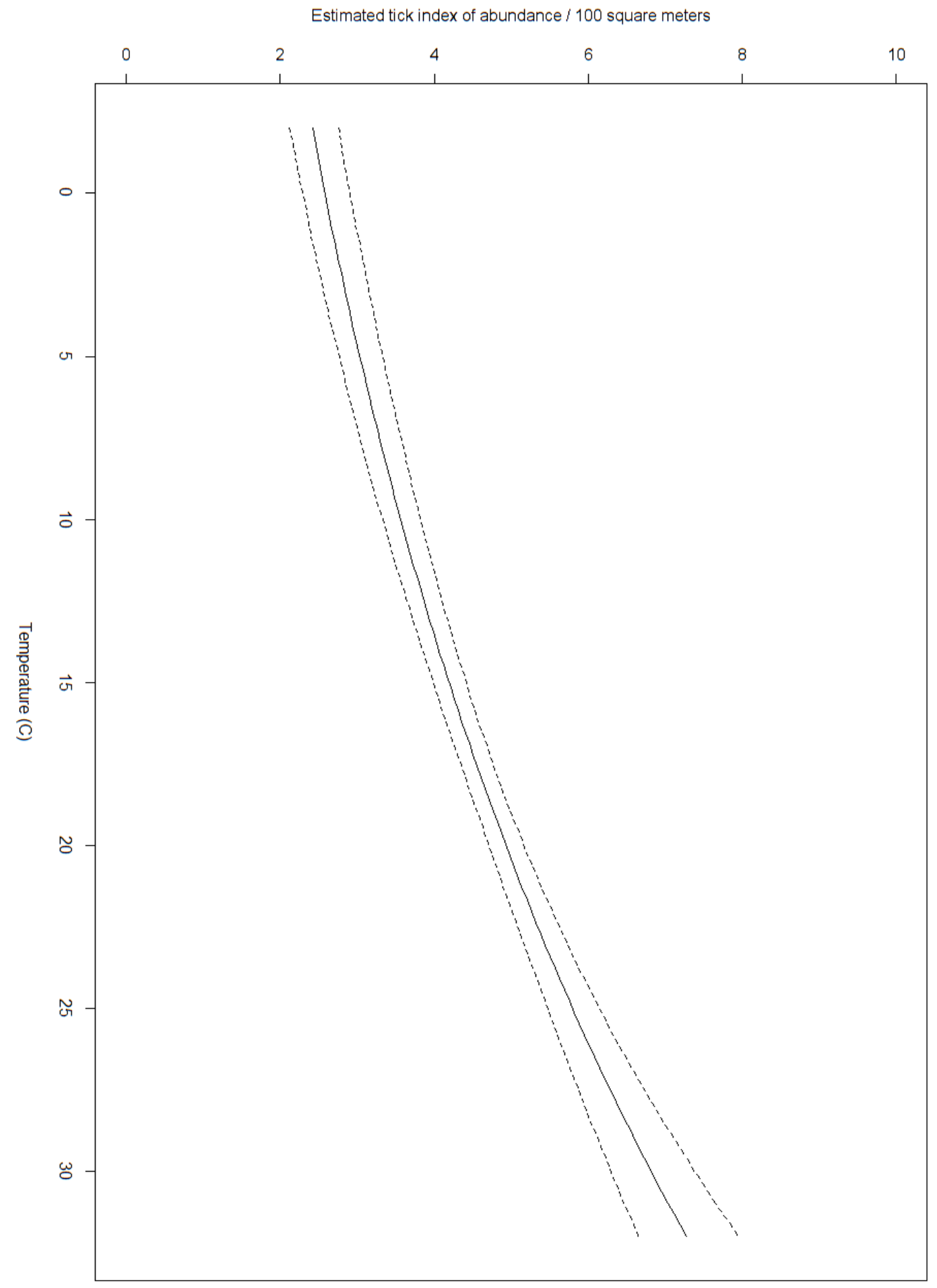

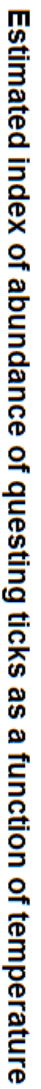

Figure 2.7. Estimated index of abundance of ticks related to temperature with a $95 \%$ confidence interval on Fort Drum Military Installation, New York, during April-November, 2015-2016. 


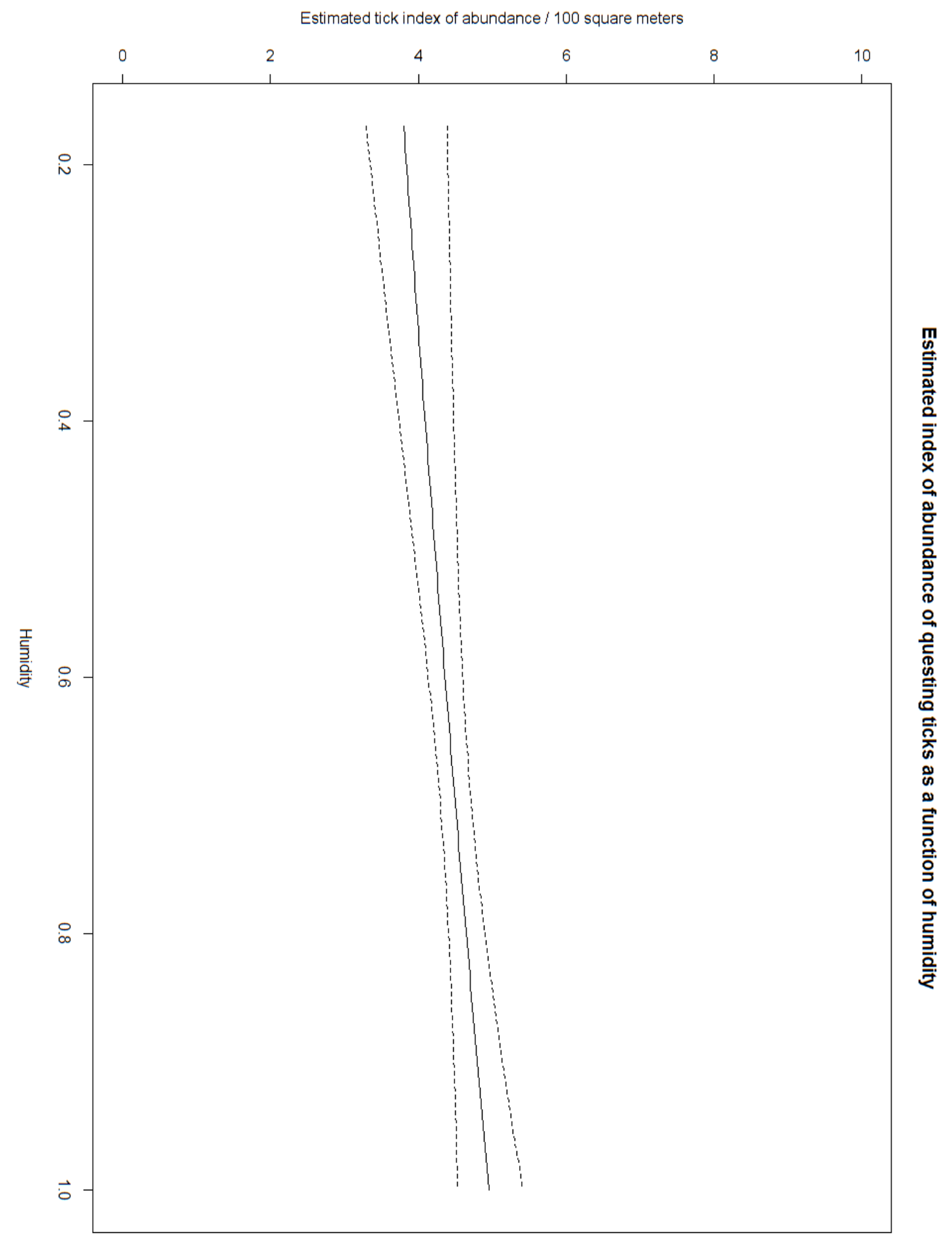

Figure 2.8. Estimated index of abundance of ticks related to relative humidity with a $95 \%$ confidence interval on Fort Drum Military Installation, New York, during April-November, 20152016. 


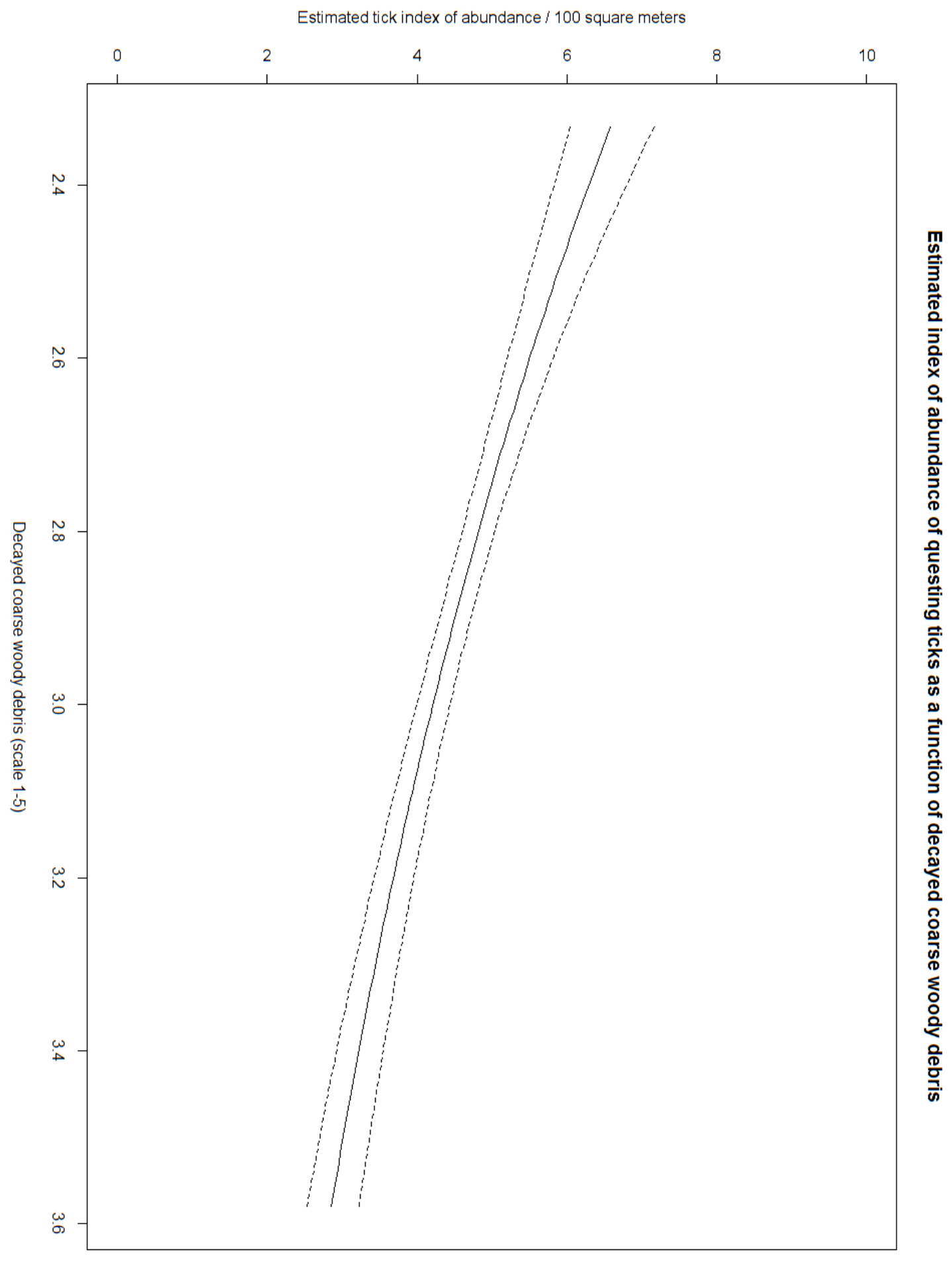

Figure 2.9. Estimated index of abundance of ticks related to coarse woody debris decay with a 95\% confidence interval on Fort Drum Military Installation, New York, during April-November, 2015-2016. 


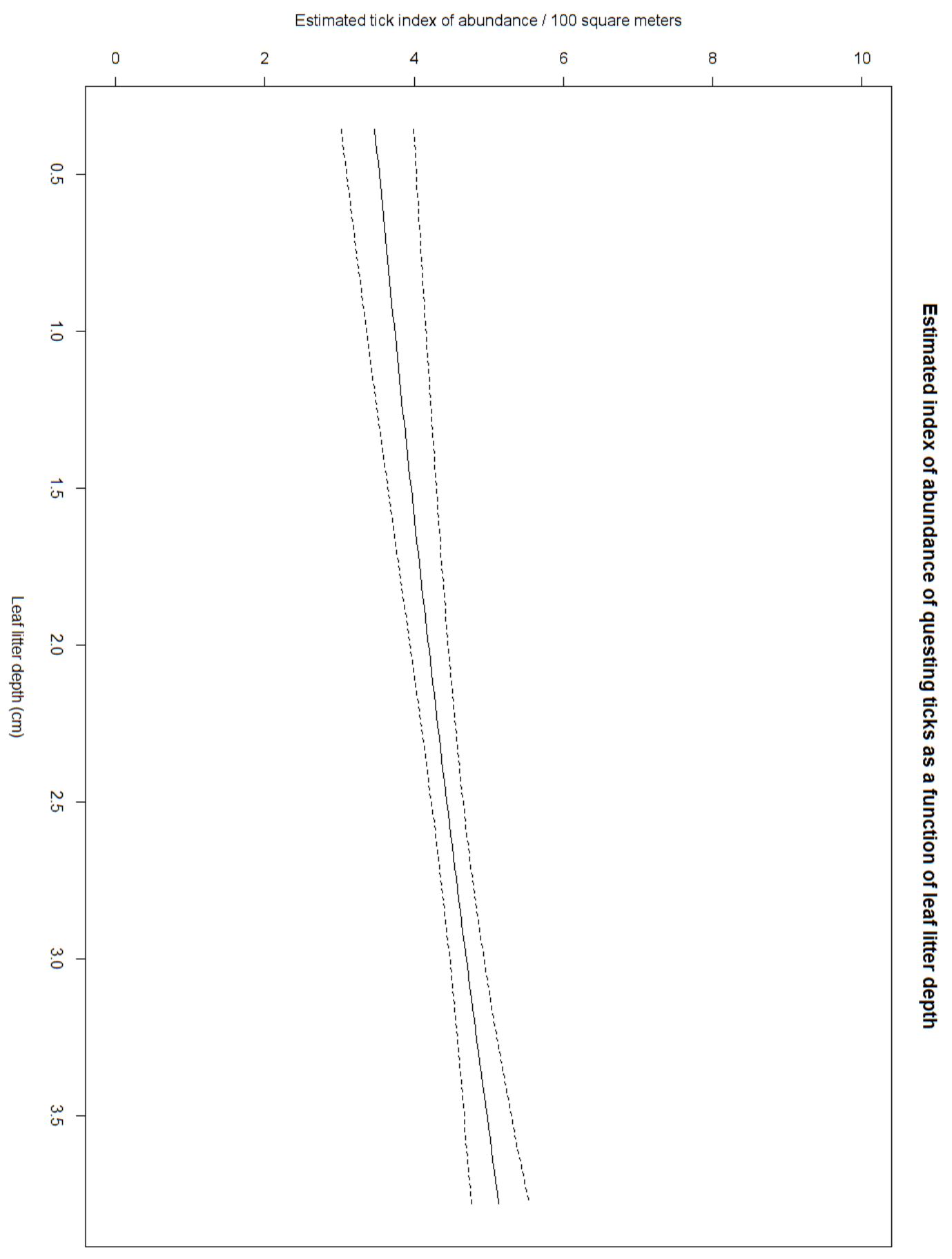

Figure 2.10. Estimated index of abundance of ticks related to leaf litter depth with a $95 \%$ confidence interval on Fort Drum Military Installation, New York, during April-November, 20152016. 


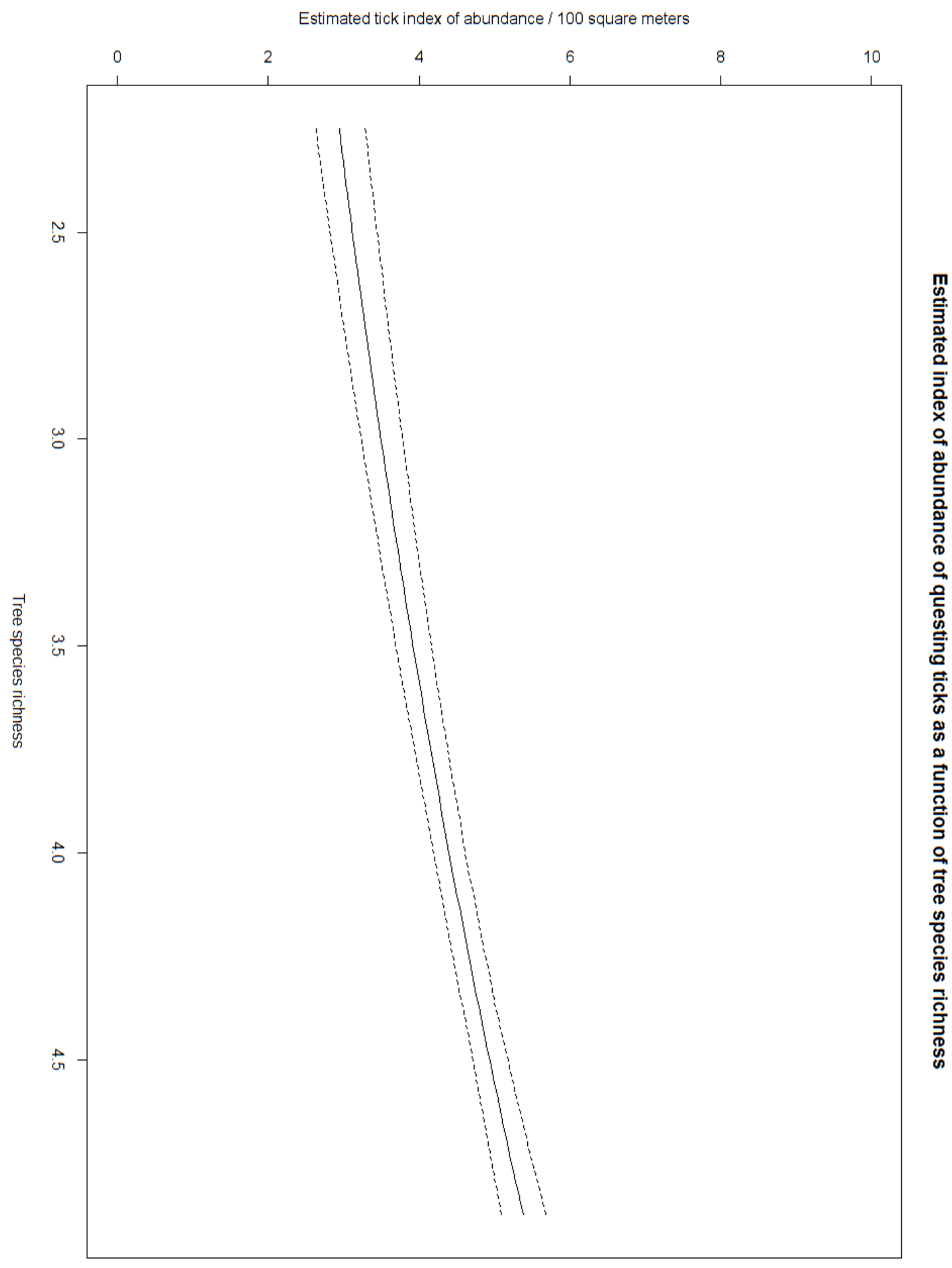

Figure 2.11. Estimated index of abundance of ticks related to tree species richness with a $95 \%$ confidence interval on Fort Drum Military Installation, New York, during April-November, 20152016. 


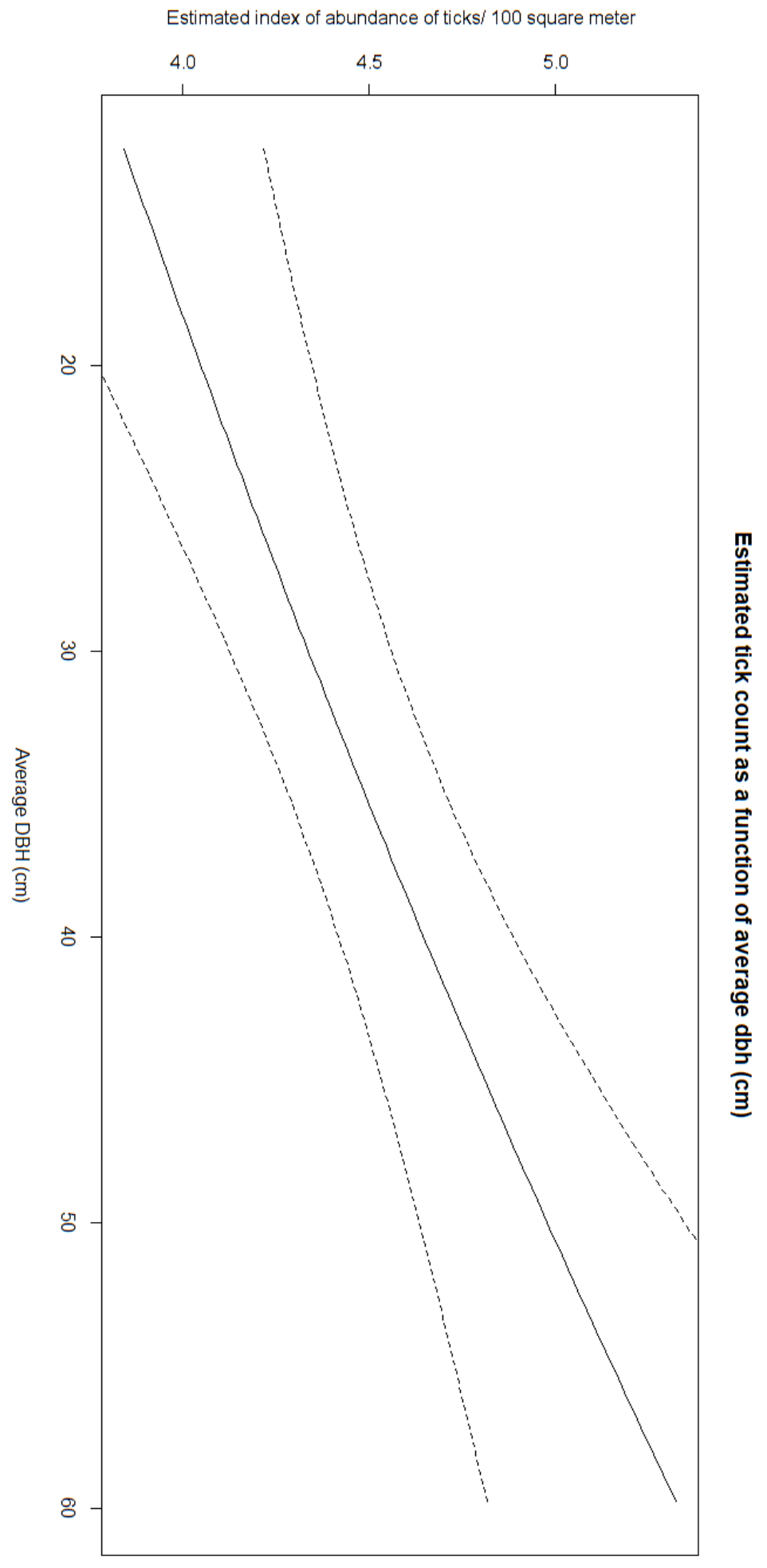

Figure 2.12. Estimated index of abundance of ticks related to $\mathrm{dbh}(\mathrm{cm})$ with a $95 \%$ confidence interval on Fort Drum Military Installation, New York, during April-November, 2015-2016. 


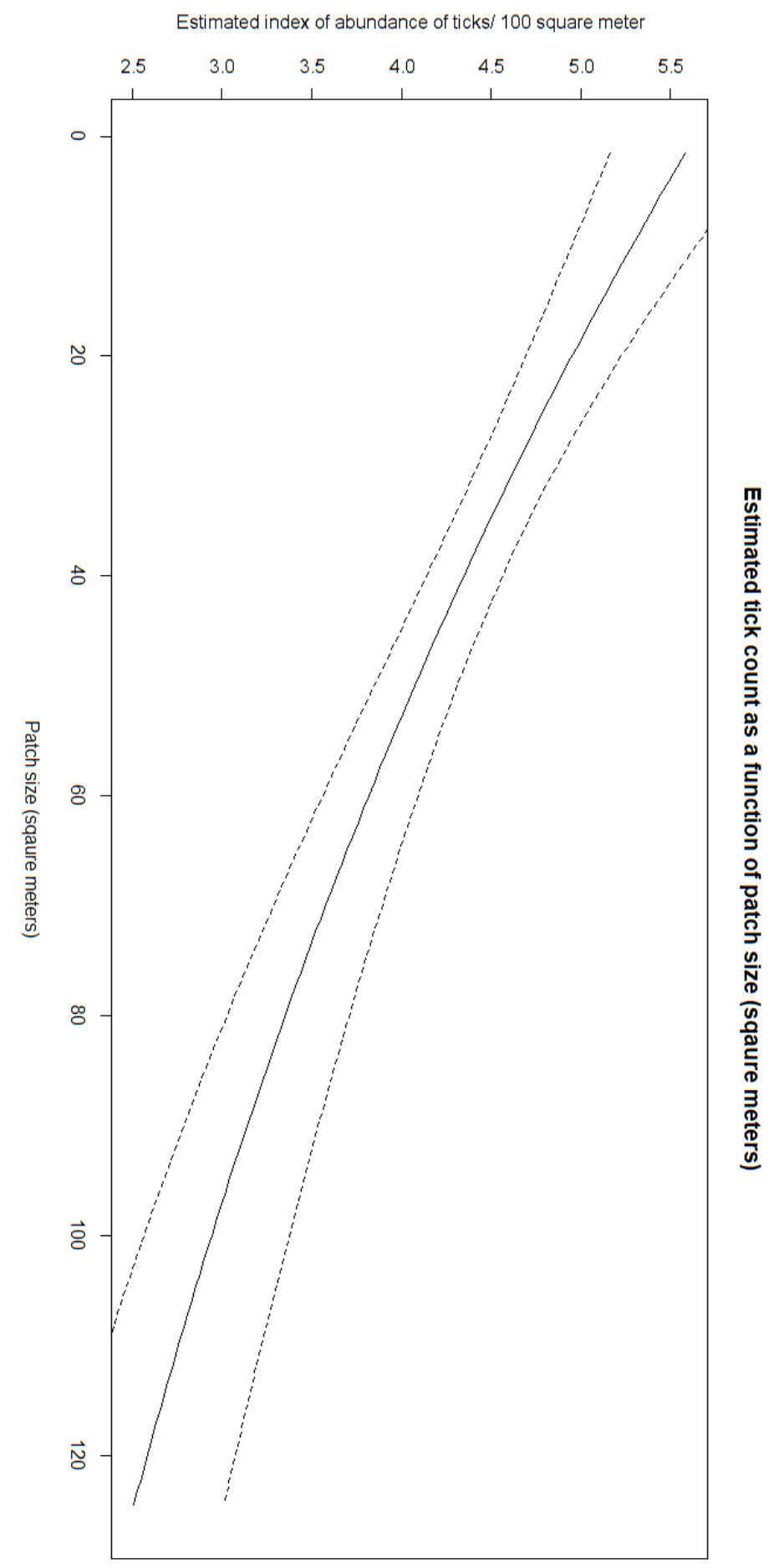

Figure 2.13. Estimated index of abundance of ticks related to patch size $\left(\mathrm{m}^{2}\right)$ with a $95 \%$ confidence interval on Fort Drum Military Installation, New York, during April-November, 20152016. 


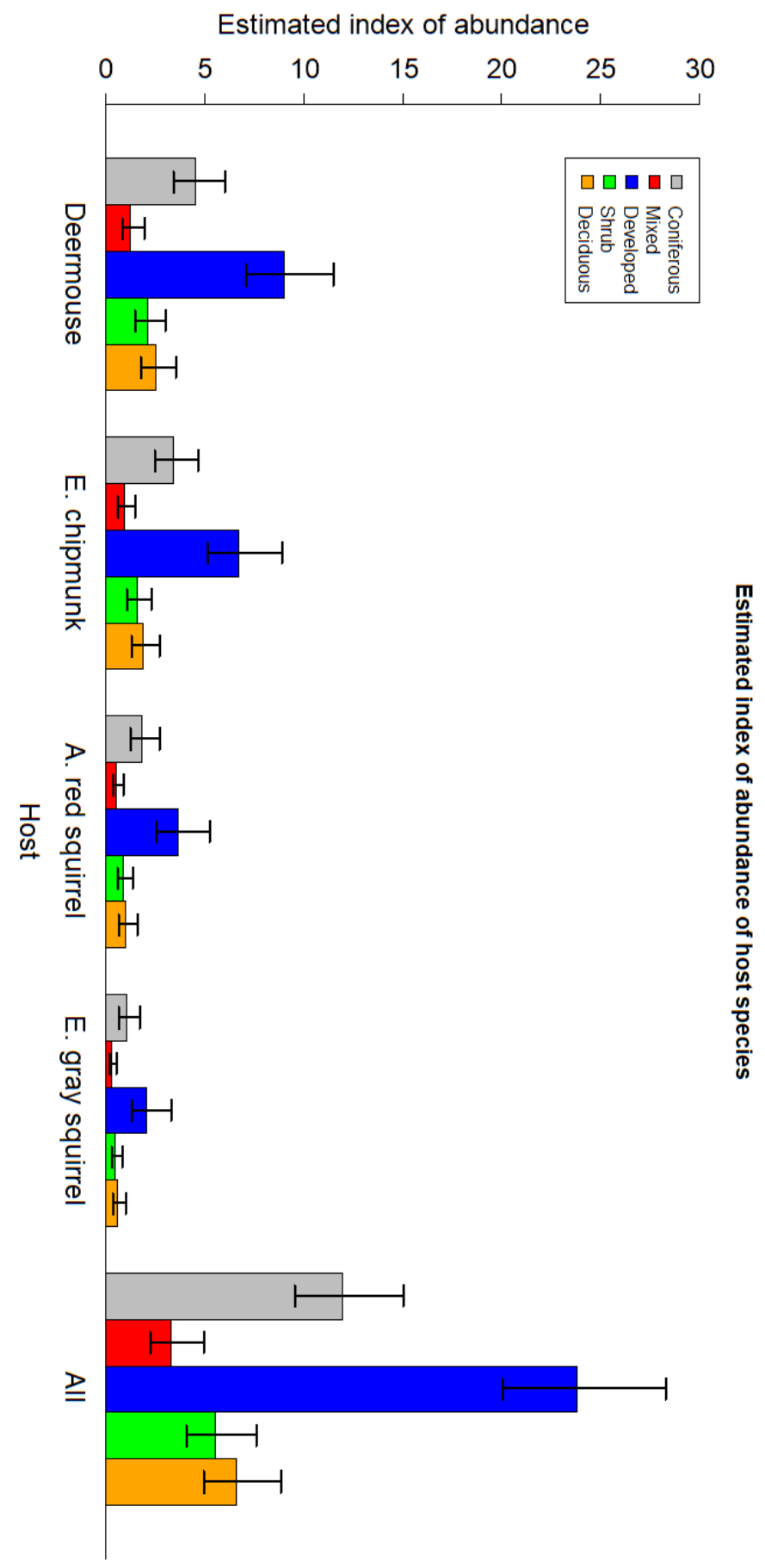

Figure 3.1. Species composition of dominate hosts in the small mammal community with a $95 \%$ confidence interval within the Cantonment Area of Fort Drum Military Installation, New York during 2015-2016. 


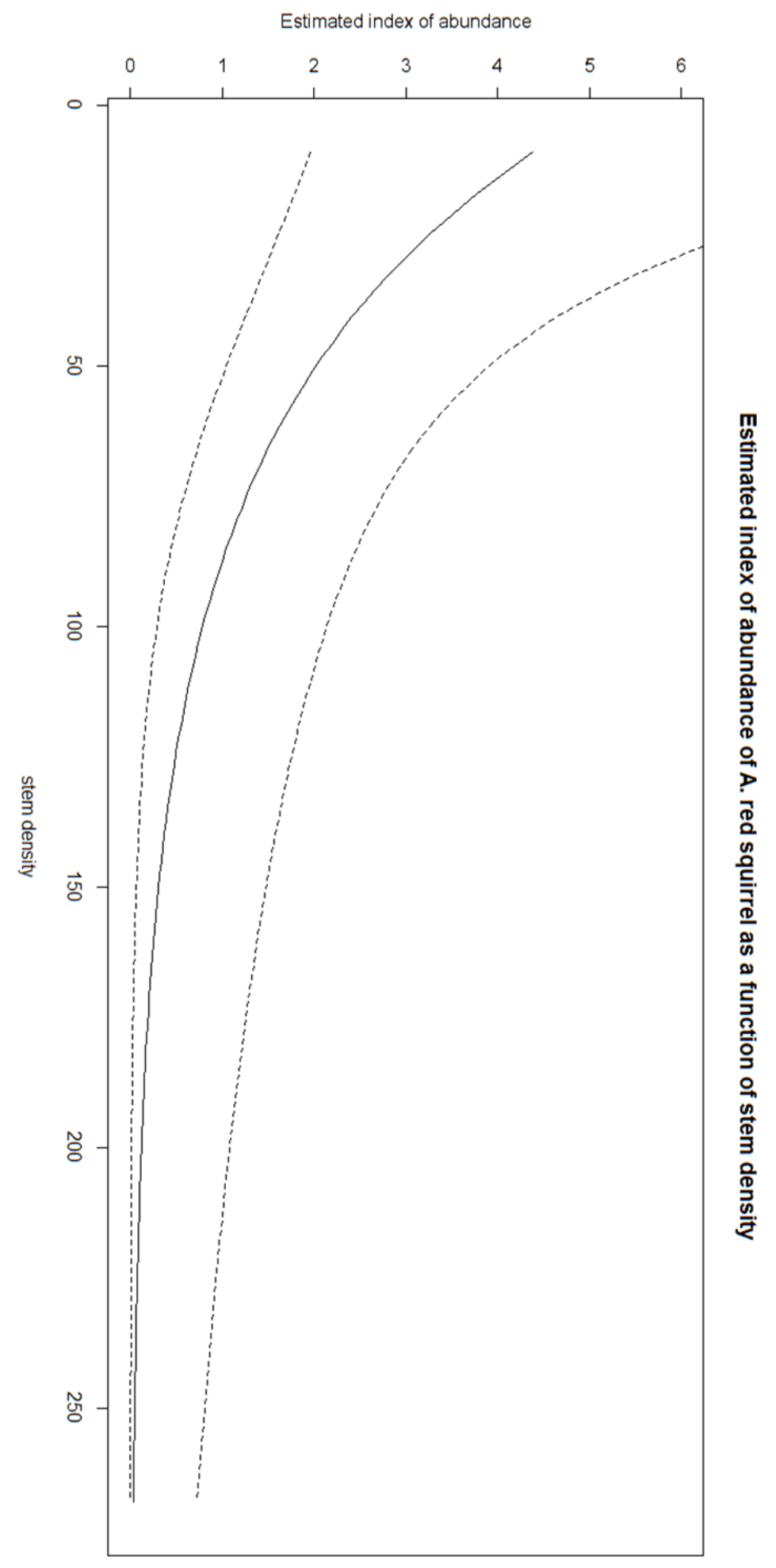

Figure 3.2. Estimated index of abundance of red squirrel related to stem density with a $95 \%$ confidence interval on Fort Drum Military Installation, New York, 2015-2016. 


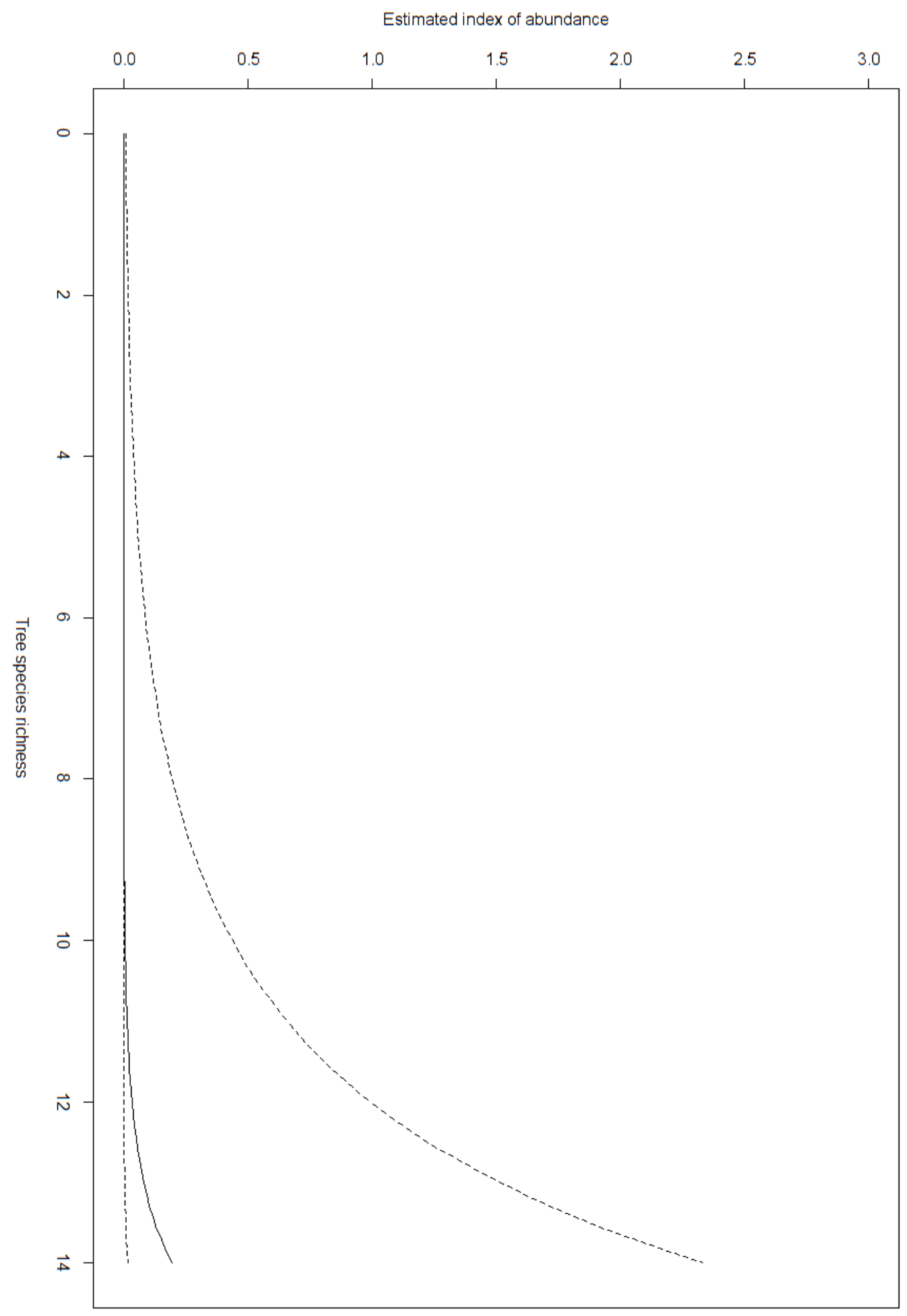

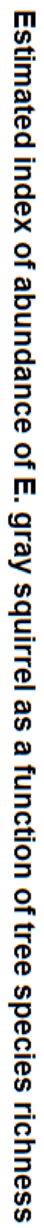

Figure 3.3. Estimated index of abundance of gray squirrel related to tree species richness with a 95\% confidence interval on Fort Drum Military Installation, New York, 2015-2016. 


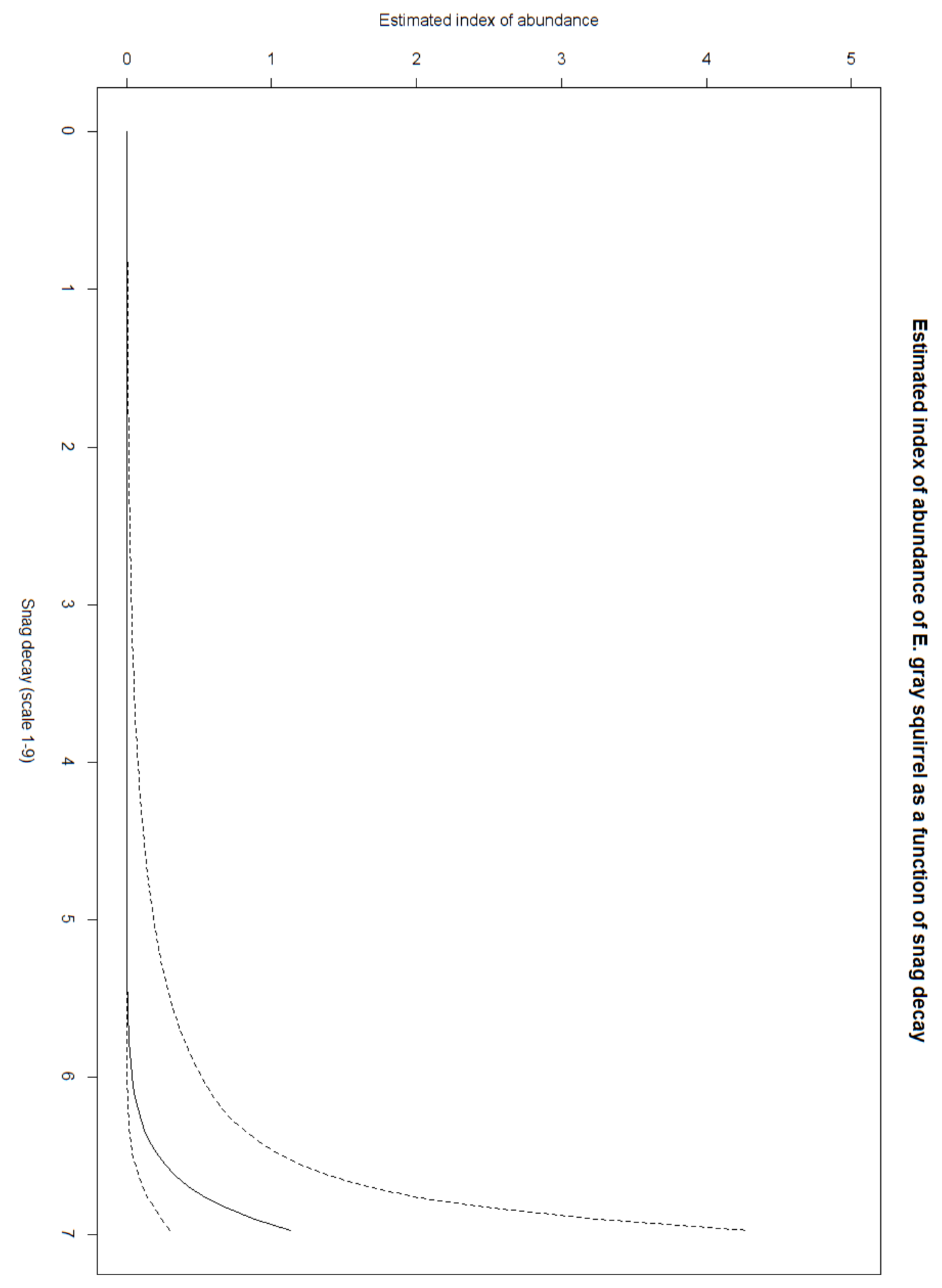

Figure 3.4. Estimated index of abundance of gray squirrel related to snag decay with a $95 \%$ confidence interval on Fort Drum Military Installation, New York, 2015-2016. 


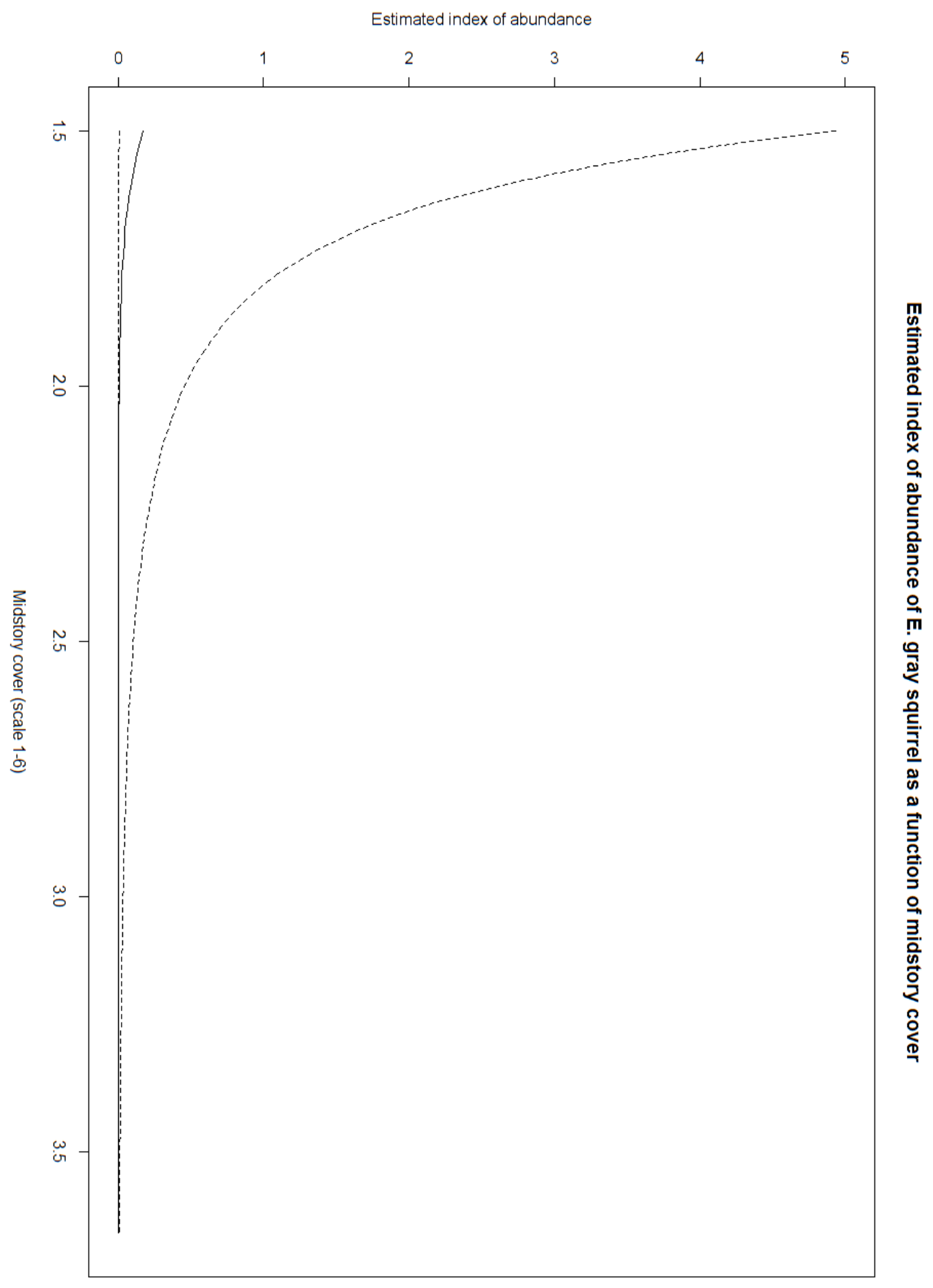

Figure 3.5. Estimated index of abundance of gray squirrel related to midstory cover with a 95\% confidence interval on Fort Drum Military Installation, New York, 2015-2016. 


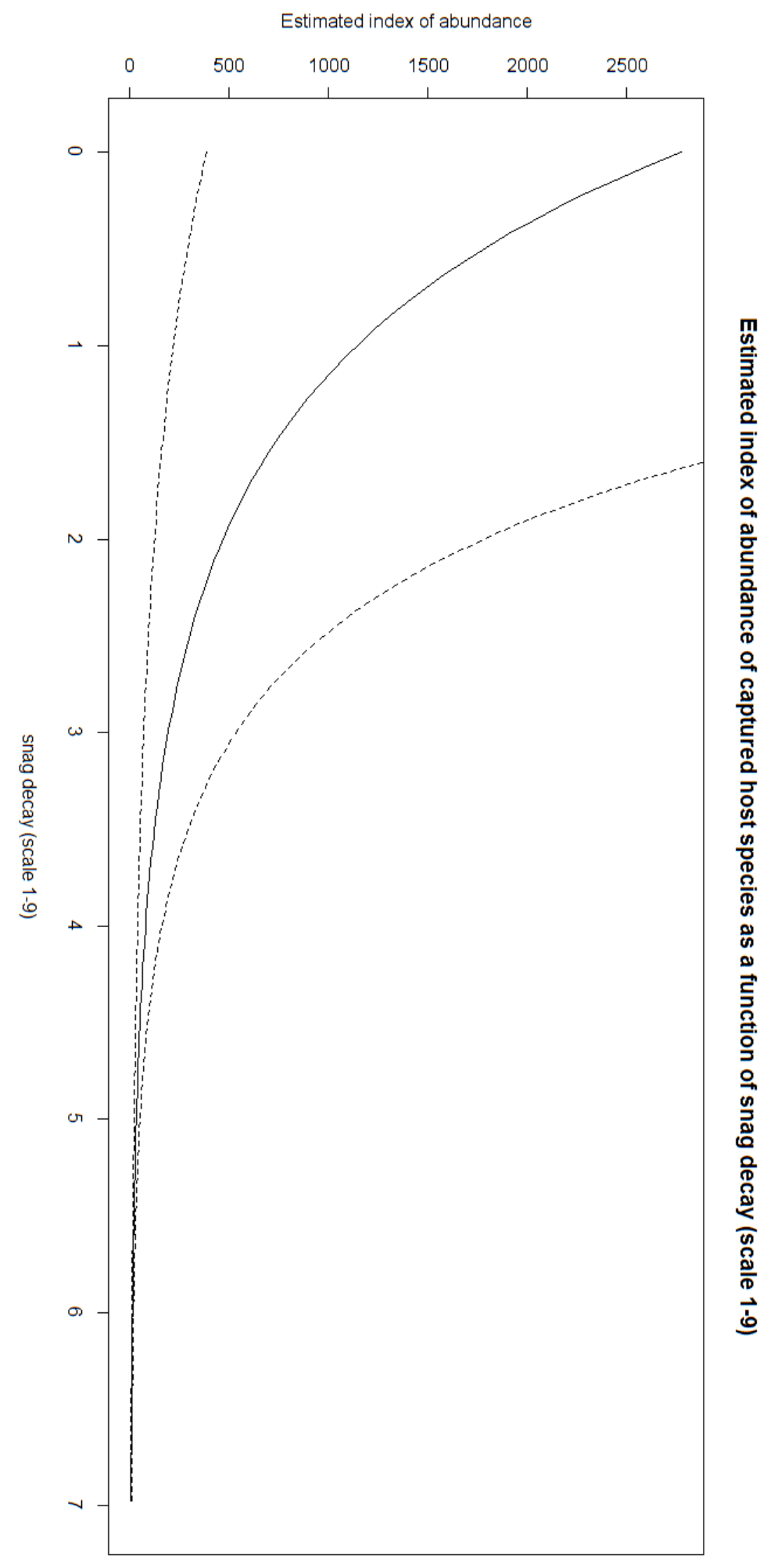

Figure 3.6. Estimated index of abundance of small mammal hosts related to snag decay with a $95 \%$ confidence interval on Fort Drum Military Installation, New York, 2015-2016. 


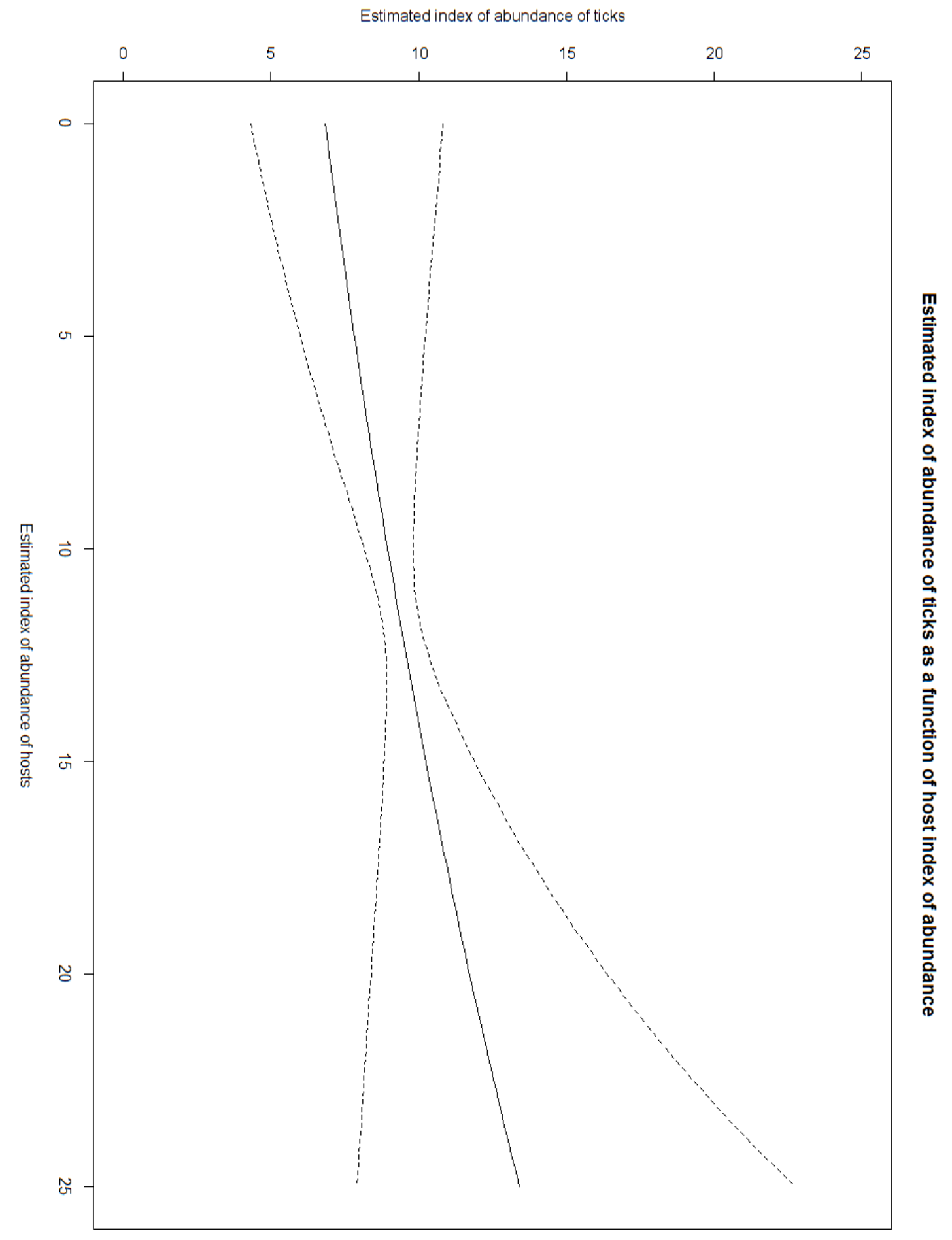

Figure 3.7. Estimated index of abundance of ticks related to estimated index of abundance of all small mammal host species with a 95\% confidence interval on Fort Drum Military Installation, New York, 2015-2016. 


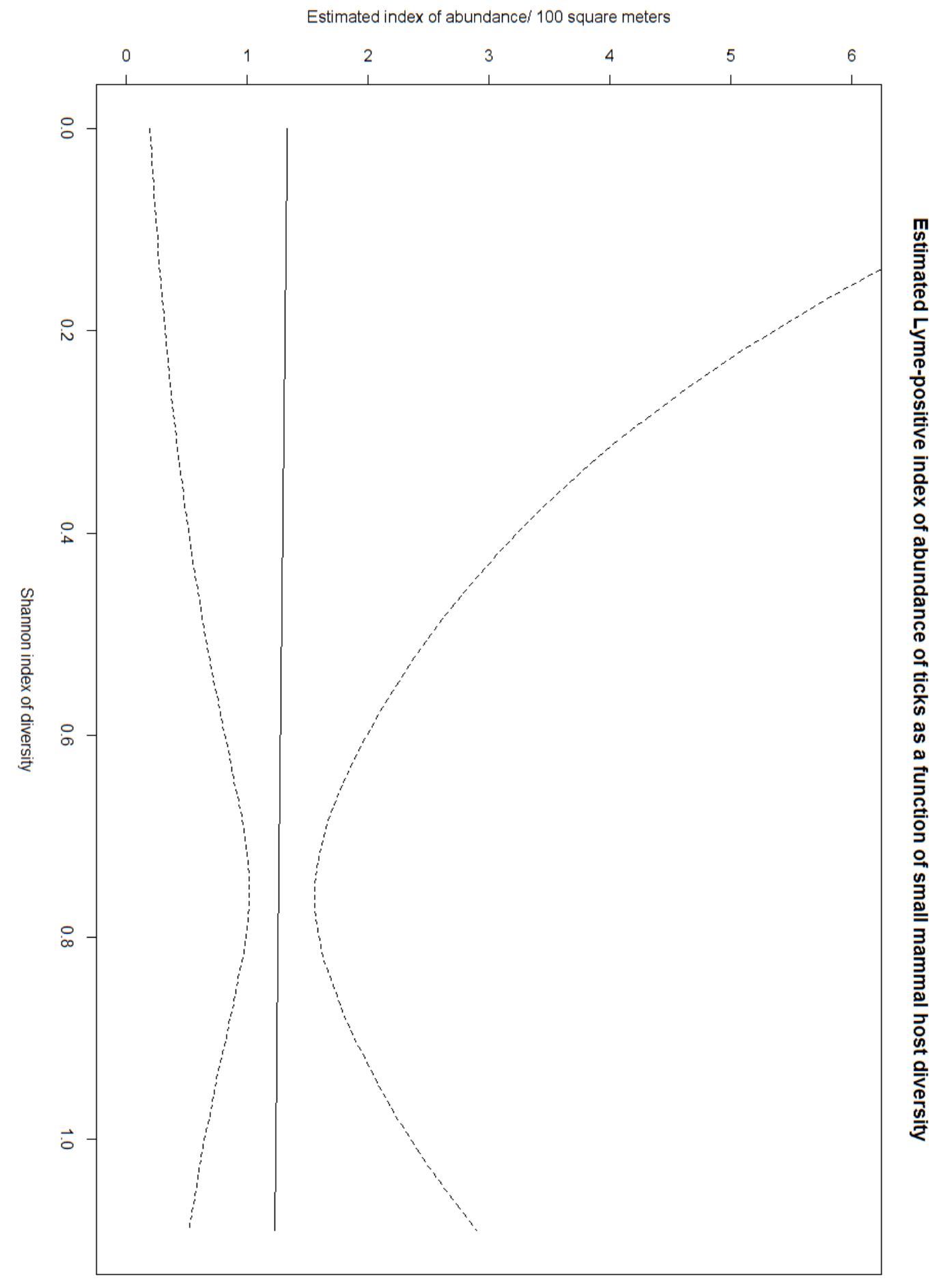

Figure 3.8. Estimated index of abundance of Lyme-positive ticks related to small mammal host Shannon's index of diversity with a 95\% confidence interval on Fort Drum Military Installation, New York, 2015-2016. 


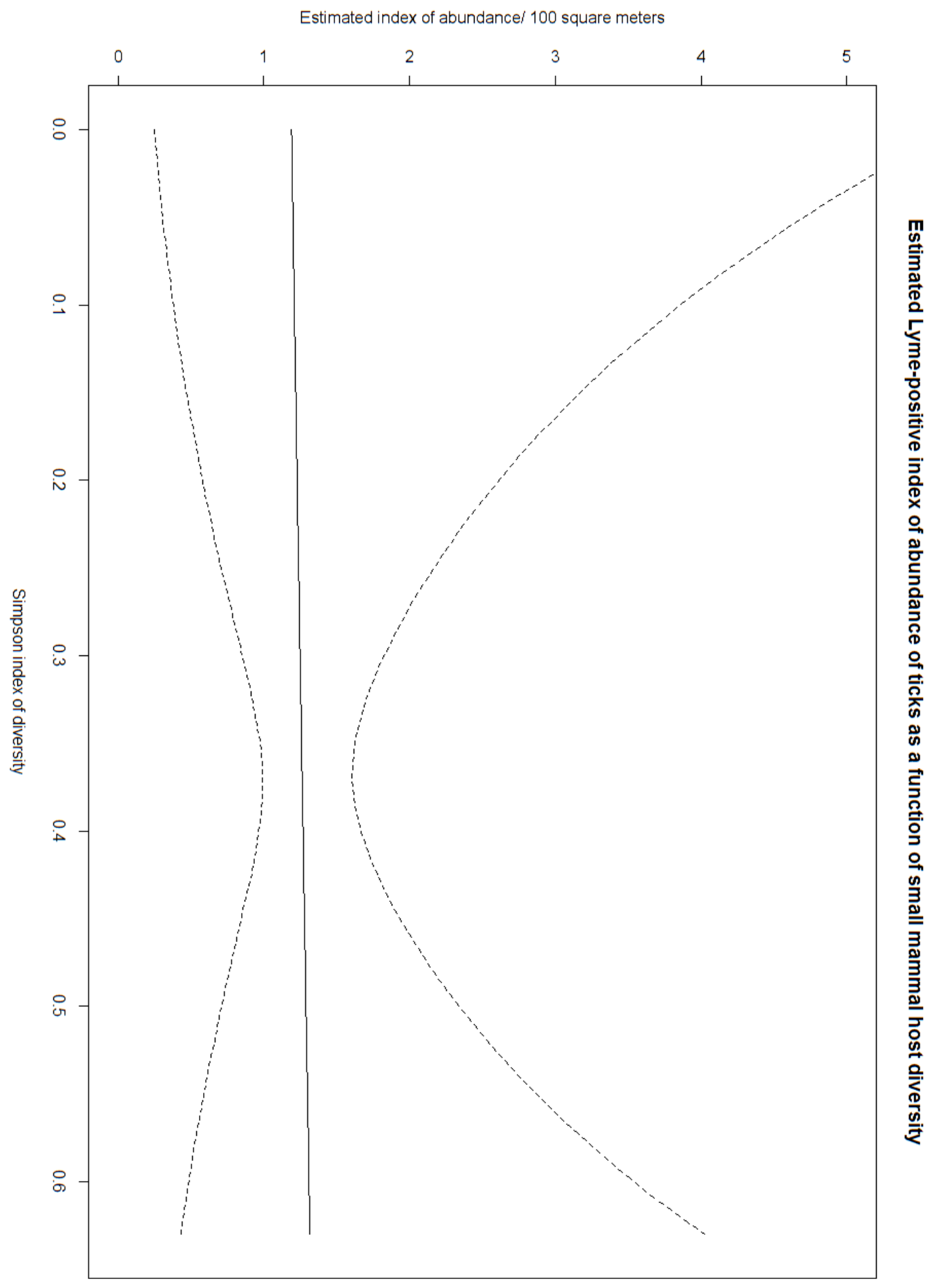

Figure 3.9. Estimated index of abundance of Lyme-positive ticks related to small mammal host Simpson's index of diversity with a 95\% confidence interval on Fort Drum Military Installation, New York, 2015-2016. 


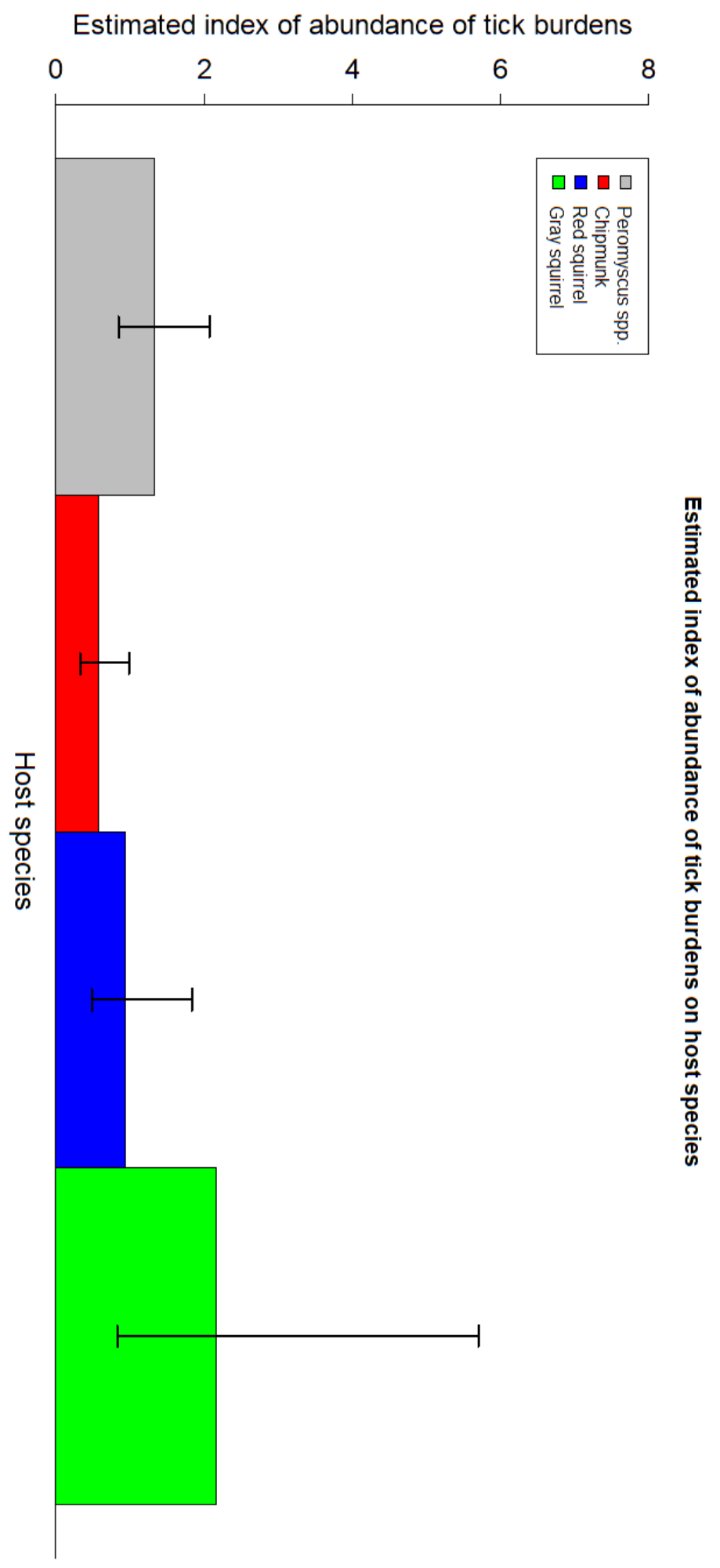

Figure 3.10. Estimated index of abundance of small mammal hosts with a tick burden with a $95 \%$ confidence interval on Fort Drum Military Installation, New York, 2015-2016. 


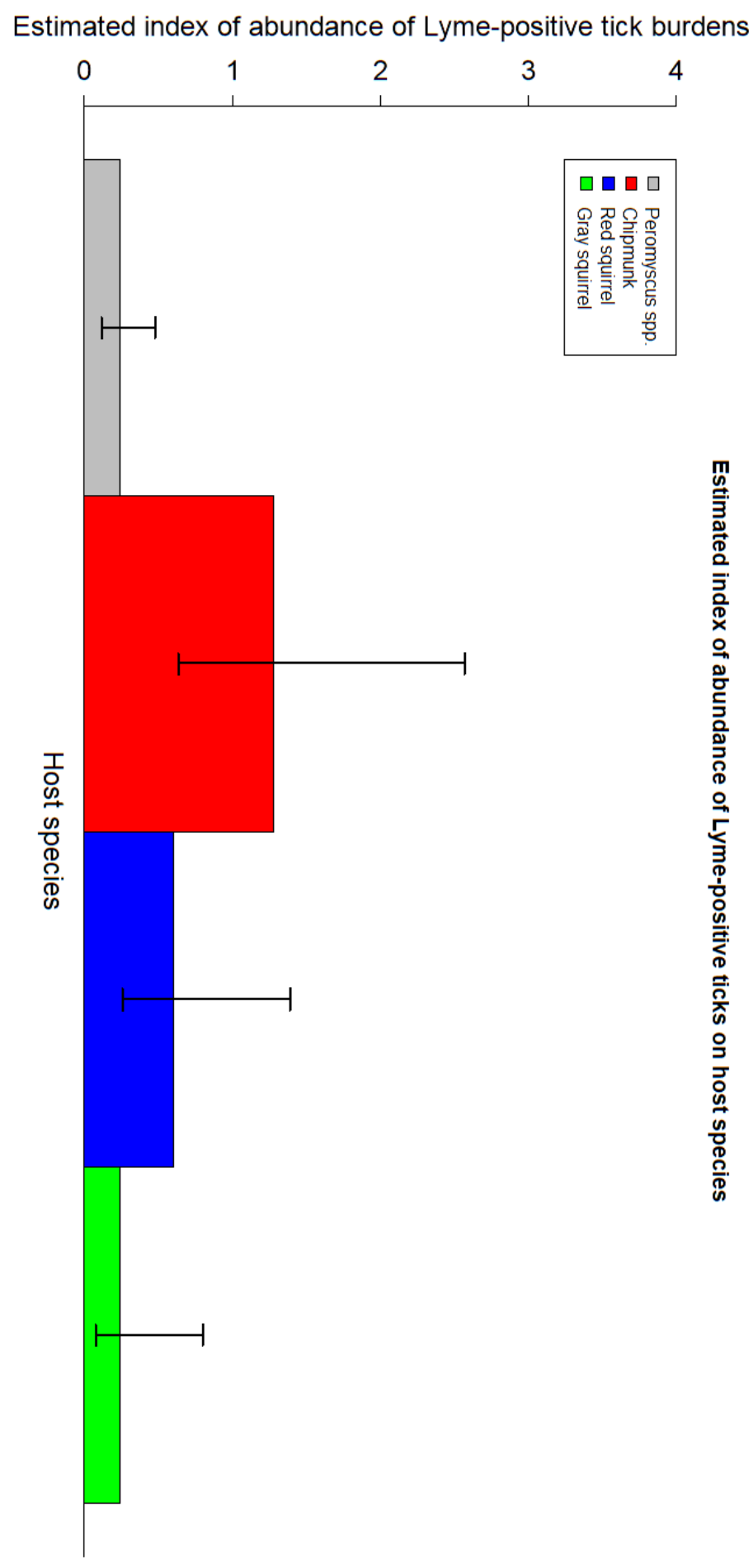

Figure 3.11. Estimated index of abundance of small mammal hosts exposed to a Lyme-positive tick burden with a 95\% confidence interval on Fort Drum Military Installation, New York, 20152016. 
Appendix 1. Quantitative PCR - Prime Time Borrelia Assay (Courtney et al. 2004).

Day 1

a. Make an excel file which contains the identification of each sample being tested and their location in reference to the wells on the PCR plate

b. Make the Master Mix (\# of samples + error)* volume of reagent

- Rox Dye 0.4ul per sample

- Assay Mix 1.0ul per sample (Primers and Probe)

- Nuclease Free $\mathrm{H}_{2} \mathrm{O}$ 6.6ul per sample

- Master Mix 10.0ul per sample

c. Make sure to keep the master mix produced in this step on ice until use!!!

d. Load 20ul of master mix in each well of the PCR plate for every well which will have a sample. Important to make sure you include some wells which will act as negative controls and wells which have the positive control!! Always do at least 2 Controls per plate

e. Add 2ul of Sample DNA template to each well changing tips between each well to prevent contamination

f. Cover the PCR plate with an optical slip mad especially for qPCR reactions and make sure it sealed by ruling the comb over the plate. Do not write on the slip cover!!

g. Centrifuge the plate with a proper balance for about $20 \mathrm{sec}$ at $8,000 \mathrm{rpm}$

$\mathrm{h}$. Now you are ready to put the plate in the qPCR machine at the following conditions:

40 Cycles

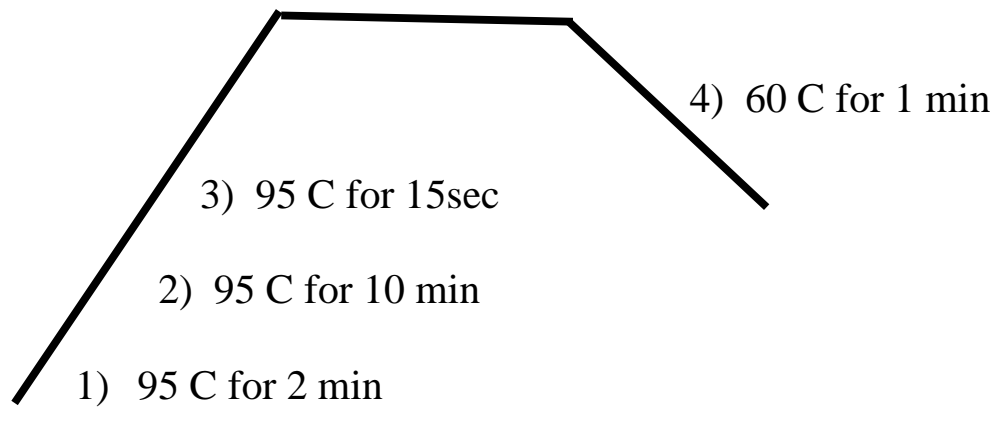

i. After the qPCR has completed the run take the plate out and label it with the organism, primer name, todays date, and the samples ran. Place in the -20 or -80 freezer 
Appendix 2. Summary statistics for ticks found in coniferous forests (per square meter) on Fort Drum Military Installation, New York, during April-November, 2015-2016.

\begin{tabular}{lcccccccc}
\hline Month & \multicolumn{2}{c}{ Larval } & \multicolumn{2}{c}{ Nymph } & \multicolumn{2}{c}{ Adult } & \multicolumn{2}{c}{ Total } \\
& Mean & SE & Mean & SE & Mean & SE & Mean & SE \\
\hline & & & \multicolumn{2015}{c}{$\mathbf{2 0 1 5}$} & & & & \\
\hline April & 0.0000 & 0.0000 & 0.0000 & 0.0000 & 0.0278 & 0.0049 & 0.0278 & 0.0049 \\
May & 0.0119 & 0.0089 & 0.0348 & 0.0082 & 0.0230 & 0.0043 & 0.0696 & 0.0094 \\
June & 0.0489 & 0.0090 & 0.0778 & 0.0088 & 0.0067 & 0.0038 & 0.1333 & 0.0113 \\
July & 0.0189 & 0.0085 & 0.0233 & 0.0042 & 0.0000 & 0.0000 & 0.0422 & 0.0059 \\
August & 0.0056 & 0.0040 & 0.0156 & 0.0015 & 0.0000 & 0.0000 & 0.0211 & 0.0030 \\
September & 0.0833 & 0.0070 & 0.0033 & 0.0021 & 0.0011 & 0.0027 & 0.0878 & 0.0067 \\
October & 0.0000 & 0.0000 & 0.0011 & 0.0027 & 0.0444 & 0.0034 & 0.0456 & 0.0030 \\
November & 0.0000 & 0.0000 & 0.0000 & 0.0000 & 0.1033 & 0.0060 & 0.1033 & 0.0060 \\
\hline & & & & $\mathbf{2 0 1 6}$ & & & & \\
\hline April & 0.0000 & 0.0000 & 0.0000 & 0.0000 & 0.0267 & 0.0051 & 0.0267 & 0.0051 \\
May & 0.0000 & 0.0000 & 0.0141 & 0.0041 & 0.0156 & 0.0031 & 0.0296 & 0.0039 \\
June & 0.0089 & 0.0066 & 0.0700 & 0.0048 & 0.0033 & 0.0032 & 0.0822 & 0.0055 \\
July & 0.0111 & 0.0047 & 0.0400 & 0.0045 & 0.0000 & 0.0000 & 0.0511 & 0.0046 \\
August & 0.1144 & 0.0078 & 0.0133 & 0.0032 & 0.0000 & 0.0000 & 0.1278 & 0.0081 \\
September & 0.0600 & 0.0018 & 0.0078 & 0.0019 & 0.0000 & 0.0000 & 0.0678 & 0.0022 \\
October & 0.0156 & 0.0079 & 0.0000 & 0.0000 & 0.0067 & 0.0030 & 0.0289 & 0.0053 \\
November & 0.0000 & 0.0000 & 0.0000 & 0.0000 & 0.0556 & 0.0056 & 0.0556 & 0.0056 \\
\hline
\end{tabular}


Appendix 3. Summary statistics for B. burgdoreri-positive ticks found in coniferous forests (per square meter) on Fort Drum Military Installation, New York, during April-November, 2015-2016.

\begin{tabular}{|c|c|c|c|c|c|c|}
\hline \multirow[t]{2}{*}{ Month } & \multicolumn{2}{|c|}{ Nymph } & \multicolumn{2}{|c|}{ Adult } & \multicolumn{2}{|c|}{ Total } \\
\hline & Mean & SE & Mean & SE & Mean & SE \\
\hline \multicolumn{7}{|c|}{2015} \\
\hline April & 0.0000 & 0.0000 & 0.0156 & 0.0042 & 0.0156 & 0.0042 \\
\hline May & 0.0030 & 0.0024 & 0.0111 & 0.0030 & 0.0141 & 0.0026 \\
\hline June & 0.0133 & 0.0000 & 0.0000 & 0.0000 & 0.0133 & 0.0000 \\
\hline July & 0.0067 & 0.0024 & 0.0000 & 0.0000 & 0.0067 & 0.0024 \\
\hline August & 0.0000 & 0.0000 & 0.0000 & 0.0000 & 0.0000 & 0.0000 \\
\hline September & 0.0000 & 0.0000 & 0.0000 & 0.0000 & 0.0000 & 0.0000 \\
\hline October & 0.0000 & 0.0000 & 0.0233 & 0.0038 & 0.0233 & 0.0038 \\
\hline November & 0.0000 & 0.0000 & 0.0389 & 0.0058 & 0.0389 & 0.0058 \\
\hline \multicolumn{7}{|c|}{2016} \\
\hline April & 0.0000 & 0.0000 & 0.0111 & 0.0034 & 0.0111 & 0.0034 \\
\hline May & 0.0052 & 0.0028 & 0.0104 & 0.0031 & 0.0156 & 0.0027 \\
\hline June & 0.0133 & 0.0021 & 0.0011 & 0.0027 & 0.0144 & 0.0018 \\
\hline July & 0.0067 & 0.0024 & 0.0000 & 0.0000 & 0.0067 & 0.0024 \\
\hline August & 0.0056 & 0.0022 & 0.0000 & 0.0000 & 0.0056 & 0.0022 \\
\hline September & 0.0011 & 0.0027 & 0.0000 & 0.0000 & 0.0011 & 0.0027 \\
\hline October & 0.0000 & 0.0000 & 0.0056 & 0.0012 & 0.0056 & 0.0012 \\
\hline November & 0.0000 & 0.0000 & 0.0222 & 0.0038 & 0.0222 & 0.0038 \\
\hline
\end{tabular}


Appendix 4. Summary statistics for ticks found in deciduous forests (per square meter) on Fort Drum Military Installation, New York, during April-November, 2015-2016.

\begin{tabular}{lcccccccc}
\hline Month & \multicolumn{2}{c}{ Larval } & \multicolumn{2}{c}{ Nymph } & \multicolumn{2}{c}{ Adult } & \multicolumn{2}{c}{ Total } \\
& Mean & SE & Mean & SE & Mean & SE & Mean & SE \\
\hline April & 0.0000 & 0.0000 & 0.0000 & 0.0000 & 0.0067 & 0.0024 & 0.0067 & 0.0024 \\
May & 0.0000 & 0.0000 & 0.0052 & 0.0030 & 0.0089 & 0.0036 & 0.0141 & 0.0070 \\
June & 0.0133 & 0.0094 & 0.0356 & 0.0069 & 0.0022 & 0.0038 & 0.0511 & 0.0000 \\
July & 0.0000 & 0.0000 & 0.0078 & 0.0046 & 0.0000 & 0.0000 & 0.0078 & 0.0046 \\
August & 0.0144 & 0.0064 & 0.0044 & 0.0027 & 0.0000 & 0.0000 & 0.0189 & 0.0068 \\
September & 0.0222 & 0.0079 & 0.0011 & 0.0027 & 0.0000 & 0.0000 & 0.0233 & 0.0082 \\
October & 0.0089 & 0.0077 & 0.0022 & 0.0038 & 0.0011 & 0.0027 & 0.0122 & 0.0081 \\
November & 0.0000 & 0.0000 & 0.0000 & 0.0000 & 0.0156 & 0.0046 & 0.0156 & 0.0046 \\
\hline & & & & $\mathbf{2 0 1 6}$ & & & & \\
\hline April & 0.0000 & 0.0000 & 0.0000 & 0.0000 & 0.0044 & 0.0054 & 0.0044 & 0.0054 \\
May & 0.0000 & 0.0000 & 0.0030 & 0.0034 & 0.0030 & 0.0034 & 0.0059 & 0.0030 \\
June & 0.0022 & 0.0038 & 0.0144 & 0.0027 & 0.0000 & 0.0000 & 0.0167 & 0.0036 \\
July & 0.0000 & 0.0000 & 0.0033 & 0.0032 & 0.0000 & 0.0000 & 0.0033 & 0.0032 \\
August & 0.0844 & 0.0230 & 0.0033 & 0.0032 & 0.0000 & 0.0000 & 0.0878 & 0.0231 \\
September & 0.0022 & 0.0038 & 0.0000 & 0.0000 & 0.0000 & 0.0000 & 0.0022 & 0.0038 \\
October & 0.0000 & 0.0000 & 0.0000 & 0.0000 & 0.0022 & 0.0038 & 0.0022 & 0.0038 \\
November & 0.0000 & 0.0000 & 0.0000 & 0.0000 & 0.0122 & 0.0037 & 0.0122 & 0.0037 \\
\hline
\end{tabular}


Appendix 5. Summary statistics for B. burgdoreri-positive ticks found in deciduous forests (per square meter) on Fort Drum Military Installation, New York, during April-November 20152016.

\begin{tabular}{lcccccc}
\hline Month & \multicolumn{2}{c}{ Nymph } & \multicolumn{2}{c}{ Adult } & \multicolumn{2}{c}{ Total } \\
& Mean & SE & Mean & SE & Mean & SE \\
\hline April & 0.0000 & 0.0000 & 0.0022 & 0.0024 & 0.0022 & 0.0024 \\
May & 0.0000 & 0.0000 & 0.0037 & 0.0030 & 0.0037 & 0.0030 \\
June & 0.0044 & 0.0054 & 0.0022 & 0.0038 & 0.0067 & 0.0067 \\
July & 0.0022 & 0.0024 & 0.0000 & 0.0000 & 0.0022 & 0.0024 \\
August & 0.0110 & 0.0027 & 0.0000 & 0.0000 & 0.0110 & 0.0027 \\
September & 0.0000 & 0.0000 & 0.0000 & 0.0000 & 0.0000 & 0.0000 \\
October & 0.0011 & 0.0027 & 0.0011 & 0.0027 & 0.0022 & 0.0024 \\
November & 0.0000 & 0.0000 & 0.0067 & 0.0042 & 0.0067 & 0.0042 \\
\hline \multicolumn{7}{c}{$\mathbf{2 0 1 6}$} \\
April & 0.0000 & 0.0000 & 0.0022 & 0.0038 & 0.0022 & 0.0038 \\
May & 0.0015 & 0.0031 & 0.0015 & 0.0031 & 0.0030 & 0.0029 \\
June & 0.0022 & 0.0024 & 0.0000 & 0.0000 & 0.0022 & 0.0024 \\
July & 0.0011 & 0.0027 & 0.0000 & 0.0000 & 0.0011 & 0.0027 \\
August & 0.0000 & 0.0000 & 0.0000 & 0.0000 & 0.0000 & 0.0000 \\
September & 0.0000 & 0.0000 & 0.0000 & 0.0000 & 0.0000 & 0.0000 \\
October & 0.0000 & 0.0000 & 0.0011 & 0.0270 & 0.0011 & 0.0270 \\
November & 0.0000 & 0.0000 & 0.0044 & 0.0017 & 0.0044 & 0.0017 \\
\hline & & & & & & \\
& & &
\end{tabular}


Appendix 6. Summary statistics for ticks found in Developed (per square meter) on Fort Drum Military Installation, New York, during April-November 2015-2016.

\begin{tabular}{|c|c|c|c|c|c|c|c|c|}
\hline \multirow[t]{2}{*}{ Month } & \multicolumn{2}{|c|}{ Larval } & \multicolumn{2}{|c|}{ Nymph } & \multicolumn{2}{|c|}{ Adult } & \multicolumn{2}{|c|}{ Total } \\
\hline & Mean & SE & Mean & SE & Mean & SE & Mean & SE \\
\hline \multicolumn{9}{|c|}{2015} \\
\hline April & 0.0000 & 0.0000 & 0.0000 & 0.0000 & 0.0100 & 0.0046 & 0.0100 & 0.0046 \\
\hline May & 0.0267 & 0.0133 & 0.0122 & 0.0090 & 0.0119 & 0.0031 & 0.0567 & 0.0131 \\
\hline June & 0.0000 & 0.0000 & 0.0067 & 0.0038 & 0.0000 & 0.0000 & 0.0067 & 0.0038 \\
\hline July & 0.0000 & 0.0000 & 0.0078 & 0.0049 & 0.0000 & 0.0000 & 0.0078 & 0.0049 \\
\hline August & 0.0000 & 0.0000 & 0.0100 & 0.0006 & 0.0000 & 0.0000 & 0.0100 & 0.0006 \\
\hline September & 0.0167 & 0.0069 & 0.0011 & 0.0027 & 0.0000 & 0.0000 & 0.0178 & 0.0072 \\
\hline October & 0.0000 & 0.0000 & 0.0011 & 0.0027 & 0.0233 & 0.0064 & 0.0244 & 0.0061 \\
\hline November & 0.0000 & 0.0000 & 0.0000 & 0.0000 & 0.0367 & 0.0114 & 0.0367 & 0.0114 \\
\hline \multicolumn{9}{|c|}{2016} \\
\hline April & 0.0000 & 0.0000 & 0.0000 & 0.0000 & 0.0133 & 0.0072 & 0.0133 & 0.0072 \\
\hline May & 0.0000 & 0.0000 & 0.0000 & 0.0000 & 0.0052 & 0.0039 & 0.0052 & 0.0039 \\
\hline June & 0.0000 & 0.0000 & 0.0033 & 0.0032 & 0.0000 & 0.0000 & 0.0033 & 0.0032 \\
\hline July & 0.0000 & 0.0000 & 0.0056 & 0.0040 & 0.0000 & 0.0000 & 0.0056 & 0.0040 \\
\hline August & 0.0500 & 0.0094 & 0.0022 & 0.0038 & 0.0000 & 0.0000 & 0.0522 & 0.0095 \\
\hline September & 0.0144 & 0.0074 & 0.0000 & 0.0000 & 0.0000 & 0.0000 & 0.0144 & 0.0074 \\
\hline October & 0.0000 & 0.0000 & 0.0000 & 0.0000 & 0.0000 & 0.0000 & 0.0000 & 0.0000 \\
\hline November & 0.0000 & 0.0000 & 0.0000 & 0.0000 & 0.0022 & 0.0038 & 0.0022 & 0.0038 \\
\hline
\end{tabular}


Appendix 7. Summary statistics for B. burgdoreri-positive ticks found in Developed (per square meter) on Fort Drum Military Installation, New York, during April-November 2015-2016.

\begin{tabular}{lcccccc}
\hline Month & \multicolumn{2}{c}{ Nymph } & \multicolumn{2}{c}{ Adult } & \multicolumn{2}{c}{ Total } \\
& Mean & SE & Mean & SE & Mean & SE \\
\hline \multicolumn{7}{c}{$\mathbf{2 0 1 5}$} \\
April & 0.0000 & 0.0000 & 0.0056 & 0.0040 & 0.0056 & 0.0040 \\
May & 0.0000 & 0.0000 & 0.0044 & 0.0024 & 0.0044 & 0.0024 \\
June & 0.0000 & 0.0000 & 0.0000 & 0.0000 & 0.0000 & 0.0000 \\
July & 0.0022 & 0.0024 & 0.0000 & 0.0000 & 0.0022 & 0.0024 \\
August & 0.0000 & 0.0000 & 0.0000 & 0.0000 & 0.0000 & 0.0000 \\
September & 0.0000 & 0.0000 & 0.0000 & 0.0000 & 0.0000 & 0.0000 \\
October & 0.0000 & 0.0000 & 0.0144 & 0.0055 & 0.0144 & 0.0055 \\
November & 0.0000 & 0.0000 & 0.0022 & 0.0094 & 0.0022 & 0.0094 \\
\hline \multicolumn{7}{c}{$\mathbf{2 0 1 6}$} \\
April & 0.0000 & 0.0000 & 0.0067 & 0.0067 & 0.0067 & 0.0067 \\
May & 0.0000 & 0.0000 & 0.0022 & 0.0038 & 0.0022 & 0.0038 \\
June & 0.0000 & 0.0000 & 0.0000 & 0.0000 & 0.0000 & 0.0000 \\
July & 0.0000 & 0.0000 & 0.0000 & 0.0000 & 0.0000 & 0.0000 \\
August & 0.0000 & 0.0000 & 0.0000 & 0.0000 & 0.0000 & 0.0000 \\
September & 0.0000 & 0.0000 & 0.0000 & 0.0000 & 0.0000 & 0.0000 \\
October & 0.0000 & 0.0000 & 0.0000 & 0.0000 & 0.0000 & 0.0000 \\
November & 0.0000 & 0.0000 & 0.0000 & 0.0000 & 0.0000 & 0.0000 \\
\hline
\end{tabular}


Appendix 8. Summary statistics for ticks found in mixed forest (per square meter) on Fort Drum Military Installation, New York, during April-November 2015-2016.

\begin{tabular}{|c|c|c|c|c|c|c|c|c|}
\hline \multirow[t]{2}{*}{ Month } & \multicolumn{2}{|c|}{ Larval } & \multicolumn{2}{|c|}{ Nymph } & \multicolumn{2}{|c|}{ Adult } & \multicolumn{2}{|c|}{ Total } \\
\hline & Mean & SE & Mean & SE & Mean & SE & Mean & SE \\
\hline \multicolumn{9}{|c|}{2015} \\
\hline April & 0.0000 & 0.0000 & 0.0000 & 0.0000 & 0.0256 & 0.0028 & 0.0256 & 0.0028 \\
\hline May & 0.0000 & 0.0000 & 0.0150 & 0.0072 & 0.0126 & 0.0022 & 0.0292 & 0.0061 \\
\hline June & 0.0156 & 0.0052 & 0.0556 & 0.0076 & 0.0089 & 0.0051 & 0.0800 & 0.0097 \\
\hline July & 0.0000 & 0.0000 & 0.0244 & 0.0087 & 0.0000 & 0.0000 & 0.0244 & 0.0087 \\
\hline August & 0.0211 & 0.0076 & 0.0078 & 0.0040 & 0.0000 & 0.0000 & 0.0289 & 0.0065 \\
\hline September & 0.0467 & 0.0071 & 0.0033 & 0.0021 & 0.0022 & 0.0024 & 0.0522 & 0.0066 \\
\hline October & 0.0000 & 0.0000 & 0.0011 & 0.0027 & 0.0411 & 0.0035 & 0.0422 & 0.0038 \\
\hline November & 0.0000 & 0.0000 & 0.0000 & 0.0000 & 0.0611 & 0.0031 & 0.0611 & 0.0031 \\
\hline \multicolumn{9}{|c|}{2016} \\
\hline April & 0.0000 & 0.0000 & 0.0000 & 0.0000 & 0.0422 & 0.0064 & 0.0422 & 0.0064 \\
\hline May & 0.0089 & 0.0077 & 0.0089 & 0.0052 & 0.0200 & 0.0030 & 0.0378 & 0.0044 \\
\hline June & 0.0844 & 0.0090 & 0.0389 & 0.0051 & 0.0044 & 0.0027 & 0.1278 & 0.0085 \\
\hline July & 0.0000 & 0.0000 & 0.0200 & 0.0026 & 0.0000 & 0.0000 & 0.0200 & 0.0026 \\
\hline August & 0.1411 & 0.0107 & 0.0111 & 0.0058 & 0.0000 & 0.0000 & 0.1522 & 0.0115 \\
\hline September & 0.0600 & 0.0011 & 0.0033 & 0.0021 & 0.0033 & 0.0047 & 0.0667 & 0.0009 \\
\hline October & 0.0000 & 0.0000 & 0.0000 & 0.0000 & 0.0333 & 0.0052 & 0.0333 & 0.0052 \\
\hline November & 0.0000 & 0.0000 & 0.0000 & 0.0000 & 0.0311 & 0.0048 & 0.0311 & 0.0048 \\
\hline
\end{tabular}


Appendix 9. Summary statistics for B. burgdoreri-positive ticks found in mixed forest (per square meter) on Fort Drum Military Installation, New York, during April-November 20152016.

\begin{tabular}{lcccccc}
\hline Month & \multicolumn{2}{c}{ Nymph } & \multicolumn{2}{c}{ Adult } & \multicolumn{2}{c}{ Total } \\
& Mean & SE & Mean & SE & Mean & SE \\
\hline April & 0.0000 & 0.0000 & 0.0200 & 0.0024 & 0.0200 & 0.0024 \\
May & 0.0007 & 0.0022 & 0.0074 & 0.0022 & 0.0081 & 0.0022 \\
June & 0.0111 & 0.0034 & 0.0022 & 0.0038 & 0.0133 & 0.0047 \\
July & 0.0056 & 0.0035 & 0.0000 & 0.0000 & 0.0056 & 0.0035 \\
August & 0.0000 & 0.0000 & 0.0000 & 0.0000 & 0.0000 & 0.0000 \\
September & 0.0022 & 0.0024 & 0.0000 & 0.0000 & 0.0022 & 0.0024 \\
October & 0.0000 & 0.0000 & 0.0167 & 0.0039 & 0.0167 & 0.0039 \\
November & 0.0000 & 0.0000 & 0.0311 & 0.0033 & 0.0311 & 0.0033 \\
\hline \multicolumn{7}{c}{} \\
\hline April & 0.0000 & 0.0000 & 0.0356 & 0.0069 & 0.0356 & 0.0069 \\
May & 0.0037 & 0.0040 & 0.0096 & 0.0026 & 0.0133 & 0.0022 \\
June & 0.0056 & 0.0022 & 0.0000 & 0.0000 & 0.0056 & 0.0022 \\
July & 0.0067 & 0.0024 & 0.0000 & 0.0000 & 0.0067 & 0.0024 \\
August & 0.0000 & 0.0000 & 0.0000 & 0.0000 & 0.0000 & 0.0000 \\
September & 0.0033 & 0.0021 & 0.0000 & 0.0000 & 0.0033 & 0.0021 \\
October & 0.0000 & 0.0000 & 0.0056 & 0.0035 & 0.0056 & 0.0035 \\
November & 0.0000 & 0.0000 & 0.0156 & 0.0046 & 0.0156 & 0.0046 \\
\hline
\end{tabular}


Appendix 10. Summary statistics for ticks found in shrub forest (per square meter) on Fort

Drum Military Installation, New York, during April-November 2015-2016.

\begin{tabular}{|c|c|c|c|c|c|c|c|c|}
\hline \multirow[t]{2}{*}{ Month } & \multicolumn{2}{|c|}{ Larval } & \multicolumn{2}{|c|}{ Nymph } & \multicolumn{2}{|c|}{ Adult } & \multicolumn{2}{|c|}{ Total } \\
\hline & Mean & SE & Mean & SE & Mean & SE & Mean & SE \\
\hline \multicolumn{9}{|c|}{2015} \\
\hline April & 0.0000 & 0.0000 & 0.0000 & 0.0000 & 0.0056 & 0.0040 & 0.0056 & 0.0040 \\
\hline May & 0.0000 & 0.0000 & 0.0000 & 0.0000 & 0.0030 & 0.0044 & 0.0030 & 0.0044 \\
\hline June & 0.0000 & 0.0000 & 0.0156 & 0.0052 & 0.0022 & 0.0038 & 0.0178 & 0.0054 \\
\hline July & 0.0000 & 0.0000 & 0.0044 & 0.0027 & 0.0000 & 0.0000 & 0.0044 & 0.0027 \\
\hline August & 0.0000 & 0.0000 & 0.0000 & 0.0000 & 0.0000 & 0.0000 & 0.0000 & 0.0000 \\
\hline September & 0.0111 & 0.0086 & 0.0011 & 0.0027 & 0.0000 & 0.0000 & 0.0122 & 0.0081 \\
\hline October & 0.0000 & 0.0000 & 0.0000 & 0.0000 & 0.0000 & 0.0000 & 0.0000 & 0.0000 \\
\hline November & 0.0000 & 0.0000 & 0.0000 & 0.0000 & 0.0078 & 0.0029 & 0.0078 & 0.0029 \\
\hline \multicolumn{9}{|c|}{2016} \\
\hline April & 0.0000 & 0.0000 & 0.0000 & 0.0000 & 0.0022 & 0.0038 & 0.0022 & 0.0038 \\
\hline May & 0.0000 & 0.0000 & 0.0000 & 0.0000 & 0.0037 & 0.0026 & 0.0037 & 0.0026 \\
\hline June & 0.0022 & 0.0038 & 0.0033 & 0.0032 & 0.0000 & 0.0000 & 0.0056 & 0.0048 \\
\hline July & 0.0000 & 0.0000 & 0.0044 & 0.0040 & 0.0000 & 0.0000 & 0.0044 & 0.0040 \\
\hline August & 0.0000 & 0.0000 & 0.0022 & 0.0038 & 0.0000 & 0.0000 & 0.0022 & 0.0038 \\
\hline September & 0.0000 & 0.0000 & 0.0000 & 0.0000 & 0.0000 & 0.0000 & 0.0000 & 0.0000 \\
\hline October & 0.0000 & 0.0000 & 0.0000 & 0.0000 & 0.0044 & 0.0040 & 0.0044 & 0.0040 \\
\hline November & 0.0000 & 0.0000 & 0.0000 & 0.0000 & 0.0078 & 0.0051 & 0.0078 & 0.0051 \\
\hline
\end{tabular}


Appendix 11. Summary statistics for B. burgdoreri-positive ticks found in shrub forest (per square meter) on Fort Drum Military Installation, New York, during April-November 20152016.

\begin{tabular}{lcccccc}
\hline Month & \multicolumn{2}{c}{ Nymph } & \multicolumn{2}{c}{ Adult } & \multicolumn{2}{c}{ Total } \\
& Mean & SE & Mean & SE & Mean & SE \\
\hline April & 0.0000 & 0.0000 & 0.0044 & 0.0040 & 0.0044 & 0.0040 \\
May & 0.0000 & 0.0000 & 0.0015 & 0.0031 & 0.0015 & 0.0031 \\
June & 0.0067 & 0.0038 & 0.0022 & 0.0038 & 0.0089 & 0.0051 \\
July & 0.0000 & 0.0000 & 0.0000 & 0.0000 & 0.0000 & 0.0000 \\
August & 0.0000 & 0.0000 & 0.0000 & 0.0000 & 0.0000 & 0.0000 \\
September & 0.0000 & 0.0000 & 0.0000 & 0.0000 & 0.0000 & 0.0000 \\
October & 0.0000 & 0.0000 & 0.0000 & 0.0000 & 0.0000 & 0.0000 \\
November & 0.0000 & 0.0000 & 0.0022 & 0.0038 & 0.0022 & 0.0038 \\
\hline & \multicolumn{7}{c}{$\mathbf{2 0 1 6}$} & & & \\
\hline April & 0.0000 & 0.0000 & 0.0000 & 0.0000 & 0.0000 & 0.0000 \\
May & 0.0000 & 0.0000 & 0.0007 & 0.0022 & 0.0007 & 0.0022 \\
June & 0.0000 & 0.0000 & 0.0000 & 0.0000 & 0.0000 & 0.0000 \\
July & 0.0011 & 0.0027 & 0.0000 & 0.0000 & 0.0011 & 0.0027 \\
August & 0.0011 & 0.0027 & 0.0000 & 0.0000 & 0.0011 & 0.0027 \\
September & 0.0000 & 0.0000 & 0.0000 & 0.0000 & 0.0000 & 0.0000 \\
October & 0.0000 & 0.0000 & 0.0033 & 0.0032 & 0.0156 & 0.0038 \\
November & 0.0000 & 0.0000 & 0.0044 & 0.0054 & 0.0044 & 0.0054 \\
\hline & & & & & & \\
\end{tabular}


Appendix 12. Summary statistics for environmental conditions in coniferous forest when ticks were obtained on Fort Drum Military Installation, New York, during April-November 20152016.

\begin{tabular}{lrrrrrrrr}
\hline \multirow{2}{*}{ Month } & \multicolumn{2}{c}{ Temperature (C) } & \multicolumn{2}{c}{ Humidity } & \multicolumn{2}{c}{ Wind speed (MPH) } & \multicolumn{2}{c}{ Pressure (mmHg) } \\
& Mean & SE & Mean & SE & Mean & SE & Mean & SE \\
\hline April & & & \multicolumn{2}{c}{$\mathbf{2 0 1 5}$} & & & & \\
May & 7.11 & 0.26 & 0.66 & 0.18 & 14.00 & 0.58 & 759.41 & 0.02 \\
June & 18.81 & 0.57 & 0.66 & 0.12 & 12.43 & 0.61 & 763.23 & 0.01 \\
July & 19.44 & 0.46 & 0.76 & 0.05 & 6.67 & 1.27 & 760.14 & 0.02 \\
August & 27.41 & 0.89 & 0.59 & 0.01 & 5.00 & 0.46 & 760.39 & 0.01 \\
September & 22.22 & 0.29 & 0.71 & 0.04 & 6.67 & 0.71 & 757.81 & 0.00 \\
October & 21.56 & 0.36 & 0.56 & 0.09 & 11.60 & 0.65 & 764.69 & 0.02 \\
November & 10.00 & 0.24 & 0.81 & 0.08 & 5.67 & 1.01 & 763.99 & 0.01 \\
& 8.06 & 0.55 & 0.79 & 0.04 & 7.33 & 0.45 & 768.35 & 0.01 \\
\hline April & & & & $\mathbf{2 0 1 6}$ & & & & \\
May & 10.19 & 0.55 & 0.52 & 0.11 & 7.67 & 0.67 & 768.10 & 0.00 \\
June & 17.28 & 0.55 & 0.63 & 0.07 & 7.33 & 0.45 & 752.12 & 0.02 \\
July & 22.04 & 0.68 & 0.72 & 0.04 & 8.33 & 0.40 & 744.64 & 0.00 \\
August & 26.57 & 0.26 & 0.73 & 0.05 & 5.33 & 0.54 & 747.73 & 0.01 \\
September & 25.56 & 0.30 & 0.52 & 0.08 & 6.50 & 0.41 & 758.78 & 0.03 \\
October & 23.33 & 0.12 & 0.65 & 0.04 & 5.83 & 0.86 & 764.58 & 0.00 \\
November & 17.41 & 0.41 & 0.82 & 0.06 & 9.00 & 0.52 & 762.30 & 0.02 \\
\hline & 7.13 & 0.40 & 0.59 & 0.07 & 6.33 & 0.59 & 764.12 & 0.01 \\
\hline
\end{tabular}


Appendix 13. Summary statistics for environmental conditions in deciduous forest when ticks were obtained on Wheeler-Sack Army Airfield, New York, during April-November 2015-2016.

\begin{tabular}{lrrrrrrrr}
\hline Month & \multicolumn{2}{c}{ Temperature (C) } & \multicolumn{2}{c}{ Humidity } & \multicolumn{2}{c}{ Wind speed (MPH) } & \multicolumn{2}{c}{ Pressure (mmHg) } \\
& Mean & SE & Mean & SE & Mean & SE & Mean & SE \\
\hline & & & \multicolumn{2}{c}{$\mathbf{2 0 1 5}$} & & & & \\
\hline April & 8.19 & 0.96 & 0.58 & 0.22 & 13.25 & 0.74 & 759.84 & 0.02 \\
May & 17.22 & 0.62 & 0.72 & 0.10 & 11.00 & 0.56 & 764.71 & 0.02 \\
June & 20.19 & 0.38 & 0.74 & 0.04 & 11.33 & 1.59 & 760.05 & 0.02 \\
July & 19.44 & 1.47 & 0.75 & 0.13 & 3.50 & 0.27 & 760.35 & 0.01 \\
August & 23.89 & 0.20 & 0.68 & 0.03 & 10.00 & 0.84 & 757.26 & 0.01 \\
September & 19.17 & 0.92 & 0.79 & 0.15 & 5.50 & 0.21 & 764.79 & 0.02 \\
October & 12.22 & 0.14 & 0.76 & 0.01 & 7.50 & 2.01 & 762.89 & 0.01 \\
November & 9.44 & 0.74 & 0.70 & 0.06 & 6.00 & 0.69 & 768.16 & 0.01 \\
\hline & & & & $\mathbf{2 0 1 6}$ & & & & \\
\hline April & 6.11 & 0.00 & 0.81 & 0.00 & 12.00 & 0.00 & 767.33 & 0.00 \\
May & 20.28 & 0.71 & 0.55 & 0.14 & 7.00 & 0.94 & 748.86 & 0.02 \\
June & 21.89 & 0.61 & 0.78 & 0.03 & 6.00 & 0.26 & 744.58 & 0.01 \\
July & 25.83 & 0.51 & 0.75 & 0.17 & 5.50 & 1.07 & 748.67 & 0.01 \\
August & 25.83 & 0.40 & 0.54 & 0.14 & 4.00 & 0.50 & 749.30 & 0.01 \\
September & 23.89 & 0.00 & 0.72 & 0.00 & 7.00 & 0.00 & 762.76 & 0.00 \\
October & 18.89 & 0.00 & 0.84 & 0.00 & 14.00 & 0.00 & 755.14 & 0.00 \\
November & 6.11 & 0.46 & 0.66 & 0.06 & 9.25 & 1.18 & 764.16 & 0.01 \\
\hline
\end{tabular}


Appendix 14. Summary statistics for environmental conditions in Developed when ticks were obtained on Wheeler-Sack Army Airfield, New York, during April-November 2015-2016.

\begin{tabular}{|c|c|c|c|c|c|c|c|c|}
\hline \multirow[t]{2}{*}{ Month } & \multicolumn{2}{|c|}{ Temperature (C) } & \multicolumn{2}{|c|}{ Humidity } & \multicolumn{2}{|c|}{ Wind speed (MPH) } & \multicolumn{2}{|c|}{ Pressure (mmHg) } \\
\hline & Mean & SE & Mean & SE & Mean & SE & Mean & SE \\
\hline \multicolumn{9}{|c|}{2015} \\
\hline April & 8.33 & 1.06 & 0.65 & 0.24 & 7.67 & 0.52 & 756.41 & 0.03 \\
\hline May & 17.59 & 0.83 & 0.65 & 0.09 & 9.67 & 0.40 & 764.29 & 0.00 \\
\hline June & 20.28 & 0.54 & 0.88 & 0.03 & 14.50 & 2.49 & 758.32 & 0.03 \\
\hline July & 20.93 & 0.86 & 0.76 & 0.10 & 5.00 & 0.26 & 759.80 & 0.01 \\
\hline August & 19.44 & 0.24 & 0.79 & 0.02 & 13.00 & 0.28 & 757.81 & 0.00 \\
\hline September & 19.72 & 1.16 & 0.63 & 0.09 & 7.50 & 0.91 & 762.89 & 0.04 \\
\hline October & 10.00 & 0.35 & 0.75 & 0.09 & 7.25 & 1.53 & 764.67 & 0.01 \\
\hline November & 9.44 & 0.00 & 0.67 & 0.08 & 8.00 & 0.41 & 767.59 & 0.03 \\
\hline \multicolumn{9}{|c|}{2016} \\
\hline April & 13.89 & 0.79 & 0.45 & 0.10 & 2.50 & 0.32 & 768.99 & 0.00 \\
\hline May & 20.28 & 0.79 & 0.72 & 0.01 & 9.50 & 0.16 & 747.14 & 0.00 \\
\hline June & 20.00 & 1.33 & 0.87 & 0.02 & 5.50 & 0.21 & 745.11 & 0.01 \\
\hline July & 30.56 & 0.21 & 0.61 & 0.36 & 6.50 & 1.37 & 750.06 & 0.00 \\
\hline August & 22.59 & 0.16 & 0.71 & 0.06 & 5.00 & 0.45 & 755.99 & 0.05 \\
\hline September & 18.33 & 0.12 & 0.79 & 0.05 & 6.00 & 1.22 & 765.81 & 0.01 \\
\hline October & 17.31 & 0.22 & 0.86 & 0.03 & 7.77 & 0.48 & 760.73 & 0.01 \\
\hline November & 8.89 & 0.00 & 0.55 & 0.00 & 5.00 & 0.00 & 760.98 & 0.00 \\
\hline
\end{tabular}


Appendix 15. Summary statistics for environmental conditions in mixed forest when ticks were obtained on Wheeler-Sack Army Airfield, New York, during April-November 2015-2016.

\begin{tabular}{|c|c|c|c|c|c|c|c|c|}
\hline \multirow[t]{2}{*}{ Month } & \multicolumn{2}{|c|}{ Temperature (C) } & \multicolumn{2}{|c|}{ Humidity } & \multicolumn{2}{|c|}{ Wind speed (MPH) } & \multicolumn{2}{|c|}{ Pressure (mmHg) } \\
\hline & Mean & SE & Mean & SE & Mean & SE & Mean & SE \\
\hline \multicolumn{9}{|c|}{2015} \\
\hline April & 8.98 & 0.49 & 0.50 & 0.17 & 15.33 & 0.71 & 759.04 & 0.02 \\
\hline May & 17.50 & 0.49 & 0.63 & 0.10 & 11.63 & 0.78 & 762.89 & 0.01 \\
\hline June & 20.56 & 0.54 & 0.70 & 0.05 & 9.33 & 1.15 & 743.20 & 0.14 \\
\hline July & 22.50 & 0.67 & 0.76 & 0.07 & 8.00 & 0.29 & 760.03 & 0.01 \\
\hline August & 16.39 & 0.15 & 0.93 & 0.05 & 7.25 & 0.85 & 758.57 & 0.01 \\
\hline September & 19.33 & 0.52 & 0.68 & 0.13 & 7.60 & 0.58 & 765.35 & 0.02 \\
\hline October & 10.46 & 0.18 & 0.82 & 0.07 & 7.33 & 1.44 & 764.71 & 0.01 \\
\hline November & 8.43 & 0.64 & 0.79 & 0.05 & 8.17 & 0.40 & 767.93 & 0.01 \\
\hline \multicolumn{9}{|c|}{2016} \\
\hline April & 12.22 & 0.28 & 0.46 & 0.11 & 5.33 & 2.10 & 768.52 & 0.01 \\
\hline May & 17.90 & 0.71 & 0.62 & 0.10 & 8.33 & 0.45 & 750.63 & 0.02 \\
\hline June & 20.37 & 0.55 & 0.77 & 0.01 & 6.83 & 0.42 & 743.50 & 0.00 \\
\hline July & 24.22 & 0.52 & 0.74 & 0.09 & 5.20 & 0.49 & 745.79 & 0.01 \\
\hline August & 25.09 & 0.31 & 0.56 & 0.06 & 8.00 & 0.52 & 758.11 & 0.03 \\
\hline September & 20.65 & 0.35 & 0.70 & 0.07 & 5.67 & 0.68 & 766.36 & 0.01 \\
\hline October & 9.67 & 1.00 & 0.93 & 0.05 & 3.80 & 0.55 & 761.90 & 0.02 \\
\hline November & 8.47 & 0.24 & 0.60 & 0.09 & 6.75 & 0.55 & 762.00 & 0.01 \\
\hline
\end{tabular}


Appendix 16. Summary statistics for environmental conditions in shrub forest when ticks were obtained on Wheeler-Sack Army Airfield, New York, during April-November 2015-2016.

\begin{tabular}{|c|c|c|c|c|c|c|c|c|}
\hline \multirow[t]{2}{*}{ Month } & \multicolumn{2}{|c|}{ Temperature (C) } & \multicolumn{2}{|c|}{ Humidity } & \multicolumn{2}{|c|}{ Wind speed (MPH) } & \multicolumn{2}{|c|}{ Pressure (mmHg) } \\
\hline & Mean & SE & Mean & SE & Mean & SE & Mean & SE \\
\hline \multicolumn{9}{|c|}{2015} \\
\hline April & 11.11 & 2.77 & 0.51 & 0.48 & 16.50 & 2.09 & 757.17 & 0.04 \\
\hline May & 23.89 & 0.00 & 0.70 & 0.00 & 9.00 & 0.00 & 764.54 & 0.00 \\
\hline June & 22.22 & 0.24 & 0.77 & 0.02 & 14.00 & 2.67 & 758.19 & 0.02 \\
\hline July & 21.85 & 0.65 & 0.69 & 0.07 & 4.33 & 0.89 & 760.22 & 0.01 \\
\hline August & 0.00 & 0.00 & 0.00 & 0.00 & 0.00 & 0.00 & 0.00 & 0.00 \\
\hline September & 19.17 & 1.04 & 0.81 & 0.15 & 6.00 & 0.00 & 764.67 & 0.02 \\
\hline October & 0.00 & 0.00 & 0.00 & 0.00 & 0.00 & 0.00 & 0.00 & 0.00 \\
\hline November & 10.69 & 0.85 & 0.75 & 0.02 & 12.00 & 0.79 & 764.41 & 0.00 \\
\hline \multicolumn{9}{|c|}{2016} \\
\hline April & 6.67 & 0.00 & 0.90 & 0.00 & 8.00 & 0.00 & 767.08 & 0.00 \\
\hline May & 14.63 & 0.57 & 0.73 & 0.12 & 5.00 & 0.26 & 754.63 & 0.01 \\
\hline June & 25.83 & 0.17 & 0.77 & 0.01 & 9.00 & 0.33 & 744.35 & 0.00 \\
\hline July & 23.06 & 0.52 & 0.77 & 0.09 & 3.50 & 0.27 & 747.14 & 0.02 \\
\hline August & 27.22 & 0.00 & 0.65 & 0.00 & 4.00 & 0.00 & 749.81 & 0.00 \\
\hline September & 0.00 & 0.00 & 0.00 & 0.00 & 0.00 & 0.00 & 0.00 & 0.00 \\
\hline October & 18.89 & 0.00 & 0.94 & 0.00 & 15.00 & 0.00 & 754.63 & 0.00 \\
\hline November & 4.72 & 0.24 & 0.69 & 0.03 & 9.50 & 0.16 & 760.86 & 0.00 \\
\hline
\end{tabular}


Appendix 17. Summary statistics of fall mast production on Fort Drum Military Installation, New York, 2015-2016. 


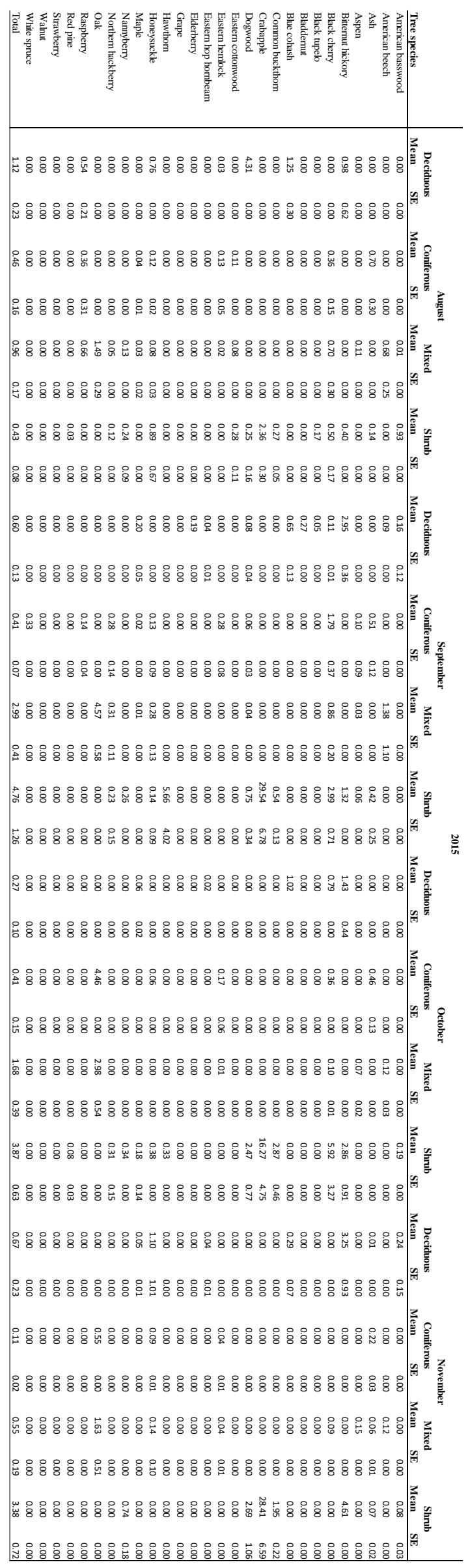




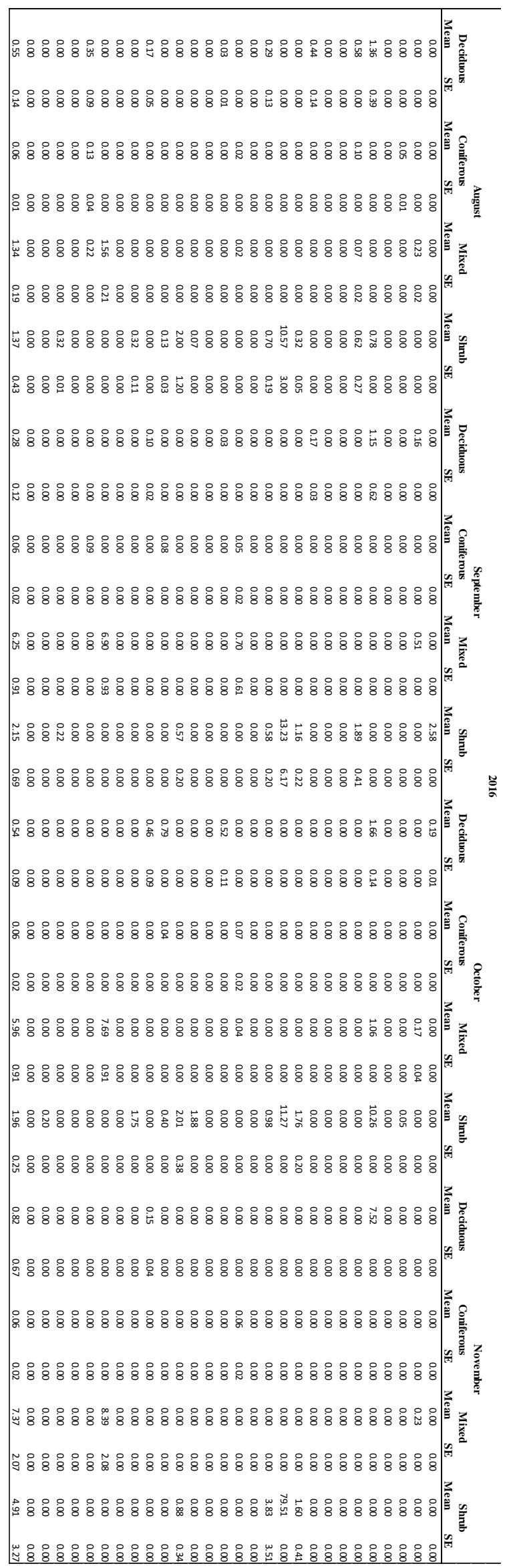


Appendix 18. Summary statistics for stand variables on Fort Drum Military Installation, New York, during April-November 2015-2016.

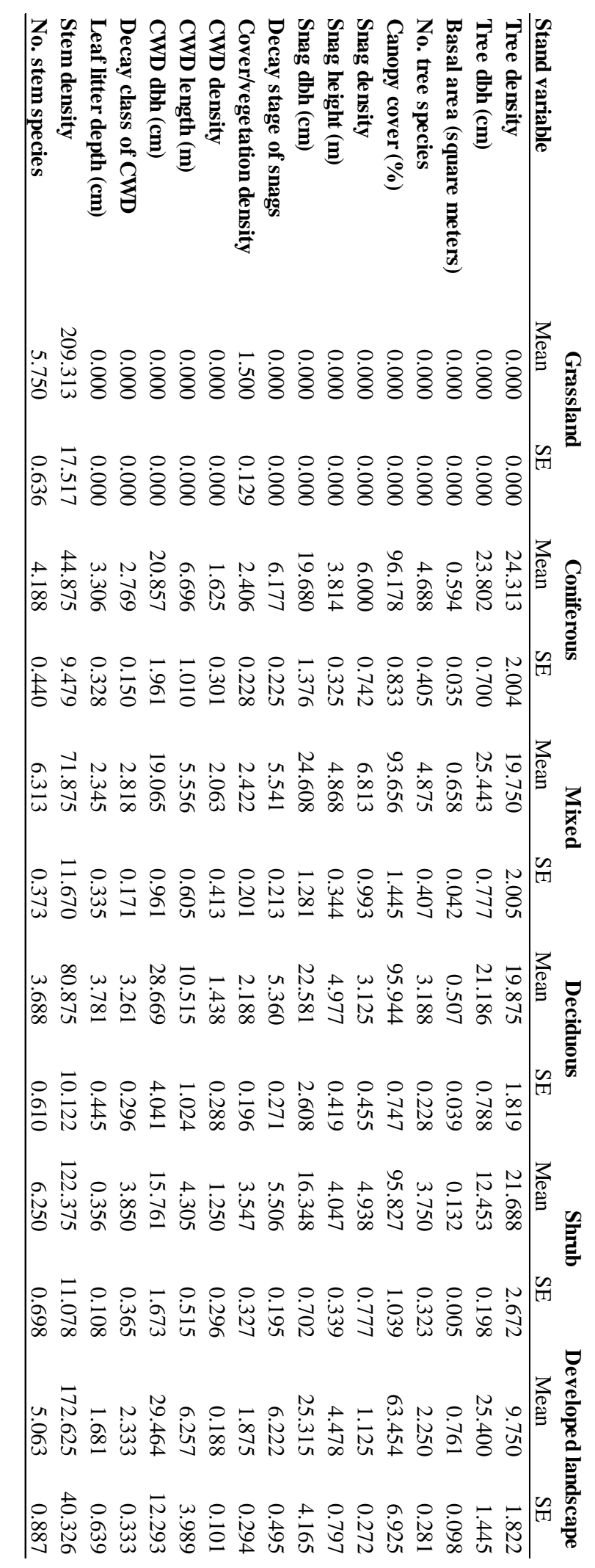


Appendix 19. Description of habitat variables to be ${ }^{m}$ easured nearby small mammal trapping grids for cover type characterization on Fort Drum Military Installation, New York, during April-November 2015-2016.

\begin{tabular}{lll}
\hline Spatial Level & Vegetative Parameter & Measurement Description \\
\hline Stand & Species & Tree species; when determinable \\
& Dbh $(\mathrm{cm})$ & Average dbh/0.04 ha plot; measured using calipers \\
& Crown class & When determinable (USDA Forest Service 2002) \\
& Average \% coverage, measurements at the center and \\
& 10-m in each cardinal direction from the center of \\
& Canopy cover & each 0.04-ha plot; visually estimated using \\
& densiometer \\
& \# of snags/0.04 ha plot; measured using tape \\
& Snag density and volumes & $1-9 ;$ see Maser et al. 1979, Thomas et al. 1979 for \\
& Decay stage of snags & description
\end{tabular}

Midstory

Cover/vegetation density

Coarse woody debris

(CWD)

Decay class of CWD
\% coverage/1-6; visually estimated using cover board Length and diameter; visually estimated using measuring tape and calipers at midpoint 1-5; see Maser et al. 1979, Thomas et al. 1979 for description

Understory

Leaf litter depth

When determinable, average of measurements from each corner of the 0.001-ha nested plot; visually estimated using ruler

Ground cover composition 
Appendix 20. Covariance of habitat variables on Fort Drum Military Installation, New York, during April-November 2015-2016. Colinearity of $>0.70$ was considered high covariance. 


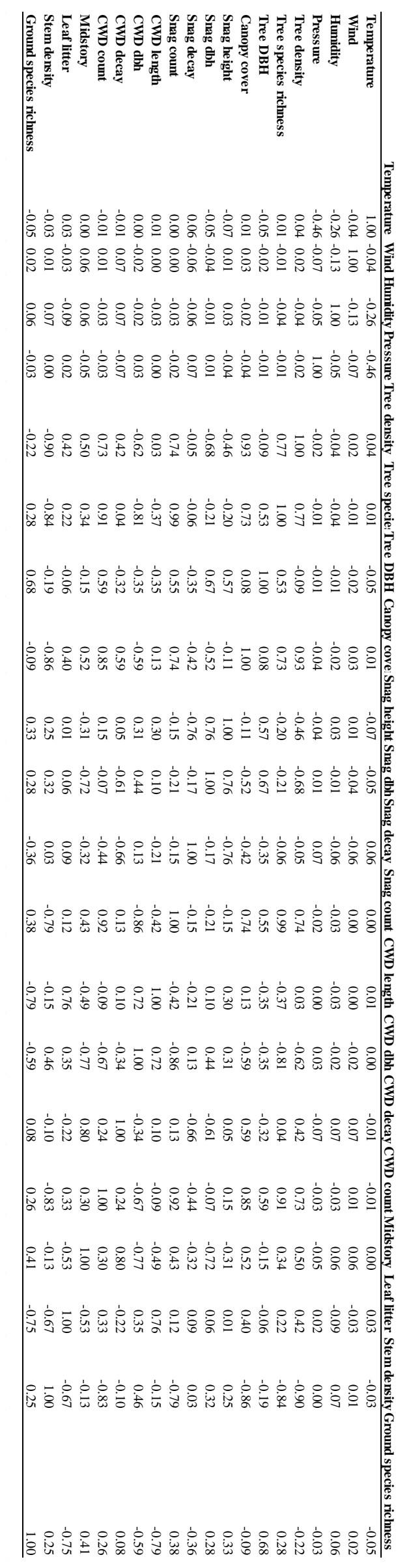


Appendix 21. Coniferous forest cover type.

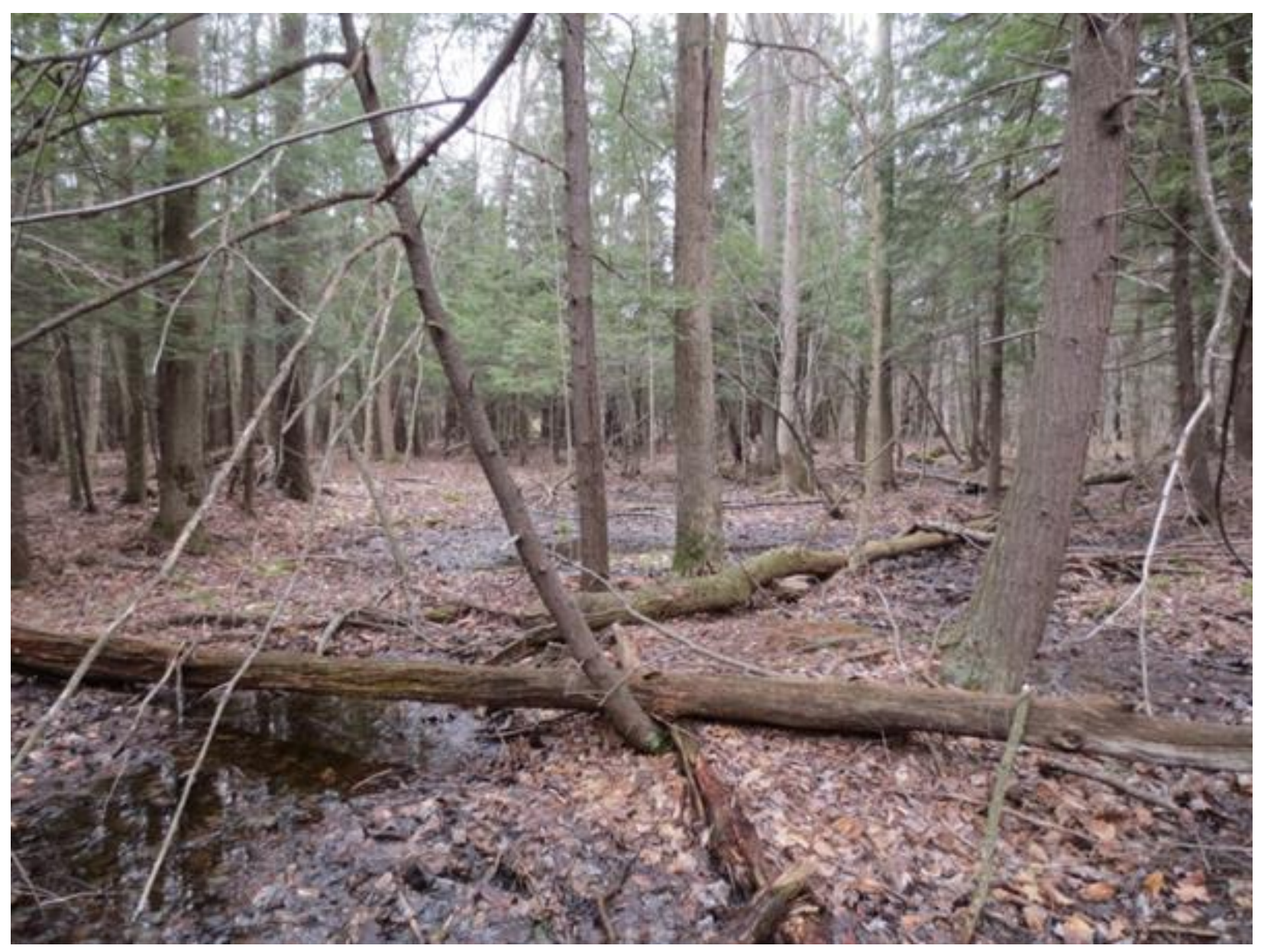


Appendix 22. Deciduous forest cover type.

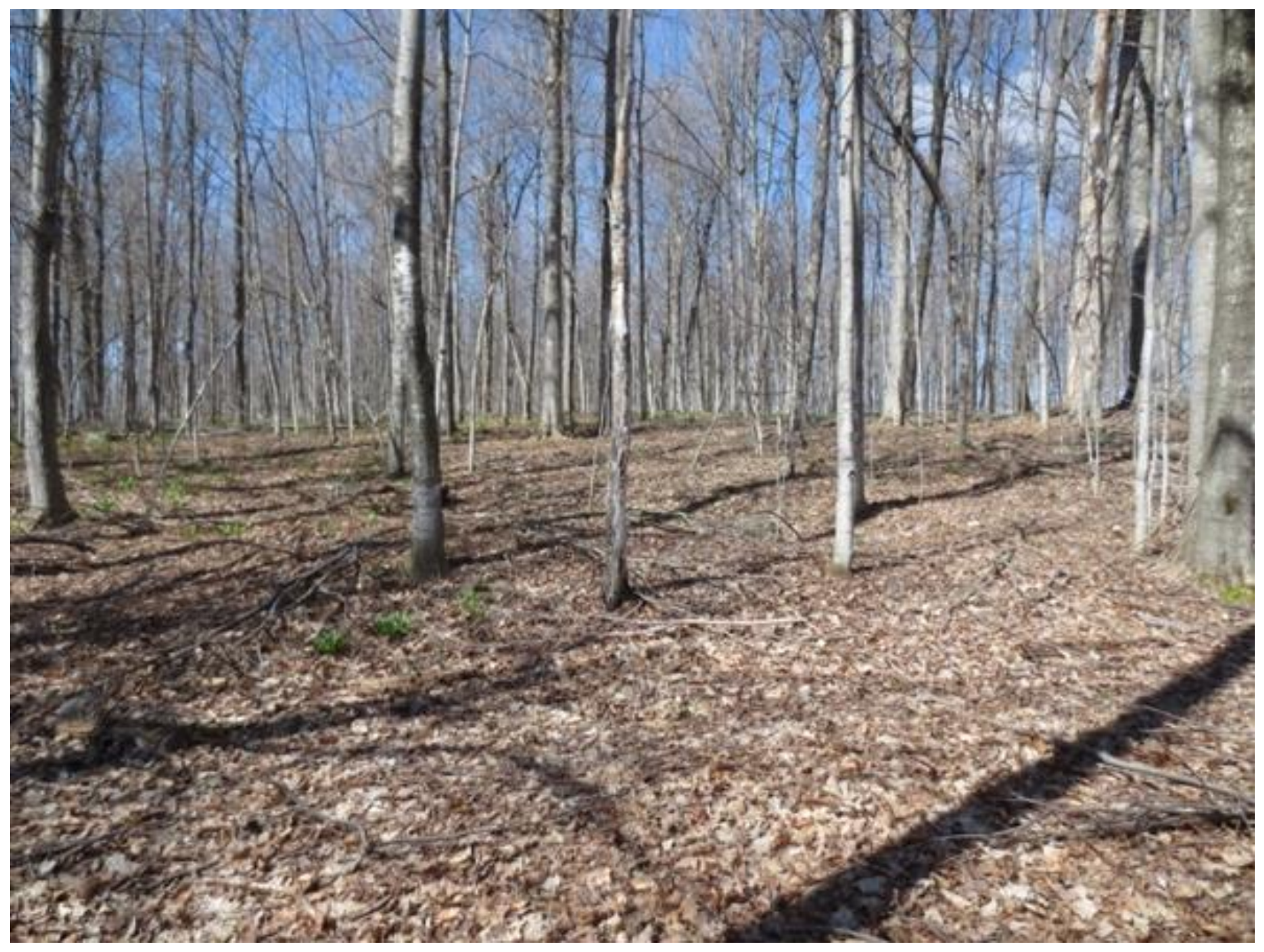


Appendix 23. Developed cover type.

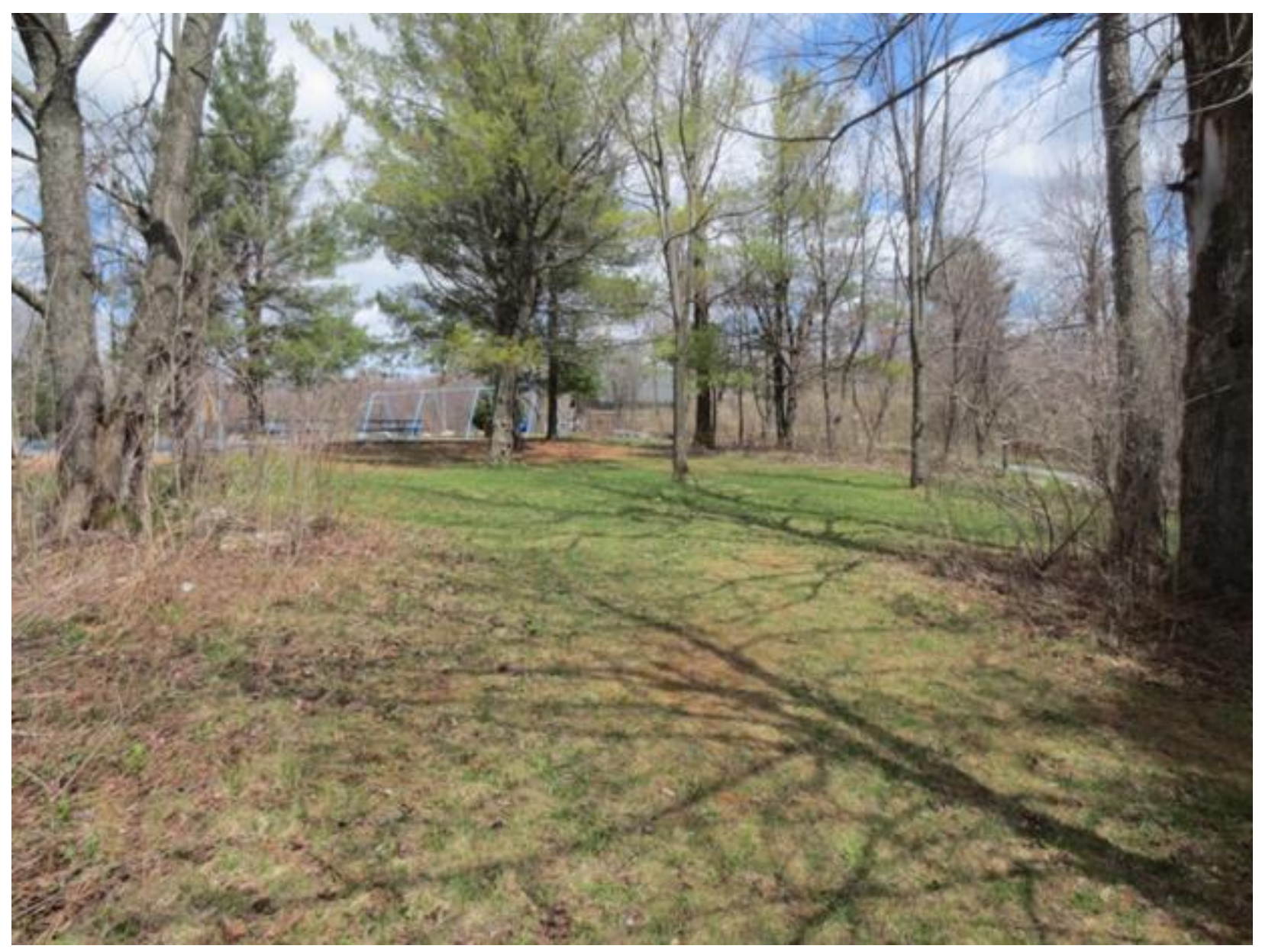


Appendix 24. Grassland cover type.

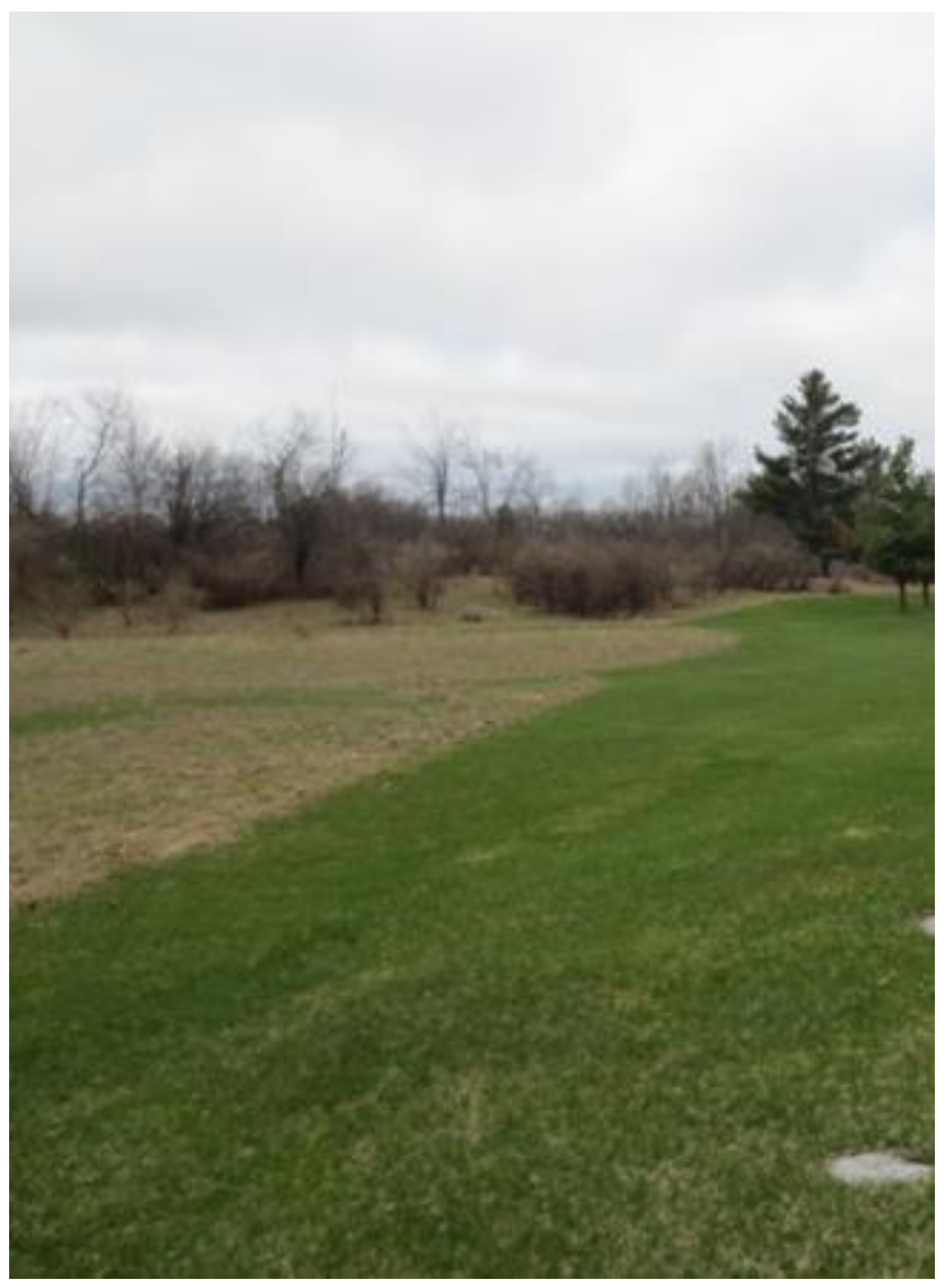


Appendix 25. Mixed forest cover type.

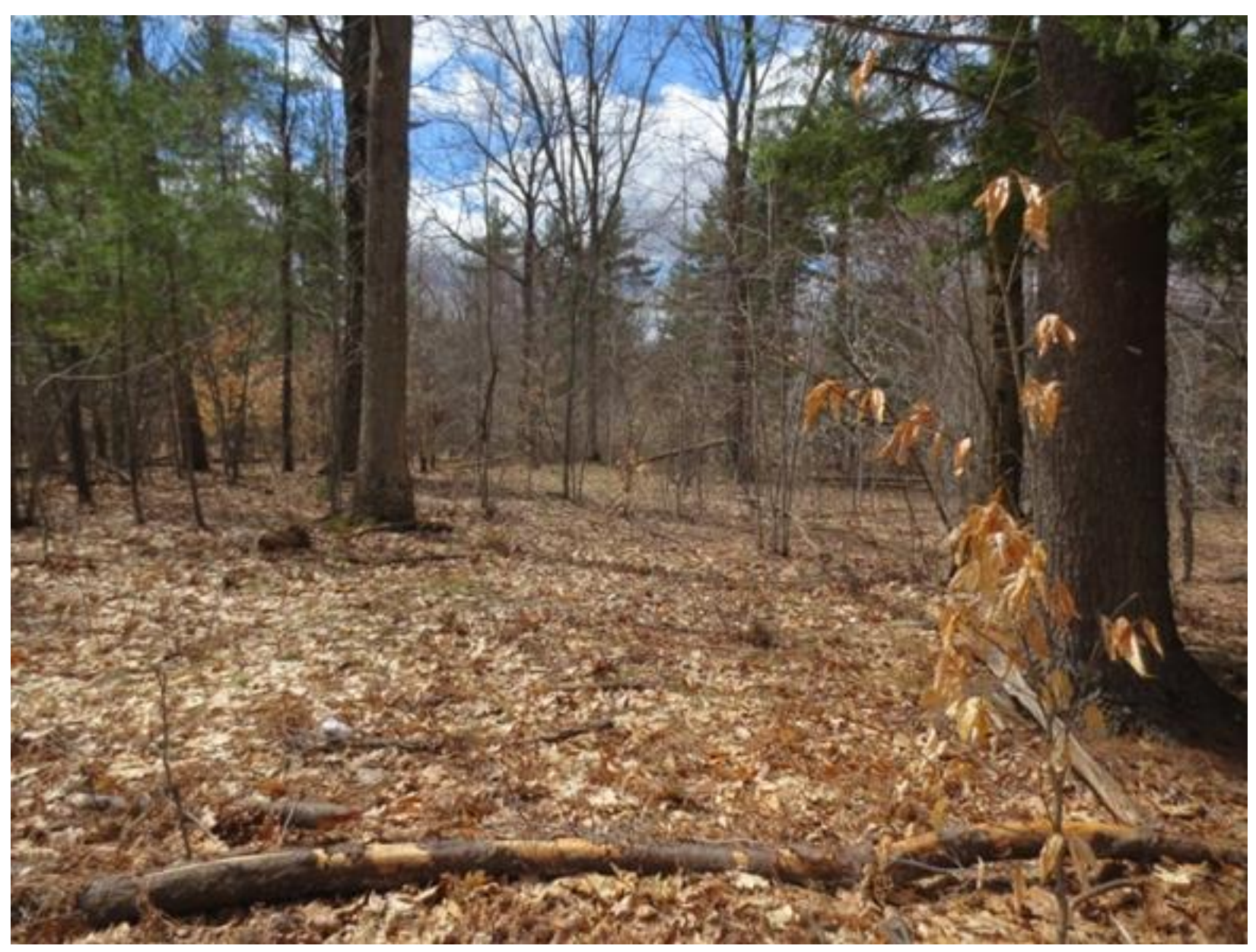


Appendix 26. Shrub forest cover type.

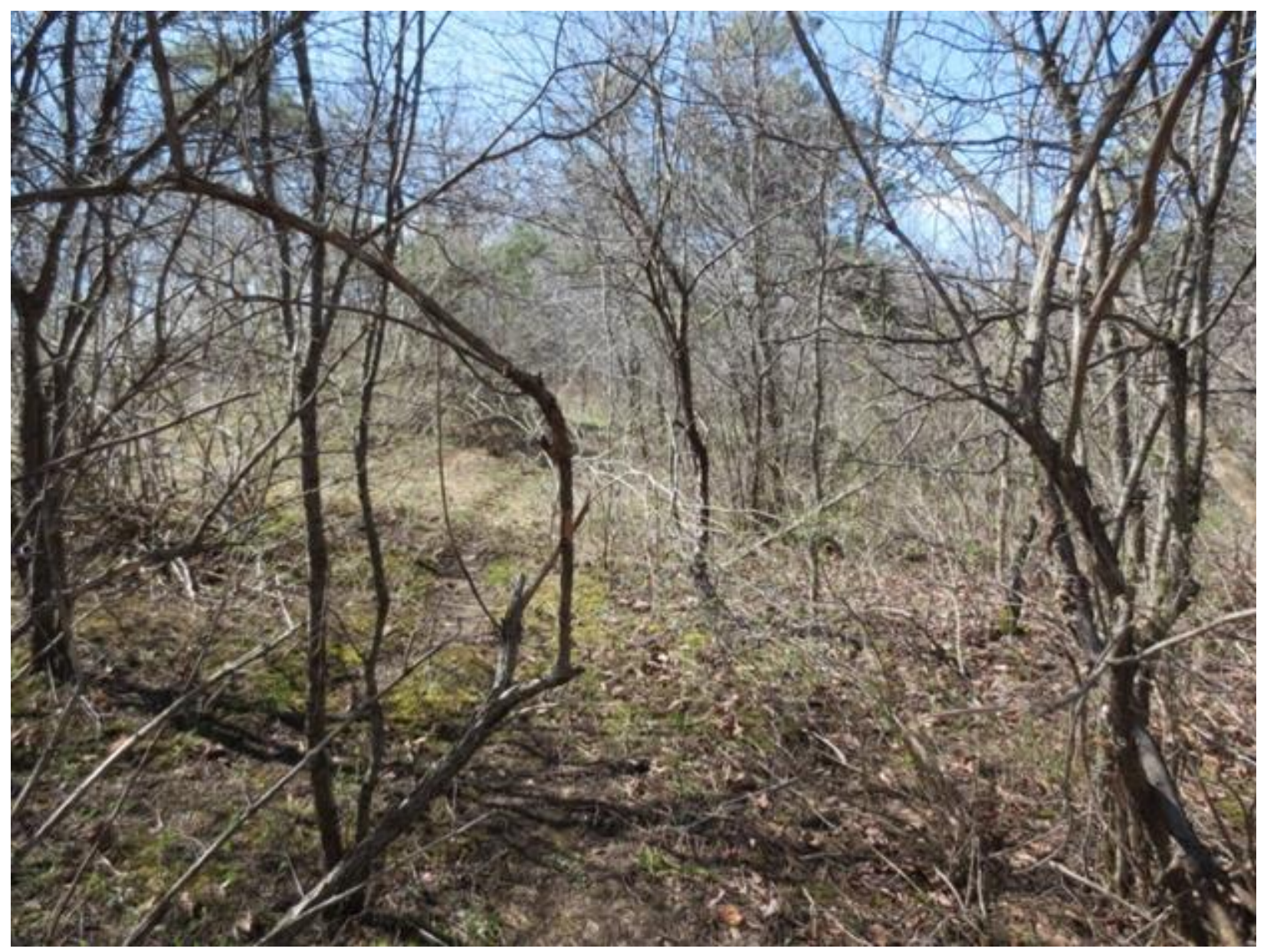


Appendix 27. Locations of small mammal, tick drag and mast trap grids within the Cantonment Area of Fort Drum Military Installation, NY.

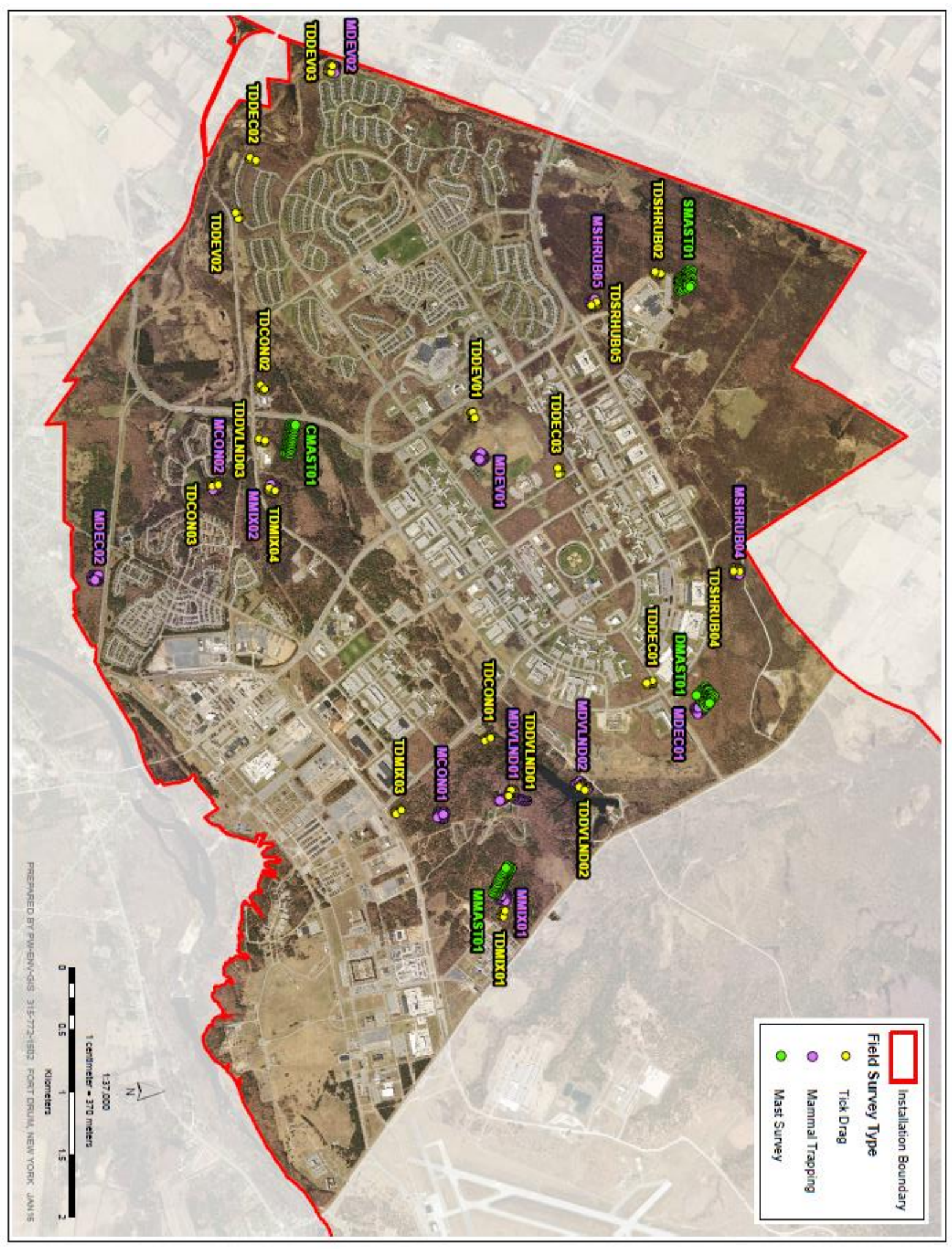


Appendix 28. An example of a tick drag grid within the Cantonment Area of Fort Drum Military Installation, NY.

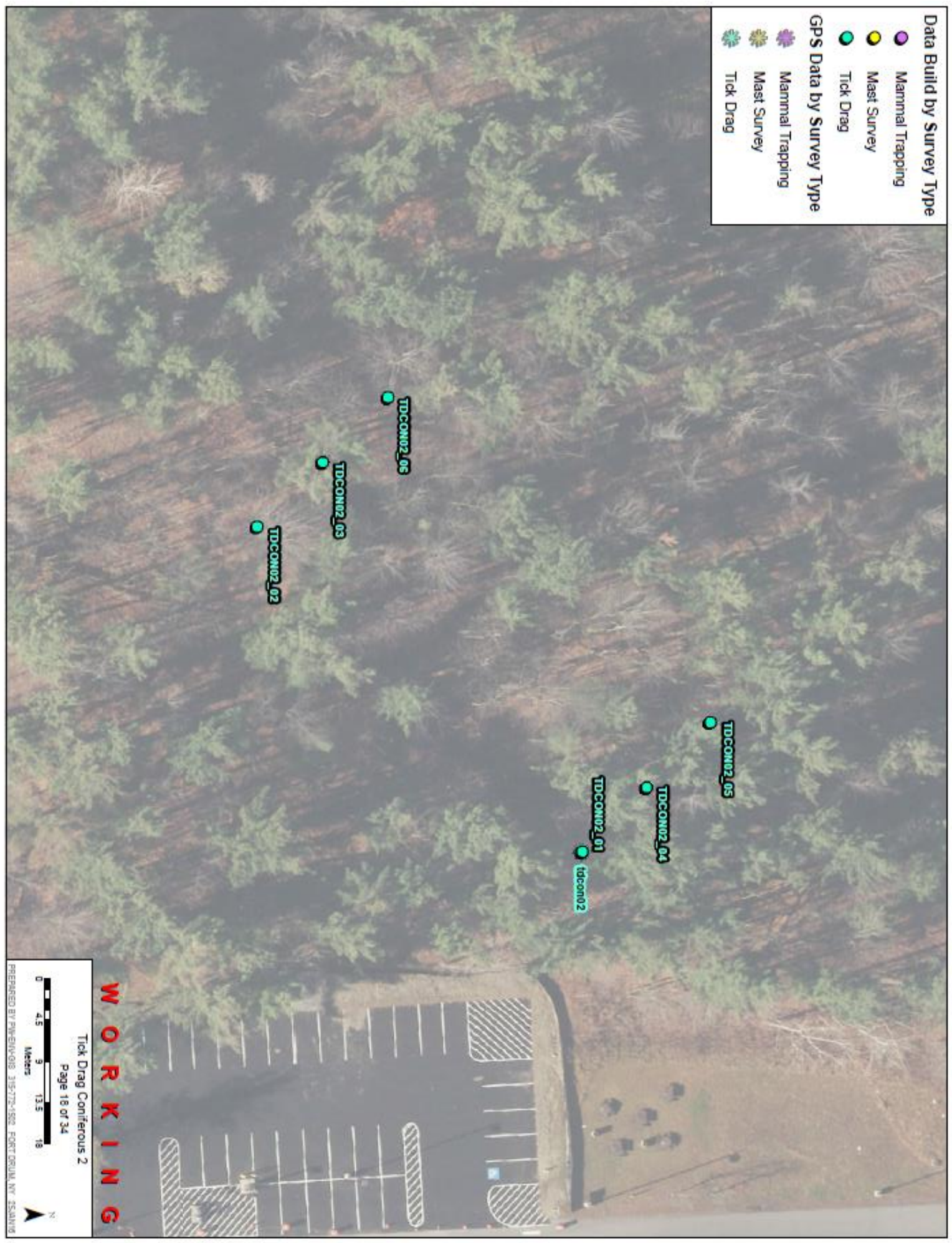


Appendix 29. An example of a small mammal trapping grid within the Cantonment Area of Fort Drum Military Installation, NY.

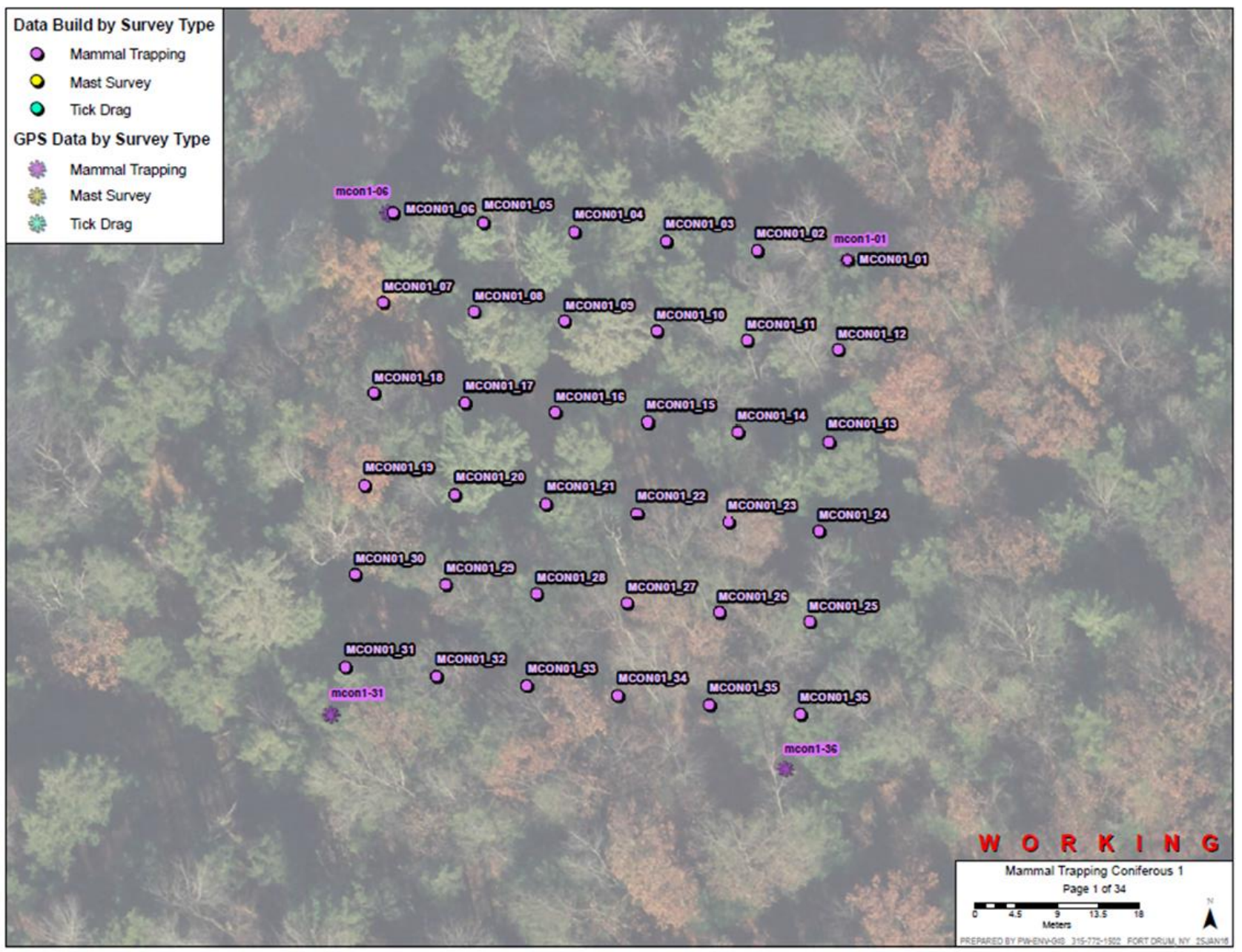


Appendix 30. An example of a mast collection grid within the Cantonment Area of Fort Drum Military Installation, NY.

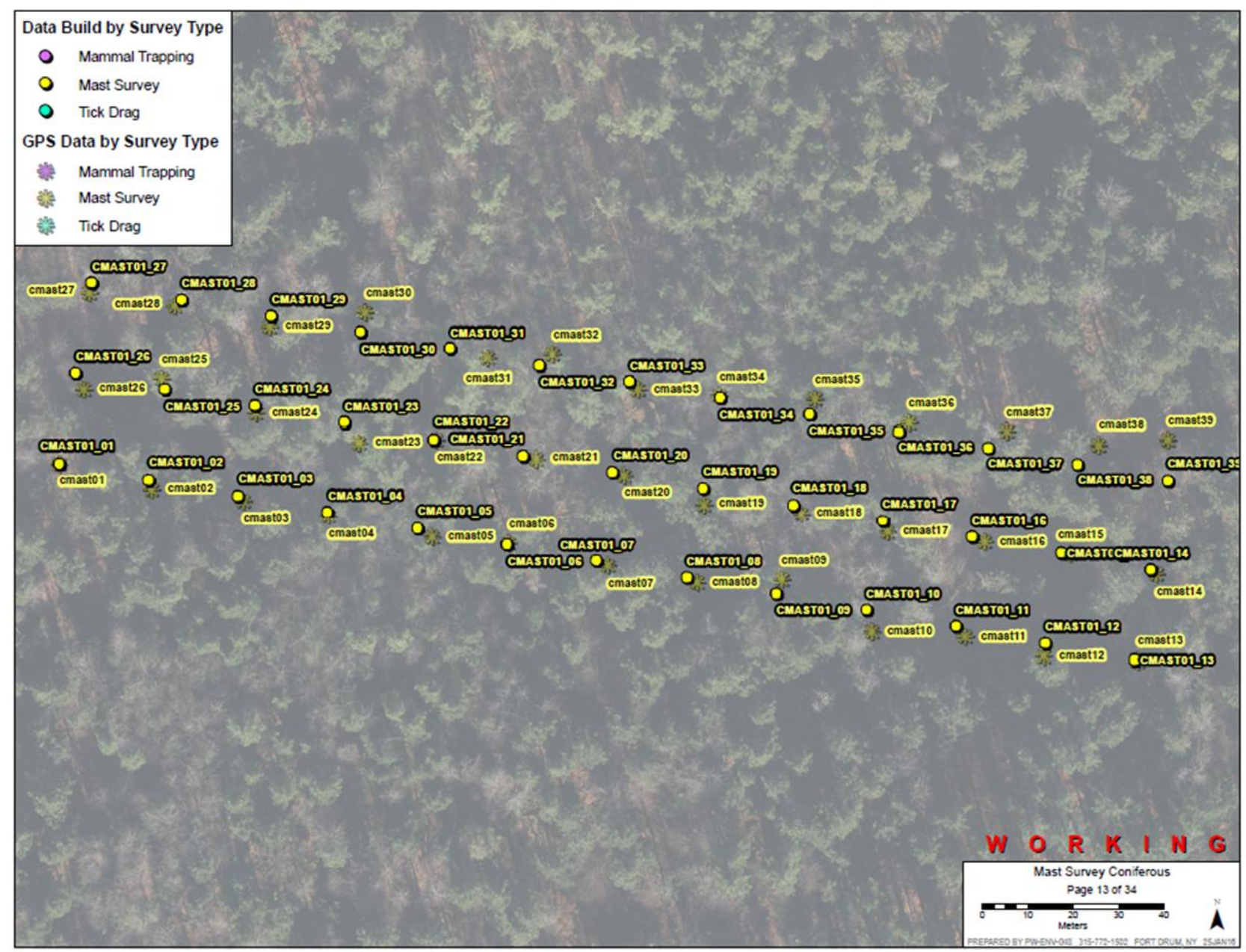


Appendix 31. An example of a mast trap within the Cantonment Area of Fort Drum Military Installation, NY.

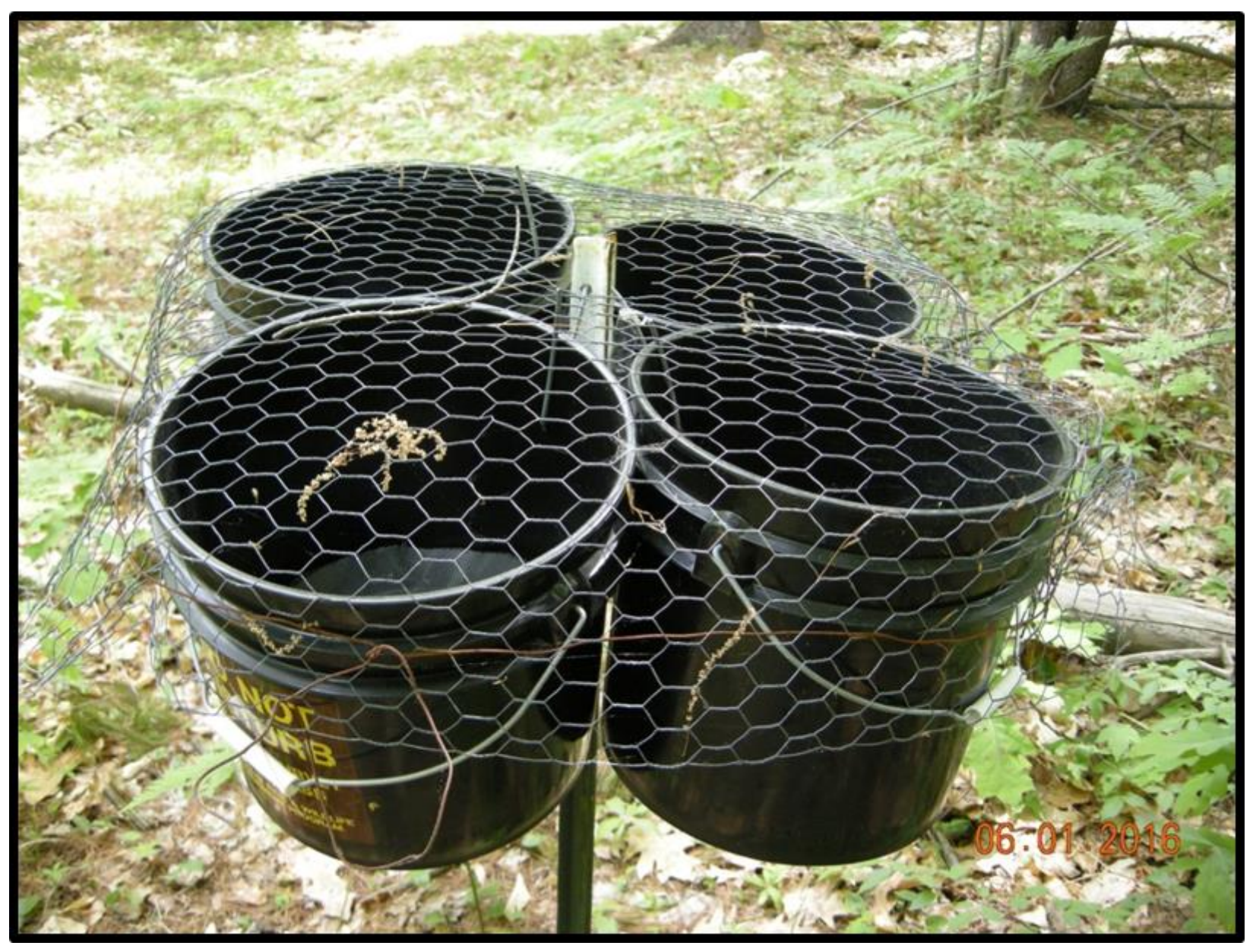

